\title{
UM MODELO COMPUTACIONAL DE ANÁLISE DA INTERAÇÃO ESTRUTURA - MACIÇO DE SOLOS EM EDIFÍCIOS
}

\section{JocÉlio CABRal Mendonça}

Dissertação apresentada à Escola de Engenharia de São Carlos, da Universidade de São Paulo, como parte dos requisitos para obtenção do título de Mestre em Geotecnia

ORIENTADOR: PROF. DR. NELSON AOKI

São Carlos

2000 
Ficha cataloerdfica preparda pela Seclo de Trataniento da Informaçio do Serviço de Glbioteca - EESCIUSP

M53910

Meridonca, Joge] 10 Dabral

Um fundefo computacibnal de analise da Lnteracso entrutura-macico de nolor em odifjoior 7 opcojio

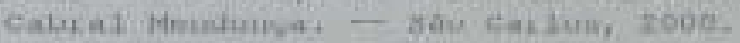

Diesertacko (Nestrado) - Facola de Fingenharia din

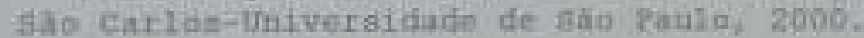

Atea: Gebtecmla.

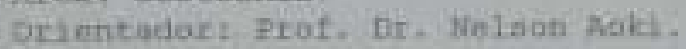

1. Interacalo entrutura - macico de volos.

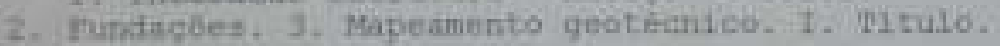




\section{FOLHA DE APROVACÃO}

Candidato: Engenheiro JOCÉLIO CABRAL MENDONÇA

Dissertação defendida e aprovada em 28-03-2000 pela Comissão Julgadora:

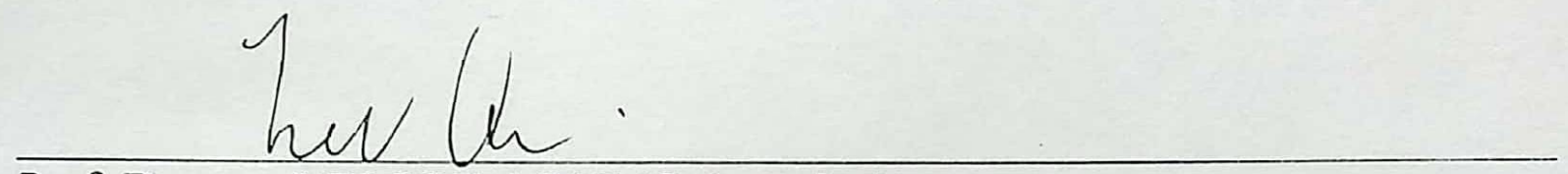

Prof. Doutor NELSON AOKI (Orientador)

(Escola de Engenharia de São Carlos - Universidade de São Paulo)

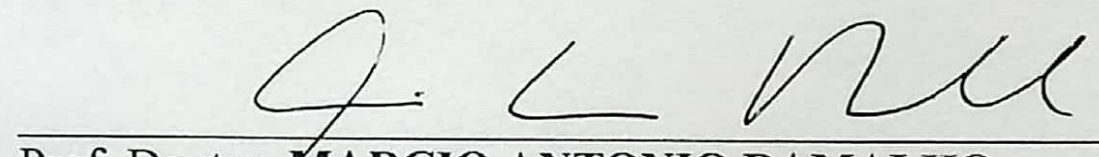

Prof. Doutor MARCIO ANTONIO RAMALHO

(Escola de Engenharia de São Carlos - Universidade de São Paulo)

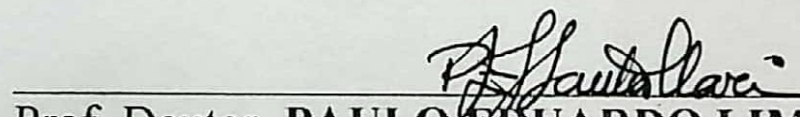

Prof. Doutor PAULO EOUARDO LIMA DE SANTA MARIA

(COPPE - Universidade Federal do Rio de Janeiro)

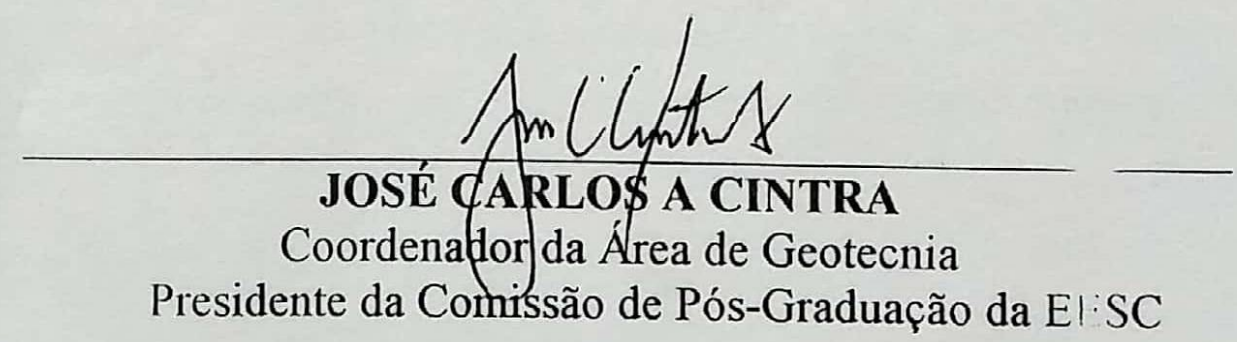


Aos meus

pais, irmãs, filho e esposa. 
Ao Prof. Nelson Aoki, pela amizade e dedicação; Ao Prof. Ronaldo Barros Gomes, pelo incentivo e apoio; Aos Profs. Benedito Bueno, Lázaro Zuquete, Eldon Londe e Márcio Correa, pela orientação em assuntos afins; Aos Analistas Maksuel Oliveira e Eloísio Damascena, pela contribuição no desenvolvimento do software; Ao Eng $^{0}$ Humberto Rezende, pelo auxílio na análise estrutural; À Eng. Kenia Mendonça, pela revisão; Aos colegas Eng. Miguel Soto, Geól. Fernando Boff e Eng. Andreu Sanches, pelo companheirismo; Aos demais docentes, discentes e funcionários do SGS/EESC/USP, pela convivência; À PRPPG-UFG/CAPES, pela concessão da bolsa de estudos. 


\section{SUMÁRIO}

LISTA DE FIGURAS.................................................................................... ix

LISTA DE TABELAS................................................................................ xiii

LISTA DE ABREVIATURAS E SIGLAS................................................................ xvi

LISTA DE SÍMBOLOS................................................................................. x xii

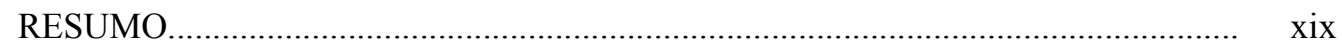

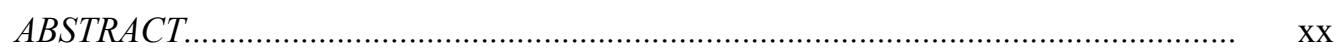

1 INTRODUÇÃO

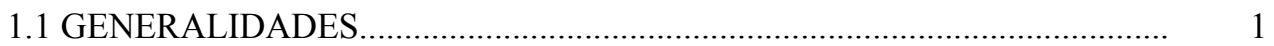

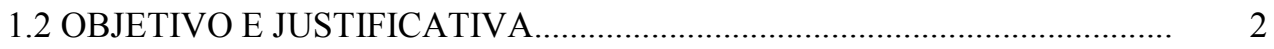

1.3 DEFINIÇÕES E CONVENÇÕES................................................................. 3

1.3.1 DisCRETIZAÇÃO DO SISTEMA ESTRUTURA - MACIÇO DE SOLOS.............. 4

1.3.2 MOVIMENTOS DA SUPERFÍCIE DO MACIÇO SUPORTE............................... 5

2 INTERAÇÃO ESTRUTURA - MACIÇO DE SOLOS.............................................. 7

2.1 GENERALIDADES................................................................................... 7

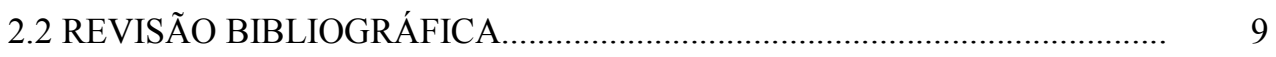

2.2.1 ANÁLISE DA INTERAÇÃO ESTRUTURA - MACIÇO DE SOLOS...................... 9

2.2.1.1 Metodologias.......................................................................... 9

2.2.1.2 Ferramentas computacionais.................................................... 11

2.2.2 Métodos de CÁlculo DE ResistÊnCia E DE RECALQUe DA

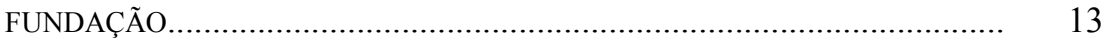

2.2.3 LITERATURA SOBRE A INTERAÇÃO ESTRUTURA - MACIÇO DE SOLOS

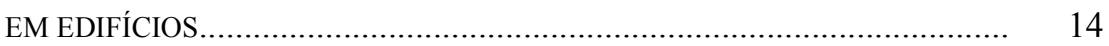

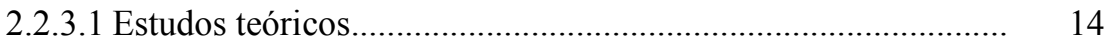

2.2.3.2 Casos práticos......................................................................... 16

2.2.4 INFLUÊNCIA DO PROCESSO CONSTRUTIVO.............................................. 18

2.3 ANÁLISE TEÓRICA............................................................................. 19 
2.3.1 Modelos DE ESTUdo DA INTERAÇÃO ESTRUTURA - MACIÇO DE SOLOS.

2.3.1.1 Interação elemento isolado - maciço de solos...

2.3.1.2 Interação grupo de elementos isolados - maciço de solos

2.3.1.3 Interação de grupo de elementos unidos por bloco de coroamento - maciço de solos.

2.3.1.4 Interação grupo de elementos unidos por bloco de coroamento - maciço de solos - grupo de elementos................ 21

2.3.1.5 Interação edifício completo - maciço de solos........................... 22

2.3.1.6 Interação grupo de edifícios - maciço de solos......................... 22

2.3.2 Modelagem do Sistema ESTRUtURA - MACiÇO DE SOLOS.................. 22

2.3.2.1 Subdivisão do sistema estrutura - maciço de solos................... 22

2.3.2.2 Modelagem da superestrutura.................................................. 24

2.3.2.3 Modelagem da fundação.............................................................. 24

2.3.3 PRoPosta DE UMA NOVA SOLUÇÃO COMPUTACIONAL............................. 27

3 O SISTEMA COMPUTACIONAL..................................................................... 30

3.1 BREVE HISTÓRICO.......................................................................... 30

3.2 GENERALIDADES............................................................................ 30

3.3 ANÁLISE E PROJETOS......................................................................... 34

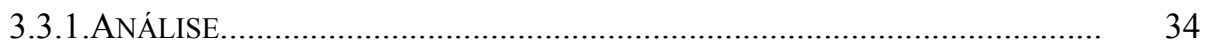

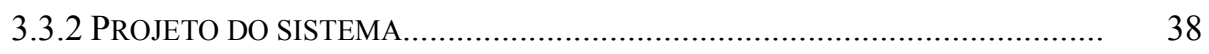

3.3.3 PROJETO DE ALGORITMOS...................................................................... 42

3.3.4 SUGESTÕES DE OTIMIZAÇÃO E EXPANSÃO............................................. 42

3.4 O SOFTWARE STRUCTSOIL .................................................................. 44

3.4.1 MENU RETAGUARDA........................................................................ 45

3.4.1.1 Maciço de solos........................................................................ 46

3.4.1.1.1 Modelo geotécnico de resistência (MGR)........................ 46

3.4.1.1.2 Modelo geotécnico de deformabilidade elástica (MGDE) 47

3.4.1.1.3 Modelo de transferência de carga (MTC)......................... 48

3.4.1.1.4 Modelo da camada de solos complementar (MCSC)........ 48

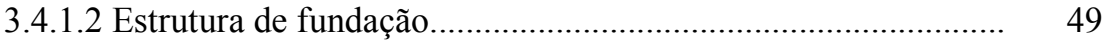

3.4.1.3 Materiais de construção........................................................... $\quad 50$

3.4.2 MENU PRINCIPAL....................................................................... 50

3.4.2.1 Controle.......................................................................... 50 
3.4.2.2 Entrada de dados e pré-processamento...................................... 51

3.4.2.2.1 Superestrutura............................................................. 51

3.4.2.2.2 Maciço de solos................................................................. 53

3.4.2.2.3 Estrutura de fundação........................................................ 56

3.4.2.2.4 Processamento.............................................................. 58

3.4.2.2.4.1 Matrizes de flexibilidade........................................ 58

3.4.2.2.4.2 Interação................................................................ $\quad 60$

3.4.2.2.5 Relatórios, gráficos e ajuda............................................ 62

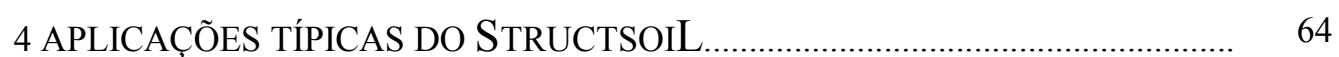

4.1 ESTRUTURA COM DUPLA SIMETRIA............................................................ 64

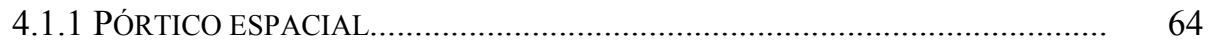

4.1.2 MACIÇO DE SOLOS................................................................................ 66

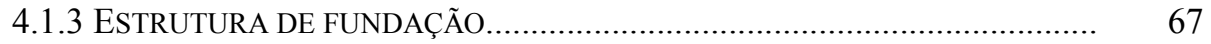

4.1.3.1 Solução em sapatas isoladas......................................................... 67

4.1.3.2 Solução em tubulões a céu aberto................................................ 68

4.1.3.3 Solução em estacas cravadas...................................................... 68

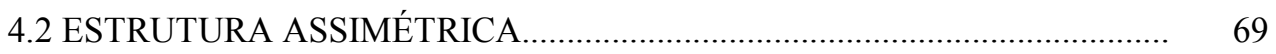

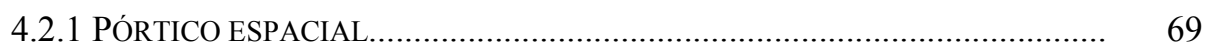

4.2.2 MACIÇO DE SOLOS........................................................................ 71

4.2.2.1 Maciço residual....................................................................... 71

4.2.2.2 Maciço sedimentar....................................................................... $\quad 72$

4.2.3 ESTRUTURA DE FUNDAÇÃO...................................................................

4.2.3.1 Solução em sapatas isoladas...................................................... $\quad 75$

4.2.3.2 Solução em tubulões a céu aberto.............................................. 76

4.2.3.3 Solução em estacas cravadas...................................................... 76

4.2.3.4 Solução em estacas escavadas de grande diâmetro (estacão).... 77

4.3 ESTRUTURA SIMÉTRICA EM RELAÇÃO A UM PLANO PRINCIPAL.... 77

4.3.1 PóRTICO ESPACIAL............................................................................. 78

4.3.2 MACIÇO DE SOLOS............................................................................. 79

4.3.3 ESTRUTURA DE FUNDAÇÃO................................................................. 79

4.3.3.1 Solução em tubulões a céu aberto............................................ 80

4.3.3.2 Solução em estacas cravadas tipo SCAC................................... 81

4.3 EFEITOS DA INUNDAÇÃO DO MACIÇO DE SOLOS RESIDUAL........... 81

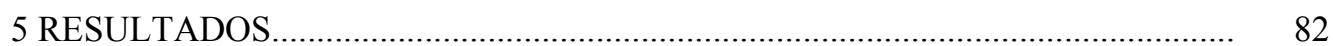


5.1 ESTRUTURA COM DUPLA SIMETRIA.................................................. 82

5.1.1 SOLUÇÃO EM SAPATAS ISOLADAS.......................................................... 82

5.1.2 SOLUÇÃO EM TUBULÕES A CÉU ABERTO................................................. 82

5.1.3 SOLUÇÃO EM ESTACAS CRAVADAS......................................................... 83

5.2 ESTRUTURA ASSIMÉTRICA................................................................... 84

5.2.1 SOLUÇÃO EM SAPATAS ISOLADAS......................................................... 84

5.2.2 SOLUÇÃO EM TUBULÕES A CÉU ABERTO................................................. 84

5.2.3 SOLUÇÃO EM ESTACAS CRAVADAS........................................................ 85

5.2.4 SOLUÇÃO EM ESTACAS ESCAVADAS DE GRANDE DIÂMETRO (ESTACÃO) 85

5.3 ESTRUTURA SIMÉTRICA EM RELAÇÃO A UM PLANO PRINCIPAL.... 86

5.3.1 SOLUÇÃO EM TUBULÕES A CÉU ABERTO................................................. 86

5.3.2 SOLUÇÃO EM ESTACAS CRAVADAS TIPO SCAC...................................... 86

5.4 EFEITOS DA INUNDAÇÃO DO MACIÇO DE SOLOS RESIDUAL............ 87

5.4.1 SOLUÇÃO EM SAPATAS ISOLADAS........................................................... 87

5.4.2 SOLUÇÃO EM TUBULÕES A CÉU ABERTO............................................... 88

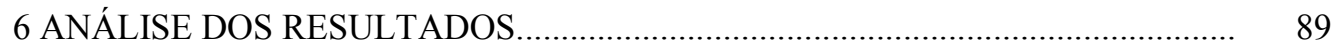

6.1 ESTRUTURA COM DUPLA SIMETRIA....................................................... 89

6.2 ESTRUTURA ASSIMÉTRICA................................................................ 94

6.3 ESTRUTURA SIMÉTRICA EM RELAÇÃO A UM PLANO PRINCIPAL.... 100

6.4 EFEITOS DA INUNDAÇÃO DO MACIÇO DE SOLOS RESIDUAL........... 103

7 CONSIDERAÇÕES FINAIS................................................................................ 107

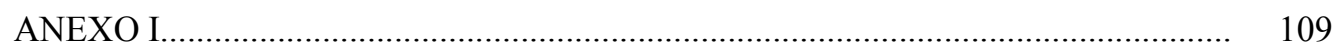

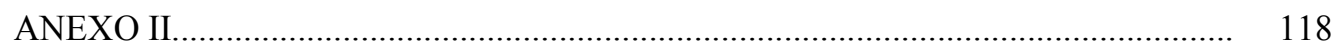

REFERÊNCIAS BIBLIOGRÁFICAS....................................................................... 146

APÊNDICE

GLOSSÁRIO 


\section{LISTA DE FIGURAS}

FIGURA 01 - Definições dos movimentos da superfície do maciço suporte...... 6

FIGURA 02 - Estrutura e maciço de solos............................................................ 7

FIGURA 03 - O sistema estrutura - maciço de solos e a transferência de tensões ao maciço........................................................................ 8

FIGURA 04 - Modelos para estudo da interação estrutura - maciço de solos, caso de fundação profunda, desprezando a superestrutura............ 20

FIGURA 05 - Modelos para estudo da interação estrutura - maciço de solos, caso de fundação profunda, considerando a superestrutura.......... 21

FIGURA 06 - Definição do nível de referência do modelo................................... 22

FIGURA 07 - Quadro de dificuldades de modelagem da interação estrutura maciço de solos em edificações........................................................ 23

FIGURA 08 - Diagrama de Contexto.................................................................. 32

FIGURA 09 - Diagrama Entidade e Relacionamento do StructsoiL.................... 33

FIGURA 10 - Quadro analítico dos pontos críticos do software........................ 34

FIGURA 11 - Nível de objeto final (atributos e serviços)................................... 35

FIGURA 12 - Modelo de objetos inicial do StructsoiL......................................... 36

FIGURA 13 - Diagramas de estado das superclasses........................................... 37

FIGURA 14 - Divisão do StructsoiL em subsistemas............................................ 38

FIGURA 15 - Diagrama de Fluxo de Dados da Retaguarda................................ 39

FIGURA 16 - Diagrama de Fluxo de Dados Principal....................................... 40

FIGURA 17 - Topologia do StructsoiL............................................................. 41

FIGURA 18 - Menu Principal e acesso ao Menu Retaguarda.............................. 44

FIGURA 19 - Menu Retaguarda e acessos para configuração do StructsoiL..... 45

FIGURA 20 - Configuração do MGR (modelo geotécnico de resistência)......... 46

FIGURA 21 - Configuração do MGDE (modelo geotécnico de deformabilidade elástica)............................................................ 47 
FIGURA 22 - Configuração do MTC (modelo de transferência de carga)......... 48

FIGURA 23 - Configuração do MCSC (modelo de camada de solos complementar) para aterro em solo granular................................. 49

FIGURA 24 - Configuração da técnica de execução da estrutura de

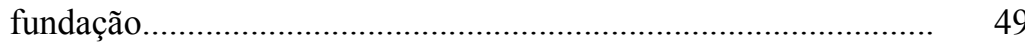

FIGURA 25 - Configuração do material de construção da estrutura de fundação............................................................................. 50

FIGURA 26 - Cenário de alteração dos dados da obra cadastrada...................... 51

FIGURA 27 - Entrada de dados da superestrutura............................................... 52

FIGURA 28 - Modelo de discretização do maciço de solos e dos elementos da estrutura de fundação.................................................................. 53

FIGURA 29 - Entrada de dados do maciço de solos por ensaios SPT e cálculo dos parâmetros de resistência e de deformabilidade elástica ....... 54

FIGURA 30 - Entrada de dados do maciço de solos por mapeamento geotécnico....................................................................... 54

FIGURA 31 - Entrada de dados da camada de solos complementar (aterro)..... 55

FIGURA 32 - Entrada de dados da estrutura de fundação................................... 56

FIGURA 33 - Escolha do MTC para modelagem da estrutura de fundação....... 57

FIGURA 34 - Entrada de dados dos elementos estruturais da fundação............. 57

FIGURA 35 - Significado físico dos índices de fatores de influência................ 59

FIGURA 36 - Cenário de controle do cálculo e emissão de relatórios das matrizes MFMS e MFEF............................................................... 59

FIGURA 37 - Cenário de controle do cálculo e convergência do processo

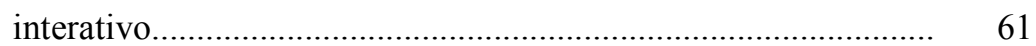

FIGURA 38 - Cenário de acesso ao relatório de resultados (cargas e recalques

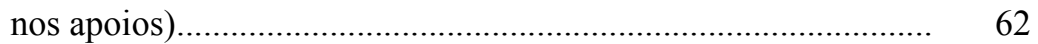

FIGURA 39 - Sobre do software StructsoiL....................................................... 62

FIGURA 40 - Pórtico espacial e locação dos pilares e furos de sondagem exemplo didático......................................................................... 65

FIGURA $41 \quad-\quad$ Sondagem SPT - Furo 1............................................................. 66

FIGURA $42-$ Sondagem SPT - Furo 2 ……………....................................... 66

FIGURA 43 - Sondagem SPT - Furo 3............................................................ 67

FIGURA 44 - Pórtico espacial - edifício assimétrico.............................................. 69 
FIGURA 45 - Planta de locação dos pilares do edifício assimétrico e dos furos de sondagem SPT em maciço de solos residual............................ $\quad 70$

FIGURA 46 - Sondagem SPT - Furo FR1 …………......................................... 71

FIGURA 47 - Sondagem SPT - Furo FR2 ……………....................................... 71

FIGURA 48 - Sondagem SPT - Furo FR3 …………………………………...... 72

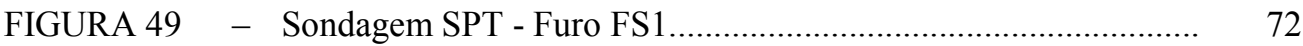

FIGURA 50 - Sondagem SPT - Furo FS2 ……………………………........... 73

FIGURA 51 - Sondagem SPT - Furo FS3 ……………………….................. 73

FIGURA 52 - Sondagem SPT - Furo FS4.................................................... 74

FIGURA 53 - Sondagem SPT - Furo FS5 ………………………………...... 74

FIGURA 54 - Pórtico espacial - edifício simétrico................................................ 78

FIGURA 55 - Planta de locação dos pilares do edifício simétrico e dos furos de sondagem SPT em maciço de solos sedimentar....................... $\quad 78$

FIGURA 56 - Curvas iso-recalques, em milímetros, para análise convencional (tracejadas) e análise interada (contínuas) - sapatas isoladas exemplo didático

FIGURA 57 - Curvas iso-recalques, em milímetros, para análise convencional (tracejadas) e análise interada (contínuas) - tubulões a céu aberto - exemplo didático............................................................ 91

FIGURA 58 - Curvas iso-recalques, em milímetros, para análise convencional (tracejadas) e análise interada (contínuas) - estacas cravadas -

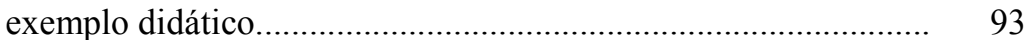

FIGURA 59 - Curvas iso-recalques, em milímetros, para análise convencional (tracejadas) e análise interada (contínuas) - sapatas isoladas maciço residual - edifício assimétrico............................................ 95

FIGURA 60 - Curvas iso-recalques, em milímetros, para análise convencional (tracejadas) e análise interada (contínuas) - tubulões a céu aberto - maciço residual - edifício assimétrico

FIGURA 61 - Curvas iso-recalques, em milímetros, para análise convencional (tracejadas) e análise interada (contínuas) - estacas cravadas maciço sedimentar - edifício assimétrico........................................ 97

FIGURA 62 - Curvas iso-recalques, em milímetros, para análise convencional (tracejadas) e análise interada (contínuas) - estacão - maciço sedimentar - edifício assimétrico 
FIGURA 63 - Curvas iso-recalques, em milímetros, para análise convencional (tracejadas) e análise interada (contínuas) - tubulões a céu aberto - maciço residual - edifício simétrico.

FIGURA 64 - Curvas iso-recalques, em milímetros, para análise convencional (tracejadas) e análise interada (contínuas) - estacas cravadas maciço sedimentar - edifício simétrico

FIGURA 65 - Curvas iso-recalques, em milímetros, para análise interada em condições naturais (tracejadas) e após inundação permanente (contínuas) - sapatas - maciço residual - edifício assimétrico......

FIGURA 66 - Curvas iso-recalques, em milímetros, para análise interada em condições naturais (tracejadas) e após inundação permanente (contínuas) - tubulões - maciço residual - edifício assimétrico.... 


\section{LISTA DE TABELAS}

TABELA 01 - Lista de entidades e atributos..................................................

TABELA 02 - Cargas nos apoios para condição de apoios indeslocáveis exemplo didático....................................................................... 65

TABELA 03 - Estrutura de fundação - sapatas - exemplo didático...................... 68

TABELA 04 - Estrutura de fundação - tubulões - exemplo didático..................... 68

TABELA 05 - Estrutura de fundação - estacas cravadas - exemplo didático...... 69

TABELA 06 - Cargas nos apoios para condição de apoios indeslocáveis edifício assimétrico..................................................................... 70

TABELA 07 - Estrutura de fundação - sapatas - edifício assimétrico.................. 75

TABELA 08 - Estrutura de fundação - tubulões - edifício assimétrico................. 76

TABELA 09 - Estrutura de fundação - estacas cravadas - edifício assimétrico... 76

TABELA 10 - Estrutura de fundação - estacão - edifício assimétrico.................. 77

TABELA 11 - Cargas nos apoios para condição de apoios indeslocáveis edifício simétrico.......................................................................... 79

TABELA 12 - Estrutura de fundação - tubulões - edifício simétrico..................... 80

TABELA 13 - Estrutura de fundação - estacas cravadas - edifício simétrico...... 80

TABELA 14 - Cargas e recalques nos apoios - sapatas - exemplo didático........ 82

TABELA 15 - Cargas e recalques nos apoios - tubulões - exemplo didático...... 83

TABELA 16 - Cargas e recalques nos apoios - estacas cravadas - exemplo

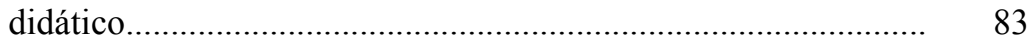

TABELA 17 - Cargas e recalques nos apoios - sapatas - edifício assimétrico.... 84

TABELA 18 - Cargas e recalques nos apoios - tubulões - edifício assimétrico.. 84

TABELA 19 - Cargas e recalques nos apoios - estacas cravadas - edifício assimétrico...................................................................... 85

TABELA 20 - Cargas e recalques nos apoios - estacão - edifício assimétrico.... 85

TABELA 21 - Cargas e recalques nos apoios - tubulões - edifício simétrico...... 86 
TABELA 22 - Cargas e recalques nos apoios - estacas cravadas - edifício simétrico

TABELA 23 - Cargas e recalques nos apoios - sapatas - edifício assimétrico maciço residual inundado

TABELA 24 - Cargas e recalques nos apoios - tubulões - edifício assimétrico maciço residual inundado.

TABELA 25 - Coeficientes de segurança e recalques - sapatas - exemplo didático

TABELA 26 - Coeficientes de segurança e recalques - tubulões - exemplo didático

TABELA 27 - Coeficientes de segurança e recalques - estacas cravadas exemplo didático.

TABELA 28 - Eficiência da interação com a superestrutura - exemplo didático.

TABELA 29 - Coeficientes de segurança e recalques - sapatas - edifício assimétrico

TABELA 30 - Coeficientes de segurança e recalques - tubulões - edifício assimétrico

TABELA 31 - Coeficientes de segurança e recalques - estacas cravadas edifício assimétrico.

TABELA 32 - Coeficientes de segurança e recalques - estacão - edifício assimétrico

TABELA 33 - Eficiência da interação com a superestrutura - edifício assimétrico..

TABELA 34 - Coeficientes de segurança e recalques - tubulões - edifício simétrico.

TABELA 35 - Coeficientes de segurança e recalques - estacas cravadas edifício simétrico.

TABELA 36 - Eficiência da interação com a superestrutura - edifício simétrico

TABELA 37 - Comparação dos coeficientes de segurança e recalques obtidos para as condições de maciço residual natural e inundado sapatas - edifício assimétrico 
TABELA 38 - Variação da eficiência da interação com a superestrutura sapatas - edifício assimétrico - maciço residual (normal x inundado).

TABELA 39 - Comparação dos coeficientes de segurança e recalques obtidos para as condições de maciço residual natural e inundado tubulões - edifício assimétrico.

TABELA 40 - Variação da eficiência da interação com a superestrutura tubulões - edifício assimétrico - maciço residual (normal $\mathrm{x}$ inundado) 


\section{LISTA DE ABREVIATURAS E SIGLAS}

$\begin{array}{lll}\text { CC } & - & \text { Capacidade de carga } \\ \text { CPT } & - & \text { Cone Penetration Test } \\ \text { CS } & - & \text { Coeficiente de segurança } \\ \text { DER } & - & \text { Diagrama Entidade Relacionamento } \\ \text { DFD } & - & \text { Diagrama de Fluxo de Dados } \\ \text { MCSC } & - & \text { Modelo da Camada de Solos Complementar } \\ \text { MFEF } & - & \text { Matriz de Flexibilidade da Estrutura de Fundação } \\ \text { MFMS } & - & \text { Matriz de Flexibilidade do Maciço de Solos } \\ \text { MGDE } & - & \text { Modelo Geotécnico de Deformabilidade Elástica } \\ \text { MGR } & - & \text { Modelo Geotécnico de Resistência } \\ \text { MRS } & - & \text { Matriz de Rigidez da Superestrutura } \\ \text { MTC } & - & \text { Modelo de Transferência de Carga } \\ \text { NA } & - & \text { Nível d'água } \\ \text { NR } & - & \text { Nível de referência } \\ \text { PP } & - & \text { Peso próprio } \\ \text { RL } & - & \text { Resistência lateral } \\ \text { RLUU } & - & \text { Resistência lateral última unitária } \\ \text { RPUU } & - & \text { Resistência de ponta última unitária } \\ \text { SGBD } & - & \text { Sistema Gerencial de Banco de Dados } \\ \text { SPT } & - & \text { Standard Penetration Test } \\ \text { UF } & - & \text { Unidade de fundação }\end{array}$




\section{LISTA DE SÍMBOLOS}

\begin{tabular}{|c|c|c|}
\hline $\mathrm{c}$ & - & coesão \\
\hline $\mathrm{C}$ & - & coeficiente adimensional de correlação de correlação do módulo de \\
\hline & & Young com ensaios de penetração dinâmica (CPT) e estática (SPT) \\
\hline $\mathrm{CS}_{\text {interado }}$ & - & coeficiente de segurança da unidade de fundação na análise interada \\
\hline $\mathrm{D}$ & - & distância entre dois pontos de referência \\
\hline $\mathrm{dV}$ & - & variação da carga aplicada no apoio \\
\hline $\mathrm{E}$ & - & módulo de Young \\
\hline F1 & - & fator de correção da resistência de interface na base \\
\hline $\mathrm{F} 2$ & - & fator de correção da resistência de interface no fuste \\
\hline fc & - & resistência de projeto do concreto \\
\hline fck & - & resistência característica do concreto \\
\hline fef & - & $\begin{array}{l}\text { fator de influência da deformabilidade elástica longitudinal do elemento } \\
\text { discreto }\end{array}$ \\
\hline fms & - & fator de influência entre os apoios pela continuidade do maciço de solos \\
\hline fs & - & fator de influência entre os apoios pela continuidade do pórtico espacial \\
\hline HX & - & esforço horizontal na direção do eixo $\mathrm{X}$ aplicado à unidade de fundação \\
\hline HY & - & esforço vertical na direção do eixo $\mathrm{Y}$ aplicado à unidade de fundação \\
\hline $\mathrm{K}$ & - & fator de correlação CPT/SPT \\
\hline 1 & - & número de iterações \\
\hline MX & - & momento fletor em torno do eixo $\mathrm{X}$ aplicado à unidade de fundação \\
\hline MY & - & momento fletor em torno do eixo $\mathrm{Y}$ aplicado à unidade de fundação \\
\hline neduf & - & número de elementos discretos da referida unidade de fundação \\
\hline neuf & - & número de elementos estruturais da referida unidade de fundação \\
\hline $\mathrm{N}_{\mathrm{SPT}}$ & - & número de golpes obtidos no SPT \\
\hline nuf & - & número de apoios da superestrutura (unidades de fundação) \\
\hline $\mathrm{T}$ & - & momento torsor aplicado à unidade de fundação \\
\hline
\end{tabular}




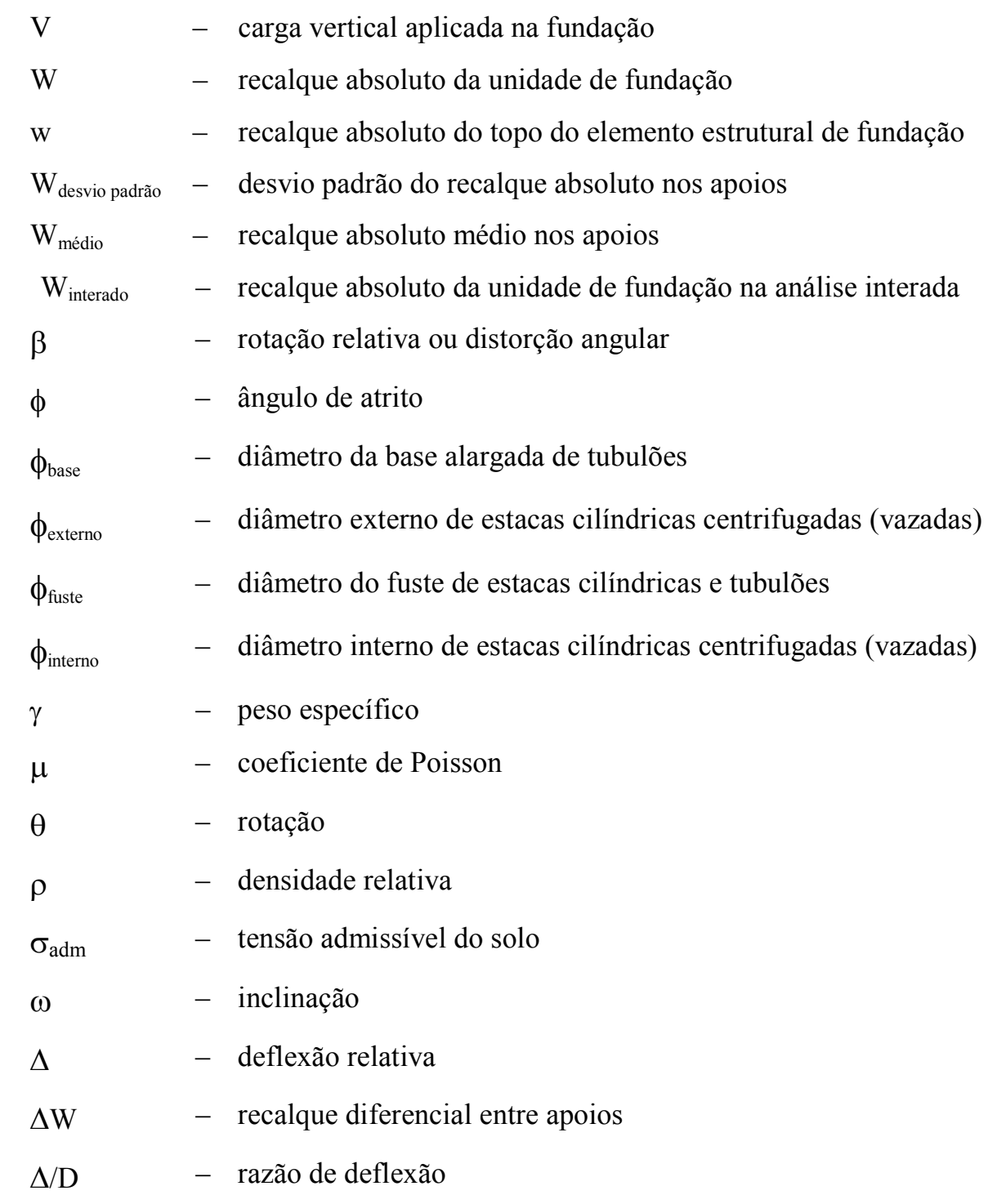

\section{Simbologia adotada na revisão bibliográfica}

I $\quad-\quad$ matriz identidade

$\{V\} \quad-\quad$ vetor das reações de apoio

$\left\{V_{0}\right\} \quad-\quad$ vetor das reações de apoio para a condição de sistema principal

[FM] - matriz de flexibilidade do solo

[SM] - matriz de rigidez da superestrutura

$\delta_{0} \quad-\quad$ recalque total na cota de ligação do pilar com o bloco de fundação

$\delta_{\mathrm{p}} \quad-\quad$ encurtamento axial do elemento de fundação

$\delta_{\mathrm{s}} \quad-\quad$ deslocamento proveniente da deformação do maciço de solos 


\section{RESUMO}

MENDONÇA, J. C. (2000). Um modelo computacional de análise da interação estrutura maciço de solos em edifícios. São Carlos, 2000. Dissertação (Mestrado) - Escola de Engenharia de São Carlos, Universidade de São Paulo.

Uma solução computacional geral e expansível de análise da interação estrutura maciço de solos foi desenvolvida adotando metodologia orientada a objetos. A técnica computacional apresenta um menu de retaguarda que torna a manipulação dos dados de entrada e os processos computacionais mais criteriosos e seguros. Os materiais possuem comportamento perfeitamente elástico-linear, enquanto o mecanismo de transferência de carga estrutura-solo é não linear. O maciço de solos é modelado através de dados de sondagens SPT e mapeamento geotécnico. A fundação é discretizada verticalmente para se obter as matrizes de flexibilidade da estrutura de fundação (MFEF) e do maciço de solos (MFMS). O processo interativo básico consiste em obter o vetor de recalques nos apoios pelo produto do vetor de cargas verticais com as matrizes MFEF e MFMS. Na seqüência, calcula-se o vetor de redistribuição de cargas pelo produto do vetor de recalques com a matriz de rigidez da superestrutura (MRS). Um procedimento iterativo condiciona a convergência de recalques e cargas verticais nos apoios. A solução foi utilizada para analisar o comportamento de edifícios de diferentes geometrias em planta e espacial, variando o perfil geotécnico do maciço suporte e a técnica de execução da estrutura de fundação.

Palavras-chave: interação estrutura - maciço de solos, fundações, mapeamento geotécnico. 


\section{ABSTRACT}

MENDONÇA, J. C. (2000). A computational model for the soil-structure interaction analysis in the case of spatial framed structures. São Carlos, 2000. Dissertação (Mestrado) - Escola de Engenharia de São Carlos, Universidade de São Paulo.

A general and expansible computational code based in the oriented to object programming technique was developed aiming the soil-structure interaction analysis. This computational technique has a special feature that makes the data input operations and the computer processing safer and more criterious. This model considers that all materials behaves as perfectly linear elastic materials, although the soil-structure transfer mechanism is of non-linear nature. The soil mass compressibility and resistance are modelled from soil data obtained from geotechnical mapping techniques and SPT boreholes data. The flexibility matrix (MFEF) of the structural foundation elements and the flexibility matrix (MFMS) of soil mass elements are obtained through a numerical discretization procedure. The basic interative process consists in the calculation of the supports displacement vectors obtained by the multiplication of the vertical load vector by the MFEF and the MFMS matrix. Finally, the load redistribution is obtained by the multiplication of the displacement vector by the structural rigidity matrix (MRS). The uniqueness of the solution is guaranteed by the convergence of the displacements and vertical supports reactions by using an iterative procedure. This computational code was applied to the analysis of the behaviour of spatial framed buildings with varied geometry, taking into account different geotechnical soil conditions and different types of foundations.

Keywords: soil-structure interaction, foundations, geotechnical mapping. 


\section{INTRODUÇÃO}

\subsection{GENERALIDADES}

Os métodos de cálculo estrutural aproximados pela subdivisão da estrutura tornaramse obsoletos devido ao desenvolvimento computacional ocorrido nos últimos anos. Antigamente, as vigas $\mathrm{e}$ as lajes eram calculadas por aproximações práticas. $\mathrm{O}$ desenvolvimento da máquina calculadora tornou possível modelar pórticos simples e com os primeiros computadores pode-se modelar pórticos planos, painéis e pórticos espaciais por elementos de barra e grelhas. Hoje, consegue-se modelar todos os elementos da superestrutura conjuntamente, podendo inclusive, impor condições de apoios deformáveis através de molas. Por outro lado, o apoio representado por mola de comportamento elásticolinear não representa o comportamento do solo, por este ser um contínuo, principalmente no caso de fundações profundas. Portanto, a última barreira para eliminar a subdivisão do sistema estrutura - maciço de solos ainda está por ser vencida e consiste em modelar o sistema estrutura - maciço de solos definindo-se o projeto da superestrutura considerando as características da fundação e vice-versa.

Geralmente, a verificação da segurança aos estados limites último e de utilização dos elementos estruturais da superestrutura é efetuado pelo projetista da superestrutura, que atendendo essa verificação preliminar, fornece as cargas na fundação. A partir do valor dessas cargas e das características do maciço de solos, o projetista da fundação determina a área da superfície de contato e a cota da base do elemento de fundação superficial, ou a seção transversal e a profundidade da ponta, do elemento de fundação profunda. Deste modo, a consideração da interação estrutura - maciço de solos, é reduzida a uma discussão sobre valores admissíveis de recalques, resultantes da experiência em obras similares. Na prática, pela medição de recalques em obras monitoradas, está comprovado que os recalques calculados pelos métodos convencionais são bastante imprecisos, sendo que os recalques diferenciais são os mais influenciados pela interação estrutura - maciço de solos. Como consequência, o custo da estrutura sobe ao atender a um estado limite de utilização irreal. Por 
outro lado, a redistribuição de esforços compromete a segurança dos elementos estruturais, principalmente os pilares e suas fundações.

Existem vários trabalhos que pesquisaram os efeitos da interação estrutura - maciço de solos para edifícios apoiados em sapatas (GUSMÃO (1990) e NOORZAEI et al. (1991)), enquanto há poucos métodos computacionais que permitem o estudo da interação estrutura maciço de solos para fundações profundas. CHAMECKI (1955) propôs um método pioneiro de interação estrutura - maciço de solos baseado na prática rotineira da engenharia estrutural e de fundações, fundamentado em um processo iterativo entre os resultados da análise estrutural e do cálculo de recalques dos apoios. POULOS (1975) apresentou uma metodologia baseada no cálculo matricial de estruturas para a estimativa de recalques da fundação incorporando a interação estrutura - maciço de solos. O método de CHAMECKI (1955) é adequado para todos os tipos de fundações (superficial ou profunda), mas de maior custo computacional quando comparado às equações de interação apresentadas por POULOS (1975), as quais são adequadas para fundações diretas individuais. A solução apresentada por este trabalho compatibiliza o cálculo matricial com um procedimento iterativo que condiciona a convergência do comportamento linear de fundações superficiais e não-linear de fundações profundas, modeladas elasticamente.

\subsection{OBJETIVO E JUSTIFICATIVA}

O objetivo deste trabalho é apresentar uma ferramenta simples, mas geral e expansível, que permita o estudo da interação estrutura - maciço de solos em estruturas aporticadas, dando enfoque ao carregamento vertical. Visualiza-se que, a partir desta estruturação principal, o software poderá ser adaptado para outros fins como lançamento da superestrutura, cálculo da estrutura de fundação e consideração de carregamentos secundários (forças horizontais e momentos), entre outros.

Como comentado, relativamente poucos trabalhos analisam a interação estrutura maciço de solos para fundações profundas. Os trabalhos que fornecem métodos computacionais de cálculo de interação estrutura - maciço de solos sob carregamento estático, em quase sua totalidade se preocupam ou se detêm às fundações diretas. Neste trabalho, propõe-se um modelo computacional baseado na teoria da elasticidade, que permite a consideração dos efeitos da interação estrutura - maciço de solos em edifícios apoiados em pilares com fundações individuais, sejam elas superficiais ou profundas verticais. 
O trabalho vem preencher uma lacuna no estudo do cálculo de recalques de fundações de estruturas aporticadas de concreto armado com fundações profundas. A justificativa está baseada na sua notória aplicabilidade como ferramenta acadêmica de estudo da interação estrutura - maciço de solos. Para uso prático, o trabalho permite que seja verificada a segurança de obras executadas com um mínimo controle de execução e que tenham estudos do maciço de solos usado como apoio, como sondagens de simples reconhecimento. Estudos dedicados à interação entre estruturas aporticadas apoiadas em sapatas e o maciço de solos concluem que a consideração da interação entre os dois subsistemas pode conduzir a projetos mais realistas, seguros e econômicos.

O projeto de fundação, usando-se a técnica computacional apresentada, passa a ser dependente, não só da magnitude do carregamento e das condições naturais do maciço, mas também, da rigidez da superestrutura e do maciço de solos. O dimensionamento da superestrutura será influenciado pelas propriedades do maciço suporte e pelo tipo de estrutura de fundação escolhido. Nesse caminho, todos os empreendimentos, mesmo que idênticos arquitetonicamente, terão em maior ou menor grau, características estruturais próprias definidas pelas características do maciço de apoio. Por essa visão, a estrutura de fundação e a superestrutura passam a constituir um único conjunto, ou sistema, interagindo com o maciço de solos.

\subsection{DEFINIÇÕES E CONVENÇÕES}

O seguinte trecho: '... a interação estrutura - maciço de solos em projeto de edifícios pode detectar uma significativa redistribuição dos esforços nos elementos estruturais, principalmente nos pilares. A diminuição dos recalques diferenciais pode ser uma outra conseqüência dessa interação. Por outro lado, a magnitude dos efeitos da interação estrutura - maciço de solos é função da rigidez relativa entre a estrutura e o maciço ...' poderia estar contido em quase todos os capítulos desse trabalho e contém algumas expressões de uso restrito do estudo da interação estrutura - maciço de solos e do comportamento de fundações. Expõe-se, a seguir, as principais convenções para discretização do sistema estrutura - maciço de solos e definições dos movimentos da superfície do maciço suporte. 


\subsubsection{DISCRETIZAÇÃO DO SISTEMA ESTRUTURA - MACIÇO DE SOLOS}

Para o estudo da interação do sistema estrutura - maciço de solos define-se a estrutura como o conjunto [superestrutura + estrutura de fundação] e a fundação como o subsistema [estrutura de fundação + maciço de solos]. Abaixo, define-se a subdivisão do sistema e convenciona-se uma terminologia (....):

- obra - representa, a nível de modelagem, um objeto que recebe os atributos do sistema estrutura - maciço de solos, localizando-o no espaço e definindo suas características gerais;

- estrutura - conjunto que engloba todas as peças responsáveis pela sustentação da edificação, sendo subdividida em superestrutura e estrutura de fundação;

- superestrutura - representada pelo pórtico espacial e composto pela associação de lajes, vigas, pilares e outros elementos que confiram rigidez ao conjunto;

- estrutura de fundação - composta por blocos e elementos estruturais com função de transferência de cargas provenientes da superestrutura ao maciço suporte;

- maciço de solos e/ou rocha - definição mais abrangente de solo de fundação que representa um material estratificado de composição variável ao longo de um mesmo plano, que resiste às tensões devido ao carregamento da edificação;

- unidade de fundação - é o conjunto de elementos da estrutura de fundação associado ao maciço de solos que o envolve, responsável por suportar um ou mais pontos de apoio da superestrutura, e pode ser representada por: um elemento isolado (sapata, tubulão ou estaca), um grupo de elementos unidos por um bloco de capeamento (grupo de estacas), uma fundação associada ou ligada por viga de fundação, um radier simples ou estaqueado;

- elemento de fundação - é o elemento da estrutura de fundação que possui função de transferir cargas ao solo (sapata, estaca, radier, etc);

- elemento discreto de fundação - representa um segmento de fuste ou a base de um elemento de fundação;

- camada de solos complementar - representa o aterro superficial executado na terraplanagem e que não foi reconhecido pela sondagem SPT;

- indeslocável ou superfície indeformável - horizonte definido pela superfície gerada pelas cotas do impenetrável de sondagens SPT ou outro critério. Para cálculo de recalques em edificações considera-se que o maciço subjacente não sofre deformações devido às tensões provenientes das cargas transferidas ao maciço de solos; 
- MRS - matriz de rigidez da superestrutura; oferece a redistribuição de cargas entre os apoios quando se aplica um deslocamento vertical unitário aos mesmos;

- MFEF - matriz de flexibilidade da estrutura de fundação; oferece a deformabilidade longitudinal dos elementos verticais discretizados devido aos esforços normais;

- MFMS - matriz de flexibilidade do maciço de solos; oferece a deformabilidade do maciço de solos na vertical de um apoio, entre a cota do mesmo e o indeslocável, devido a distribuição de cargas ao maciço pelos elementos discretizados da estrutura de fundação;

- rigidez relativa superestrutura-fundação - é a relação entre a rigidez absoluta da superestrutura e a da fundação (também conhecida como rigidez relativa estrutura-solo, denominação válida somente para fundações superficiais, já que estas não induzem aumento de rigidez ao maciço contínuo).

\subsubsection{MOVIMENTOS DA SUPERFÍCIE DO MACIÇO SUPORTE}

Há uma extensa variedade de símbolos e terminologias para descrição dos movimentos da superfície do maciço suporte. Adotou-se um conjunto das principais definições que descrevem esses movimentos, adaptando as definições propostas por BURLAND \& WROTH (1974):

- recalque absoluto $(\mathrm{W})$ - é o deslocamento vertical descendente de um ponto discreto da estrutura de fundação ou do maciço suporte; pode ser causado por deformações do maciço ou deformações axiais dos elementos da estrutura de fundação;

- recalque diferencial $(\Delta \mathrm{W})$ - é a diferença entre o recalque absoluto de dois diferentes pontos de apoio da superestrutura e representa o movimento vertical relativo entre os mesmos;

- rotação $(\theta)$ - é a rotação de uma reta unindo dois pontos quaisquer da estrutura de fundação ou do maciço suporte;

- inclinação $(\omega)$ - rotação da reta que une dois pontos de apoio extremos da estrutura;

- rotação relativa ou distorção angular $(\beta)$ - descreve a rotação de uma reta unindo dois diferentes pontos de apoio de uma edificação, descontada a inclinação da mesma; 
- deflexão relativa $(\Delta)$ - é o deslocamento vertical máximo em relação a uma reta que une os dois pontos de referência (extremos de uma linha de apoios de uma edificação);

- razão de deflexão $(\Delta / \mathrm{D})$ - é a relação entre deflexão relativa e a distância (D) entre os dois pontos de referência.

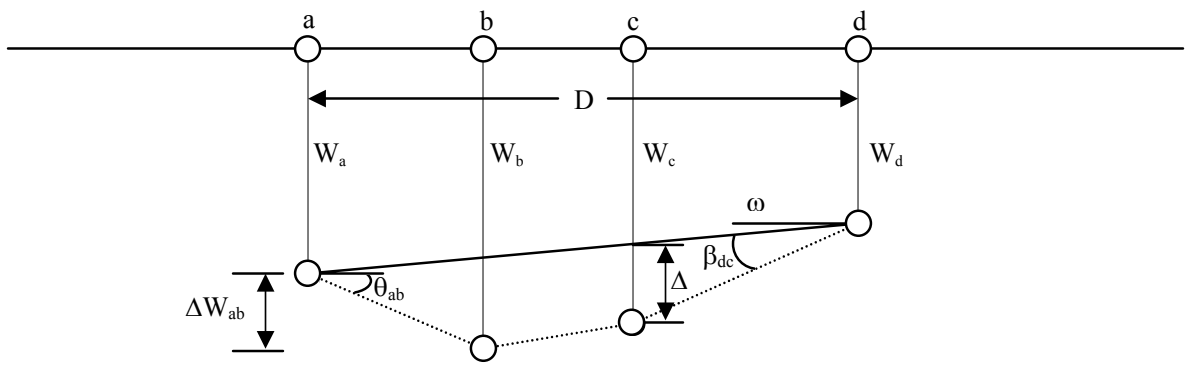

FIGURA 01 - Definições dos movimentos da superfície do maciço suporte 


\section{INTERAÇÃO ESTRUTURA - MACIÇO DE SOLOS}

\subsection{GENERALIDADES}

$\mathrm{Na}$ concepção geral de edifícios, pode-se dividir o sistema estrutura - maciço de solos em três partes:

i) superestrutura;

ii) estrutura de fundação e;

iii) maciço de solos e/ou rocha.

Em uma concepção mais abrangente, AOKI \& CINTRA (1996) definem maciço de solos como sendo o conjunto formado por um certo número de elementos de solos, estratificados ou não, ocupando continuamente o espaço físico delimitado pela superfície do terreno e do indeslocável.

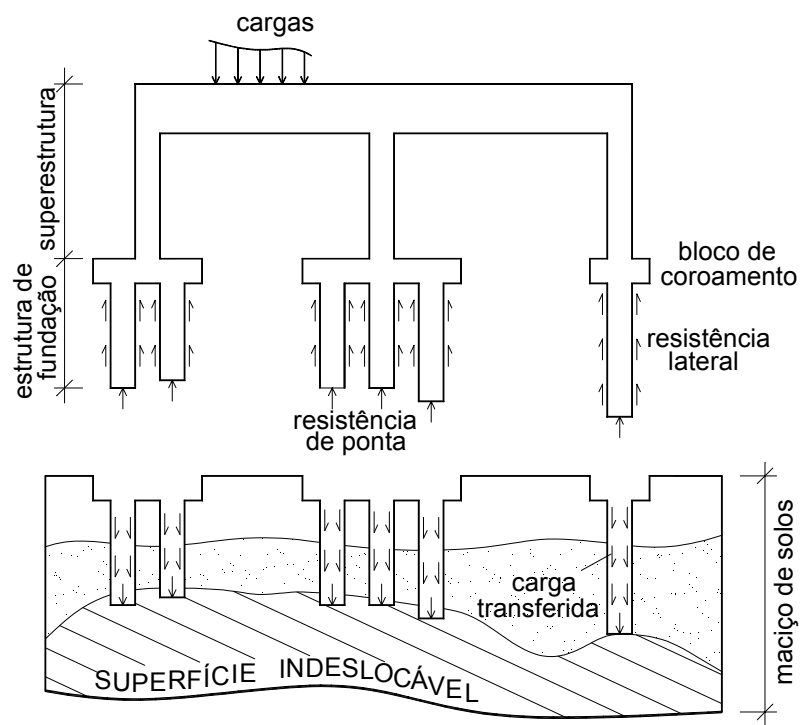

FIGURA 02 - Estrutura e maciço de solos 
Para estudar a interação estrutura - maciço de solos é preciso adotar um modelo de transferência de carga de um pórtico a uma fundação individual ou em grupo, e a transmissão de carga ao maciço de solos pela interface estaca-solo, conforme a FIGURA 02. O modelo de deformabilidade do maciço de solos adotado deve prescrever a condição de que, sob a ação de carga imposta pela fundação, as camadas de solo situadas entre a base da fundação e o indeslocável sofram deformações. Para uso de um modelo, é de extrema importância o conhecimento da reologia do maciço de solos (relação tensão - deformação - tempo) e dos materiais de construção que compõem a estrutura de fundação.

A FIGURA 03 mostra esquematicamente a distribuição de tensões ao maciço pela fundação em grupos de estacas. Visualiza-se a superposição de campos de tensões e a interação entre as fundações dos apoios através do maciço suporte.

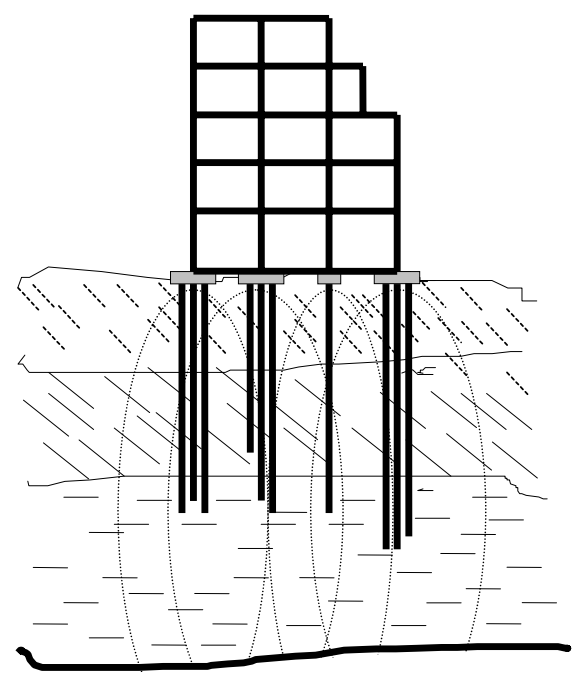

FIGURA 03 - O sistema estrutura - maciço de solos e a transferência de tensões ao maciço

Atualmente, o projeto da superestrutura é desenvolvido admitindo-se hipótese de apoios indeslocáveis. Assim, o cálculo das cargas na fundação e o dimensionamento dos elementos da estrutura de fundação são executados baseando-se nessa hipótese. Isso deve-se à concepção corriqueira de que a superestrutura é carregada pelo peso próprio, pelas cargas de serviço e cargas acidentais e as transmite à estrutura de fundação, que por sua vez, as transfere ao maciço de solos ou rocha. Na verdade, o desempenho da edificação é definido pelo comportamento interativo entre as três partes acima definidas, sob a ação do mecanismo denominado, neste trabalho, interação estrutura - maciço de solos, ou interação soloestrutura, como é mais conhecido. 


\subsection{REVISÃO BIBLIOGRÁFICA}

\subsubsection{ANÁLISE DA INTERAÇ̃̃o ESTRUTURA - MACIÇO DE SOLOS}

\subsubsection{Metodologias}

Segundo GUSMÃO (1990), existem alguns modelos disponíveis para a consideração da interação estrutura - maciço de solos em projetos, mas boa parte destes modelos são bastante complexos em suas análises e isto inviabiliza o uso prático. É consenso da bibliografia especializada que para ser utilizado na prática, os modelos devem ser simples, considerar a estratificação do solo e levar em conta efeitos de grupo e efeitos da interação do maciço de solos contínuo com a estrutura de fundação e com a superestrutura.

CHAMECKI (1955) publicou um método pioneiro para considerar a interação estrutura - maciço de solos. Baseou-se na prática rotineira da engenharia estrutural e de fundações, na qual o engenheiro estrutural fornece as reações totais nos apoios, admitindo a hipótese dos mesmos serem indeslocáveis, além dos coeficientes de transferência de carga, que são as reações verticais dos apoios, provenientes de recalques unitários de cada apoio em separado, formando o que se denomina matriz de rigidez da superestrutura. Em seguida, o engenheiro de fundações calcula os recalques para as reações de apoio da estrutura indeslocável. A partir daí, inicia-se um processo interativo com a consideração da rigidez da superestrutura onde, através da utilização de expressões estabelecidas, são fornecidas as novas reações de apoio, sendo em seguida, obtidos os valores dos novos recalques. Este processo é repetido até a convergência dos valores das reações e recalques nos apoios. Mas, com o uso do método, observou-se que a consideração da rigidez da estrutura no cálculo dos recalques da fundação influencia os recalques diferenciais, aproximando-os dos recalques medidos. LANARCH (1970) propôs um método computacional para o método de CHAMECKI (1955), que permite uma solução de convergência global.

POULOS (1975) propôs uma metodologia de análise baseada no cálculo matricial de estruturas para a estimativa de recalques da fundação incorporando a interação estrutura maciço de solos. A análise requer o desenvolvimento de duas equações:

i) Equação de interação superestrutura-fundação, que relaciona o comportamento da superestrutura e da fundação em termos das cargas estruturais aplicadas e das reações desconhecidas na fundação:

$$
\{V\}=\left\{V_{0}\right\}+[\mathrm{SM}]\{\delta\}
$$


ii) Equação de interação fundação - maciço de solos, que relaciona o comportamento da fundação e do maciço de solos em termos das reações desconhecidas na fundação e das propriedades do solo:

$$
\{\delta\}=[\mathrm{FM}]\{V\}
$$

sendo:

$\{V\}$ - vetor das reações de apoio, considerando a interação estrutura - maciço de solos;

$\left\{V_{0}\right\}$ - vetor das reações de apoio, obtidas a partir da análise convencional da superestrutura, considerando os apoios indeslocáveis;

$\{\delta\}$ - vetor dos deslocamentos (translações e rotações) dos apoios considerando-se a interação estrutura - maciço de solos;

[SM] - matriz de rigidez da superestrutura, que relaciona adicionais de carga a deslocamentos unitários nos apoios;

[FM] - matriz de flexibilidade da fundação, que relaciona deslocamentos dos apoios a transferências de cargas unitárias.

Considerando o modelo completo de cargas e deslocamentos, existem seis componentes de reação (três forças e três momentos) e seis componentes de deslocamento (três translações e três rotações) em cada apoio. Sendo n o número de apoios da estrutura, os vetores definidos acima serão de ordem 6 n e as matrizes de rigidez e flexibilidade serão representadas por matrizes quadradas de dimensão $6 \mathrm{n} \times 6 \mathrm{n}$. Vale ressaltar que o deslocamento em um apoio pode não depender apenas do seu carregamento, mas também do carregamento dos demais apoios, isto é, pela continuidade do maciço de solos modelado como meio perfeitamente elástico, em termos matriciais os elementos fora da diagonal principal das matrizes de flexibilidade e de rigidez podem ser não nulos. A interação estrutura - maciço de solos é estabelecida pela combinação das eq.(1) e eq.(2), resultando em:

$$
\left\{V_{0\}}\right\}=(I-[\mathrm{SM}][\mathrm{FM}])\{V\}
$$

A solução da eq.(3) fornece as reações de apoio desconhecidas $\{V\}$ e daí, através da eq.(2), pode-se determinar os deslocamentos. Na eq.(3), I é a matriz identidade. Por conseguinte, pode-se verificar a superestrutura aplicando-se os deslocamentos $\{\delta\}$ na modelagem estrutural obtendo-se as solicitações nesta devido à interação estrutura - maciço de solos.

AOKI $(1982,1985,1987,1997)$ propõe um modelo completo de interação entre estacas verticais e um bloco rígido baseando-se no método de cálculo estático de 
estaqueamento proposto por SCHIEL (1957) e sistematizado por STAMATO (1971), considerando o efeito do grupo de estacas sob o mesmo bloco. A partir dessa consideração, propõe procedimento idêntico ao proposto por CHAMECKI (1955) para proceder a interação entre a estrutura e o maciço de solos.

O modelo interativo proposto é constituído dos passos abaixo, sendo iterativo até alcançar a convergência:

a) inicialmente procede-se ao cálculo convencional considerando-se apoios indeslocáveis;

b) as reações de apoio, cargas verticais e momentos de engastamento, são aplicados aos blocos sobre estacas; o movimento do bloco do pilar k sob ação destas cargas é calculado e a parcela do recalque sob a base da estaca (j,k), são calculados considerando a ação simultânea das cargas transmitidas ao solo por todas as estacas de todos os blocos;

c) na $\mathrm{m}^{\text {ésima }}$ iteração volta-se ao programa de análise estrutural, substitui-se o apoio indeslocável por um mola de rigidez conhecida e recalcula-se as novas reações de apoio;

d) repete-se esta operação até que as reações obtidas na $\mathrm{m}^{\text {śima }}$ iteração coincidam com os valores obtidos na (m-1) $)^{\text {ésima }}$ iteração.

\subsubsection{Ferramentas computacionais}

ZAMBROZUSKI et al. (1985) desenvolveram umas das primeiras tentativas de uma ferramenta computacional aplicável a microcomputadores para estudar a interação estrutura - maciço de solos em edifícios. Utilizaram o processo proposto por AOKI (1982), o qual aplica e integra a solução de MINDLIN (1936) para forças em meio elástico, através da discretização da carga transferida proposta por AOKI \& LOPES (1975). As considerações referentes ao meio estratificado baseiam-se na proposta de STEINBRENNER (1934); os diagramas de transferência de carga são adotados de acordo com o método AOKI \& VELLOSO (1975). A modelagem do pórtico espacial foi executada segundo GERE \& WEAVER Jr. (1981).

PINHO \& BRITO (1986) deram sequência ao trabalho de ZAMBROZUSKI et al. (1985) desenvolvendo uma outra ferramenta computacional, denominada TREFIC-86, que modela pórticos planos e incorpora a interação de grupos de estacas pela consideração de capeamento rígido segundo método proposto por SCHIEL (1957). 
AOKI \& AOKI (1989) produziram o SOILDEF, desenvolvido em BASIC. O SOILDEF calcula o recalque de elementos de fundação profunda vertical (tubulões e estacas) e superficial (sapatas). Essa ferramenta também é baseada na solução de MINDLIN (1936) e usa a discretização proposta por AOKI \& LOPES (1975). A entrada de dados consiste na estratificação do maciço de solos em camadas homogêneas de acordo com os relatórios de ensaios SPT, cadastro concomitante de parâmetros elásticos de deformabilidade e funções lineares de transferência de tensões ao longo do fuste do elemento de fundação profunda vertical. Os resultados de recalques verticais devido às deformações no maciço de solos são oferecidos para os pontos definidos na entrada de dados. O software não permite a análise automática da interação estrutura - maciço de solos, mas é ferramenta suficiente para esta análise quando utilizada a proposta original de CHAMECKI (1955). MENDONÇA et. al (1998) aplicaram este modelo computacional para estudar o comportamento de grupo de edifícios vizinhos construídos sobre maciço composto por espessa camada de argila mole e com fundação superficial.

RIBEIRO \& REIS (1990), prosseguindo a mesma linha de pesquisa, utilizaram um sistema comercial de análise estrutural acoplado a um software desenvolvido para calcular os esforços nos apoios e proceder a reanálise da estrutura pela imposição de recalques aos apoios. Nesse trabalho despreza-se a rigidez do bloco de coroamento, mas oferece alternativa de pré-dimensionamento e escolha do tipo de fundação mais econômico levando em conta a rigidez da superestrutura.

Esses trabalhos pioneiros são limitados pela carência, na época, de equipamentos que suportassem cálculo robusto e pela deficiência da linguagem de programação empregada. No entanto, servem como referência para os trabalhos que seguem a mesma filosofia de desenvolvimento de uma técnica que propicie o estudo da interação estrutura - maciço de solos.

Enquanto os trabalhos citados anteriormente usaram a metodologia proposta por CHAMECKI (1955), GUSMÃO (1990) desenvolveu uma ferramenta computacional, chamada INTERA, usando a filosofia proposta por POULOS (1975). GUSMÃO (1990) apresentou análise qualitativa de fatores que influenciam o mecanismo de interação estrutura - maciço de solos em edificações. Por força da metodologia utilizada, sua análise é restrita a edificações com fundações superficiais e individuais para cada apoio e usa o $\mathrm{SAFE}^{\odot}$ (Structural Analysis by Finite Elements), versão 5.1, para obter vetor de cargas nos apoios e a matriz de rigidez da superestrutura. Os principais fatores estudados foram: rigidez relativa estrutura - solo, efeitos da construção dos primeiros pavimentos, presença de cintas, forma em planta da edificação e distância da superfície de apoio ao indeslocável. 
Outros trabalhos posteriores, como GUSMÃO \& GUSMÃO FILHO (1990, 1994a), GUSMÃO \& LOPES (1990), LOPES \& GUSMÃO (1991), JUCÁ et al. (1994), FONTE et al. (1994), partiram da mesma formulação e modelagem. Prosseguindo essa linha de pesquisa, MOURA (1995) desenvolveu um módulo computacional que acoplado a um software de análise estrutural permitiu a consideração dos efeitos da interação estrutura maciço de solos em edifícios apoiados em sapatas. A estrutura foi modelada de forma linear e não-linear e foram estudados os efeitos do processo construtivo, por uma análise incremental. Os resultados foram comparados com dados de instrumentação.

VILADKAR \& SARAN (1994) propuseram uma outra técnica automática para análise interativa de pórticos planos e espaciais, suportado por fundação rasa independente em cada apoio. O processo desconsidera deformações transversais e o efeito de grupo na fundação. $\mathrm{O}$ solo é representado por um semi-espaço elástico tridimensional. O processo proposto impõe os recalques nos apoios do pórtico e aplica as reações de apoio consequentes, juntamente com as reações devido ao carregamento, ao maciço de solos através dos elementos de fundações até que todos os deslocamentos de apoio tenham convergido a um mesmo valor.

\subsubsection{MÉTODOS DE CÁLCULO DE RESISTÊNCIA E DE RECALQUE DA FUNDAÇÃo}

AOKI \& VELLOSO (1975) propuseram um critério de estimativa da capacidade de carga de estacas de diferentes tipos a partir dos resultados dos ensaios de penetração dinâmica. A prática consagrou esse método utilizando-o para estacas cravadas, escavadas e outros tipos. O método oferece correlações, entre ensaios de penetração dinâmica (SPT) e ensaios de penetração estática (CPT), usadas nas formulações que oferecem a capacidade de carga: seja lateral (fuste) ou de ponta (base). A grande vantagem desse método é a facilidade de ser automatizado, pois a formulação matemática é a mesma para todos os tipos de estrutura de fundação, alterando-se somente os coeficientes de correção, relativos à técnica empregada.

DÉCOURT \& QUARESMA (1978) propuseram outro método semi-empírico de previsão de capacidade de carga baseado em ensaios de penetração estática, também consagrado pela prática. Esse método possui a desvantagem de ter uma formulação matemática variável com a técnica de implantação da fundação e mesmo com a granulometria do solo suporte.

AOKI \& LOPES (1975) apresentaram um procedimento numérico, segundo o qual as cargas que um grupo de estacas ou tubulões transmitem ao maciço são discretizadas e 
substituídas por um sistema equivalente de cargas concentradas, cujos efeitos são superpostos nos pontos em estudo. Os recalques são estimados utilizando a solução proposta por MINDLIN (1936) e a discretização da carga imposta pelos elementos de fundação é feita usando a formulação apresentada. As fórmulas foram deduzidas para elementos cilíndricos e prismáticos, instalados verticalmente.

\subsubsection{LITERATURA SOBRE A INTERAÇÃO ESTRUTURA - MACIÇO DE SOLOS EM EDIFÍCIOS}

A maioria dos trabalhos que modelaram a interação estrutura - maciço de solos fizeram análise paramétrica de alguns fatores que interferem no comportamento global da estrutura e que não são considerados na análise convencional (GUSMÃO (1990) e NOORZAEI et al. (1991)). Esses trabalhos foram classificados como estudos teóricos dos efeitos da interação estrutura - maciço de solos, enquanto os trabalhos que usaram esses conhecimentos acumulados para a interpretação ou projeto de casos reais são apresentados como casos práticos.

\subsubsection{Estudos teóricos}

As análises paramétricas executadas por GUSMÃO (1990) mostraram que:

i) o parâmetro que define o comportamento de uma edificação é a rigidez relativa superestrutura-fundação;

ii) o aumento do número de pavimentos da edificação aumenta a rigidez da superestrutura, exercendo influência na tendência à uniformização dos recalques e;

iii) a análise tridimensional condiciona maior uniformização dos recalques.

NOORZAEI et al. (1991) usam a formulação proposta por GODBOLE et al. (1990) para o estudo da interação pórtico espacial - radier - maciço de solos, usando elementos de barra para representar vigas e colunas e elementos de placa para modelar o radier e as lajes da superestrutura. Através de estudo paramétrico analisou-se a influência da variação da rigidez das lajes e do radier no comportamento global. Com a análise dos resultados concluiu-se que:

i) a representação da laje como parte da superestrutura torna a modelagem mais realística do ponto de vista estrutural. Isso se o processo construtivo usa lajes maciças moldadas in loco e devidamente engastadas na estrutura; 
ii) o acréscimo da rigidez do radier reduz os recalques diferenciais e as pressões de contato, e acresce os valores máximos de momentos no radier. Por conseguinte, conduz uma redistribuição de momentos nos membros da superestrutura;

iii) o acréscimo da rigidez das lajes causa insignificantes alterações nos recalques, pressões de contato e momentos no radier. Por outro lado, produz significantes modificações dos momentos fletores nos membros da superestrutura.

VILADKAR et al. (1991) e NOORZAEI et al. (1993) prosseguiram a mesma linha de pesquisa, modelando o solo com a consideração da não-linearidade através de um modelo tensão-deformação hiperbólico do solo, além de incluir a não homogeneidade do maciço em pelo menos duas camadas.

CHANDRASHEKHARA \& ANTONY (1993) estudaram a solução no estado plano de tensões para análise de interação de estrutura aporticada apoiada por uma viga de fundação sobre um maciço de solos estratificado. Para análise teórica, usaram dois métodos analíticos para o meio estratificado semi-infinito: o modelo de Winkler e o meio equivalente semi-infinito; e o método dos elementos finitos para a superestrutura aporticada. A análise teórica foi comparada com os resultados de modelos. O método de Winkler se mostrou inadequado para o sistema estratificado analisado, enquanto o modelo equivalente se mostra adequado quanto a distribuição de tensões, assim como para determinar os esforços na estrutura. Mas este método não é satisfatório para determinar os recalques ao longo da profundidade.

NOORZAEI et al. (1995a, 1995b) investigaram o comportamento interativo de um sistema pórtico plano - sapata corrida - maciço de solos considerando o comportamento elasto-plástico do solo com minoração linear da deformabilidade com a profundidade usando os dois critérios de ruptura de Drucker-Prager. A análise sugere que, em geral, a interação do sistema conduz à transferências de forças e momentos das colunas externas para as internas quando há plastificação de zonas no contorno devido a carregamentos elevados. SRINAVASA RAO et al. (1995) mostraram uma comparação entre uma modelagem para o solo em semi-espaço contínuo e no estado plano de deformações. A interação entre pórticos planos vizinhos apoiados em sapatas foi estudada a partir da análise do efeito de confinamento do solo.

\subsubsection{Casos práticos}


Algumas experiências acumuladas nos últimos anos pela consideração da interação estrutura - maciço de solos na concepção de projetos de fundação, ou pela retroanálise do comportamento de edifícios monitorados são apresentadas.

GUSMÃO (1990) fez comparações entre resultados estimados e medidos e concluiu que o comportamento da edificação está associado a dois modelos:

a) tensão-deformação do maciço de solos;

b) interação estrutura - maciço de solos,

e comprovou o efeito da interação estrutura - maciço de solos em edificações, tais como redistribuição de cargas nos pilares e diminuição dos recalques diferenciais.

GUSMÃO \& GUSMÃO FILHO (1990) discorreram sobre o desempenho de um edifício com fundação superficial em Recife onde os efeitos da interação estrutura - maciço de solos foram considerados na fase de projeto. Para avaliação dos efeitos da interação estrutura - maciço de solos nos recalques do prédio, foi admitido que a superestrutura pudesse ser substituída por um radier com rigidez equivalente. Foram utilizados os gráficos propostos por FRASER \& WARDLE (1976) para a estimativa dos recalques, obtendo-se uma redução dos recalques diferenciais estimados da ordem de $30 \%$. Os pilares periféricos foram dimensionados com resistência $30 \%$ maior que na condição convencional de indeslocabilidade dos apoios.

RAMALHO \& CORREA (1991) analisaram a interação estrutura-solo entre uma estrutura aporticada apoiada em sapatas sobre um solo modelado como meio elástico semiinfinito, verificando a influência da flexibilidade do maciço de solos no comportamento (esforços e deslocamentos) do sistema estrutural, através de análise paramétrica da rigidez do maciço suporte. Foram tomados como objeto de estudo o sistema estrutural de dois prédios construídos em São Paulo e Goiânia. Os resultados obtidos têm sua validade comprometida por dois aspectos:

i) a não consideração da estratificação do solo e de um horizonte indeformável na modelagem por elementos finitos;

ii) o processo interativo adotado entre o maciço dos solos e a estrutura não é iterativo e portanto é não convergente. Assim, os resultados apresentados representam apenas uma iteração do sistema.

RANDOLPH \& CLANCY (1994) fizeram uma retroanálise do comportamento de um prédio com fundação em cinco radieres estaqueados e simetria em um eixo (Perth, Austrália). Concluíram que a redução dos recalques diferenciais foi provocada pela interferência da rigidez da superestrutura. No entanto, sugeriram que para melhor desempenho do sistema um caminho seria aumentar a deformabilidade das fundações no 
contorno. O artifício aumentaria os recalques totais, mas em compensação diminuiria os recalques diferenciais e minimizaria os custos da fundação.

KATZENBACH et al. (1994) apresentaram a análise numérica utilizada na definição do projeto da COMMERZBANK TOWER em Frankfurt, com $300 \mathrm{~m}$ de altura. Nesta análise, adotaram o Cap Model como modelo constitutivo do solo e o critério de ruptura de Drucker-Prager, enquanto para o radier e as estacas foi usado o modelo elástico. A análise determinou os efeitos da interação estrutura - maciço de solos, oferecendo a parcela de carga absorvida pelo radier e as deformações do estaqueamento que transferem a parcela de carga restante a uma camada de argila relativamente fraca e para um substrato calcário rígido no qual foi apoiado. KATZENBACH et al. (1997) apresentaram resultados comparáveis entre as previsões e os resultados da monitoração de 30 pontos no radier e no estaqueamento.

No caso de grandes empreendimentos, a análise prévia de recalques já é imprescindível na fase de projeto. Este foi o caso das gêmeas PETRONAS TOWERS, com 450 metros de altura, localizadas em Kuala Lumpur, Malásia. A análise prévia do comportamento dos prédios com a consideração da interação estrutura - maciço de solos resultou na mudança de localização do edifício como forma de minimizar recalques diferenciais. Neste estudo, reportado por BAKER et al. (1994), a interação com a superestrutura não foi considerada, mas somente a interação entre o radier estaqueado e o maciço de solos. O problema maior era o recalque diferencial entre as duas torres, devido a não homogeneidade vertical e horizontal do maciço de solos suporte e a presença de uma cavidade de grandes proporções no maciço rochoso.

\subsubsection{INFLUÊNCIA DO PROCESSO CONSTRUTIVO}

Como o processo construtivo de edifícios convencionais é lento e o carregamento devido ao peso próprio representa a maior parte do carregamento total, existe uma interação estrutura - maciço de solos progressiva, o que pode significar uma flexibilização da estrutura. Essa interação pode ser definida como determinante para alcançar uma modelagem completa e realística. Por outro lado, a maioria dos trabalhos analíticos publicados sobre o assunto não consideram aspectos da sequência construtiva, admitindo a estrutura completa e desprezando as acomodações do sistema durante o período construtivo. BROWN \& YU (1986) analisaram uma estrutura plana segundo o método de POULOS (1975) e uma tridimensional conforme WARDLE \& FRASER (1976), levando em consideração os casos de carregamento instantâneo e gradual. A análise dos dois casos mostrou que a rigidez efetiva do pórtico, para o propósito de interação, é reduzida à metade quando se aplica o 
carregamento progressivamente durante a construção comparando-se à edificação completa. FONTE et al. (1994) apresentam uma técnica incremental para a consideração da interação estrutura - maciço de solos usada para modelar o acréscimo sucessivo de rigidez e carregamento. Essa mesma técnica foi usada por MOURA (1995) para analisar os resultados da monitoração de um edifício de vários pavimentos.

GUSMÃO \& GUSMÃO FILHO (1994b) trataram o assunto sob o ponto de vista prático através da leitura de recalques em vários edifícios em construção na cidade do Recife. JUCÁ et al. (1994) acompanharam o comportamento de um edifício apoiado em fundação em sapata apoiada em solo melhorado por compactação dinâmica e verificou que os modelos que consideram o carregamento instantâneo sem a consideração da interação estrutura maciço de solos superestimam os recalques diferenciais, enquanto aqueles que consideram a interação com as mesmas condições, os subestimam. Assim, os modelos mais realísticos são aqueles que consideram incrementos de rigidez e carregamento ao longo do tempo, isso quando se prende apenas às deformações elásticas do sistema.

O processo construtivo limita a eficiência da rigidez da estrutura no comportamento interativo e, segundo GUSMÃO FILHO \& GUIMARÃES (1997), há um limite de acréscimo de rigidez ao sistema a partir do qual não mais contribui, mantendo-se a deformada de recalques. A partir dessa condição os recalques se mantêm constantes. Assim, em edifícios convencionais, a rigidez adicionada pelos primeiros pavimentos influenciam de forma mais significativa no comportamento do sistema.

\subsection{ANÁLISE TEÓRICA}

\subsubsection{MODELOS DE ESTUDO DA INTERAÇÃO ESTRUTURA - MACIÇO DE SOLOS}

A interação estrutura - maciço de solos, para o caso de carregamento estático, é melhor compreendida admitindo seis modelos de análise para o caso de fundações profundas. Observando os desenhos esquemáticos apresentados na FIGURA 04 e na FIGURA 05, os modelos podem ser classificados, para o caso de edifícios, como: elemento isolado, grupo de elementos isolados, grupo de elementos isolados unidos por capeamento, grupo de grupos unidos por capeamento, edifício completo e grupo de edifícios.

\subsubsection{Interação elemento isolado - maciço de solos}


É o modelo mais simples (FIGURA 04a), no qual a interação se processa na superfície de contato, pela transmissão de tensões ao maciço, gerando deformações no sistema. Os modelos de previsão de recalques em estacas isoladas retratam este caso. Pela complexidade do comportamento do solo na interface estaca-solo, é usual adotar modelo de transferência de carga que considera a estaca isolada. Os modelos propostos adotando a compatibilidade de deslocamentos na interface estaca-solo pela continuidade do meio (POULOS (1972), POULOS \& DAVIS (1980), entre outros) oferecem resultados que não condizem com o observado experimentalmente. Provas de carga monitoradas mostram que o atrito lateral é totalmente despertado para pequenos deslocamentos, enquanto a resistência de ponta não é mobilizada. O modelo proposto por AOKI (1979) admite que com o carregamento da estaca, cargas são transferidas primeiramente pelo fuste (pequenos deslocamentos), caso haja resistência lateral. Segundo este modelo a resistência de ponta só é mobilizada sob grande deslocamento do topo, após deslizamento da interface, ou seja, esgotamento da resistência lateral.

\subsubsection{Interação grupo de elementos isolados - maciço de solos}

O maciço de solos é um meio contínuo e o deslocamento de um elemento do grupo provoca deformações no meio que induzem deformações aos demais (FIGURA 04b). Há várias formas e métodos de proceder a análise do comportamento do grupo de elementos sem a consideração da rigidez do bloco de coroamento. Os métodos analíticos mais usados são os que consideram fatores de interação para representar o efeito de grupo como RANDOLPH \& WROTH (1979) e POLO \& CLEMENTE (1988); e os chamados híbridos, por exemplo O'NEILL et al. (1977).

\subsubsection{Interação de grupo de elementos unidos por bloco de coroamento - maciço de solos}

Pela tradição, o projeto de fundação em estacas é baseado na concepção de que a carga é absorvida pelas estacas sem contribuição do bloco de coroamento ou radier. A capacidade de carga total é assumida como igual a carga de ruptura de uma estaca isolada multiplicada pelo número de estacas, e a carga admissível é obtida dividindo a capacidade de carga total por um coeficiente de segurança. Por este conceito de projeto, os efeitos favoráveis devido à interação entre estacas, blocos ou radiers e o maciço de solos são completamente ignorados, e para atender condições de segurança, faz com que o resultado 
obtido seja conservador e antieconômico (HANSBO (1993)). A rigidez do bloco influencia no comportamento do grupo, pois interfere no mecanismo de transferência de carga do conjunto ao maciço de solos e impõe momentos fletores às estacas, além de redistribuir cargas axiais entre elas (FIGURA 04c). Existem alguns modelos para consideração da influência do bloco de coroamento no comportamento do grupo de estacas, como os apresentados por POULOS (1968), BUTTERFIELD \& BANERJEE (1971) e CHOW (1991). Um novo método de análise para sapatas estaqueadas é apresentado por SALES (2000).

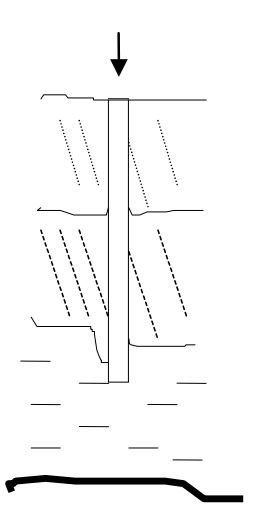

(a)

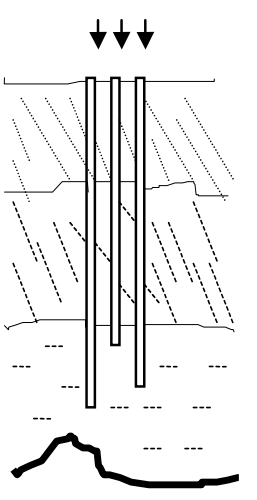

(b)

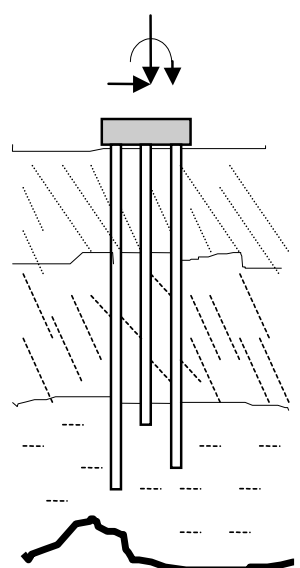

(c)

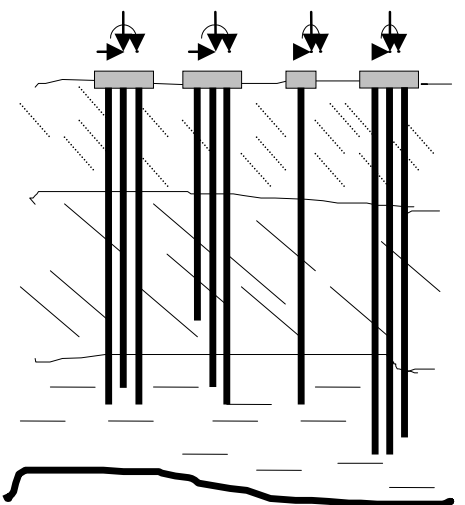

(d)

FIGURA 04 - Modelos para estudo da interação estrutura - maciço de solos, caso de fundação profunda, desprezando a superestrutura.

\subsubsection{Interação grupo de elementos unidos por bloco de coroamento - maciço de solos} - grupo de elementos

Esse modelo retrata a interação entre grupos de elementos agrupados por bloco de coroamento com outros grupos ou elementos isolados através do meio contínuo representado pelo maciço de solos (FIGURA 04d). POULOS \& DAVIS (1980) sugeriram que o grupo de estacas unidos por capeamento seja substituído por um tubulão de diâmetro e comprimento equivalente e seja aplicado a uma solução teórica de estaca. O conceito de tubulão equivalente simplifica o grupo de elementos unidos por capeamento em um único elemento de rigidez e forma equivalente, o que facilita a modelagem para considerar a interação entre grupos de grupos de elementos através do maciço. 


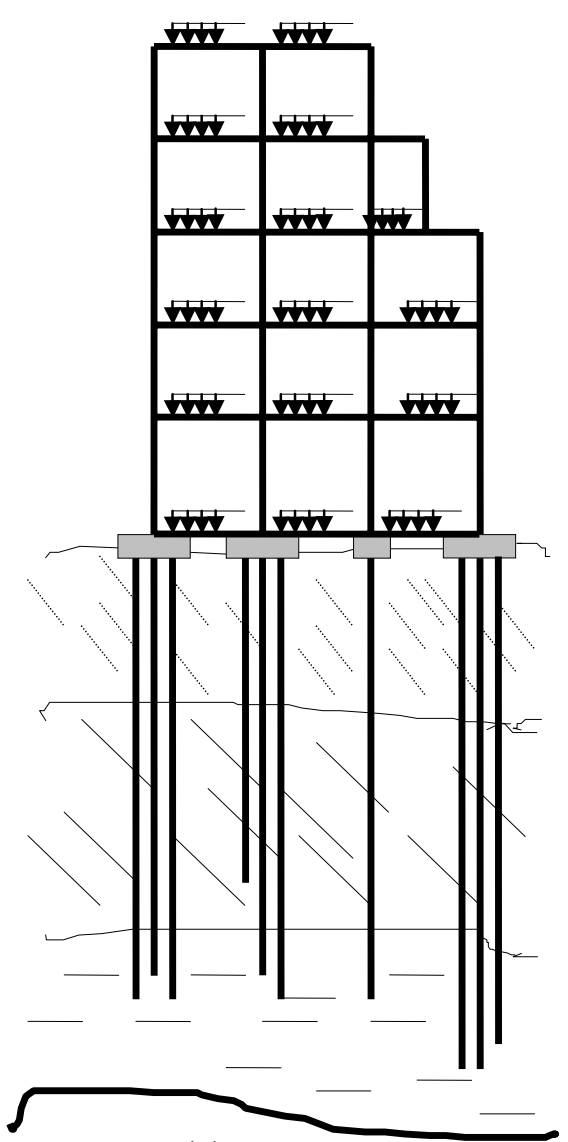

(a)

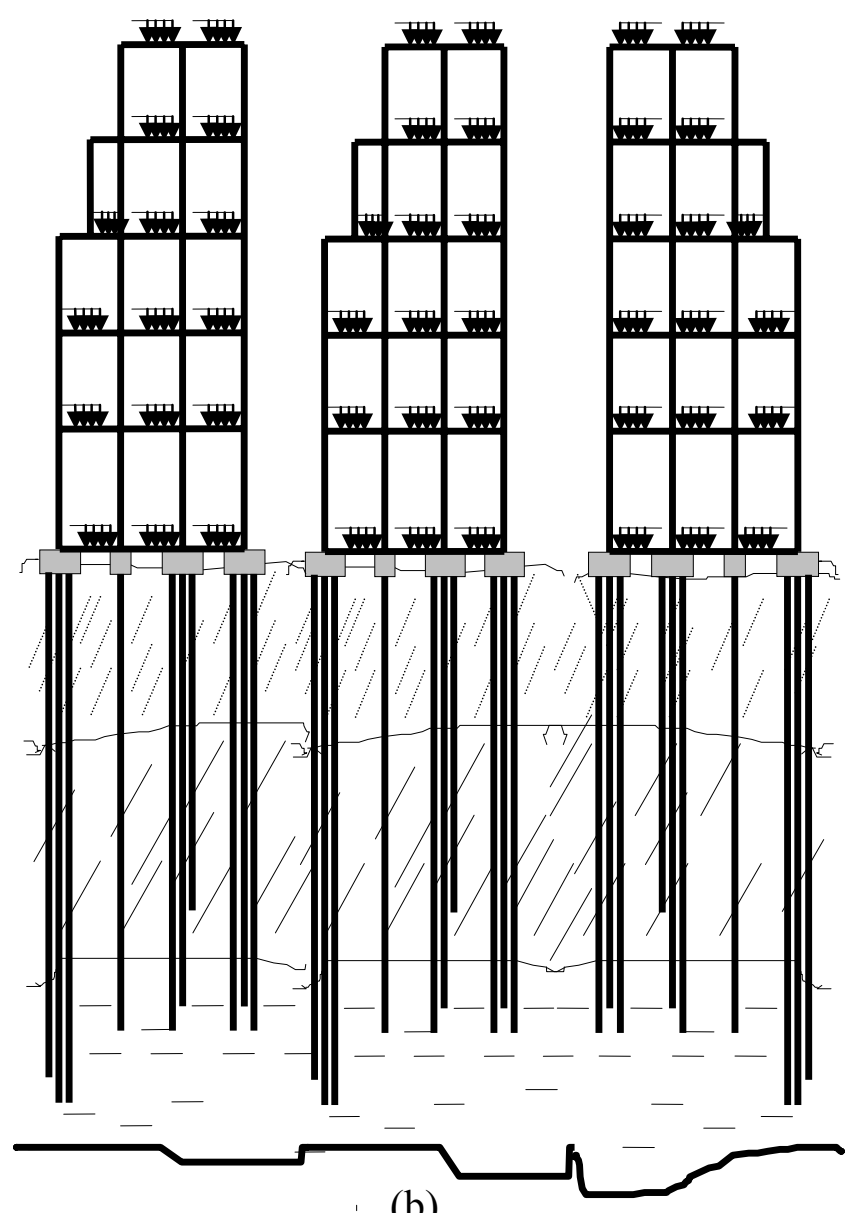

(b)

FIGURA 05 - Modelos para estudo da interação estrutura - maciço de solos, considerando a superestrutura.

\subsubsection{Interação edifício completo - maciço de solos}

Neste modelo de interação, além da continuidade do maciço de solos, há a influência da continuidade da superestrutura, que contribui com a interação pela redistribuição de cargas entre os apoios que tendem a sofrer maior distorção angular. Além disso, para o caso do grupo de estacas sob um bloco rígido, há a interação entre as estacas através do bloco (FIGURA 05a).

\subsubsection{Interação grupo de edifícios - maciço de solos}

Um modelo completo tem que considerar as condições de vizinhança, seja ela representada por prédios vizinhos, outras obras de engenharia ou condições naturais que 
interfiram no comportamento da edificação. MENDONÇA et al. (1998) tratam da importância da interação entre prédios vizinhos em regiões de argila mole e mostram que um modelo mais abrangente pode verificar a interferência de obras vizinhas no comportamento da edificação (FIGURA 05b).

\subsubsection{MODELAGEM DO SISTEMA ESTRUTURA - MACIÇO DE SOLOS}

\subsubsection{Subdivisão do sistema estrutura - maciço de solos}

Mesmo sendo importante visualizar o comportamento global da estrutura, para aplicação dos modelos interativos, é necessário subdividir o sistema estrutura - maciço de solos na ligação do pilar com o bloco de coroamento (cota do nível inferior da viga baldrame - NR), para efeito do estudo da interação.

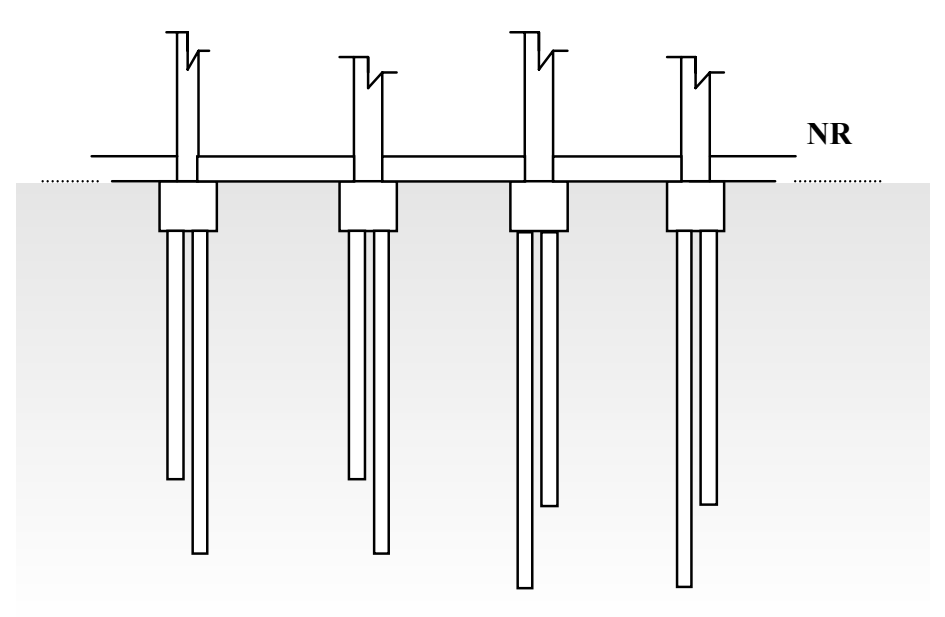

FIGURA 06 - Definição do nível de referência do modelo

Esta subdivisão é conveniente para a prática, já que existe a cultura de elaboração do projeto estrutural independentemente da concepção do projeto de fundação. Assim, define-se dois subsistemas:

- superestrutura e;

- estrutura de fundação e maciço de solos, ou simplesmente fundação. 
FIGURA 07 - Quadro de dificuldades de modelagem da interação estrutura - maciço de solos em edificações

\begin{tabular}{|l|l|}
\hline \multicolumn{1}{|c|}{ PARTES DO SISTEMA } & \multicolumn{1}{c|}{ DIFICULDADES } \\
\hline \multirow{3}{*}{ Superestrutura } & - sequência construtiva \\
& - propriedades reológicas dos materiais \\
& - carregamento externo \\
\hline \multirow{2}{*}{ Estrutura de fundação } & - transferência de carga a massa de solos \\
& - propriedades reológicas dos materiais \\
& - aspectos executivos \\
\hline \multirow{3}{*}{ Maciço de solos } & - heterogeneidade vertical e horizontal \\
& - representatividade da prospecção e ensaios \\
& - influência do tempo nos parâmetros geotécnicos \\
\hline
\end{tabular}

Para se considerar a interação estrutura - maciço de solos é necessário modelar cada uma das três partes constituintes do sistema, mesmo considerando os dois subsistemas. Cada parte possui variabilidades próprias que influenciam no comportamento de um modelo único. GUSMÃO \& GUSMÃO FILHO (1994a) resumiram as principais dificuldades que interferem na modelagem das três partes principais do sistema estrutura - maciço de solos, as quais foram levemente alteradas e apresentadas na FIGURA 07.

Há uma grande diferença de modelagem na consideração da interação entre o subsistema estrutural (superestrutura e estrutura de fundação) e o geotécnico (maciço de solos). Enquanto os elementos estruturais têm características mecânicas bastante conhecidas e podem ser executados de acordo com um controle de desempenho, os elementos de solo têm características mecânicas naturais com alta dispersão e estas características podem, no máximo, serem alteradas a partir de um processo de melhoria do maciço (injeção ou compactação, por exemplo). Essa dificuldade de modelagem do solo, devido a suas características reológicas variáveis talvez denotem o pouco desenvolvimento de métodos de modelagem de fundações profundas para efeito do estudo de interação estrutura - maciço de solos. Por outro lado, a concepção de que, de forma geral, as fundações profundas são mais rígidas que as superficiais, e portanto menos deformáveis, pode ter induzido o interesse imediato pelo estudo do efeito da interação estrutura - maciço de solos para o último tipo.

\subsubsection{Modelagem da superestrutura}

Existem vários exemplos de modelos e ferramentas computacionais para análise da superestrutura. O modelo de discretização reticulada (elementos de barra) pode ser, apesar de simples, suficiente para modelagem do pórtico espacial sob o propósito de análise da 
interação estrutura - maciço de solos. Por outro lado, há disponibidade de sistemas comerciais potentes baseados em métodos numéricos sofisticados para modelagem da superestrutura $\left(\operatorname{SAP} 2000^{\odot}, \mathrm{SAFE}^{\odot}\right.$, etc).

\subsubsection{Modelagem da fundação}

$\mathrm{Na}$ interação consideram-se a deformabilidade e a resistência do elemento estrutural da fundação e das camadas de solos entre a base da fundação e o horizonte adotado como indeslocável. Para modelagem do subsistema fundação é necessário que se adote um modelo de transferência de carga do elemento de fundação ao solo. No caso de fundações diretas, pode-se usar o conceito do sólido elástico estratificado para modelagem do maciço de solos.

No caso de fundações profundas, o mecanismo de transferência de carga pode ser considerado para um elemento isolado (caso mais simples) ou para um grupo de elementos unidos por um bloco rígido. AOKI (1979) apresentou um modelo simples de transferência de carga para o caso de um elemento de fundação (estaca ou tubulão) isolado e vertical, sujeito a carregamento estático de compressão axial. Neste modelo, considera-se que o maciço de solos é elástico-linear e a transferência de carga é não-linear e dependente da resistência última das camadas de solo ao longo e sob a ponta dos elementos estruturais de fundações. Toda vez que, em uma dada seção, a resistência última é atingida, o grau de hiperasticidade do sistema diminui e a reação incógnita na seção passa a ser um valor conhecido que atua em conjunto com as demais cargas aplicadas. O comportamento da transferência por atrito pode ser definido também como elasto-plástico (elástico-linear e plástico sem endurecimento).

O subsistema fundação, para o caso de fundações profundas, possui elevado grau de hiperestaticidade, pois as reações de apoio são superabundantes e dependem de algumas características do maciço de solos, tais como:

i) estratificação;

ii) natureza geológica e;

iii) rigidez (ZEEVAERT (1987)).

Segundo VÉSIC (1977), os três tipos de modelos mais usados para prever o comportamento de estacas e grupos de estacas imersos no maciço de solos, são os baseados em:

i) função de transferência de cargas;

ii) sólido elástico e;

iii) método dos elementos finitos. 
A adoção de modelos simplistas para fundações nas quais os apoios que o solo oferece são substituídos por molas de rigidez conhecida, obedecendo a uma lei reológica expressa por uma função de transferência de carga, faz crer que um ponto só se desloca se ali for aplicada uma carga. Na realidade, pontos distantes do local carregado, também sofrem deslocamentos, devido a continuidade do meio. A aplicação deste modelo não é adequado às condições reais de edifícios convencionais, pois as cargas são transmitidas à fundação por pilares relativamente próximos e/ou por fundações profundas.

A adoção de modelos um pouco mais realísticos como os baseados na solução de MINDLIN (1936) se mostra aceitável para deslocamentos pequenos, tais que não ativem o comportamento plástico do solo, desde que seja considerada a estratificação do solo e o horizonte indeslocável conforme STEINBRENNER (1934). A discretização proposta por AOKI \& LOPES (1975) é uma ferramenta de aplicação dessa formulação, evitando a integração direta da solução.

A estimativa de tensões e deslocamentos de um ponto induzidos por grupos de elementos estruturais de fundação carregados verticalmente é o maior problema encontrado para modelar o subsistema fundação. Este é um problema complexo que envolve um grande número de variáveis, tais como: interação elemento de fundação - maciço, alterações nas características do maciço devido ao processo construtivo e deformabilidade do maciço de solos, entre outros. O método dos elementos finitos pode resolver alguns desses problemas simultaneamente, mas requer grande esforço computacional, entre outros inconvenientes práticos. Métodos de cálculos mais simples têm maior perspectiva de uso prático, principalmente porque possibilitam a compatibilização com outros métodos para resolver questões mais amplas, como é o caso da interação estrutura - maciço de solos em edifícios. As soluções mais aceitáveis na prática são baseadas em MINDLIN (1936), tendo equações estabelecidas para um meio semi-infinito, homogêneo, isotrópico e elástico - linear, pois oferecem boa estimativa de distribuição de tensões em solos. Para recalques, a solução de MINDLIN (1936) possui aplicação limitada devido à heterogeneidade do maciço natural. Conhecendo a distribuição de tensões, pela aplicação da hipótese de STEINBRENNER (1932) e imposição de um horizonte indeslocável, uma aproximação indireta pode ser obtida determinando o recalque para cada estrato individual que compõe o solo de fundação (GIROUD (1972)). AOKI \& LOPES (1975) sugerem a discretização da carga transferida pelo elemento de fundação por um sistema de cargas pontuais estaticamente equivalentes, determinando tensões e recalques de um ponto qualquer pela superposição de contribuição das forças individuais. Essas contribuições individuiais são obtidas através das fórmulas de 
MINDLIN (1936). O procedimento tem baixo custo computacional e possibilita, por superposição, computar grupos de estacas ou tubulões e outros tipos de fundação.

O método dos elementos finitos pode ser usado, principalmente, para o caso de fundações superficiais com a discretização do maciço de solos por elementos finitos. Cita-se os trabalhos de RAMALHO \& CORREA (1991) sobre a interação estrutura - maciço de solos com fundações rasas e de VELLOSO \& SANTOS (1986), onde apresentaram análises de provas de cargas em estacas com modelagem baseada no método dos elementos finitos. Uma formulação, usando elementos finitos e infinitos para modelar o solo em espaço bidimensional semi-infinito, foi apresentada por GODBOLE et al. (1990), para a análise da interação estrutura - maciço de solos em sapatas rígidas e flexíveis. Segundo GODBOLE et al. (1990), a formulação oferece os resultados da solução de Boussinesq com uma atrativa representação de um campo físico distante, baixo custo computacional e fácil preparação de dados.

No caso de fundações profundas, usando um modelo de transferência de carga realístico que permita a ocorrência de deslizamento (slip) entre o elemento estrutural de fundação e o maciço de solos, na interface, pode-se aplicar um método que forneça as deformações sofridas no maciço pela transferência de tensões. Por exemplo, métodos baseados em discretização por elementos finitos podem modelar a transferência de carga pelo elemento de fundação conforme o nível de carregamento, e obter os deslocamentos provenientes da deformação do maciço de solos $\left(\delta_{\mathrm{s}}\right)$. Métodos semi-empíricos de previsão da capacidade de carga última (AOKI \& VELLOSO (1975) ou DÉCOURT \& QUARESMA (1978), por exemplo) fornecem dados para obtenção do diagrama de carga resistente na ruptura aproximados por uma função qualquer. Com o diagrama de esforço normal no elemento estrutural de fundação (diagrama complementar ao de carga transferida) e suas características elásticas, determina-se o encurtamento axial do elemento de fundação $\left(\delta_{\mathrm{p}}\right)$, obtendo-se da somatória, conforme VÉSIC (1975):

$$
\delta_{0}=\delta_{\mathrm{s}}+\delta_{\mathrm{p}}
$$

o recalque total $\left(\delta_{0}\right)$ na cota de ligação do pilar com a estrutura de fundação.

\subsubsection{PROPOSTA DE UMA NOVA SOLUÇÃO COMPUTACIONAL}

As propostas de AOKI $(1982,1985,1987,1997)$ oferecem uma conceituação de modelo geral que considera a interação estrutura - maciço de solos, inclusive a interação 
bloco de coroamento - grupo de elementos estruturais (estacas). Estas propostas são baseadas em CHAMECKI (1955), um modelo original constituído de um processo iterativo convergente. Essa modelagem tem o inconveniente de exigir a análise da superestrutura e da fundação em tempo de execução do processo interativo, por sucessivas vezes, até a convergência dos resultados. Para produzir um software que execute esse procedimento é necessário que seja completo e que execute tanto a análise estrutural (superestrutura), quanto o cálculo de comportamento da fundação.

A solução proposta nesse trabalho foi estabelecida a partir da concepção de utilização de um software comercial de análise estrutural e adaptação de modelo computacional que execute análise do comportamento do maciço de solos e associação de uma estrutura de fundação. É imprescindível que haja particionamento do cálculo para que não sejam necessárias interações contínuas entre os dois softwares em tempo de execução. A proposta de POULOS (1975) é adaptável à filosofia do trabalho, pois possibilita que a superestrutura seja modelada por uma matriz de rigidez e a estrutura de fundação e o maciço de solos associado tenham comportamento definido pelas suas respectivas matrizes de flexibilidade. A solução de POULOS (1975) é fechada, somente, para o caso de fundações superficiais definida pela matriz de flexibilidade da fundação. Isso implica que o comportamento da fundação deve ser linear.

Fundações profundas que transmitem carga através do fuste, além da base, possuem comportamento não linear devido à distribuição de carga ao maciço suporte pela interface do fuste e da base serem dependentes do nível de carregamento. Dessa forma, a nova solução apresentada é a unificação da proposta de POULOS (1975) com a proposta de CHAMECKI (1955), ou seja, a adequação de um processo com base em cálculo matricial a um procedimento iterativo convergente que permita a consideração da não-linearidade dos deslocamentos de apoios sobre fundação profunda.

A proposta apresentada como solução computacional consiste na obtenção da matriz de rigidez da superestrutura (MRS), e das matrizes de flexibilidade da estrutura de fundação (MFEF) e do maciço de solos (MFMS). A obtenção dessas matrizes é feita a partir de um processo de discretização de elementos de estrutura de fundação profunda. O processo interativo é regido por operações usando a MRS, a MFEF e a MFMS. O processo segue a metodologia de CHAMECKI (1955) em seu processo de convergência, já que um modelo geral que represente o comportamento da fundação deve ser não linear e dependente de um modelo de transferência de carga baseado na capacidade de transferência de carga através da interface elemento estrutural - maciço de solos. O processo também é válido para fundações superficiais, utilizando o mesmo procedimento de convergência. Esse procedimento seria 
desnecessário de acordo com a proposta de POULOS (1975), porém exige esforço computacional adicional inexpressivo. O comportamento da fundação superficial é um caso particular, ou uma simplificação do modelo sugerido.

O processo interativo segue os passos seguintes:

a) calcula-se a MRS pela aplicação sucessiva de deslocamentos unitários em um apoio e obtenção de cargas nos apoios invertendo o sinal das reações de apoios em todos os pilares;

b) calcula-se o vetor de cargas nos apoios pela análise da superestrutura sob apoios fixos, sob carregamento de serviço e peso próprio (reações de apoio com sinal contrário);

c) determina-se MFEF pela aplicação de esforço normal unitário em todos os elementos discretos dos elementos estruturais de fundação e determinação de fatores de encurtamento (nula para fundação superficial);

d) determina-se a MFMS, modelando-se o subsistema estrutura de fundação maciço de solos, pela aplicação de carga unitária distribuída na interface de cada elemento discreto de fuste ou de base e obtenção de fatores de recalques na base de todos os elementos estruturais da fundação;

e) aplicam-se cargas aos elementos de fundação, transferindo-as ao maciço de acordo com a capacidade de transferência de carga e de um modelo de transferência de carga (MTC) previamente determinado;

f) o vetor de cargas transferidas por cada elemento discreto é multiplicado à MFMS obtendo-se recalques na base dos elementos de fundação;

g) se a fundação for profunda, obtém-se os esforços normais médios em cada elemento discreto formando um vetor de esforços normais. Multiplica-se este vetor à MFEF determinando-se o encurtamento. A somatória dos encurtamentos pela compressão dos elementos que compõem um elemento estrutural resulta no recalque por encurtamento longitudinal $\left(\delta_{\mathrm{p}}\right)$;

h) o recalque de apoio é a somatória de recalques devido à deformação do maciço sob a base $\left(\delta_{\mathrm{s}}\right)$ e encurtamento longitudinal $\left(\delta_{\mathrm{p}}\right)$;

i) aplicam-se os recalques aos apoios do modelo da superestrutura e multiplica-os à MRS, obtendo-se a variação do carregamento nos apoios;

j) testa-se convergência de recalques e cargas verticais nos apoios;

k) repetem-se os passos e, $\mathrm{f}, \mathrm{g}, \mathrm{h}$, i e j até que seja alcançada a convergência.

Para considerar grupo de estacas sob um mesmo apoio deve-se incluir um procedimento de interação bloco de coroamento - estacas para determinar as cargas 
encaminhadas a cada elemento estrutural no passo (e). Esse procedimento interativo deve conter operações que calculem o recalque resultante no apoio devido aos recalques no topo dos elementos estruturais de fundação pertencentes à unidade, modelando engastes estacabloco e pilar-bloco e considerando a rigidez das peças. 


\section{O SISTEMA COMPUTACIONAL}

\subsection{BREVE HISTÓRICO}

Em uma primeira tentativa de implementação do software, utilizou-se a programação estruturada convencional. Apesar dos processos terem sido bem definidos através de métodos de cálculos conceituados e de propostas testadas para exemplos simples, os resultados iniciais não foram satisfatórios. A complexidade do problema e a deficiência da programação baseada em processos não permitiram uma programação interativa que dinamizasse a produção do software. Alterações simples no modelo impunham grande quantidade de serviços de readaptação no processamento de dados. Os problemas foram se acumulando à medida que o software se tornava mais extenso e complexo.

A alternativa foi utilizar uma metodologia de projeto de software orientada a objetos, compatível com linguagens de programação de alto nível e baseada na análise de sistemas. A metodologia de projeto (modelo de análise) orientada a objetos proposta por RUMBAUGH et al. (1994) foi escolhida e adaptada. Para melhor entendimento da metodologia empregada descreve-se no APÊNDICE os principais conceitos sobre a modelagem do software.

\subsection{GENERALIDADES}

O software StructsoiL é uma ferramenta computacional de análise do comportamento de edifícios considerando a influência da interação da estrutura com o maciço de solos.

A superestrutura da edificação deve ter apoios individuais, e sua análise é procedida com o auxílio de um software de análise estrutural. O modelo utilizado interpreta o comportamento do conjunto estrutura - maciço de solos sob um determinado nível de carregamento vertical admitindo continuidade da massa de solos e um horizonte indeslocável na cota impenetrável ao SPT. 
O objetivo do software é oferecer um modelo computacional que propicie, à análise estrutural, a condição de levar em conta a flexibilidade da fundação. Para atender esse objetivo, o software foi construído atendendo as seguintes especificações:

a) contém um banco de dados de retaguarda que auxilia a entrada de dados da estrutura de fundação e do maciço de solos;

b) o banco de dados de retaguarda oferece condições de configurar os procedimentos de cálculo da resistência de interface e de modelo elástico-linear para o maciço de solos e para a estrutura de fundação, além de fazer correlações entre ensaios (SPT/CPT e SPT/triaxial);

c) a configuração permite o uso de modelos empíricos e semi-empíricos, através dos quais define-se funções de transferências de carga do elemento de fundação para o maciço de solos e se estabelece modelos de transferências de carga ao longo do fuste;

d) o modelo permite a entrada de dados manual dos resultados da análise estrutural e possui a capacidade de acoplar um módulo de comunicação que gerencie a operação de um software de análise estrutural e efetue a alimentação do banco de dados da superestrutura, automaticamente;

e) o modelo de interação é baseado em um processo matricial que compatibiliza o comportamento da fundação por matrizes de flexibilidade da estrutura de fundação e do maciço de solos com a análise estrutural;

f) o processo interativo é regido por procedimento de verificação de convergência dos resultados de cada iteração.

O software modela as técnicas conceituadas de execução de estruturas de fundação, independentes a cada apoio, sejam elas superficiais ou profundas. Para serem usadas, no módulo principal, essas técnicas devem ser cadastradas no banco de dados de retaguarda. O ensaio tomado como referência para obtenção das características do maciço de solos é o SPT.

O programa possui entrada de dados com base nos seguintes documentos:

- projeto estrutural (superestrutura); opcionalmente, pode-se usar também o projeto arquitetônico para modelar paredes divisórias;

- projeto de fundação (estrutura de fundação); opcionalmente, o software serve para pré-dimensionamento e;

- relatórios de sondagens de simples reconhecimento (SPT); opcionalmente, mapas geotécnicos (maciço de solos). 
O Diagrama de Contexto apresentado na FIGURA 08 mostra os fluxos de dados e suas respectivas origens/destinos. As origens/destinos identificam-se como executáveis, módulos, unidades de saída de dados, interação para convergência de resultados, etc.

A análise de dados básica do software consiste em demonstrar o Diagrama Entidade e Relacionamento (DER) e a lista de entidades e atributos das superclasses que compõem o problema tratado. O DER foi simplificado dividindo as superclasses do modelo em Superestrutura, Estrutura de Fundação e Maciço de Solos. Os inter-relacionamentos são definidos por transferências de esforços e imposição de deslocamentos, conforme FIGURA 09. Observa-se que a superestrutura é modelada por um executável externo (um software de análise estrutural).

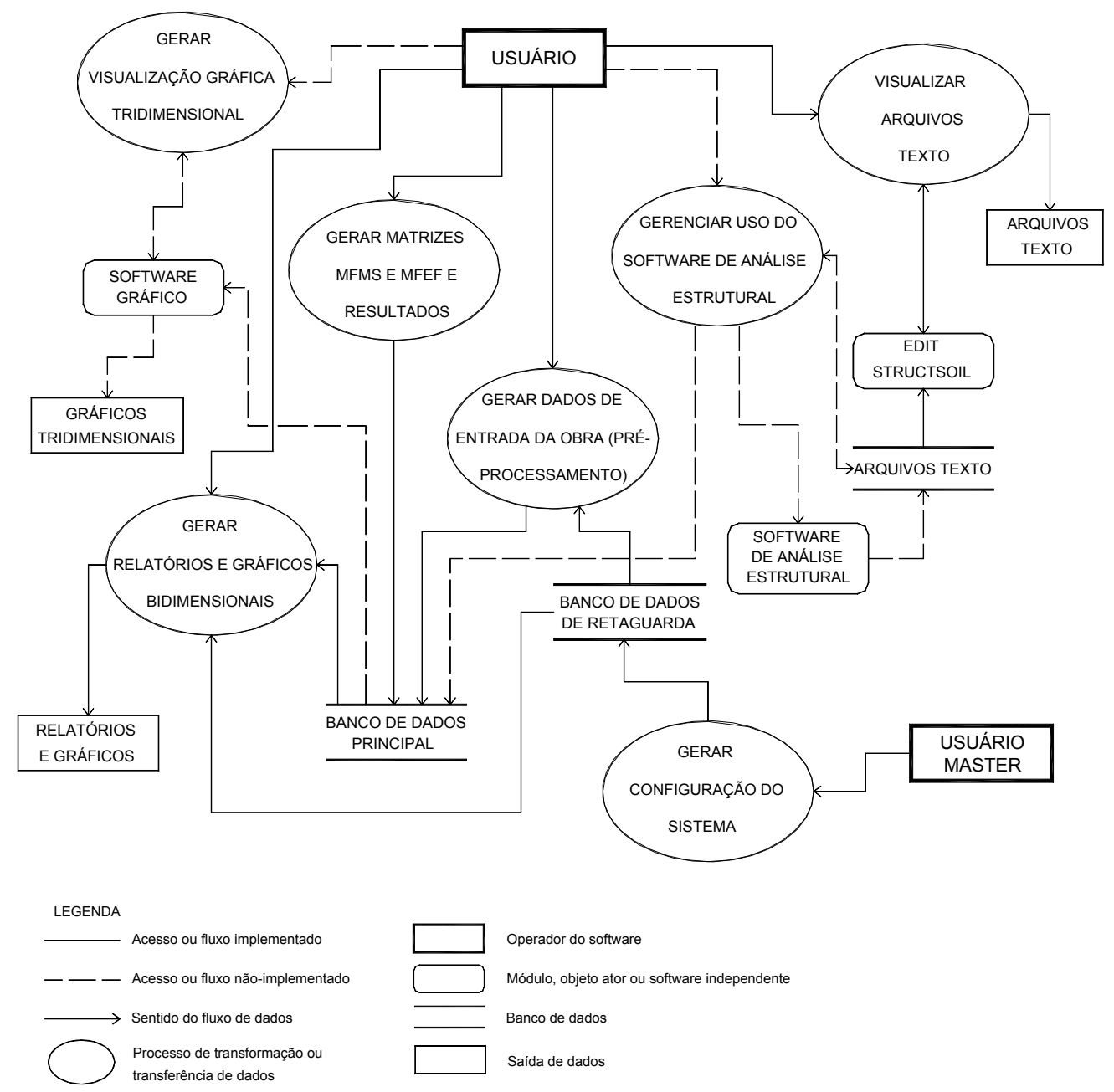

FIGURA 08 - Diagrama de Contexto 


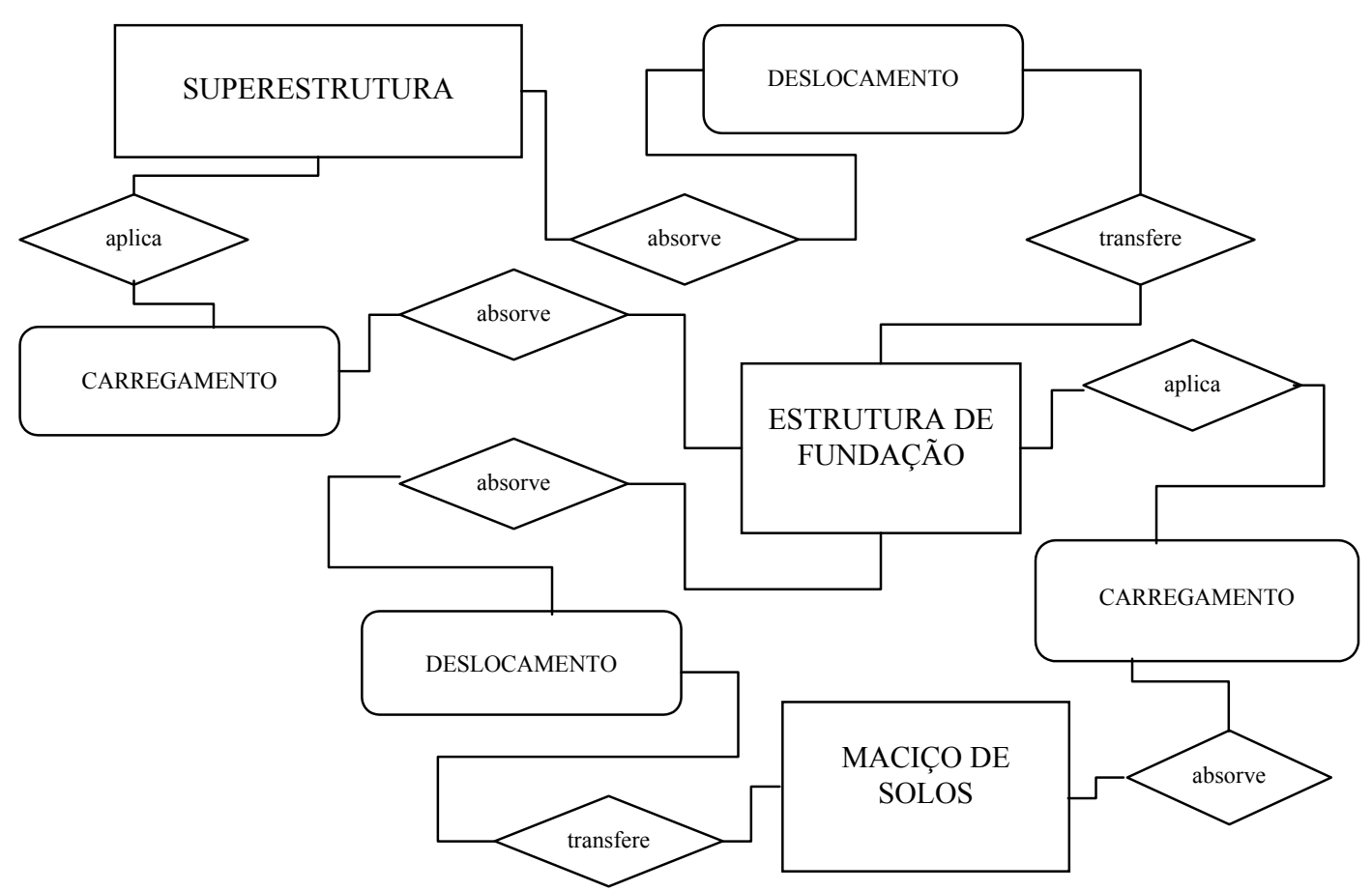

FIGURA 09 - Diagrama Entidade e Relacionamento do StructsoiL

A lista de entidades e atributos (TABELA 01) mostra os principais atributos das superclasses, não se preocupando como esses dados são coletados e tratados em suas respectivas subclasses.

TABELA 01 - Lista de entidades e atributos

\begin{tabular}{ccccc}
\hline Superclasse & & \multicolumn{2}{c}{ atributos } \\
\hline SUPERESTRUTURA & geometria & posição espacial & material de & construção \\
ESTRUTURA DE & geometria & posição espacial & $\begin{array}{c}\text { material de } \\
\text { construção }\end{array}$ & $\begin{array}{c}\text { métrodo de } \\
\text { instalação }\end{array}$ \\
FUNDAÇÃO & geometria & posição espacial & solo constituinte & gênese \\
MACIÇO DE SOLOS & geno & & \\
\hline
\end{tabular}

Para proceder a análise funcional identificaram-se os pontos críticos para informatização do problema, apresentando causas, efeitos e possíveis soluções. A FIGURA 10 contém esse estudo preliminar, mostrando a solução adotada para cada problema durante o desenvolvimento do projeto, programação, implantação e operação do software. 
FIGURA 10 - Quadro analítico dos pontos críticos do software

\begin{tabular}{|c|c|c|c|}
\hline PROBLEMAS & CAUSAS & EFEITOS & SOLUÇÃO ADOTADA \\
\hline $\begin{array}{l}\text { Definir um modelo } \\
\text { elástico baseado no SPT } \\
\text { e no mapeamento } \\
\text { geotécnico }\end{array}$ & $\begin{array}{l}\text { Dificuldade em } \text { correlacionar } \\
\text { propriedades elásticas dos } \\
\begin{array}{l}\text { ensaios a percussão e eom } \\
\text { mapeamento dados de } \\
\text { principalmente pelas características } \\
\text { regionais de gênese dos solos }\end{array}\end{array}$ & $\begin{array}{l}\text { Pouca abrangência de um } \\
\text { modelo localmente } \\
\text { adotado e alta margem de } \\
\text { erros }\end{array}$ & $\begin{array}{l}\text { Oferecer flexibilidade ao sistema } \\
\text { para que, por sua operação, haja a } \\
\text { possibilidade de adequar modelos } \\
\text { regionais comprovados por ensaios e } \\
\text { provas de carga instrumentadas }\end{array}$ \\
\hline $\begin{array}{l}\text { Avaliação da acurária } \\
\text { do cálculo pelo modelo } \\
\text { elástico do maciço de } \\
\text { solos }\end{array}$ & $\begin{array}{l}\text { Variabilidade do solo, reduzida } \\
\text { eficiência do SPT e poucas provas de } \\
\text { carga instrumentadas disponíveis para } \\
\text { definir correlações }\end{array}$ & $\begin{array}{l}\text { Interferência decisiva na } \\
\text { qualidade dos resultados }\end{array}$ & $\begin{array}{l}\text { Oferecer através da alimentação do } \\
\text { sistema, adequação de modelos } \\
\text { regionais, oferecer um default onde } \\
\text { desprezam-se os dados } \\
\text { possivelmente indisponíveis }\end{array}$ \\
\hline $\begin{array}{l}\text { Definir o modelo de } \\
\text { transferência de carga }\end{array}$ & $\begin{array}{l}\text { Variabilidade do solo, a reduzida } \\
\text { eficiência do SPT, poucas provas de } \\
\text { carga instrumentadas disponíveis para } \\
\text { definir correlações }\end{array}$ & $\begin{array}{l}\text { Redução } \\
\text { confiabilidade } \\
\text { resultados }\end{array}$ & $\begin{array}{l}\text { Oferecer possibilidade de cadastrar } \\
\text { alguns modelos funcionais empíricos } \\
\text { de transferência de carga para } \\
\text { escolha do usuário }\end{array}$ \\
\hline $\begin{array}{l}\text { Discretizar a fundação, } \\
\text { calcular e armazenar as } \\
\text { matrizes de flexibilidade } \\
\text { da fundação }\end{array}$ & $\begin{array}{l}\text { Dificuldade de expandir e gerenciar um } \\
\text { banco de dados físico para várias } \\
\text { dimensões }\end{array}$ & $\begin{array}{l}\text { Inviabilização } r \\
\text { processo computacional, } \\
\text { caso não seja usado } \\
\text { depósito físico desses } \\
\text { dados }\end{array}$ & $\begin{array}{l}\text { Armazenar os dados em múltiplos } \\
\text { bancos de dados estruturados por } \\
\text { tabelas }\end{array}$ \\
\hline $\begin{array}{l}\text { Manipular os arquivos } \\
\text { de entrada e saída do } \\
\text { Software de Análise } \\
\text { Estrutural }\end{array}$ & $\begin{array}{l}\text { Complexidade da estrutura de dados } \\
\text { desses arquivos com possibilidade de } \\
\text { erros no cadastro de dados e } \\
\text { dificuldade da manipulação automática } \\
\text { de leitura e imposição de blocos de } \\
\text { dados a esses arquivos }\end{array}$ & $\begin{array}{l}\text { A não automatização da } \\
\text { interação com o software } \\
\text { de análise estrutural } \\
\text { inviabiliza o uso prático } \\
\text { do software }\end{array}$ & $\begin{array}{l}\text { Disponibilizar entrada de dados } \\
\text { manual e oferecer condições de } \\
\text { acoplamento de um procedimento ou } \\
\text { módulo de leitura e alteração } \\
\text { automática dos arquivos gerados }\end{array}$ \\
\hline Gerenciar a Interação & Cálculo matricial robusto & $\begin{array}{l}\text { Maximiza a possibilidade } \\
\text { de erros lógicos }\end{array}$ & $\begin{array}{l}\text { Aplicar processo parcial de cálculo, } \\
\text { superposição de efeitos e oferecer } \\
\text { pós-processamento na forma de } \\
\text { relatórios e gráficos }\end{array}$ \\
\hline
\end{tabular}

\subsection{ANÁLISE E PROJETOS}

O projeto do software foi executado segundo a filosofia de trabalho apresentada na metodologia computacional. A análise foi dividida em modelagem de objetos, modelagem dinâmica e modelagem funcional.

\subsubsection{ANÁLISE}

A modelagem de objetos foi composta dos seguintes passos: 
a) definição do problema a ser resolvido pela produção do software;

b) construção do modelo de objetos inicial, o que corresponde a abstrair o problema real de forma a definir objetos representativos e seus inter-relacionamentos. $\mathrm{O}$ modelo de objetos do StructsoiL foi dividido em Retaguarda e Principal;

c) detalhamento do modelo de objetos inicial em níveis de assunto, classes, associação, atributos e serviços com definição da hierarquia do modelo e das propriedades de cada objeto.

d) preparação do dicionário de dados, que relaciona as propriedades de cada objeto, denominando o atributo, descrevendo-o e definindo o tipo de dado (caracter, inteiro, numérico, etc), tamanho, edição, formatação, e valores mínimos, máximos e default;

e) definição das tabelas físicas do software aproveitando o dicionário de dados e impondo associações compatíveis com a hierarquia do modelo de objetos e;

f) redefinição da associação hierárquica de objetos e respectivos atributos e serviços (modelo de objeto final) atendendo a possíveis imposições da construção das tabelas.

Os modelos de objetos iniciais da Retaguarda e Principal e seus interrelacionamentos hierárquicos estão apresentados na FIGURA 12. Para melhor entendimento dos modelos de objetos é necessário consultar as tabelas físicas do software apresentadas no ANEXO I.

\begin{tabular}{|l|}
\hline classe \& objeto \\
\hline atributo 1 \\
atributo 2 \\
\hline serviço 1 \\
serviço 2 \\
\hline
\end{tabular}

FIGURA 11 - Nível de objeto final (atributos e serviços)

O modelo de objetos final é idêntico ao modelo de objetos inicial (FIGURA 12), sendo que cada objeto contém os respectivos atributos e serviços, conforme a FIGURA 11. Para cada classe e objeto, os atributos estão expressos nas tabelas do ANEXO I e os serviços estão representados nos cenários de interação do software, item 3.4. 


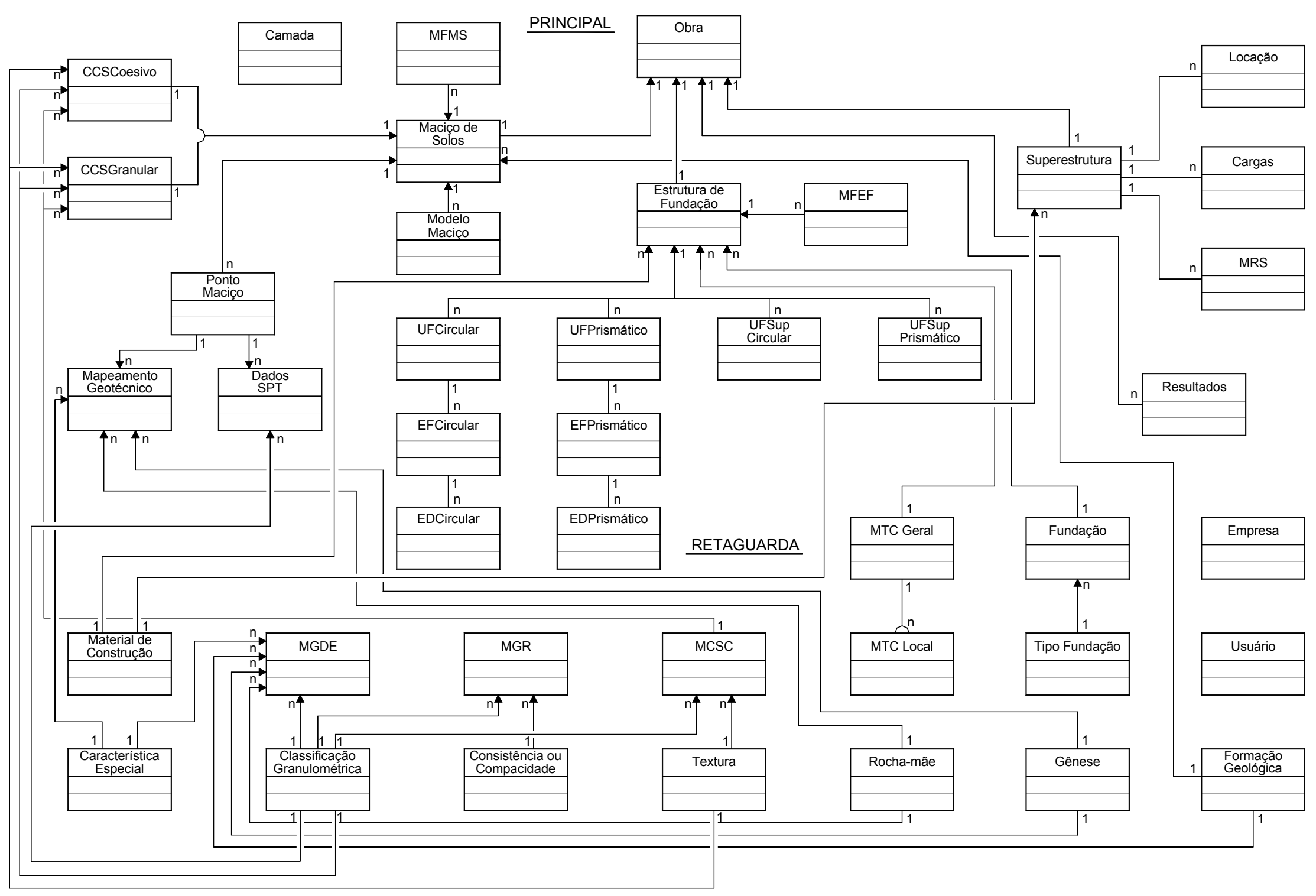

FIGURA 12 - Modelo de objetos inicial do StructsoiL 
A modelagem dinâmica foi composta dos seguintes passos:

a) preparação dos cenários de interação usuário - sistema - banco de dados, com o planejamento de todas as operações possivelmente solicitadas (exemplos de cenários: entrada de dados da superestrutura, configuração do MTC, emissão do relatório de resultados, etc);

b) identificação de eventos e construção dos diagramas de eventos para cada cenário;

c) preparação do diagrama de fluxos de eventos do software a partir dos diagramas de eventos de cada cenário e;

d) preparação dos diagramas de estados das superclasses (FIGURA 13).

Superestrutura

descarregada

carregada

deformada

apoios deslocados

Estrutura de Fundação

descarregada

carregada

deformada

deslocada

Maciço de Solos

descarregado

carregado

deformado

FIGURA 13 - Diagramas de estados das superclasses
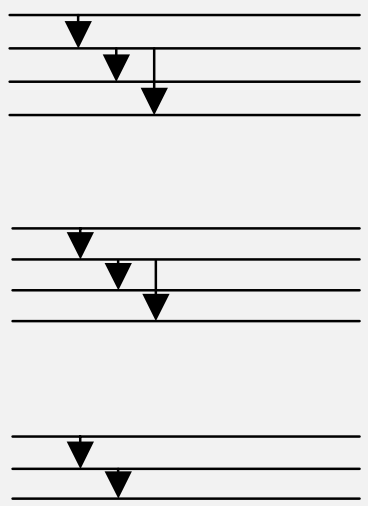

O modelo dinâmico define a consistência do sistema impondo a dinâmica da interação do usuário com o software e deste com seu banco de dados.

A modelagem funcional foi composta dos seguintes passos:

a) identificação dos valores (dados) de entrada para a Retaguarda e Principal, identificando o tipo de usuário que interage com o sistema;

b) preparação dos diagramas de fluxo de dados (DFD's) para a Retaguarda e Principal e o relacionamento entre estes, aproveitando o diagrama de contexto e os DFD's desenvolvidos na fase de anteprojeto;

c) descrição de funções através da previsão de todas as situações interativas com o usuário e o banco de dados e definição das respostas do software, seja através de processos ou pela emissão de mensagens de apoio. Os processos podem ser entrada de dados, cálculos ou emissão de relatórios e; 
d) identificação de restrições que definam consistência rígida a algumas partes do sistema (por exemplo, a restrição de que para executar o cenário principal é preciso abrir uma obra já cadastrada).

Os Diagramas de Fluxo de Dados (DFD's) estão apresentados nas FIGURA 15 (Retaguarda) e FIGURA 16 (Principal) e foram baseados nos Diagrama de Contexto e de Entidade e Relacionamento. Os DFD's trazem os detalhes do fluxo de dados, desde a configuração do software até a emissão de relatórios, tanto para a retaguarda como para o módulo principal.

\subsubsection{PROJETO DO SISTEMA}

O projeto do sistema consiste na subdivisão do problema em subsistemas. $\mathrm{O}$ software StructsoiL foi subdividido em módulos internos que compõem o aplicativo (FIGURA 14).

O software possui a capacidade de interagir com executáveis como o EditStructsoiL, um editor de texto associado ao sistema, além de um módulo de comunicação de gerenciamento do software de análise estrutural. Softwares acessórios, para edição gráfica por exemplo, podem ser associados.

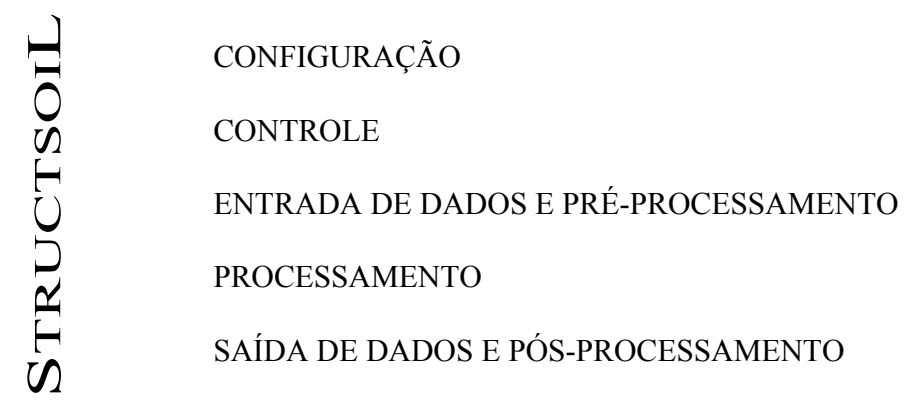

FIGURA 14 - Divisão do StructsoiL em subsistemas

O uso de banco de dados físico em todas as operações propicia uma subdivisão interna do Menu Principal em partes com dependência cronológica, oferecendo uma consistência rígida que inibe saídas acidentais que possam danificar os dados. A topologia do software está definida na FIGURA 17, onde os componentes com acessos tracejados não foram construídos ou acoplados. 


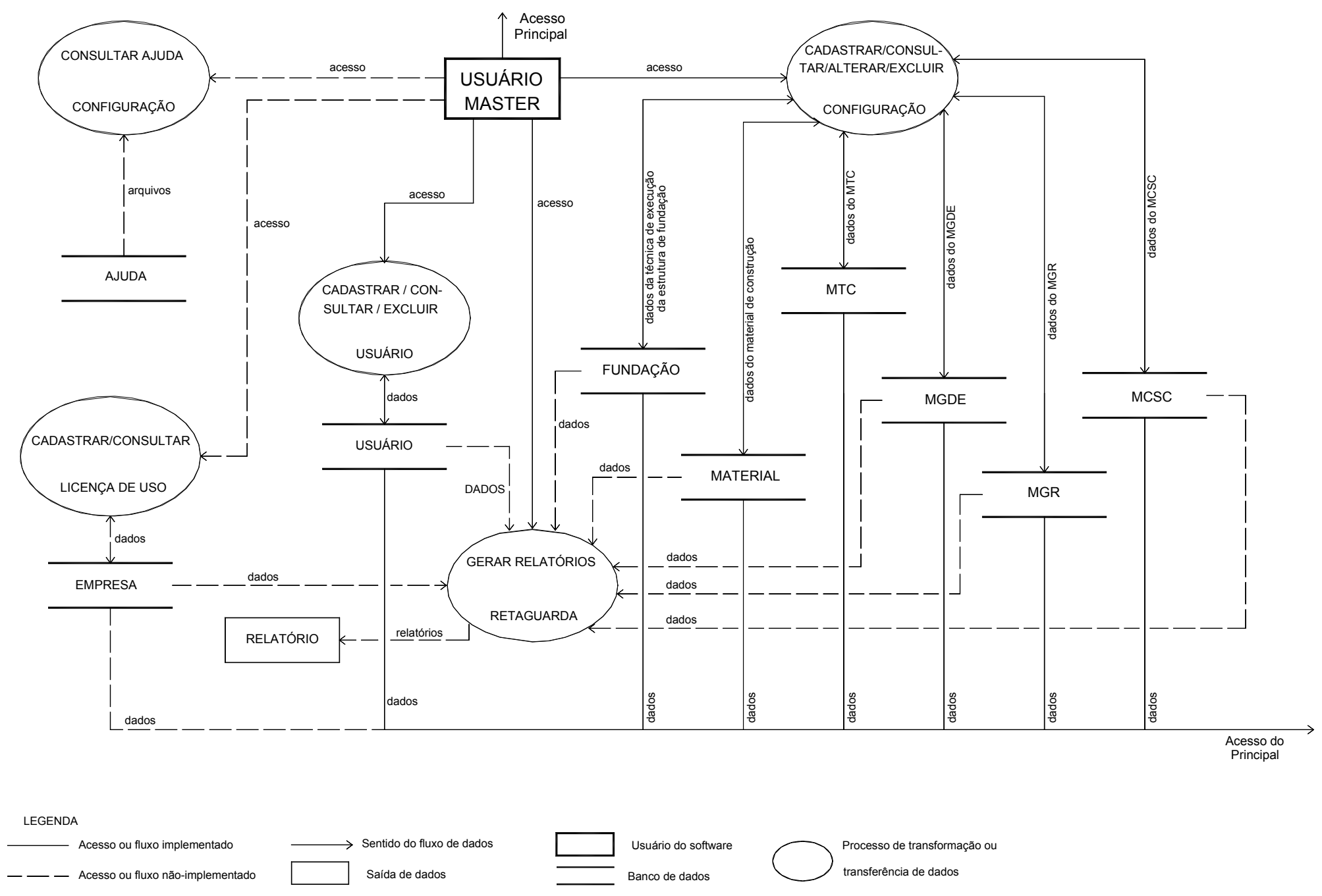

FIGURA 15 - Diagrama de Fluxo de Dados da Retaguarda 


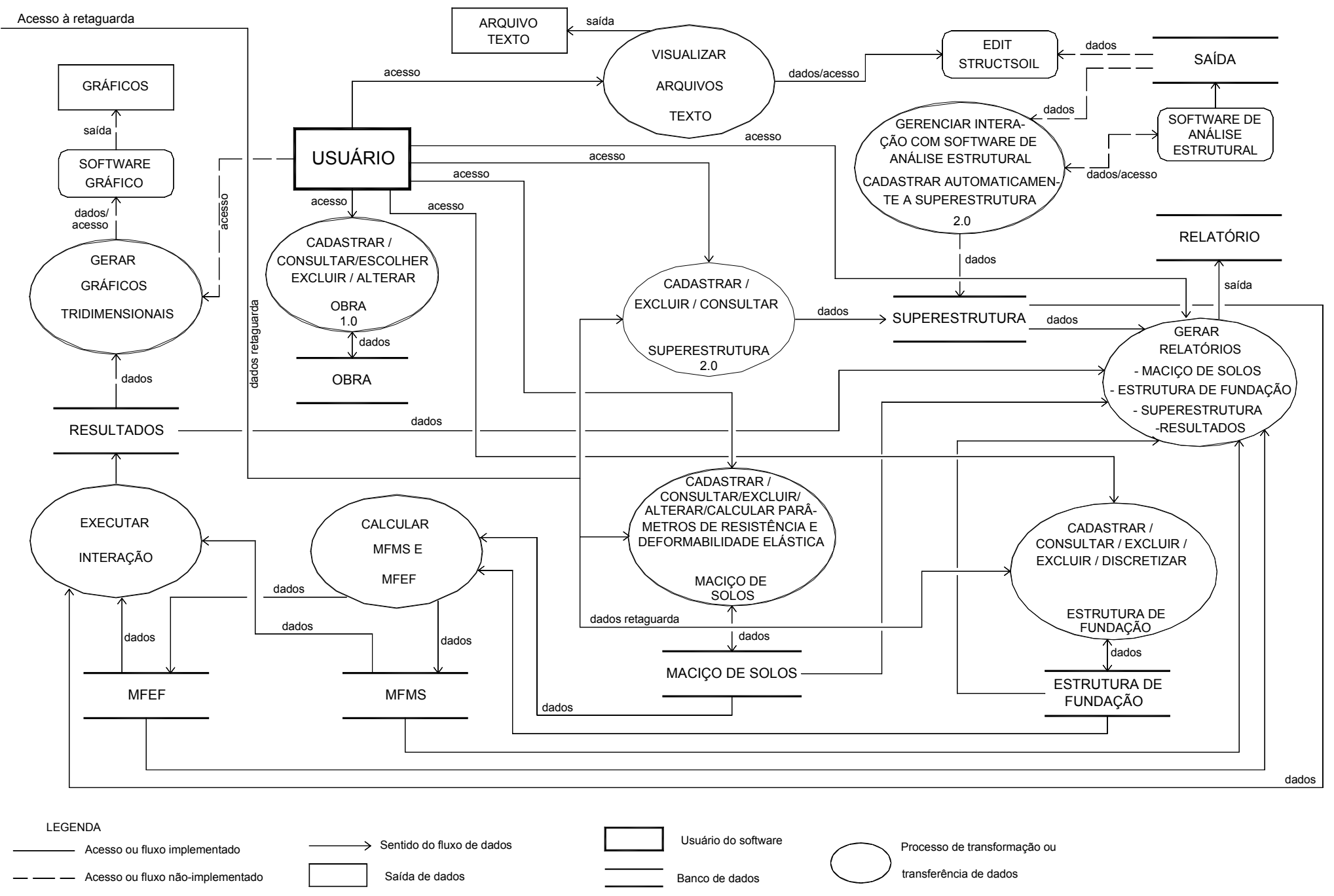

FIGURA 16 - Diagrama de Fluxo de Dados Principal 


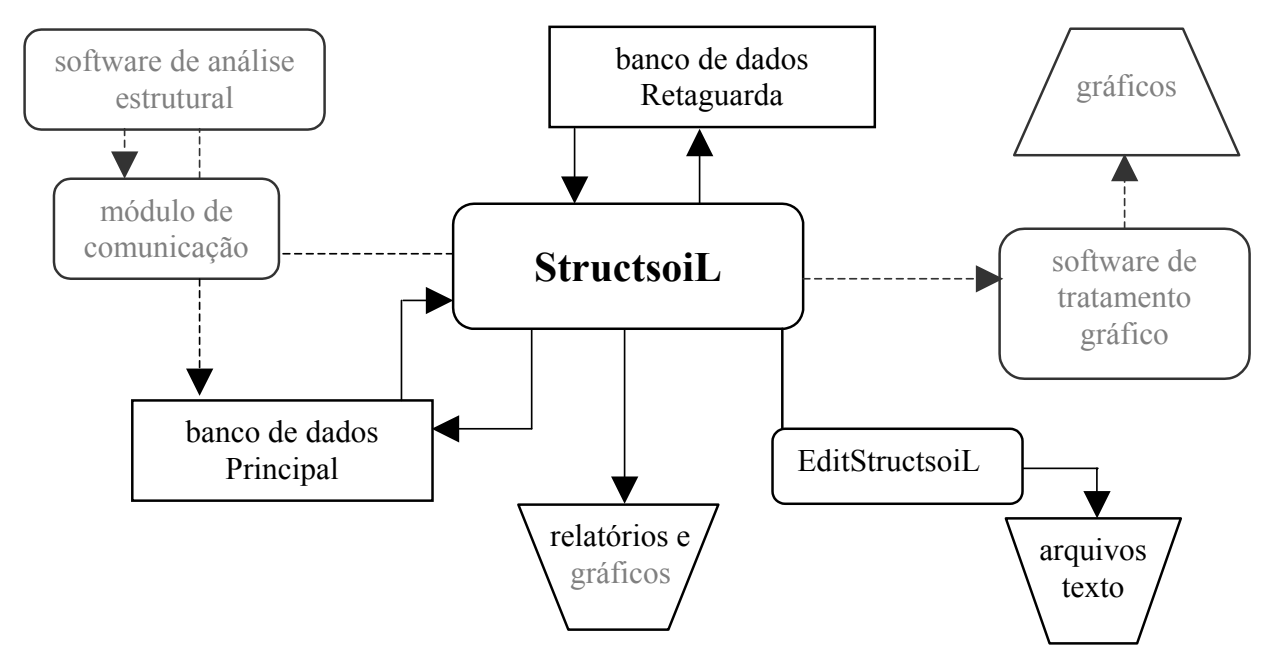

FIGURA 17 - Topologia do StructsoiL

No StructsoiL, todos os subsistemas trabalham de forma exclusiva, em um único fio de controle; estando um subsistema aberto, para abrir outro é preciso que este seja fechado. Isso foi feito para se obter uma melhor performance, e evitar problemas como conflitos de acesso ao banco de dados ou falta de memória. Os dados do sistema são armazenados, em um banco de dados relacional, e gerenciado pelo Sistema Gerencial de Banco de Dados (SGBD). O banco de dados utiliza plataforma Paradox ${ }^{\odot} 7$ e os dados são armazenados em tabelas relacionais. A comunicação entre o software e o banco de dados é feita através de eventos enviados do software para o SGBD, que controla as tabelas.

As exigências de hardware para o uso do software são uma CPU de emprego geral, memória principal e secundária, e uma impressora. As unidades físicas são controladas pelo Sistema Operacional, como a impressora e as unidades de armazenamento.

As condições externas a serem consideradas pelo software são: inicialização, processamento, falha e término. Na inicialização, o software é levado do estado de repouso (desativado, desligado) a um início estático (espera), através do qual necessitará da interação com um usuário. A partir dessa primeira interação, que é a seleção de uma base, é inicializada a abertura das classes e dos objetos necessários. O pré-processamento se restringe à entrada de dados e a transformação de características geométricas e geotécnicas em parâmetros de resistência e de deformabilidade elástica. O processamento é entendido como a aplicação dos processos de cálculo e de transferência de dados e inclui a determinação das MFEF e MFMS e a aplicação do procedimento interativo. As falhas, como por exemplo, inconsistência de dados ou operações ilegais são tratadas com mensagens de erro, cancelamento de operações ilegais e solicitação de correção da falha pelo usuário. $O$ 
término é realizado quando da solicitação por parte do usuário ou quando não satisfizer a condição de escolha de base, sendo que antes serão fechados todos os objetos que estiverem abertos.

Ainda que não exista uma forma nítida de determinação e avaliação de qualidade, foram estabelecidas como prioridades na implementação:

- uma configuração que iniba o usuário a executar análise sem base na realidade e na boa técnica aplicada à Engenharia Geotécnica;

- facilidade de operação do sistema;

- agilidade nas operações, digitação e localização de registros;

- facilidade de manutenção e portabilidade, assim como possibilidade de alterações nos procedimentos de cálculo com aproveitamento da arquitetura do software;

- interface amigável e;

- documentação do software.

O StructsoiL reúne características de diferentes estruturas arquitetônicas, tais como: transformação contínua, interface interativa e gerenciamento de transações. A transformação contínua é a estrutura arquitetônica que define que as saídas do software dependam ativamente das entradas que podem ser alteradas inúmeras vezes. O modelo funcional e o modelo de objetos definem os valores que estão sendo processados e modificados. A interface interativa é a estrutura arquitetônica que permite que o software suporte interação com agentes externos. O software trabalha com Windows ${ }^{\odot} 95,98$, NT ou superior, com coleções de janelas, menus, botões, caixas de entrada típicas desse sistema operacional, o que facilita a interação com o usuário. O gerenciamento de transações é a estrutura arquitetônica que permite que o software trabalhe com banco de dados, cuja principal função é armazenar e acessar informações.

\subsubsection{Projeto DE ALGoritmos}

No projeto de algoritmos foram especificados os procedimentos que definem o tratamento de dados, seja por transformação ou transferência. Os processos de manipulação de banco de dados são comuns no âmbito da linguagem orientada a objetos, portanto, neste caso, apresenta-se somente os procedimentos de cálculo específicos do StructsoiL. Os procedimentos de cálculo estão colocados no ANEXO II, divididos hierarquicamente em unidades e procedimentos ou funções. 
Os principais procedimentos e funções específicas do StructsoiL estão incluídos nas unidades Processamento e Interação. Os procedimentos de discretização dos elementos de fundação (circular ou prismática), o cálculo de resistência unitária equivalente e resistência de interface dos elementos discretos com o maciço de solos, além de modelo elástico do maciço ao longo do perfil vertical localizado no ponto de execução de ensaio SPT, são também expostos para melhor compreensão do projeto de algoritmos.

A unidade Processamento contém os métodos de cálculo para modelar o maciço contínuo de solos através dos parâmetros de deformabilidade elástica (módulo de Young e coeficiente de Poisson), além de definir posição indeslocável. Essa modelagem está baseada em dados do pré-processamento, onde a partir de dados de SPT, mapeamento geotécnico e aterro compactado, calcula-se um perfil de comportamento do maciço em cada ponto de ensaio SPT. Extrapola-se esses valores para os perfis verticais de interesse na modelagem, ou seja, o trecho entre a cota de apoio do elemento estrutural de fundação e a superfície indeformável. Com isso, calcula-se a MFMS através da influência de elementos discretos normalmente carregados dos tipos: superfície de placa circular e retangular; e tangencialmente carregados dos tipos: superfície vertical de cilindros e prismas. A carga aplicada a cada elemento é unitária e distribuída uniformemente em sua superfície. Carga unitária axialmente aplicada ao elementos discretos resulta em variação de comprimento correspondente, gerando a MFEF.

A unidade Interação contém os procedimentos de interação que resultam nos recalques dos apoios usando as matrizes MRS, MFEF e MFMS e o carregamento aplicado. A função de convergência do processo iterativo também compõe a unidade.

\subsubsection{SUGESTÕES DE OTIMIZAÇ̃̃o E EXPANSÃo}

Durante a implementação do software foram documentadas e aplicadas alternativas mais econômicas às procedidas na análise inicial. Mesmo assim, após esta primeira versão do software, lista-se algumas alternativas para otimizá-lo e expandi-lo nas fases de análise e projetos do sistema e dos algoritmos, como:

a) a análise do sistema pode ser melhorada em vários pontos, mas o ponto mais evidente é o modelo de objetos, especificamente na compactação do modelo de objetos da estrutura de fundação e na generalização do modelo de objetos do aterro complementar;

b) o projeto do sistema pode ser implementado atingindo os objetivos macros do sistema pela implementação de interface interativa com softwares de análise estrutural e tratamento gráfico tridimensional e; 
c) o projeto de algoritmos pode ser expandido aplicando modelagem de grupo de estacas considerando a rigidez do bloco de capeamento, procedendo interação bloco elemento estrutural de fundação.

Além disso, pode ser implementada uma modelagem para consideração de esforços horizontais, momento fletor e torsor aplicados aos apoios. Finalmente, a partir da implementação da interface interativa com o software de análise estrutural, o software poderá conter um procedimento de análise incremental da superestrutura para avaliação da influência do processo construtivo no comportamento da edificação.

\subsection{O SOFTWARE STRUCTSOIL}

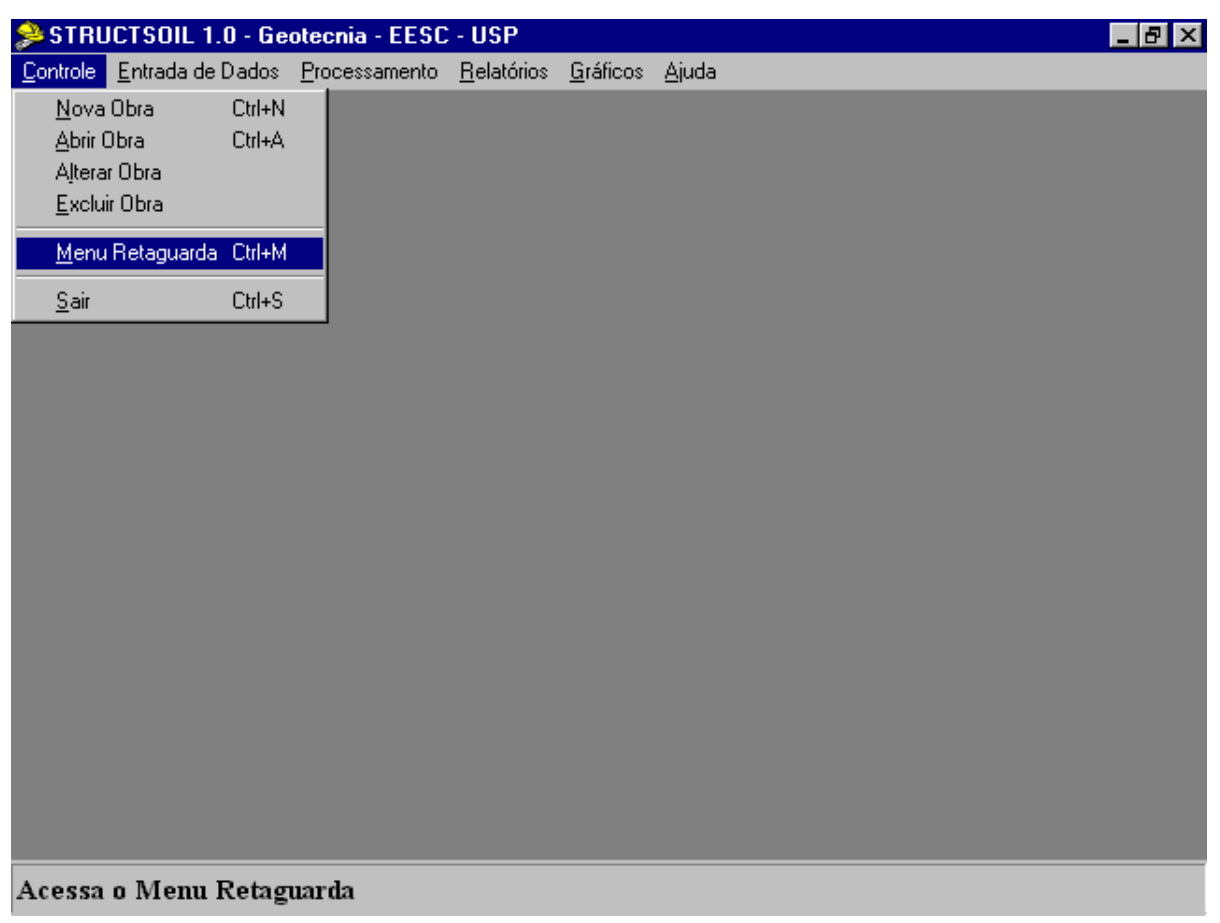

FIGURA 18 - Menu Principal e acesso ao Menu Retaguarda

O StructsoiL 1.0 é uma ferramenta de análise do comportamento de edifícios altos com fundação individual em cada apoio, seja ela por sapatas, tubulões ou estacas. O software compatibiliza os deslocamentos nos apoios devido a aplicação do carregamento vertical. $\mathrm{O}$ modelo utilizado interpreta o comportamento do conjunto estrutura de fundação - maciço de solos sob um determinado nível de carregamento vertical admitindo continuidade da massa de solos. 
O software foi desenvolvido em projeto orientado a objetos, devidamente documentado, em linguagem de programação Borland Delphi ${ }^{\odot}$ 3.0. Para possibilitar análises coerentes com a realidade, o software possui, além de um Menu Principal, o Menu Retaguarda, onde alimenta-se um banco de dados de retaguarda que auxilia o usuário na operação do próprio sistema. A análise do sistema definiu Obra como classe master, gerando, no Diagrama Entidade e Relacionamento (DER), três objetos filhos: superestrutura, estrutura de fundação e maciço de solos.

\subsubsection{Menu Retaguarda}

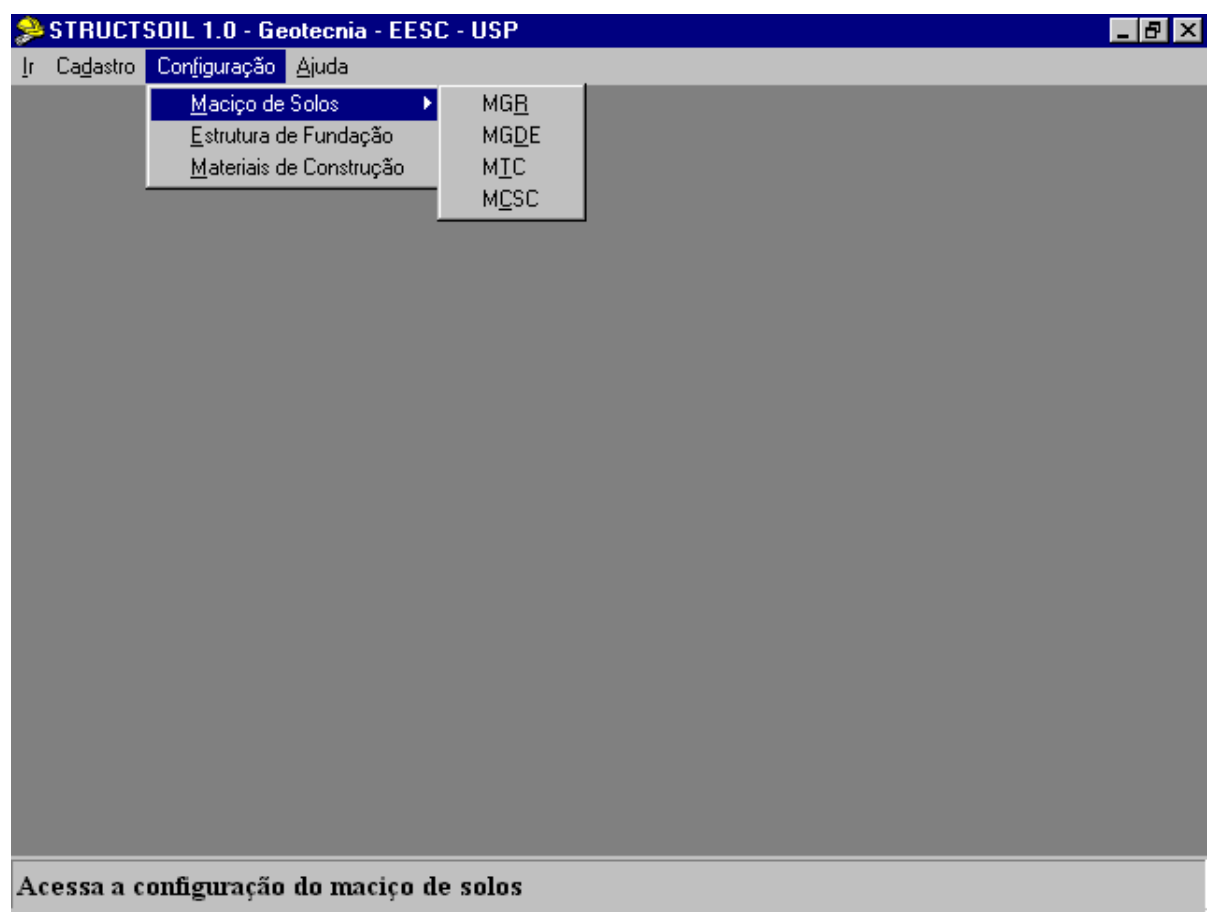

FIGURA 19 - Menu Retaguarda e acessos para configuração do StructsoiL

O uso de um banco de dados de retaguarda para configuração do software foi imposto pela necessidade de definir, por correlações empíricas com ensaios SPT e dados de mapeamento geotécnico, parâmetros de resistência e de deformabilidade do maciço de solos. Além disso, serve para definir correlações entre resultados de ensaios triaxiais em aterros compactados, ou outro material, com ensaios SPT e definir parâmetros elásticos para os materiais de construção dos elementos estruturais.

As várias técnicas de execução de estruturas de fundação são cadastradas na configuração do software de forma que o usuário não tenha que se preocupar com a modelagem da estrutura de fundação. Além disso, através do MTC o usuário master pode 
impor funções lineares de transferência de carga na interface elemento estrutural de fundação - maciço de solos.

\subsubsection{Maciço de solos}

A configuração do maciço de solos oferece flexibilidade ao software, pois possibilita ao usuário master adequar modelos regionais comprovados por ensaios e provas de cargas instrumentadas. A configuração pode ser feita para os modelos de resistência e de deformabilidade do maciço de solos, para o modelo de transferência de carga elemento estrutural - solo e para correlacionar ensaios.

\subsection{Modelo geotécnico de resistência (MGR)}

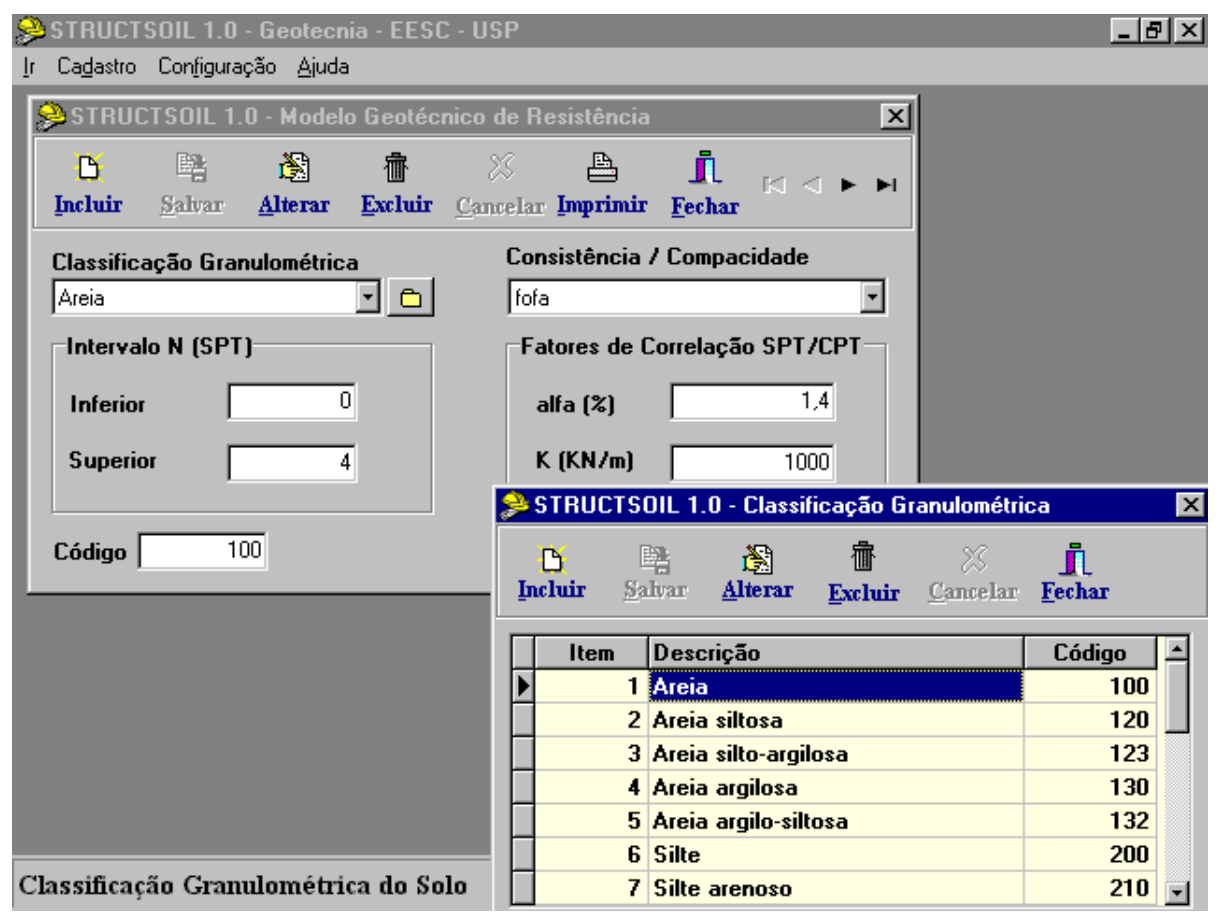

FIGURA 20 - Configuração do MGR (modelo geotécnico de resistência)

O MGR correlaciona resultados do ensaio SPT com modelos de resistência baseados no CPT através de fatores definidos de acordo com a classificação granulométrica. Além disso, define níveis de consistência ou compacidade do solo com base nos resultados de ensaios SPT. A FIGURA 20 mostra o cenário de configuração do MGR e o acesso ao cenário auxiliar de classificação granulométrica. 
3.4.1.1.2 Modelo geotécnico de deformabilidade elástica (MGDE)

O MGDE define o coeficiente de Poisson por correlação empírica com os parâmetros gênese, granulometria e condição de saturação do solo. Por correlação empírica com os parâmetros gênese, características especiais, rocha de origem, formação geológica e condição de saturação do solo define o coeficiente adimensional $C$ da equação empírica:

$$
E=C K N_{S P T}
$$

onde $E$ é o módulo de Young, $K$ é o fator de correlação CPT/SPT e $N_{S P T}$ representa o número de golpes obtido pelo Standard Penetration Test.

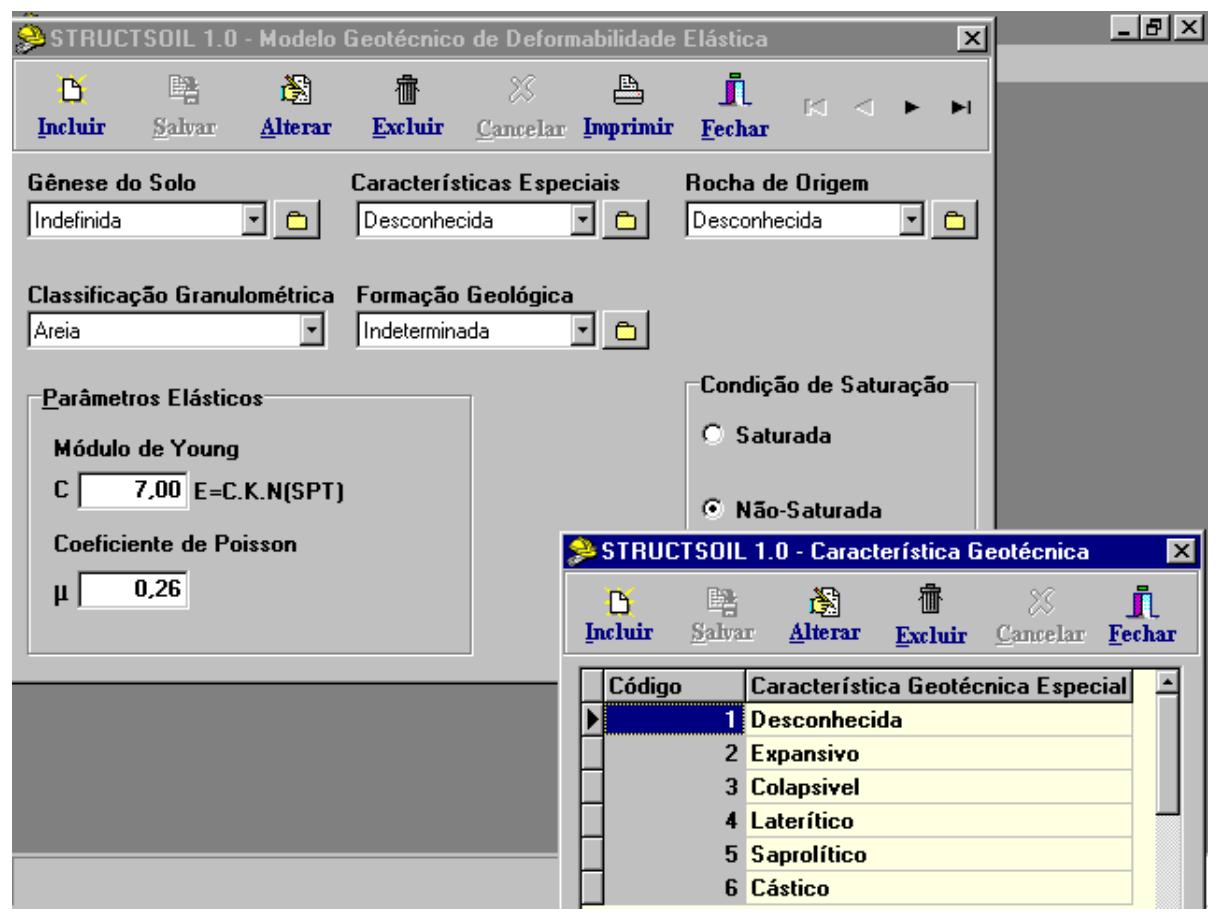

FIGURA 21 - Configuração do MGDE (modelo geotécnico de deformabilidade elástica)

A FIGURA 21 mostra o cenário de configuração do MGDE e o acesso ao cenário auxiliar sobre a característica especial do maciço de solos. A configuração do MGDE possui ainda os cenários auxiliares gênese, rocha de origem, classificação granulométrica e formação geológica.

3.4.1.1.3 Modelo de transferência de carga (MTC) 
O MTC é um conjunto de condições de contorno impostas para compatibilizar a capacidade resistente por atrito lateral. As funções de transferência são linearmente proporcionais à resistência última (minorada por um coeficiente de segurança) oferecida pelo maciço de solos ao longo da interface com o elemento de fundação e pela base. Esse modelo considera a não linearidade do material de modo indireto: a reação do solo é variável ao longo do fuste e base em função do nível de carregamento, tendo como limite a resistência lateral máxima do solo, ou seja, a plastificação do solo.

O MTC é composto por um coeficiente de segurança global aplicado à resistência última e por percentuais de transferência imediata para trechos do fuste (grupo de elementos discretos) e para a base (ponta), conforme a FIGURA 22.

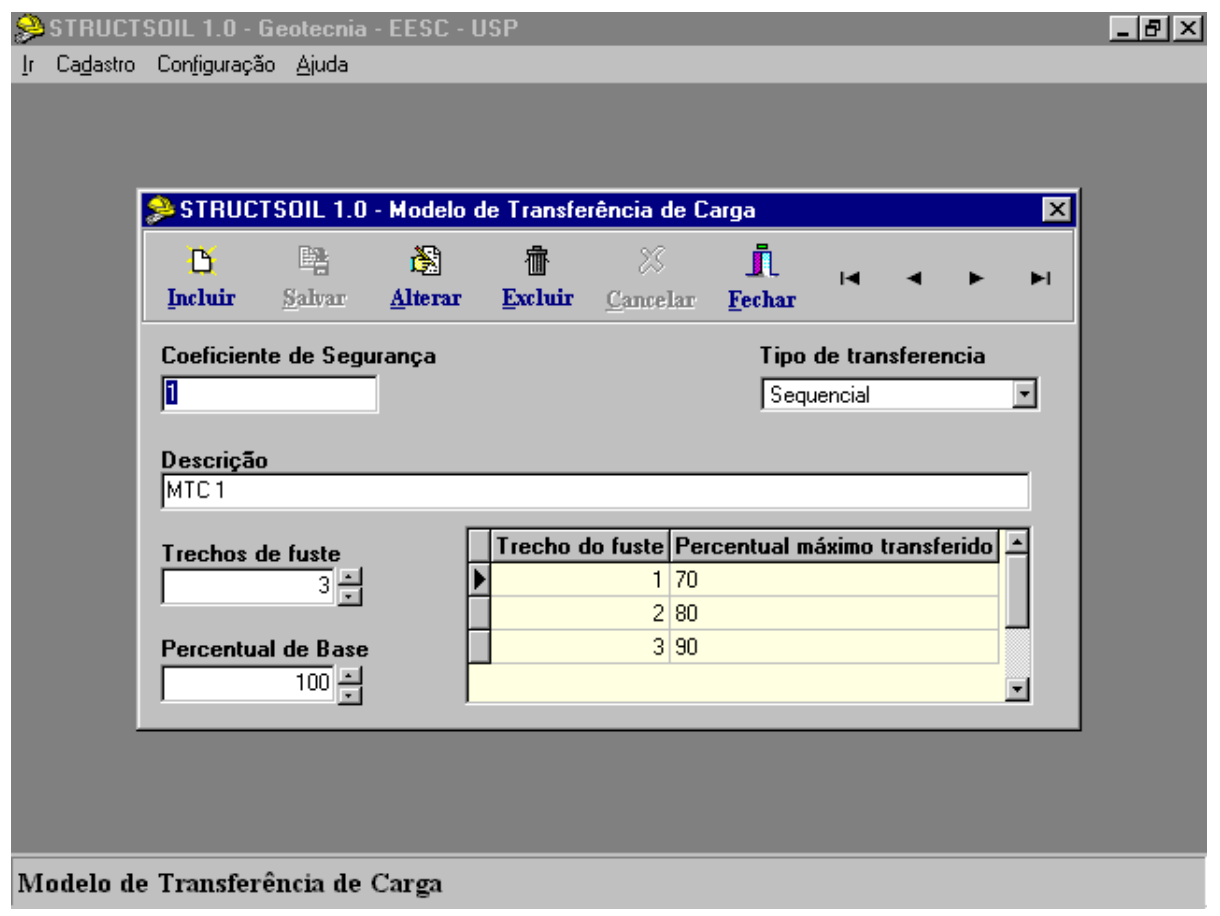

FIGURA 22 - Configuração do MTC (modelo de transferência de carga)

\subsection{Modelo da camada de solos complementar (MCSC)}

O MCSC oferece a possibilidade de correlacionar granulometria, textura e intervalos de valores de peso específico, densidade relativa e coesão ou ângulo de atrito com um $\mathrm{N}_{\mathrm{SPT}}$ equivalente, para solos coesivos ou granulares, respectivamente (FIGURA 23). 


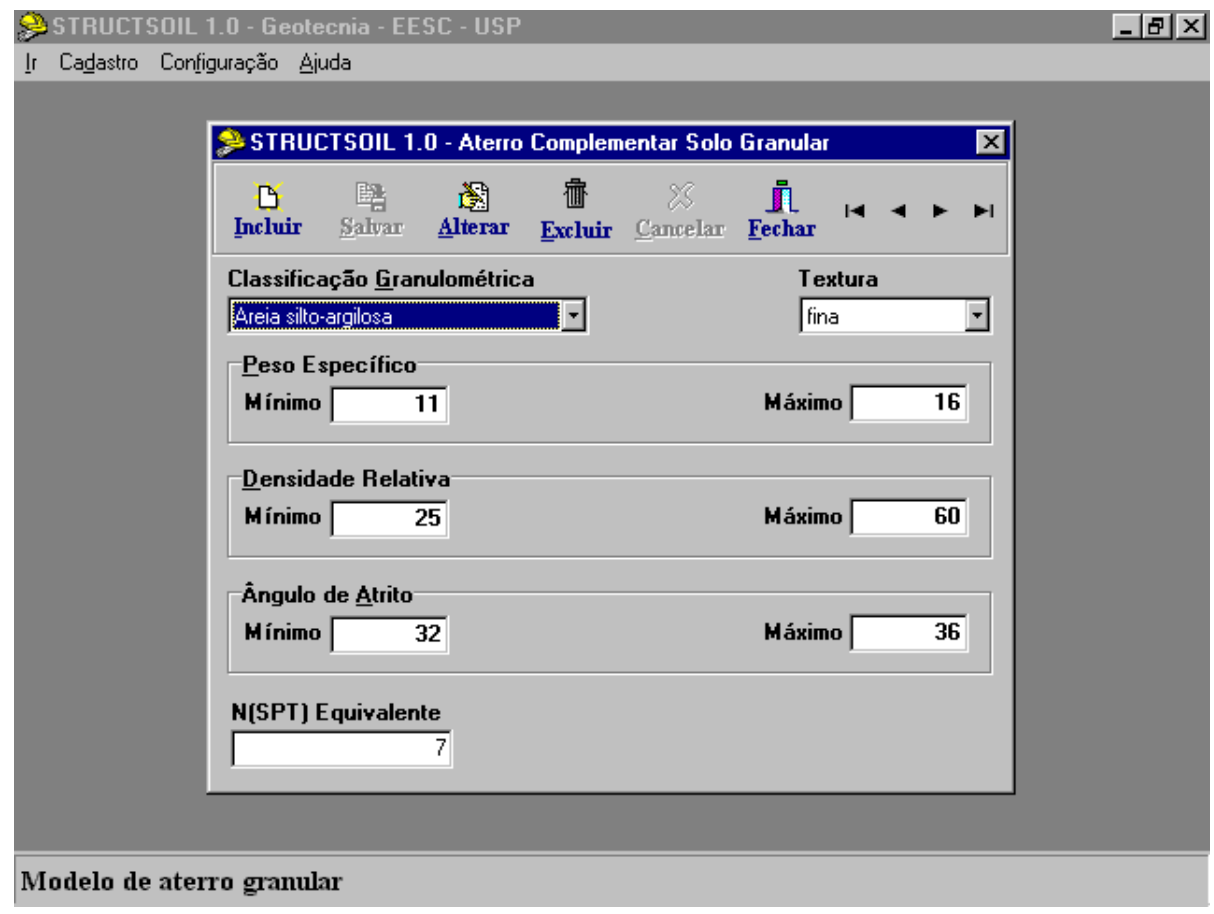

FIGURA 23 - Configuração do MCSC (modelo da camada de solos complementar) para aterro em solo granular

\subsubsection{Estrutura de fundação}

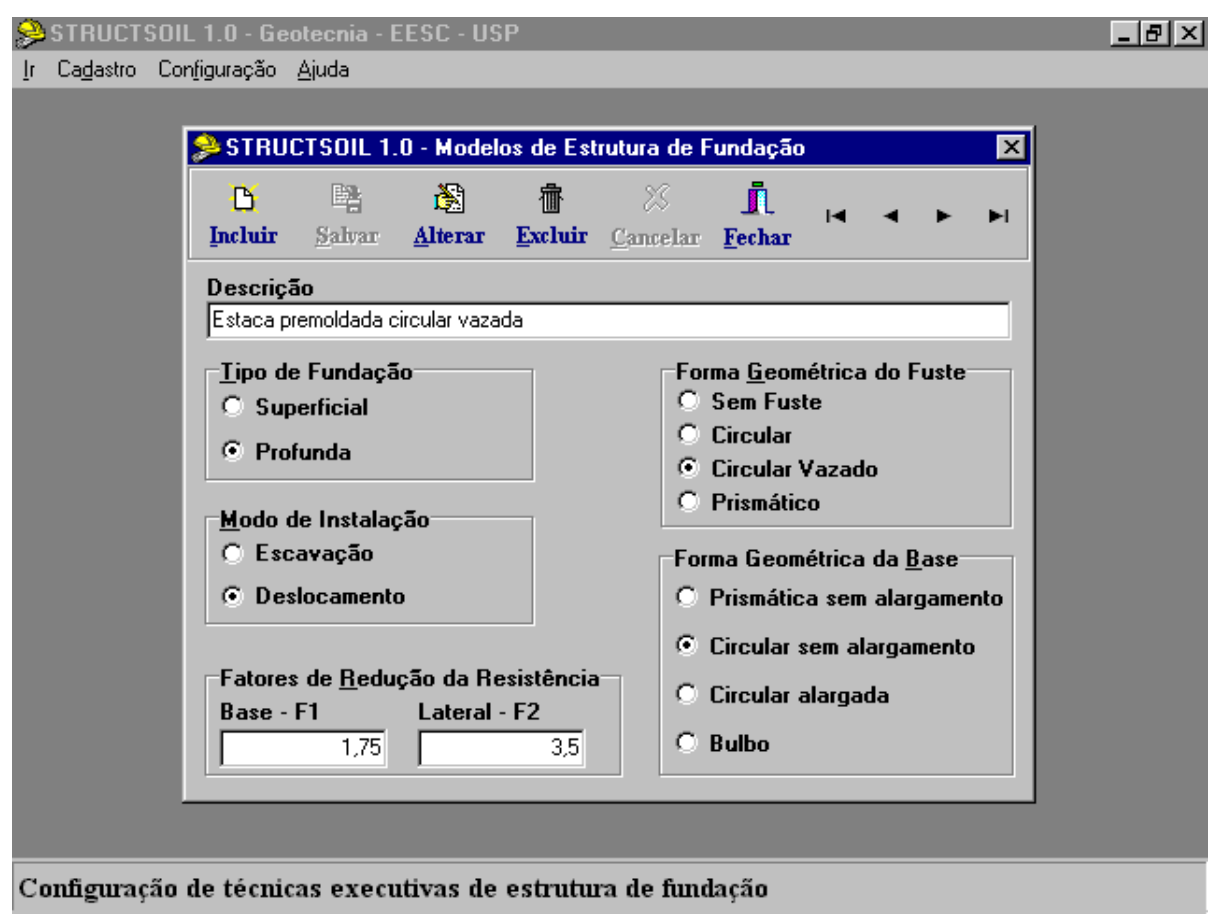

FIGURA 24 - Configuração da técnica de execução da estrutura de fundação 
$\mathrm{Na}$ configuração da estrutura de fundação o usuário master cadastra a técnica de execução através do tipo (superficial ou profunda), modo de instalação (escavação ou deslocamento), forma geométrica do fuste (se houver) e da base. Cada técnica possui um fator de correção de resistência de interface na base (F1) e no fuste (F2), quando profunda. A esses fatores são embutidos efeitos de construção impostos ao maciço e efeito escala, entre outros. A FIGURA 24 mostra o cenário de configuração da técnica de execução de estrutura de fundação usando como exemplo o caso de estaca pré-moldada circular vazada.

\subsubsection{Materiais de construção}

Na configuração de materiais de construção da estrutura de fundação cadastra-se a denominação e os parâmetros de deformabilidade elástica do material, esse cadastro também é usado na entrada de dados da superestrutura.

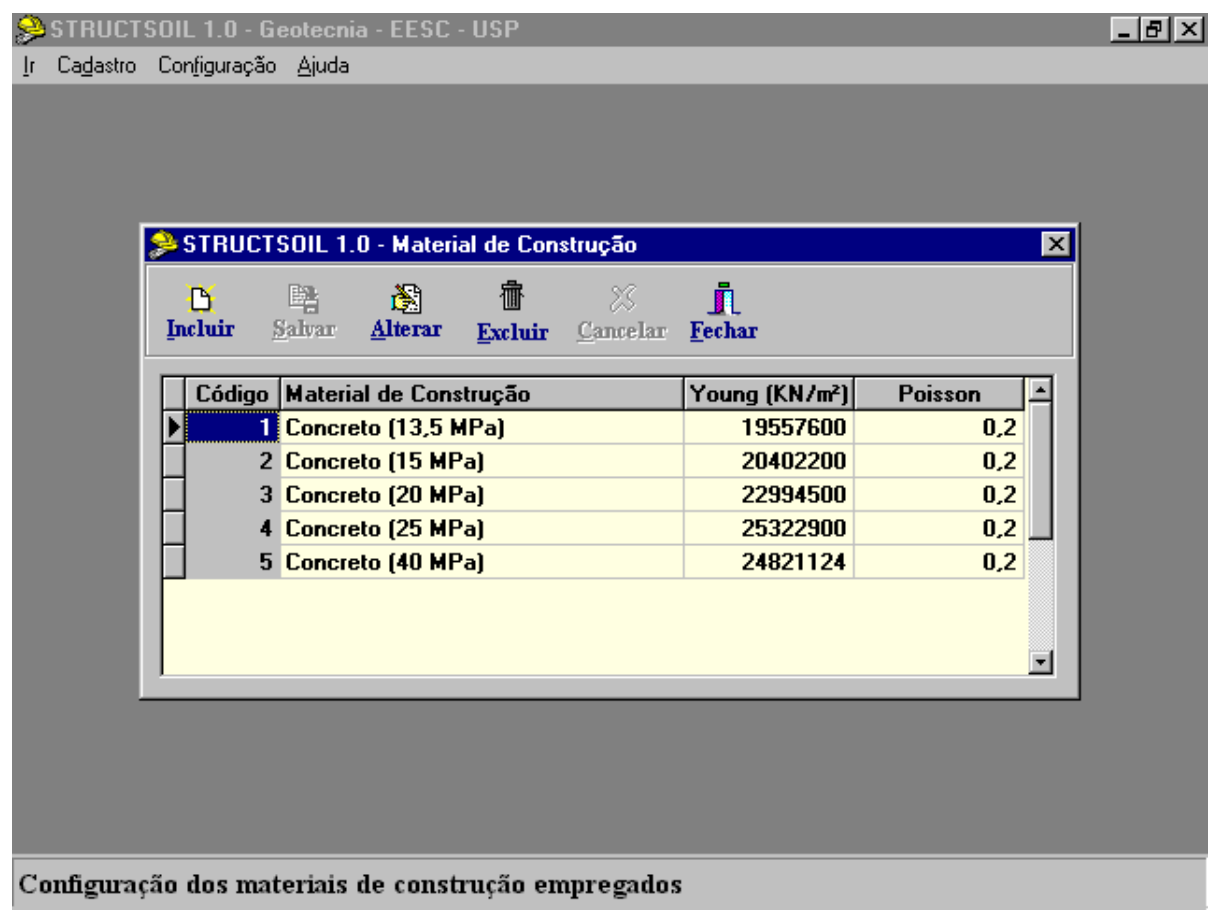

FIGURA 25 - Configuração do material de construção da estrutura de fundação

\subsubsection{MENU PRINCIPAL}

\subsubsection{Controle}


O submenu controle serve para gerenciar os serviços da classe master Obra, acessar ao Menu Retaguarda e o terminar (sair) a execução do software. A FIGURA 18 mostra os acessos do submenu controle, enquanto a FIGURA 26 mostra o cenário de alteração de dados gerais da obra.

\subsubsection{Entrada de dados e pré-processamento}

A entrada de dados está contida no Menu Principal. Uma obra cadastrada pelo usuário e aberta para trabalho admite a entrada de dados da superestrutura, da estrutura de fundação e do maciço de solos.

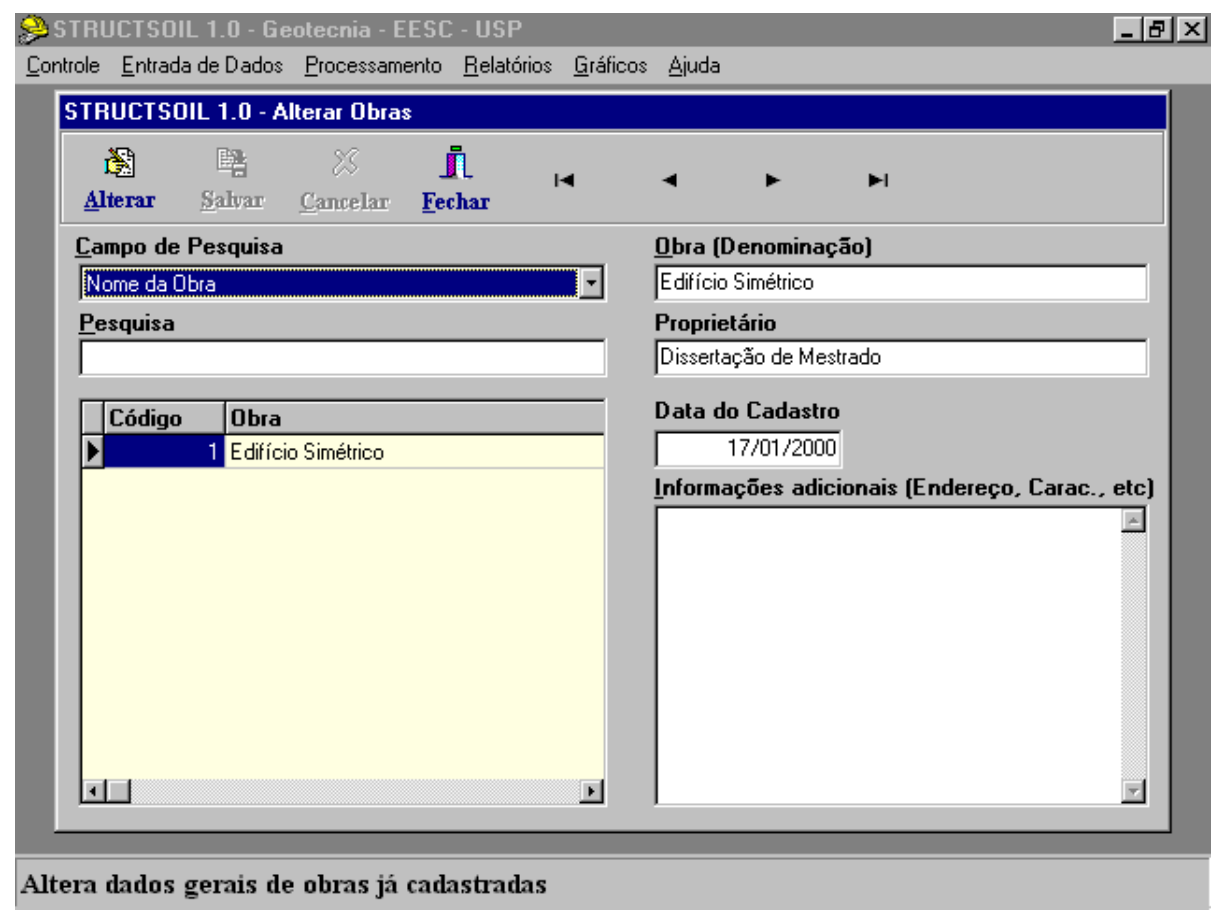

FIGURA 26 - Cenário de alteração dos dados da obra cadastrada

\subsection{Superestrutura}

O projeto do software admite que a superestrutura seja cadastrada manualmente ou de forma automática. Na forma manual, o usuário cadastra a locação e a geometria dos pilares de apoio, as cargas nos apoios obtidas na análise estrutural convencional (apoios indeslocáveis) e a matriz de rigidez da superestrutura (MRS). A MRS é definida pelos esforços obtidos nos apoios na aplicação de deslocamento vertical unitário em cada apoio. É composta por fatores $f_{s_{i, u}}$, onde $i$ representa o apoio influenciado por absorção ou 
transferência de esforços e $u$ representa o apoio da superestrutura deslocado verticalmente em uma unidade de medida $(\mathrm{m})$. Nos casos apresentados por este trabalho o cadastro da superestrutura foi executado de forma manual e a análise estrutural foi procedida usando uma licença do SAP $2000^{\circ}$ STD.

A FIGURA 27 mostra o cenário principal da entrada de dados da superestrutura, onde cadastra-se o tipo de entrada de dados, o processo construtivo, o material de construção, a cota de referência da obra (nível da ligação superestrutura - estrutura de fundação) e o projetista estrutural. Se a entrada de dados é manual o software disponibiliza o acesso aos cenários de entrada de dados da locação e geometria dos pilares, das cargas na fundação e da MRS (rigidez). Esses cenários auxiliares estão habilitados à emitir relatórios locais.

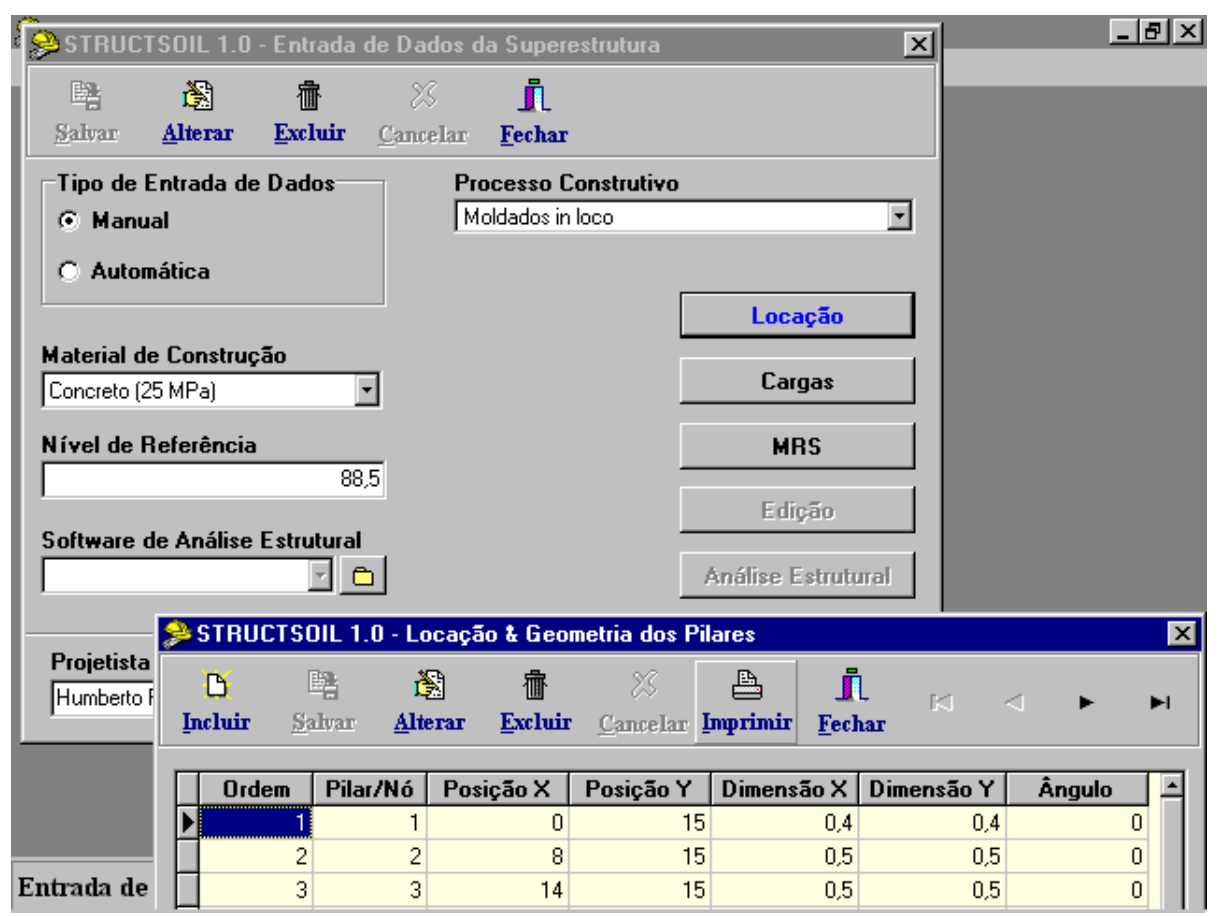

FIGURA 27 - Entrada de dados da superestrutura

Se a entrada de dados for automática, o StructsoiL disponibiliza a escolha do software de análise estrutural, o acesso ao editor de textos EditStructsoiL (edição) e o acesso ao módulo de análise estrutural responsável por gerar os dados de entrada da superestrutura. O cadastro automático da superestrutura requer um módulo de comunicação que gerencie o uso de um software de análise da superestrutura e a transferência dos dados de saída para o banco de dados de entrada da superestrutura. 


\subsection{Maciço de solos}

Considera-se que o maciço de solos é formado por camadas horizontais justapostas até a superfície do indeslocável (FIGURA 28). O conjunto de elementos de solos possui variabilidade tridimensional, no entanto cada camada é modelada como verticalmente homogênea pelos parâmetros definidos para a cota média. Caso haja mais de um furo de SPT cadastrado a camada é modelada com heterogeneidade na direção horizontal, caso contrário o modelo de camada é perfeitamente homogêneo.

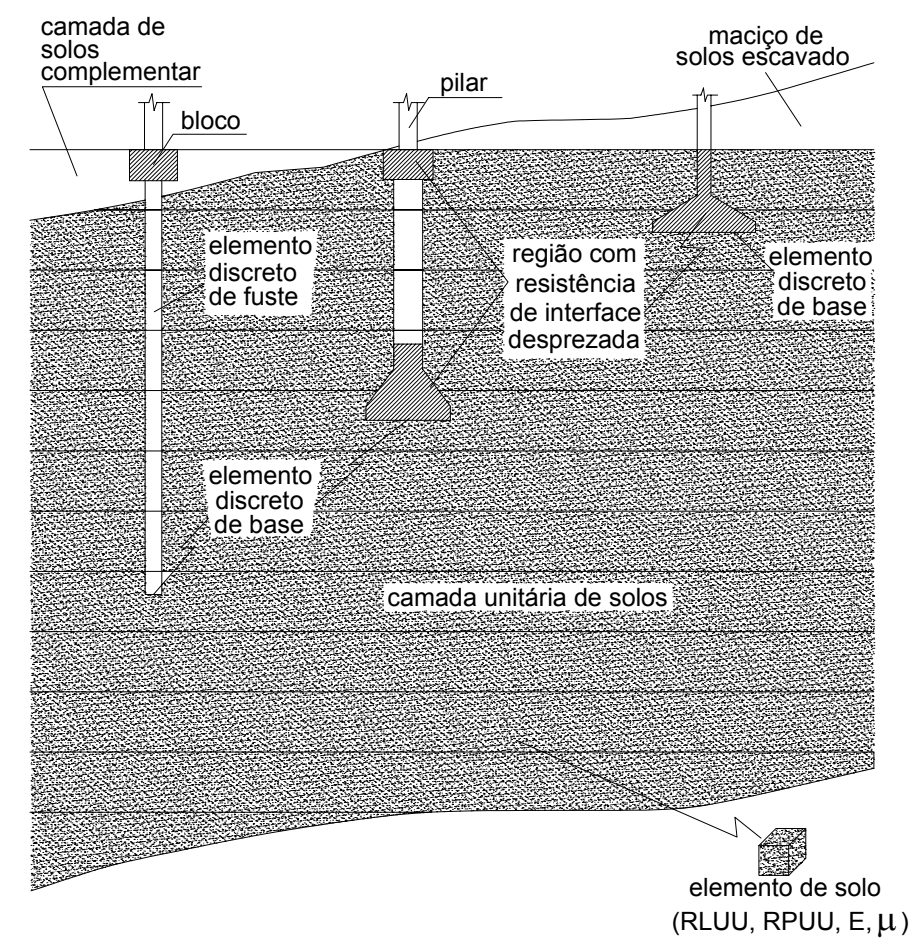

FIGURA 28 - Modelo de discretização do maciço de solos e dos elementos da estrutura de fundação

O maciço de solos é dividido em maciço de solos existente e camada de solo complementar, construída na execução da obra. $\mathrm{O}$ maciço de solos existente corresponde à massa de solos ensaiada por sondagem SPT, mesmo que constituída por aterro antigo. A camada de solo complementar é usado nos pontos ensaiados onde a cota de superfície do maciço existente está abaixo da cota de referência (ligação superestrutura - estrutura de fundação). O maciço de solos é discretizado a cada metro a partir da cota de referência até o indeslocável, possuindo características elásticas e de resistência influenciadas pelo ponto ensaiado mais próximo de cada perfil definido por ensaios de sondagem SPT, inversamente proporcional à distância espacial. 
a) maciço de solos existente

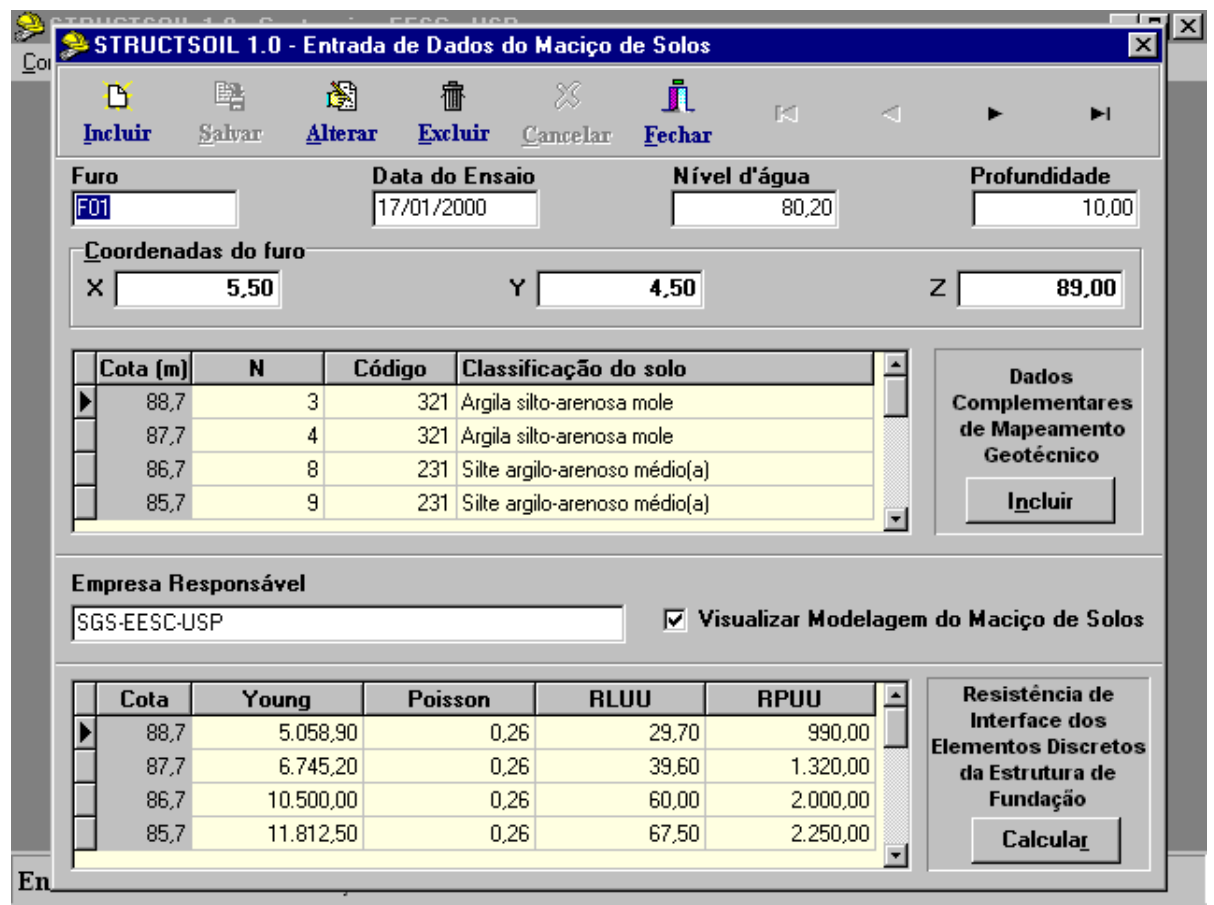

FIGURA 29 - Entrada de dados do maciço de solos por ensaios SPT e cálculo dos parâmetros de resistência e de deformabilidade elástica

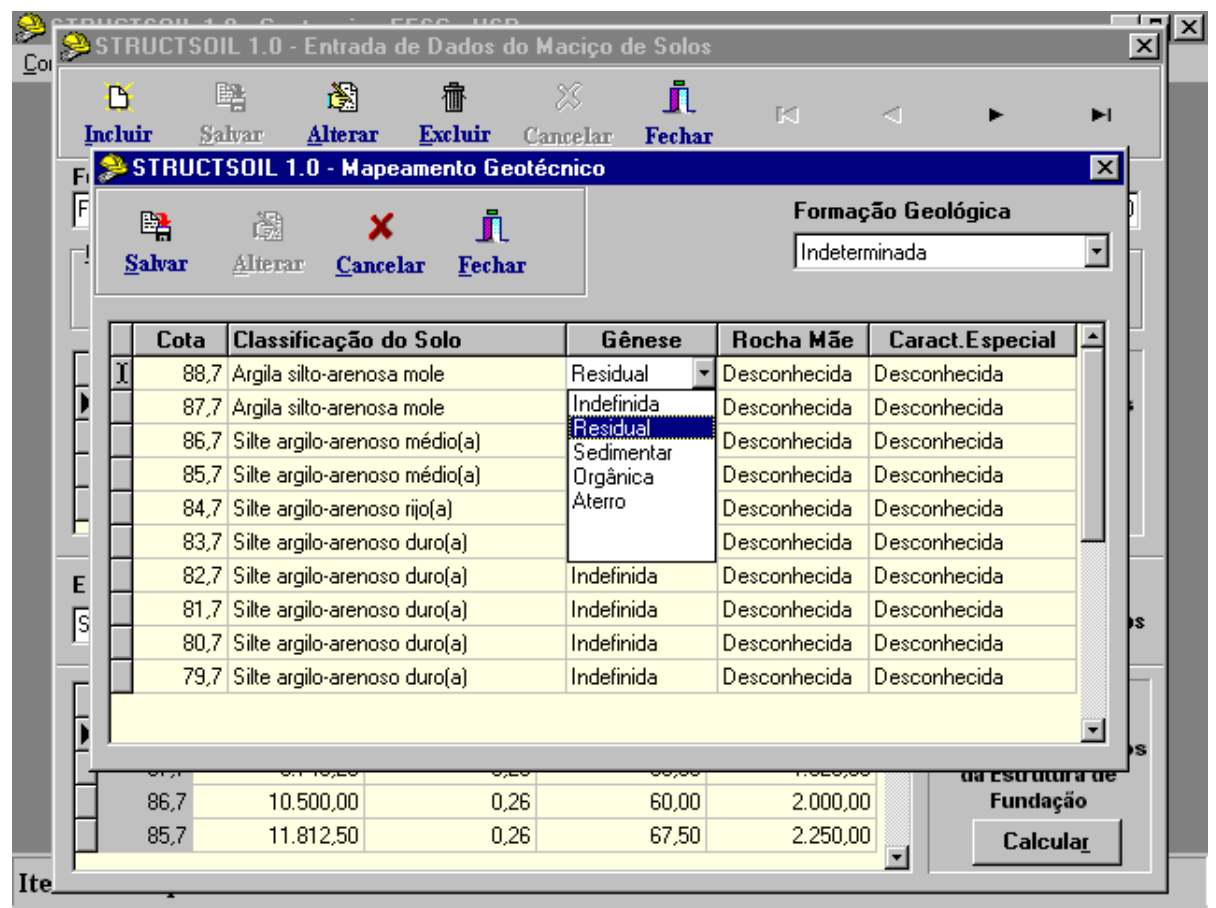

FIGURA 30 - Entrada de dados do maciço de solos por mapeamento geotécnico 
O maciço existente é cadastrado de acordo com relatórios de ensaio SPT e pode receber dados provenientes de mapeamento geotécnico. O sistema modela o perfil definido por cada sondagem cadastrada. Baseando-se no MGDE e no MGR oferece a cada cota ensaiada o módulo de Young, o coeficiente de Poisson e as resistências unitárias últimas para contorno de fuste (RLUU) e base (RPUU).

A FIGURA 29 mostra o acesso ao cenário de entrada de dados de mapeamento geotécnico (FIGURA 30), também oferece a alternativa de calcular a resistência de interface da estrutura de fundação. Esse último evento é usualmente ativado pelo usuário quando modificam-se os dados do maciço de solos, seja por correção ou inclusão de novos pontos de ensaio SPT ou dados de mapeamento geotécnico.

b) camada de solos complementar

A camada de solo complementar é cadastrada a partir de especificações mínimas, ou relatórios, de ensaio triaxial. As características: tipo de solo (granular ou coesivo), granulometria, textura, densidade relativa, peso específico e coesão ou ângulo de atrito são inseridas. O software oferece, a partir do banco de dados de configuração, um $\mathrm{N}_{\mathrm{SPT}}$ equivalente, nível de consistência ou compacidade, fatores de correlação SPT/CPT e parâmetros elásticos e de resistência do material (FIGURA 31).

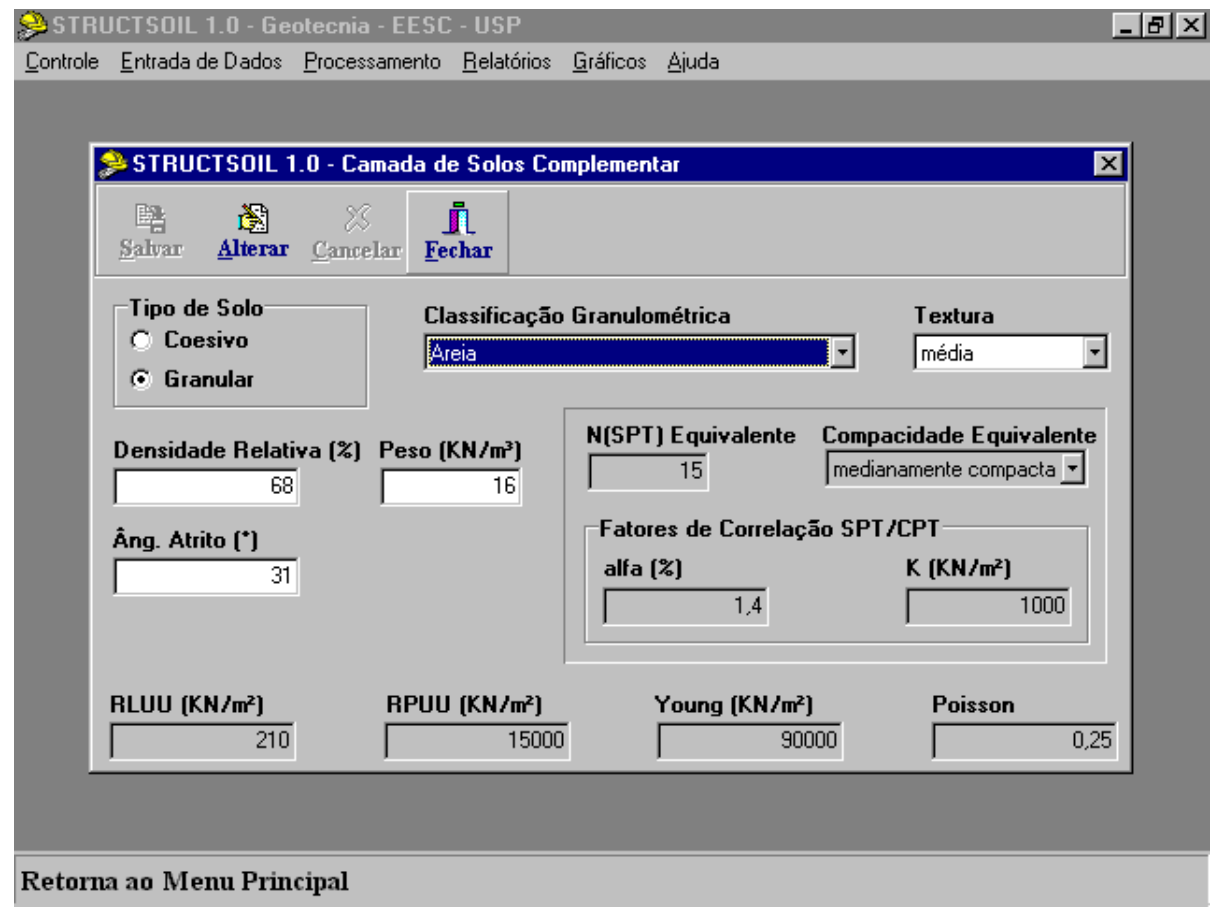

FIGURA 31 - Entrada de dados da camada de solos complementar (aterro) 


\subsection{Estrutura de fundação}

A estrutura de fundação é cadastrada a partir do projeto de fundação da obra ou de um relatório as built. O usuário define o tipo de fundação (superficial ou profunda) e uma das técnicas de execução da estrutura de fundação cadastrada na configuração do sistema. Além disso, escolhe o material de construção e, se a fundação for profunda, o modelo de transferência de carga (MTC).

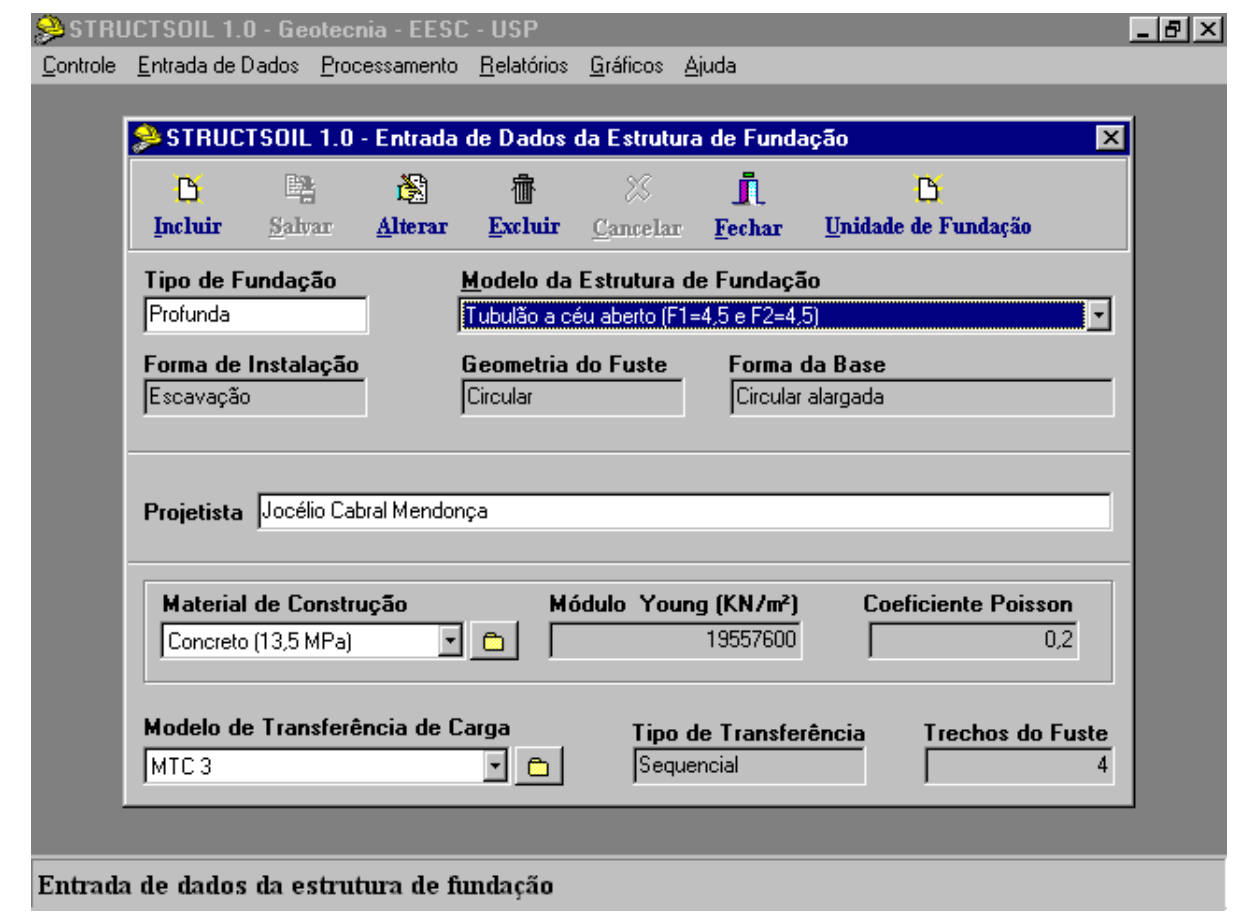

FIGURA 32 - Entrada de dados da estrutura de fundação

A análise do sistema definiu o objeto unidade de fundação como o conjunto de elementos que suporta um apoio da superestrutura. Cada elemento da unidade de fundação é cadastrado e discretizado em elementos de contorno cilíndricos ou prismáticos para fuste e elementos planos circulares ou retangulares, para base. Para o caso de elemento único de estrutura de fundação profunda temos no mínimo um elemento discreto de fuste e um de base. Por outro lado, se a fundação for superficial, a unidade é constituída por um único elemento estrutural de fundação que, decomposto, gera apenas um elemento de base; pelo qual o carregamento é transferido ao solo subjacente por distribuição uniforme.

O objeto elemento discreto herda do elemento estrutural os atributos posição horizontal, geometria seccional e propriedades do material de construção, enquanto possui como atributos próprios cota superior e inferior, área e resistência de interface, calculada 
conforme AOKI \& VELLOSO (1975). Com esses atributos o elemento se torna o objeto básico dos modelos de resistência e deformabilidade e, a partir de seu comportamento intrínseco, gera a matriz de flexibilidade da estrutura de fundação.

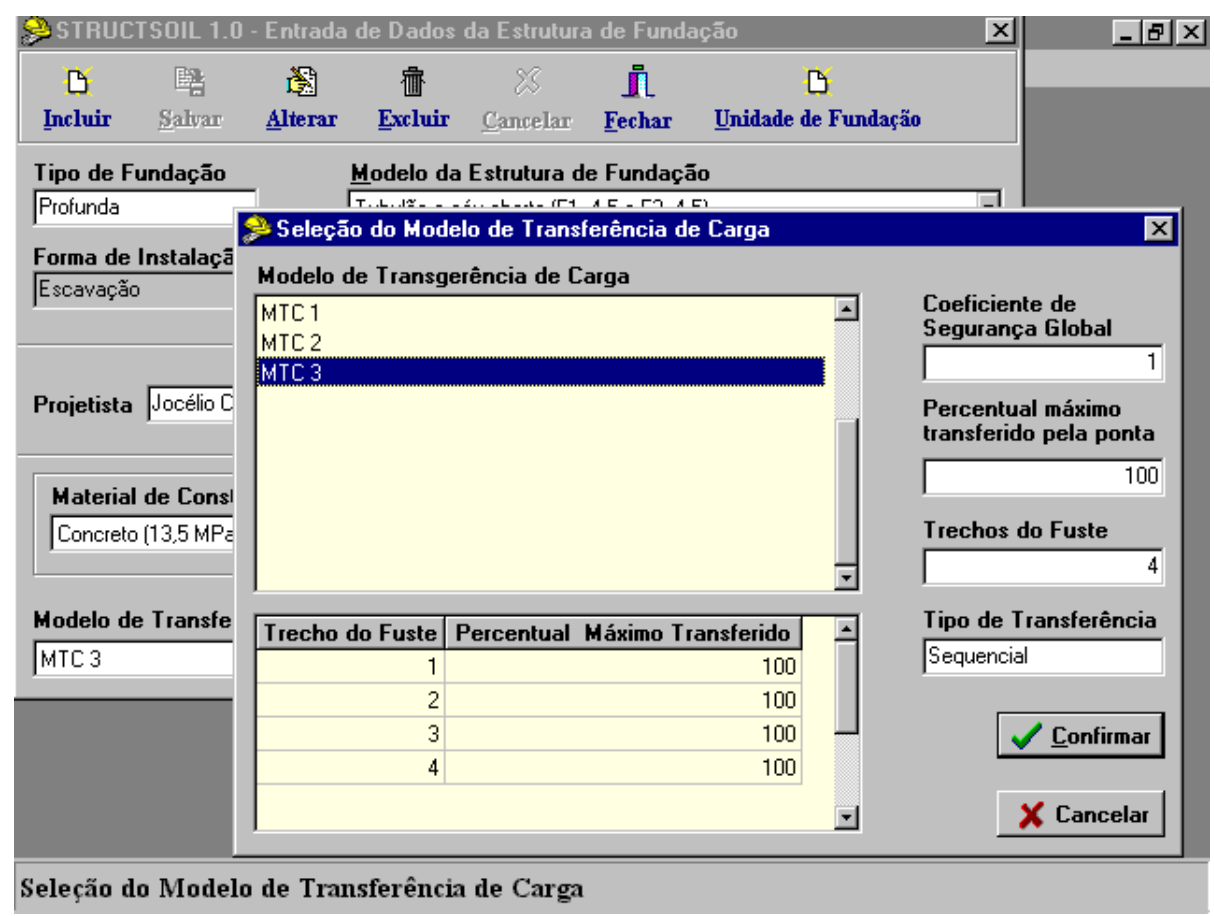

FIGURA 33 - Escolha do MTC para a modelagem da estrutura de fundação

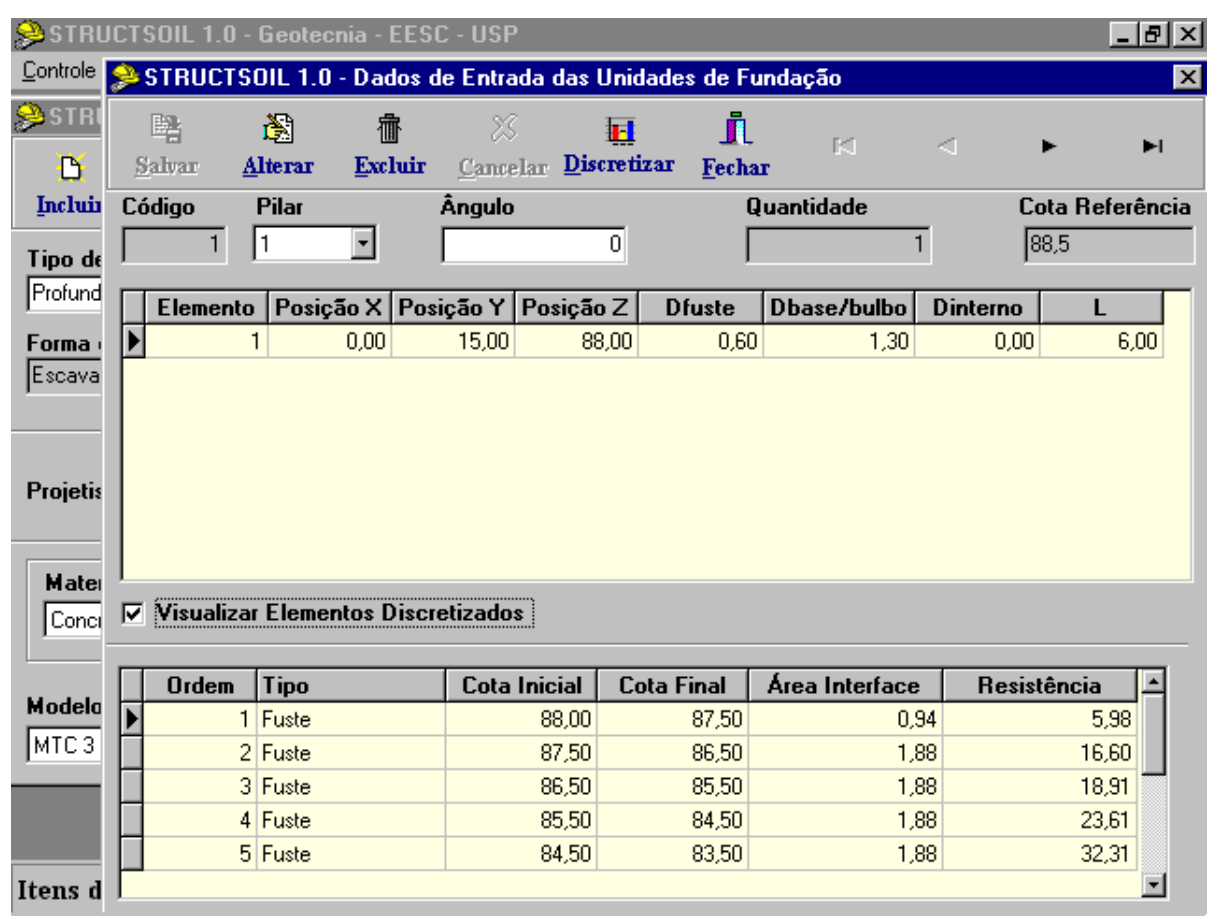

FIGURA 34 - Entrada de dados dos elementos estruturais da fundação 
Os elementos da estrutura de fundação, quando profunda, são discretizados, a cada metro, a partir da cota de referência da obra. O procedimento de discretização coincide cota superior e inferior do elemento discreto com os limites da camada discreta que o envolve ou com as extremidades longitudinais do elemento estrutural (FIGURA 34). Com o maciço de solos cadastrado, o sistema oferece a resistência última de interface de cada elemento discreto e assim, opcionalmente, serve para pré-dimensionamento da estrutura de fundação.

\subsection{Processamento}

A análise do sistema restringiu a denominação processamento ao cálculo das matrizes de flexibilidade da estrutura de fundação (MFEF) e do maciço de solos (MFMS) e ao procedimento iterativo convergente de interação da superestrutura com a fundação. $\mathrm{O} \mathrm{s}$ algoritmos dos métodos de cálculo envolvidos estão expostos na unidade Processamento no ANEXO II.

\subsection{Matrizes de flexibilidade}

As matrizes de flexibilidade são constituídas por coeficientes elásticos lineares de deslocamento de um ponto, obtido pela aplicação de uma carga unitária em um elemento discreto da estrutura de fundação.

\section{a) MFMS}

A MFMS é constituída por fatores de influência no deslocamento de pontos do maciço de solos, e é obtida aplicando uma carga unitária distribuída no contorno lateral dos elementos de fuste cilíndricos ou prismáticos e na superfície dos elementos de base circulares ou retangulares. Os coeficientes $f m_{u, v, i, j, k}$ representam o recalque do ponto do maciço de solos sob a base do elemento estrutural $v$ da unidade de fundação $u$ pela aplicação de carga unitária vertical ao maciço, pela interface com o elemento discreto $k$ do elemento estrutural $j$ da unidade de fundação $i$ (FIGURA 35). O procedimento de cálculo foi baseado na solução do sólido elástico proposta por MINDLIN (1936), considerando a estratificação das camadas sob o ponto em estudo e o horizonte indeslocável conforme a proposta de STEINBRENNER (1934). A discretização da interface elemento discreto - camada de maciço de solos foi implementada de acordo com a proposta de AOKI \& LOPES (1975). 


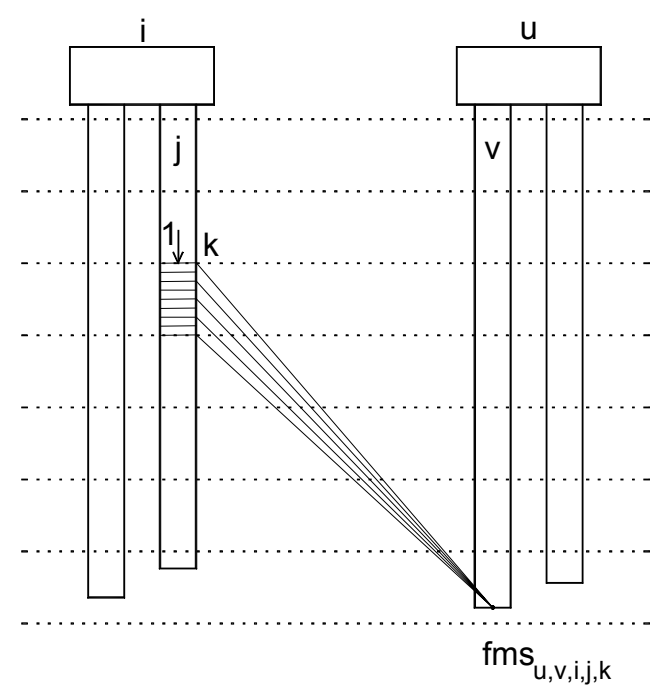

FIGURA 35 - Significado físico dos índices de fatores de influência

b) MFEF

A MFEF é composta por coeficientes $f e f_{i, j, k}$ que representam a deformabilidade elástica longitudinal do elemento discreto $k$ do elemento estrutural $j$ da unidade de fundação $i$, calculada aplicando esforço normal unitário (FIGURA 35).

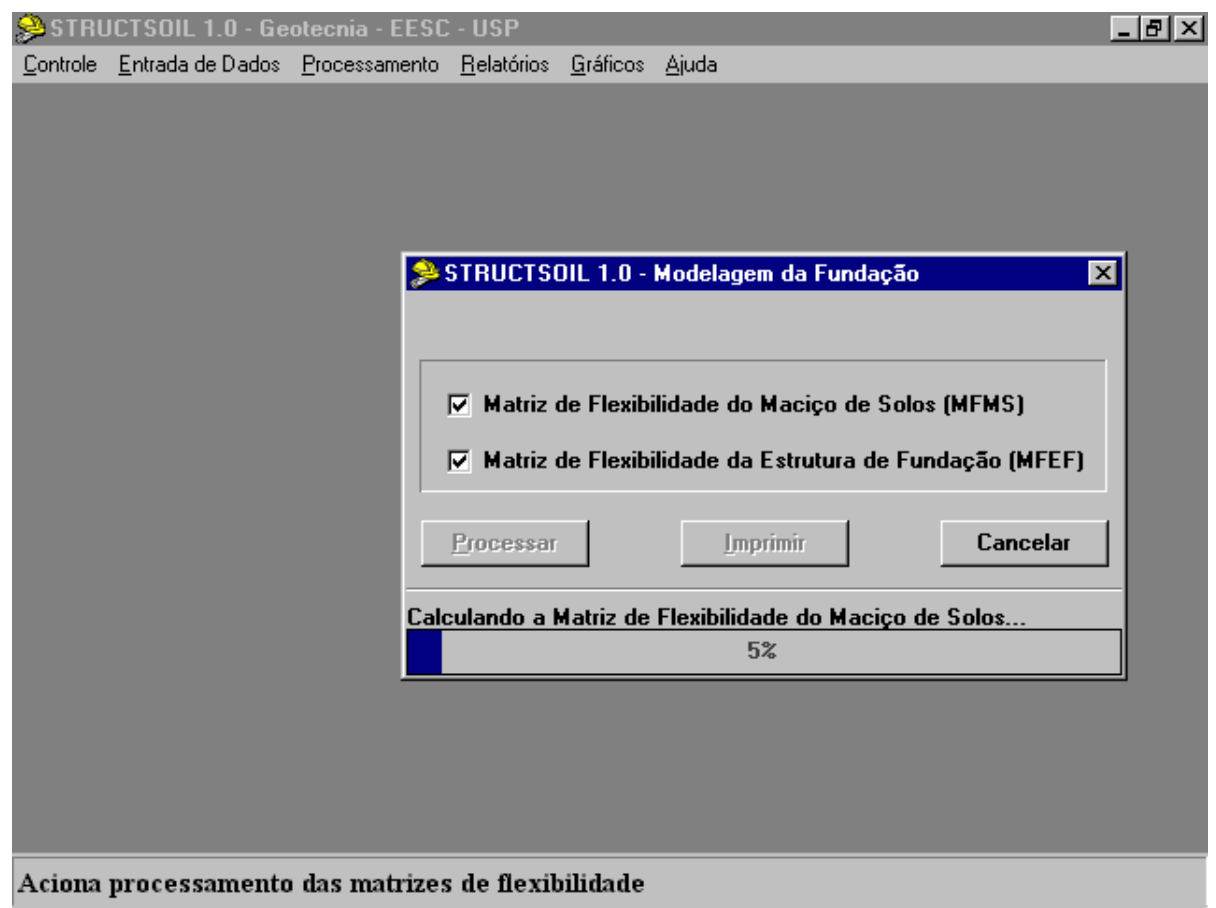

FIGURA 36 - Cenário de controle do cálculo e emissão de relatórios das matrizes MFMS e MFEF 


\subsection{Interação}

A interação é procedida através de método fundamentado na análise matricial e em procedimento iterativo convergente. Para cada iteração obtém-se o carregamento $V_{i, j, k}$ aplicado ao elemento discreto usando um MTC. Adotando transferência sequencial, de cima para baixo, distribui-se a carga aplicada pelo elemento de apoio $\left(V_{i, j}\right)$, através da sua interface com o solo. Atingido o percentual de transferência ao longo de todo o elemento, transfere-se o complemento até alcançar o nível de carregamento aplicado ou a resistência última corrigida pelo coeficiente de segurança. Em último caso, aplica-se o restante do carregamento aplicado através do elemento discreto da base. Ainda não foi implementado a transferência de carga devido à tração.

$\mathrm{O}$ recalque do topo do elemento estrutural é calculado atendendo à seguinte formulação:

$$
w_{u, v}=\sum_{i=1}^{\text {nuf }} \sum_{j=1}^{\text {neuf }} \sum_{k=1}^{\text {neduf }} f m s_{u, v, i, j, k} \cdot V_{i, j, k}+\sum_{k=1}^{\text {neduf }} f e f_{u, v, k} \cdot V_{u, v, k}
$$

onde nuf, neuf e neduf correspondem às quantidades de apoios da superestrutura (unidades de fundação), de elementos estruturais da referida unidade de fundação e de elementos discretos do referido elemento estrutural, respectivamente.

Para facilitar a convergência, a carga aplicada no apoio $\left(V_{i}\right)$ é tomada como a média das últimas $l$ iterações:

$$
V_{i}=\frac{1}{l} \sum_{m=n-l}^{n}\left(V_{i}\right)_{m}
$$

onde $l$ é igual a 6 e $n$ é o contador da iteração vigente.

A variação do carregamento aplicado no apoio devido à nova configuração de recalques nos apoios é obtida por:

$$
d V_{i}=\sum_{u=1}^{n u f} f_{i, u} \cdot w_{u}
$$

sendo que,

$$
\left(V_{i}\right)_{n+1}=\left(V_{i}\right)_{0}+\left(d V_{i}\right)_{n}
$$

onde $\left(V_{i}\right)_{0}$ corresponde ao carregamento para apoios indeslocáveis. A convergência é alcançada quando o par de valores $\left|\left(d V_{i}\right)_{n}-\left(d V_{i}\right)_{n-l}\right|$ e $\left|\left(w_{i}\right)_{n}-\left(w_{i}\right)_{n-l}\right|$ atendem 
simultaneamente a condição de alcançar valores inferiores a um dos seguintes pares: $(1,0 \mathrm{kN}$; $0,002 \mathrm{~m}),(5,0 \mathrm{kN} ; 0,001 \mathrm{~m}),(20,0 \mathrm{kN} ; 0,0005 \mathrm{~m})$ e $(50,0 \mathrm{kN} ; 0,00025 \mathrm{~m})$ para todas a unidades de fundação.

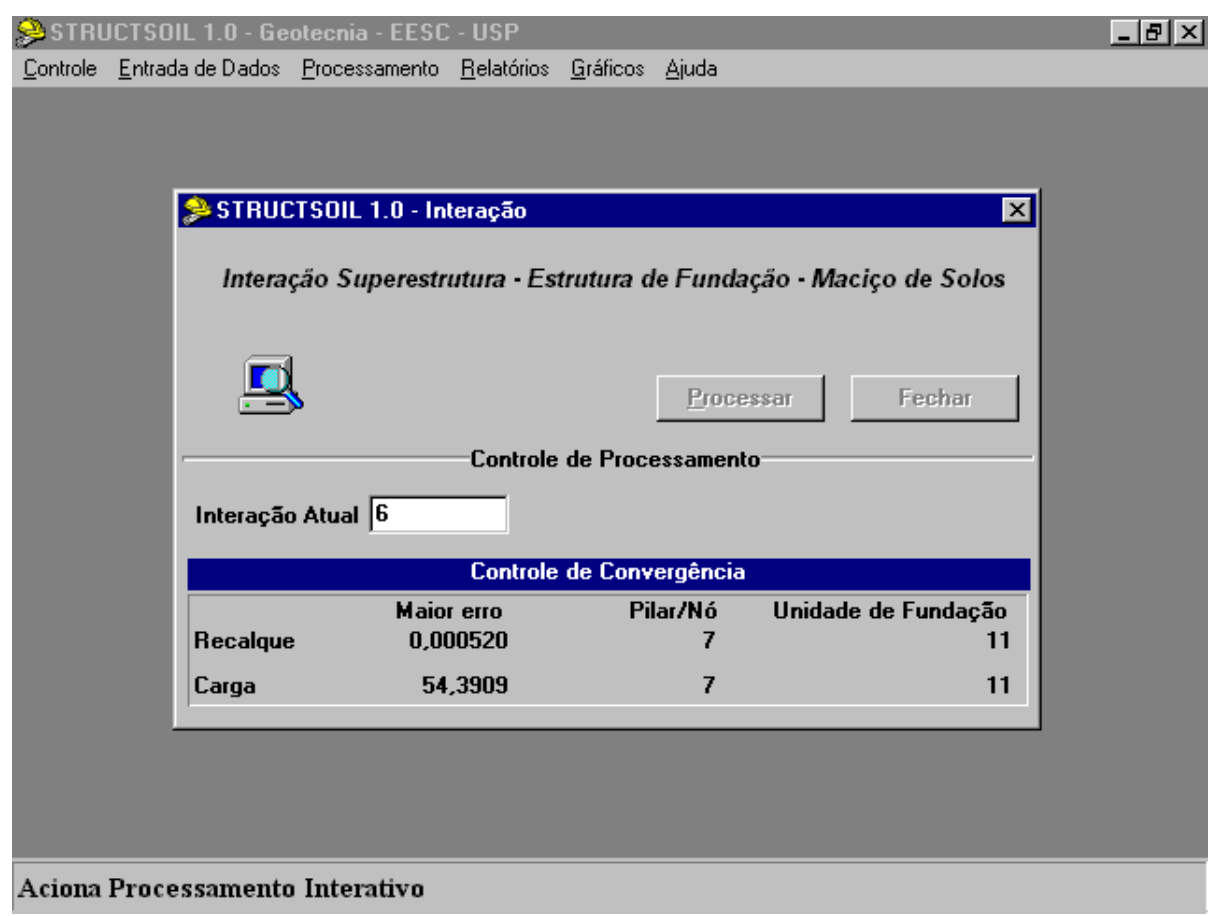

FIGURA 37 - Cenário de controle do cálculo e convergência do processo interativo

O sistema foi projetado prevendo o cálculo de grupo de estacas, mas o procedimento de interação bloco de coroamento - grupo de estacas não é objeto deste trabalho. Dessa forma, cada unidade de fundação é composta de único elemento estrutural, e portanto na formulação apresentada anteriormente, considere que os contadores $v$ e $j$ são constantes e unitários.

No caso particular de fundação superficial em sapatas isoladas, o contador de elemento discreto $(k)$ também é constante e unitário, o que, teoricamente, condiciona a compatibilidade superestrutura - fundação imediata. Neste caso, os fatores $f e f_{i, j, k}$ são nulos e os dois sistemas são regidos por matrizes de rigidez e flexibilidade de mesma dimensão, respectivamente, coincidente à proposta de POULOS (1975). No entanto, o software utiliza a formulação geral de convergência.

$\mathrm{Na}$ entrada de dados da superestrutura, a MRS pode conter a influência de recalque vertical em todos os esforços (força vertical, forças horizontais, momentos fletores e torsor), caso de apoios engastados. Após a convergência, o software oferece a nova configuração de reações nos apoios considerando os deslocamentos verticais obtidos. 
3.4.2.2.5 Relatórios, gráficos e ajuda

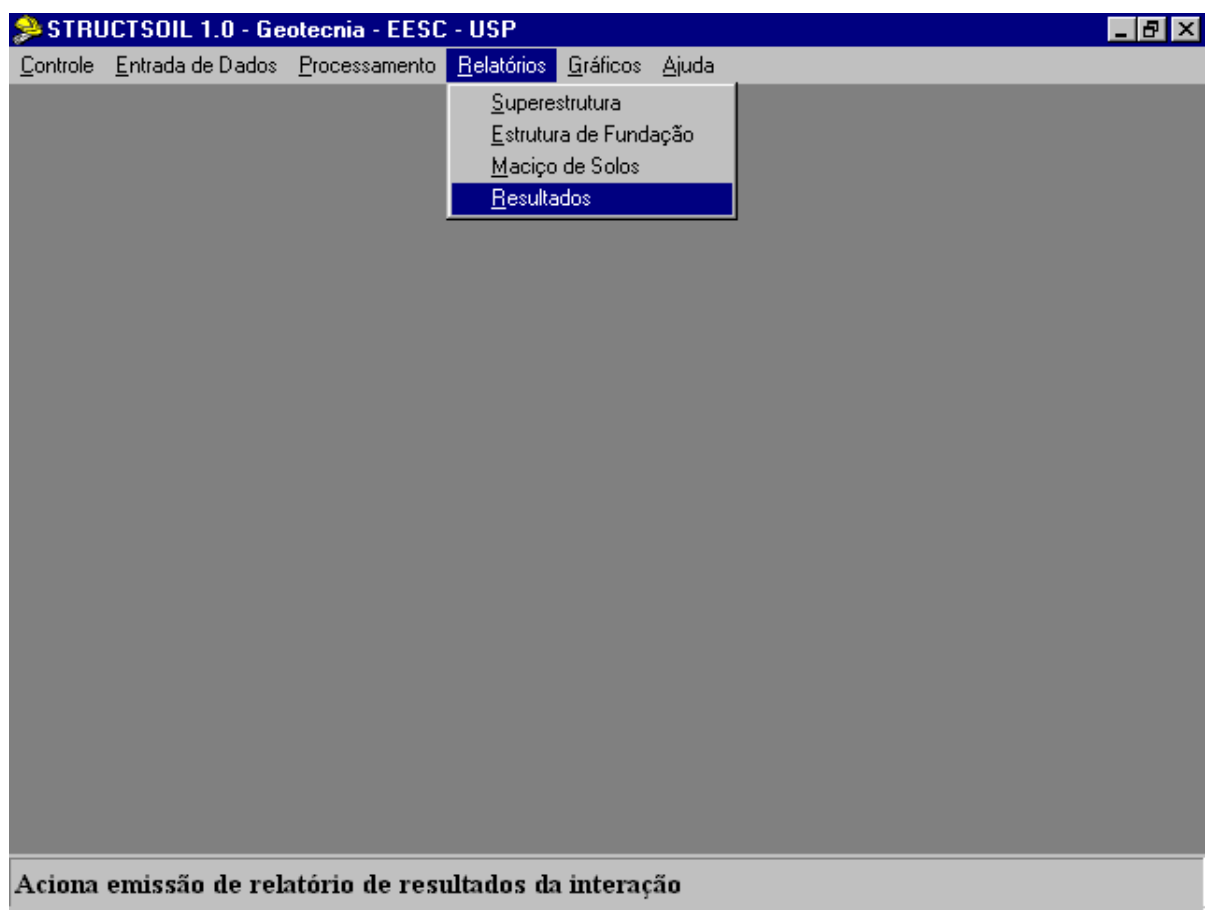

FIGURA 38 - Cenário de acesso ao relatório de resultados (cargas e recalques nos apoios)

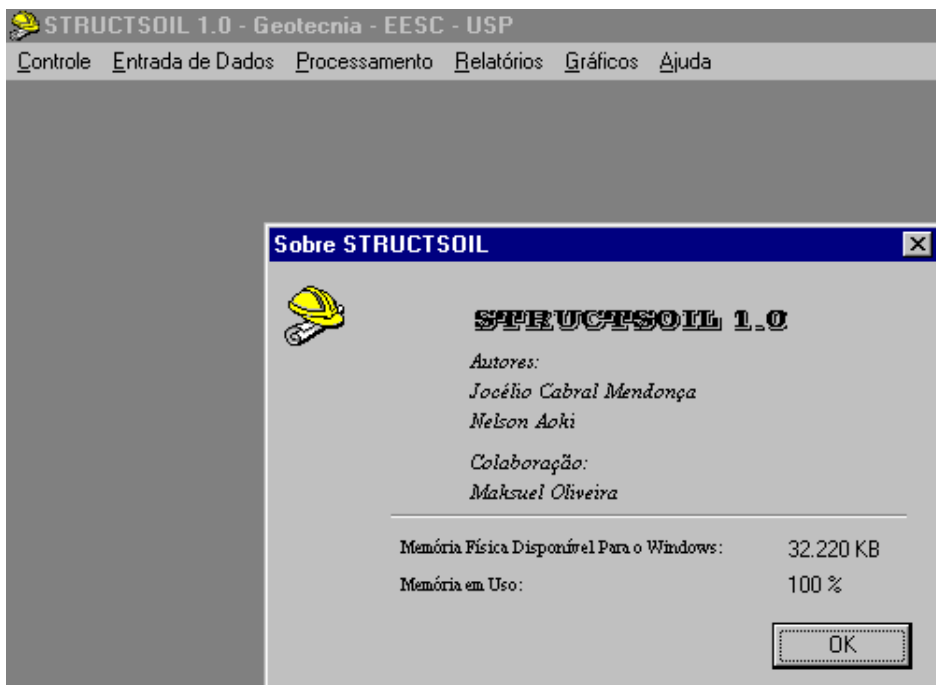

FIGURA 39 - Sobre do software StructsoiL 
O software foi projetado para oferecer pós-processamento (saída de dados) na forma de relatórios e gráficos e ajuda on-line que auxilia, tecnicamente, a sua utilização. Para os cenários onde haja necessidade, emite-se relatórios locais.

A FIGURA 38 mostra o cenário de acesso aos relatórios gerais da superestrutura, estrutura de fundação, maciço de solos e resultados. A FIGURA 39 mostra o Sobre do software. 


\section{APLICAÇÕES TÍPICAS DO STRUCTSOIL}

Neste capítulo, expõem-se as características de cada caso estudado. Todos os dados referentes à superestrutura, à estrutura de fundação e ao maciço de solos são apresentados. No capítulo 5, apresentam-se os principais resultados do estudo desses casos, usando o modelo proposto e o capítulo 6 contém a análise desses resultados. Os três capítulos possuem a mesma estrutura de exposição dos casos, para melhor entendimento.

\subsection{ESTRUTURA COM DUPLA SIMETRIA}

Para exemplificar o funcionamento do software StructsoiL modela-se o comportamento de um pórtico espacial constituído por elementos lineares com dupla simetria em relação aos planos principais, levando em conta a influência da interação estrutura maciço de solos. Denomina-se este caso como exemplo didático.

O maciço de solos é exemplificado por três furos de sondagem executados na formação geológica Pimenteiras, Palmas - TO. A estrutura de fundação é modelada através de três alternativas: sapatas isoladas, tubulões a céu aberto e estacas cravadas.

\subsubsection{PóRTICo ESPACIAL}

O pórtico espacial modelado (FIGURA 40) possui 9 pilares engastados à fundação, na configuração $3 \times 3$, com 4 pavimentos. As vigas e pilares foram modelados nas seções $(0,15 \times 0,50) \mathrm{m}$ e $(0,3 \times 0,3) \mathrm{m}$, respectivamente. Foram aplicadas cargas verticais de serviço, ao longo das vigas, de 17,0 kN/m; o concreto armado possui $\mathrm{fc}=27,5 \mathrm{MPa}, \mathrm{E}=24821,1$ MPa, $\mu=0,2$ e $\gamma=23,56 \mathrm{kN} / \mathrm{m}^{3}$. A TABELA 02 apresenta as coordenadas dos apoios, bem como as cargas aplicadas nos mesmos. 

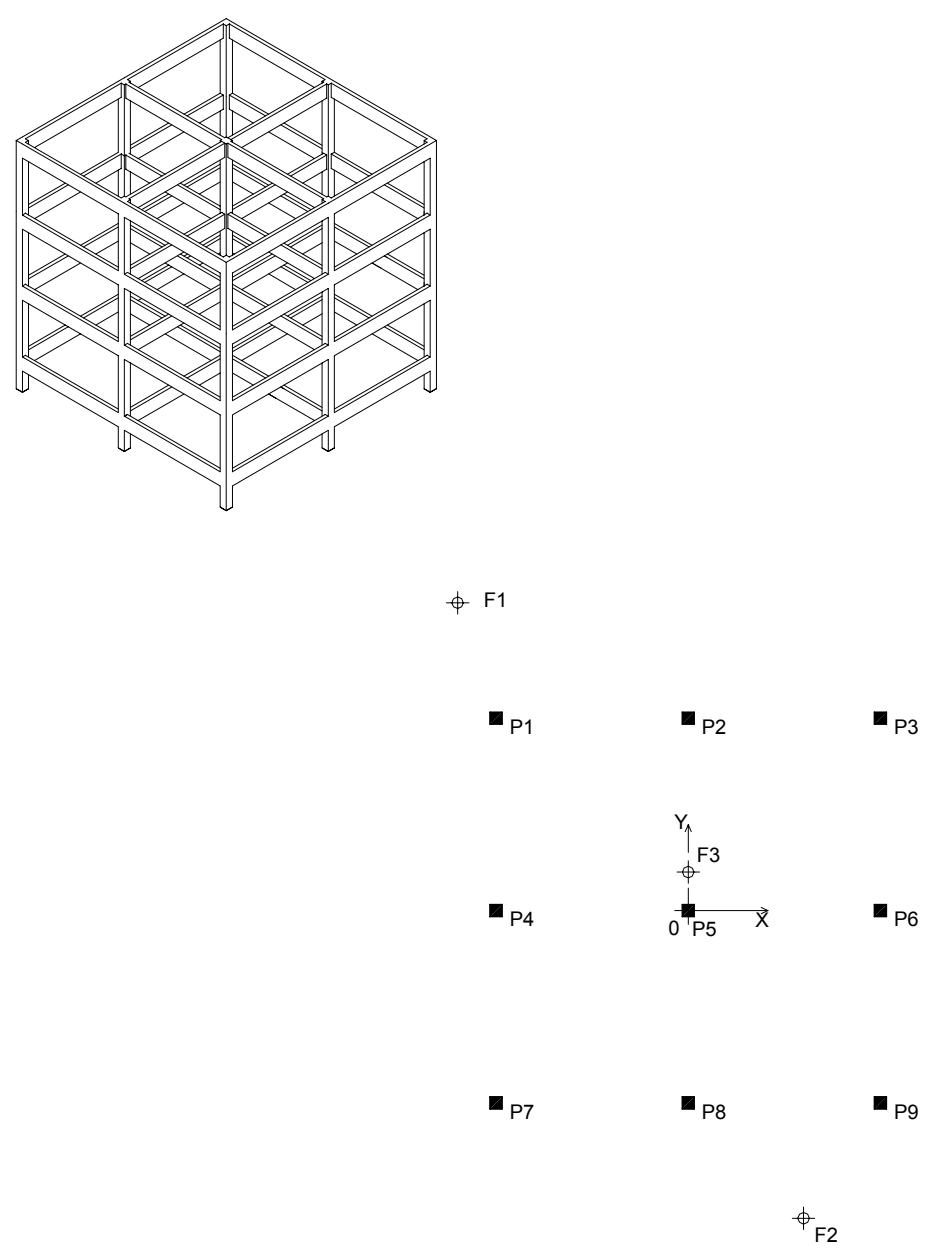

FIGURA 40 - Pórtico espacial e locação dos pilares e furos de sondagem - exemplo didático

TABELA 02 - Cargas nos apoios para condição de apoios indeslocáveis - exemplo didático

\begin{tabular}{cccccccc}
\hline & Coordenadas & $\mathrm{HX}$ & $\mathrm{HY}$ & $\mathrm{V}$ & $\mathrm{MX}$ & $\mathrm{MY}$ & $\mathrm{T}$ \\
$\mathrm{UF}$ & $\mathrm{X}, \mathrm{Y}, \mathrm{Z}$ & $(\mathrm{kN})$ & $(\mathrm{kN})$ & $(\mathrm{kN})$ & $(\mathrm{kN} . \mathrm{m})$ & $(\mathrm{kN} . \mathrm{m})$ & $(\mathrm{kN} . \mathrm{m})$ \\
& $(\mathrm{m})$ & & & & & & \\
\hline 1 & $-5 ; 5 ; 99,5$ & $-5,50$ & 5,50 & $-377,46$ & $-5,47$ & $-5,47$ & 0,00 \\
2 & $0 ; 5 ; 99,5$ & 0,00 & 5,50 & $-600,14$ & $-5,47$ & 0,00 & 0,00 \\
3 & $5 ; 5 ; 99,5$ & 5,50 & 5,50 & $-377,46$ & $-5,47$ & 5,47 & 0,00 \\
4 & $-5 ; 0 ; 99,5$ & $-5,50$ & 0,00 & $-600,14$ & 0,00 & $-5,47$ & 0,00 \\
5 & $0 ; 0 ; 99,5$ & 0,00 & 0,00 & $-822,83$ & 0,00 & 0,00 & 0,00 \\
6 & $5 ; 0 ; 99,5$ & 5,50 & 0,00 & $-600,14$ & 0,00 & 5,47 & 0,00 \\
7 & $-5 ;-5 ; 99,5$ & $-5,50$ & $-5,50$ & $-377,46$ & 5,47 & $-5,47$ & 0,00 \\
8 & $0 ;-5 ; 99,5$ & 0,00 & $-5,50$ & $-600,14$ & 5,47 & 0,00 & 0,00 \\
9 & $5 ;-5 ; 99,5$ & 5,50 & $-5,50$ & $-377,46$ & 5,47 & 5,47 & 0,00 \\
\hline
\end{tabular}




\subsubsection{MACIÇO DE SOLOS}

O maciço de solos foi modelado conforme três sondagens aleatoriamente executadas em maciço de solos residual. As sondagens são apresentadas na FIGURA 41, FIGURA 42 e FIGURA 43. A capacidade resistente de interface elemento da estrutura de fundação maciço de solos foi calculada de acordo com o modelo básico (default) do MGR baseado em AOKI \& VELLOSO (1975).

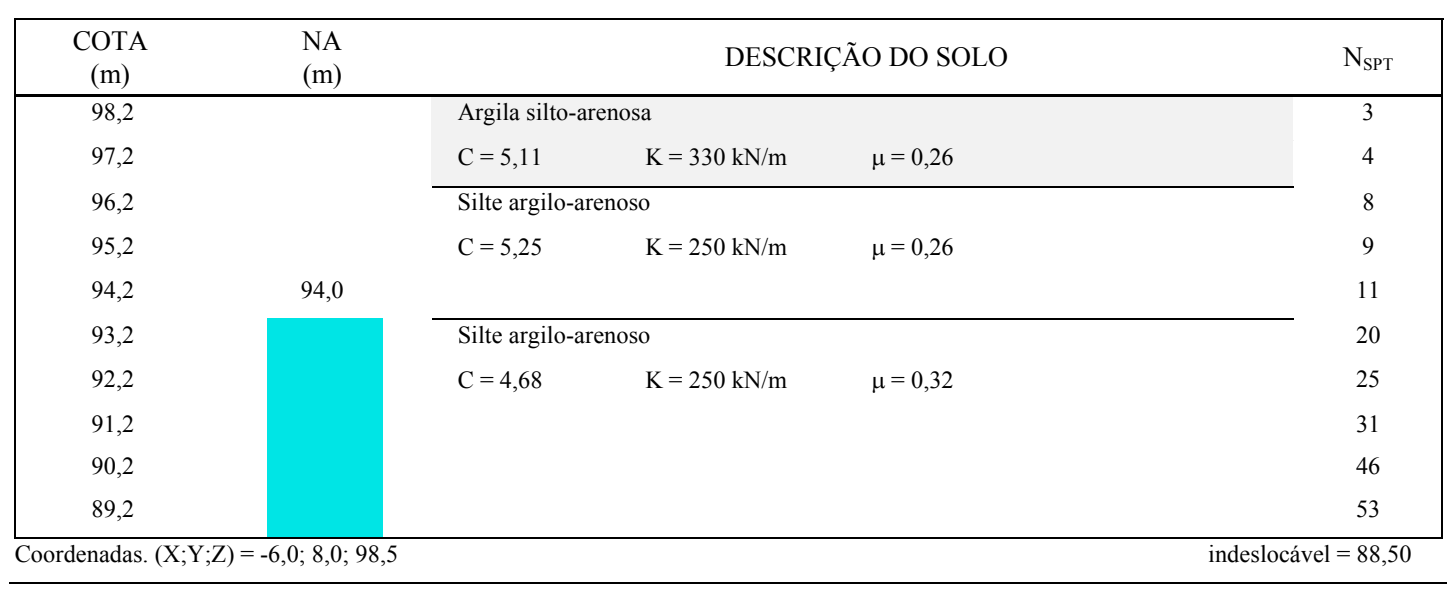

FIGURA 41 - Sondagem SPT - Furo 1

\begin{tabular}{|c|c|c|c|c|}
\hline $\begin{array}{c}\text { COTA } \\
(\mathrm{m})\end{array}$ & $\begin{array}{l}\text { NA } \\
(\mathrm{m})\end{array}$ & \multicolumn{2}{|c|}{ DESCRIÇÃO DO SOLO } & $\mathrm{N}_{\mathrm{SPT}}$ \\
\hline 100,2 & & \multicolumn{2}{|l|}{ Argila silto-arenosa } & 1 \\
\hline 99,2 & & $\mathrm{~K}=330 \mathrm{kN} / \mathrm{m}$ & $\mu=0,26$ & 3 \\
\hline 98,2 & & & & 4 \\
\hline 97,2 & & \multicolumn{2}{|l|}{ Silte argilo-arenoso } & 6 \\
\hline 96,2 & & \multirow[t]{3}{*}{$C=5,25$} & \multirow[t]{3}{*}{$\mu=0,26$} & 6 \\
\hline 95,2 & & & & 8 \\
\hline 94,2 & 94,5 & & & 8 \\
\hline 93,2 & & \multicolumn{2}{|l|}{ Silte argilo-arenoso } & 11 \\
\hline 92,2 & & \multirow[t]{4}{*}{$\mathrm{K}=250 \mathrm{kN} / \mathrm{m}$} & \multirow[t]{6}{*}{$\mu=0,32$} & 10 \\
\hline 91,2 & & & & 17 \\
\hline 90,2 & & & & 19 \\
\hline 89,2 & & & & 31 \\
\hline 88,2 & & & & 33 \\
\hline 87,2 & & & & 37 \\
\hline
\end{tabular}

FIGURA 42 - Sondagem SPT - Furo 2

O software também oferece um banco de dados, tomado como default, que define a formação geológica como indeterminada e rocha de origem, gênese (residual, sedimentar, 
etc...) e características especiais (laterítico, saprolítico, colapsível, etc...) como desconhecidas.

\begin{tabular}{|c|c|c|c|c|}
\hline $\begin{array}{c}\text { COTA } \\
(\mathrm{m})\end{array}$ & $\begin{array}{l}\text { NA } \\
\text { (m) }\end{array}$ & \multicolumn{2}{|c|}{ DESCRIÇÃO DO SOLO } & $\mathrm{N}_{\mathrm{SPT}}$ \\
\hline 99,9 & & \multicolumn{2}{|l|}{ Argila silto-arenosa } & 1 \\
\hline 98,9 & & $\mathrm{~K}=330 \mathrm{kN} / \mathrm{m}$ & $\mu=0,26$ & 4 \\
\hline 97,9 & & \multicolumn{2}{|l|}{ Silte argilo-arenoso } & 4 \\
\hline 96,9 & & \multirow[t]{2}{*}{$C=5,25$} & \multirow[t]{2}{*}{$\mu=0,26$} & 7 \\
\hline 95,9 & 95,0 & & & 9 \\
\hline 94,9 & & \multicolumn{2}{|l|}{ Silte argilo-arenoso } & 12 \\
\hline 93,9 & & \multirow[t]{5}{*}{$\mathrm{C}=4,68$} & \multirow[t]{5}{*}{$\mu=0,32$} & 13 \\
\hline 92,9 & & & & 34 \\
\hline 91,9 & & & & 39 \\
\hline 90,9 & & & & 43 \\
\hline 89,9 & & & & 41 \\
\hline
\end{tabular}

FIGURA 43 - Sondagem SPT - Furo 3

Pela dificuldade em obter dados através de mapeamento geotécnico, esses não foram cadastrados e o software determinou automaticamente os parâmetros elásticos do maciço de acordo com o modelo básico (default) do MGDE, considerando a granulometria e a condição de saturação. A camada complementar é granular, composta de areia média com densidade relativa $(\rho)$ igual a $66 \%$, peso específico $(\gamma) 17 \mathrm{kN} / \mathrm{m}^{3}$ e ângulo de atrito $(\phi) 34^{0}$.

\subsubsection{ESTRUTURA DE FUNDAÇÃO}

A estrutura de fundação foi projetada em três alternativas para demonstrar a capacidade do software em modelar as várias técnicas de execução de estrutura de fundação, e também para mostrar como a rigidez relativa superestrutura-fundação influencia no comportamento estrutural. O MTC adotado divide o fuste em 3 trechos, os quais transferem respectivamente, 70,80 e $90 \%$ da resistência lateral ao solo. A ponta transfere $100 \%$ de sua capacidade resistente, enquanto o coeficiente de segurança global é 1,0, condição de serviço.

\subsubsection{Solução em sapatas isoladas}

Para efeito de análise comparativa, foi dimensionada a solução em sapatas isoladas, apesar de o maciço suporte não ser adequado para o emprego de fundação superficial, pois possui camadas superficiais bastante deformáveis. 
TABELA 03 - Estrutura de fundação - sapatas - exemplo didático

\begin{tabular}{ccc}
\hline UF & Dimensões $(\mathrm{m})$ & Observações \\
\hline $1,3,7,9$ & $2,20 \times 2,20$ & cota de apoio $=98,00 \mathrm{~m}$ \\
5 & $3,20 \times 3,20$ & $\sigma_{\text {adm }}=80 \mathrm{kN} / \mathrm{m}^{2}$ \\
$2,4,6,8$ & $2,75 \times 2,75$ & fck $=20 \mathrm{MPa}$ \\
\hline
\end{tabular}

A TABELA 03 mostra a geometria, posição e taxa admissível $\left(\sigma_{\mathrm{adm}}\right)$ da estrutura de fundação em sapatas isoladas. A taxa admissível $80 \mathrm{kPa}$ foi tomada pela correlação empírica $\mathrm{N}_{\mathrm{SPT}} / 0,05\left(\mathrm{~N}_{\mathrm{SPT}}\right.$ mínimo). O peso próprio foi desprezado.

\subsubsection{Solução em tubulões a céu aberto}

A solução em tubulões a céu aberto foi projetada adotando taxa admissível $366 \mathrm{kPa}$ na base pela correlação empírica $\mathrm{N}_{\mathrm{SPT}} / 0,03 \mathrm{em} \mathrm{kPa}\left(\mathrm{N}_{\mathrm{SPT}}\right.$ médio). Desprezou-se o peso próprio e a resistência por atrito lateral. Foram consideradas as seguintes propriedades para $\mathrm{o}$ concreto armado: $\mathrm{fck}=13,5 \mathrm{MPa}, \mathrm{E}=19557,6 \mathrm{MPa}$ e $\mu=0,2$.

TABELA 04 - Estrutura de fundação - tubulões - exemplo didático

\begin{tabular}{cccc}
\hline UF & $\phi_{\text {fuste }}(\mathrm{m})$ & $\phi_{\text {base }}(\mathrm{m})$ & Observações \\
\hline $1,3,7,9$ & 0,50 & 1,15 & cota de apoio $=93,50 \mathrm{~m}$ \\
5 & 0,50 & 1,70 & cota de topo $=99,00 \mathrm{~m}$ \\
$2,4,6,8$ & 0,50 & 1,45 & $\sigma_{\text {adm }}=366 \mathrm{kN} / \mathrm{m}^{2}$ \\
\hline
\end{tabular}

O StructsoiL despreza a resistência lateral e o encurtamento elástico do tubulão no trecho entre a cota de apoio e a cota $1,5 \mathrm{H}_{\text {base }}$ superior a esta.

\subsubsection{Solução em estacas cravadas}

A solução em estacas cravadas de seção quadrada foi projetada usando o método AOKI \& VELLOSO (1975) para $\mathrm{N}_{\mathrm{SPT}}$ médio dos três furos de sondagem SPT. A TABELA 05 mostra a geometria e a posição dos elementos da estrutura de fundação em estacas cravadas. A resistência de projeto para as estacas de seções $(0,3 \times 0,3) \mathrm{m},(0,45 \times 0,45) \mathrm{m}$ e $(0,4 \times 0,4)$ m são: $799 \mathrm{kN}, 1735 \mathrm{kN}$ e $1254 \mathrm{kN}$, respectivamente. O concreto armado utilizado tem como propriedades: $\mathrm{fck}=20 \mathrm{MPa}, \mathrm{E}=22994,5 \mathrm{MPa}$ e $\mu=0,2$. 
TABELA 05 - Estrutura de fundação - estacas cravadas - exemplo didático

\begin{tabular}{cccc}
\hline UF & Dimensões $(\mathrm{m})$ & L $(\mathrm{m})$ & Observações \\
\hline $1,3,7,9$ & $0,30 \times 0,30$ & 9,00 & \\
5 & $0,45 \times 0,45$ & 10,00 & cota de topo $=99,0 \mathrm{~m}$ \\
$2,4,6,8$ & $0,40 \times 0,40$ & 9,00 & \\
\hline
\end{tabular}

\subsection{ESTRUTURA ASSIMÉTRICA}

A literatura especializada afirma que a interação estrutura - maciço de solos é praticamente inexpressiva para casos de superestrutura com planta na forma de L. Para comprovar essas especulações estuda-se o caso de uma estrutura com oito pilares, modelado com elementos de barras (vigas e pilares) e painéis (lajes). Denomina-se este caso como edifício assimétrico.

O maciço de solos é exemplificado por três furos de sondagem em maciço residual executados na formação geológica Pimenteiras, região de Palmas - TO, e por cinco furos de sondagem fictícios em maciço sedimentar. A estrutura de fundação é modelada através de duas alternativas para o maciço residual: sapatas isoladas e tubulões a céu aberto; e duas alternativas para o maciço sedimentar: estacas cravadas e estacas escavadas de grande diâmetro (estacão).

\subsubsection{PóRtico ESPACIAL}

FIGURA 44 - Pórtico espacial - edifício assimétrico 
O pórtico espacial modelado na configuração L (FIGURA 44) possui 8 pilares engastados à fundação, com altura variável de 8 e 11 pavimentos. As vigas foram modeladas com seção $(0,15 \times 0,60) \mathrm{m}$, os pilares de canto com seção $(0,4 \times 0,4) \mathrm{m}$ e os pilares de meio de vão (P2, P5 e P6) com seção $(0,5 \times 0,5) \mathrm{m}$, as lajes possuem espessura de $0,12 \mathrm{~m}$. Foram aplicadas cargas verticais de serviço ao longo da superfície das lajes de $2,5 \mathrm{kN} / \mathrm{m}^{2}$, o concreto armado possui fck $=25 \mathrm{MPa}, \mathrm{E}=25322,9 \mathrm{MPa}, \mu=0,2$ e $\gamma=23,56 \mathrm{kN} / \mathrm{m}^{3}$. A TABELA 06 apresenta as coordenadas e as cargas aplicadas nos apoios.

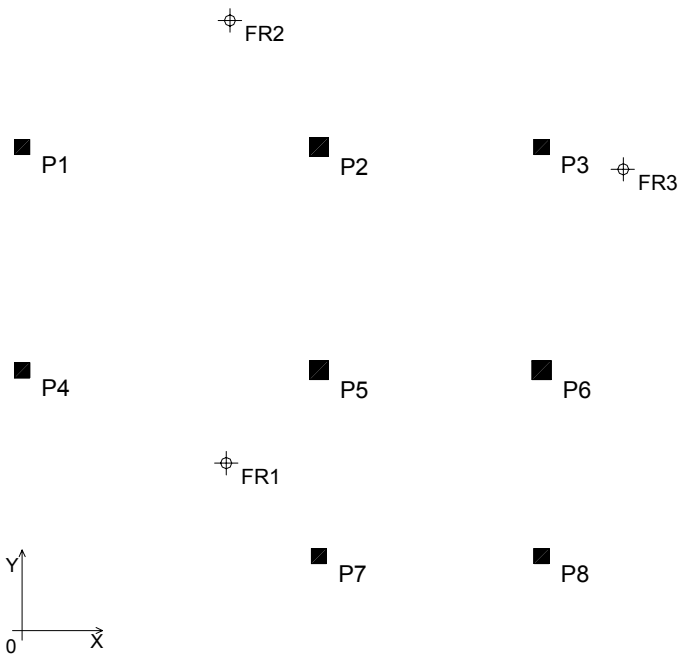

FIGURA 45 - Planta de locação dos pilares do edifício assimétrico e dos furos de sondagem SPT em maciço de solos residual

TABELA 06 - Cargas nos apoios para condição de apoios indeslocáveis - edifício assimétrico

\begin{tabular}{cccccccc}
\hline UF & $\begin{array}{c}\text { Coordenadas } \\
\mathrm{X}, \mathrm{Y}, \mathrm{Z} \\
(\mathrm{m})\end{array}$ & $\begin{array}{c}\mathrm{HX} \\
(\mathrm{kN})\end{array}$ & $\begin{array}{c}\mathrm{HY} \\
(\mathrm{kN})\end{array}$ & $\begin{array}{c}\mathrm{V} \\
(\mathrm{kN})\end{array}$ & $\begin{array}{c}\mathrm{MX} \\
(\mathrm{kN} . \mathrm{m})\end{array}$ & $\begin{array}{c}\mathrm{MY} \\
(\mathrm{kN} . \mathrm{m})\end{array}$ & $\begin{array}{c}\mathrm{T} \\
(\mathrm{kN} . \mathrm{m})\end{array}$ \\
\hline 1 & $0 ; 15 ; 88,5$ & $-8,68$ & 9,11 & $-540,38$ & 3,31 & 3,09 & $-0,07$ \\
2 & $8 ; 15 ; 88,5$ & 4,97 & 17,61 & $-1127,03$ & $-2,50$ & 0,54 & $-0,16$ \\
3 & $14 ; 15 ; 88,5$ & 3,87 & 6,31 & $-579,25$ & 6,77 & $-2,27$ & 0,06 \\
4 & $0 ; 7 ; 88,5$ & $-8,93$ & $-10,21$ & $-555,99$ & $-0,40$ & 2,42 & $-0,06$ \\
5 & $8 ; 7 ; 88,5$ & 1,22 & $-16,47$ & $-1380,51$ & 12,28 & $-4,07$ & $-0,14$ \\
6 & $14 ; 7 ; 88,5$ & 7,92 & $-7,57$ & $-983,01$ & 4,44 & 1,03 & $-0,14$ \\
7 & $8 ; 2 ; 88,5$ & $-6,51$ & 0,76 & $-747,03$ & $-3,80$ & $-0,39$ & $-0,05$ \\
8 & $14 ; 2 ; 88,5$ & 6,13 & 0,45 & $-720,03$ & $-3,20$ & -0.72 & $-0,06$ \\
\hline
\end{tabular}




\subsubsection{MACIÇO DE SOLOS}

O maciço de solos foi modelado através de dois conjuntos de sondagens, uma aplicada em maciço residual e outra em maciço sedimentar. Os furos de sondagem SPT em maciço residual estão locados na FIGURA 45, enquanto a locação dos furos em maciço sedimentar estão expostos na FIGURA 55.

Como no caso do exemplo didático, a capacidade resistente de interface elemento da estrutura de fundação - maciço de solos foi calculada de acordo com o modelo básico (default) do MGR.

\subsubsection{Maciço residual}

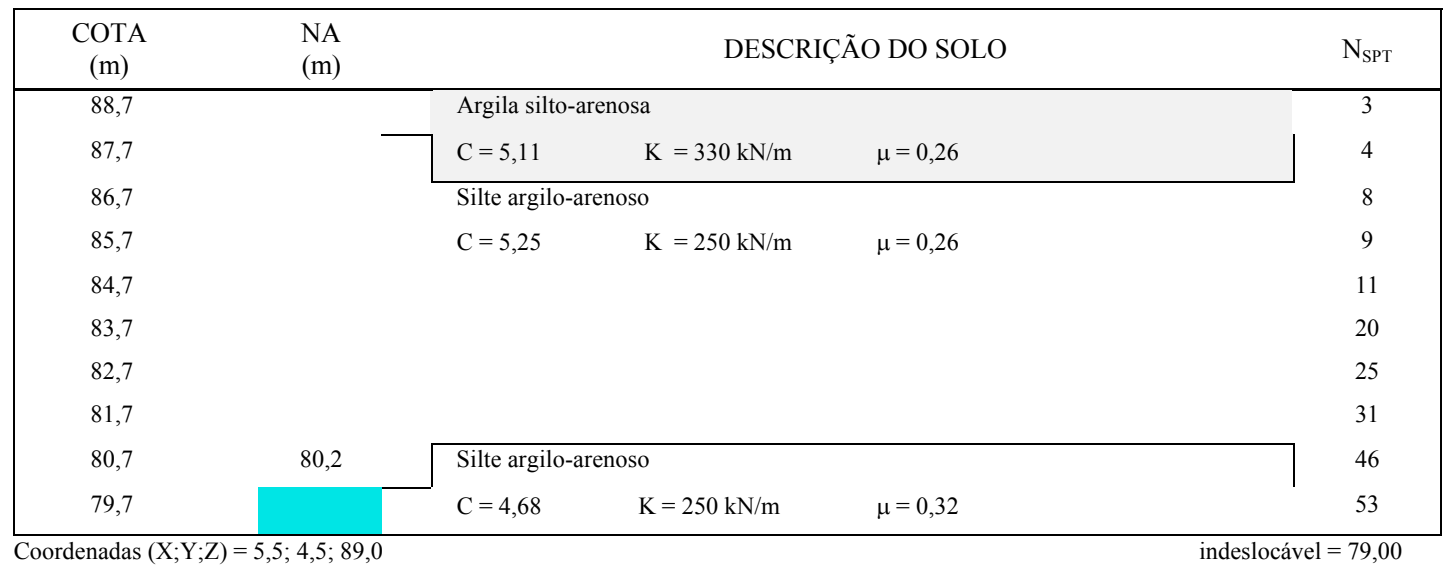

FIGURA 46 - Sondagem SPT - Furo FR1

\begin{tabular}{|c|c|c|c|c|c|}
\hline $\begin{array}{c}\text { COTA } \\
(\mathrm{m})\end{array}$ & $\begin{array}{l}\text { NA } \\
\text { (m) }\end{array}$ & \multicolumn{3}{|c|}{ DESCRIÇÃO DO SOLO } & $\mathrm{N}_{\mathrm{SPT}}$ \\
\hline 88,3 & & \multicolumn{3}{|c|}{ Argila silto-arenosa } & 1 \\
\hline 87,3 & & $\mathrm{C}=5,11$ & $\mathrm{~K}=330 \mathrm{kN} / \mathrm{m}$ & $\mu=0,26$ & 3 \\
\hline 86,3 & & & & & 4 \\
\hline 85,3 & & \multicolumn{3}{|c|}{ Silte argilo-arenoso } & 6 \\
\hline 84,3 & & \multirow[t]{5}{*}{$C=5,25$} & \multirow[t]{5}{*}{$\mathrm{K}=250 \mathrm{kN} / \mathrm{m}$} & \multirow[t]{5}{*}{$\mu=0,26$} & 6 \\
\hline 83,3 & & & & & 8 \\
\hline 82,3 & & & & & 8 \\
\hline 81,3 & & & & & 11 \\
\hline 80,3 & 80,3 & & & & 10 \\
\hline 79,3 & & \multicolumn{3}{|c|}{ Silte argilo-arenoso } & 17 \\
\hline 78,3 & & \multirow[t]{4}{*}{$\mathrm{C}=4,68$} & \multirow[t]{4}{*}{$\mathrm{K}=250 \mathrm{kN} / \mathrm{m}$} & \multirow[t]{4}{*}{$\mu=0,32$} & 19 \\
\hline 77,3 & & & & & 31 \\
\hline 76,3 & & & & & 37 \\
\hline 75,3 & & & & & 41 \\
\hline
\end{tabular}

FIGURA 47 - Sondagem SPT - Furo FR2 
O maciço de solos residual foi modelado conforme três sondagens aleatoriamente executadas. As sondagens são apresentadas na FIGURA 46, FIGURA 47 e FIGURA 48. A camada complementar é coesiva, composta de argila com $\rho=81 \%, \gamma=15 \mathrm{kN} / \mathrm{m}^{3}$ e c $=13$ $\mathrm{kPa}$.

\begin{tabular}{|c|c|c|c|c|}
\hline $\begin{array}{c}\text { COTA } \\
(\mathrm{m})\end{array}$ & $\begin{array}{l}\text { NA } \\
\text { (m) }\end{array}$ & \multicolumn{2}{|c|}{ DESCRIÇÃO DO SOLO } & $\mathrm{N}_{\mathrm{SPT}}$ \\
\hline 87,8 & & \multicolumn{2}{|l|}{ Argila silto-arenosa } & 1 \\
\hline 86,8 & & $\mathrm{~K}=330 \mathrm{kN} / \mathrm{m}$ & $\mu=0,26$ & 4 \\
\hline 85,8 & & \multicolumn{2}{|l|}{ Silte argilo-arenoso } & 4 \\
\hline 84,8 & & \multirow{5}{*}{$\mathrm{C}=5,25$} & \multirow{5}{*}{$\mu=0,26$} & 7 \\
\hline 83,8 & & & & 9 \\
\hline 82,8 & & & & 12 \\
\hline 81,8 & & & & 13 \\
\hline 80,8 & \multirow[t]{5}{*}{80,0} & & & 34 \\
\hline 79,8 & & \multicolumn{2}{|l|}{ Silte argilo-arenoso } & 39 \\
\hline 78,8 & & \multirow[t]{3}{*}{$\mathrm{C}=4,68$} & \multirow[t]{3}{*}{$\mu=0,32$} & 43 \\
\hline 77,8 & & & & 41 \\
\hline 76,8 & & & & 42 \\
\hline
\end{tabular}

FIGURA 48 - Sondagem SPT - Furo FR3

\subsubsection{Maciço sedimentar}

\begin{tabular}{|c|c|c|c|c|c|}
\hline $\begin{array}{c}\text { COTA } \\
(\mathrm{m})\end{array}$ & $\begin{array}{l}\text { NA } \\
(\mathrm{m})\end{array}$ & \multicolumn{3}{|c|}{ DESCRIÇÃO DO SOLO } & $\mathrm{N}_{\mathrm{SPT}}$ \\
\hline 90,7 & & \multicolumn{3}{|l|}{ Areia argilosa } & 1 \\
\hline 89,7 & & \multirow[t]{4}{*}{$C=6,65$} & \multirow[t]{4}{*}{$\mathrm{K}=600 \mathrm{kN} / \mathrm{m}$} & \multirow[t]{4}{*}{$\mu=0,29$} & 2 \\
\hline 88,7 & & & & & 4 \\
\hline 87,7 & & & & & 5 \\
\hline 86,7 & 86,0 & & & & 5 \\
\hline 85,7 & & \multicolumn{3}{|l|}{ Areia } & 6 \\
\hline 84,7 & & \multirow[t]{5}{*}{$\mathrm{C}=7,00$} & \multirow[t]{5}{*}{$\mathrm{K}=1000 \mathrm{kN} / \mathrm{m}$} & \multirow[t]{5}{*}{$\mu=0,26$} & 10 \\
\hline 83,7 & & & & & 15 \\
\hline 82,7 & & & & & 17 \\
\hline 81,7 & & & & & 25 \\
\hline 80,7 & & & & & 28 \\
\hline
\end{tabular}

FIGURA 49 - Sondagem SPT - Furo FS1

O maciço de solos sedimentar foi modelado conforme cinco sondagens distribuídas na área do edifício. As sondagens são apresentadas na FIGURA 49, FIGURA 50, FIGURA 51, FIGURA 52 e FIGURA 53. A camada complementar é granular, composta de areia siltoarenosa fina com $\rho=48 \%, \gamma=14 \mathrm{kN} / \mathrm{m}^{3}$ e $\phi=34^{0}$. 


\begin{tabular}{|c|c|c|c|c|c|}
\hline $\begin{array}{c}\text { COTA } \\
(\mathrm{m})\end{array}$ & $\begin{array}{l}\text { NA } \\
\text { (m) }\end{array}$ & \multicolumn{3}{|c|}{ DESCRIÇÃO DO SOLO } & $\mathrm{N}_{\mathrm{SPT}}$ \\
\hline 89,8 & & \multicolumn{3}{|l|}{ Areia argilosa } & 2 \\
\hline 88,8 & & \multirow[t]{4}{*}{$C=6,65$} & \multirow{4}{*}{$\mathrm{K}=600 \mathrm{kN} / \mathrm{m}$} & \multirow[t]{4}{*}{$\mu=0,29$} & 7 \\
\hline 87,8 & & & & & 5 \\
\hline 86,8 & & & & & 4 \\
\hline 85,8 & 85,5 & & & & 7 \\
\hline 84,8 & & \multicolumn{3}{|l|}{ Argila arenosa } & 10 \\
\hline 83,8 & & $\mathrm{C}=4,20$ & $\mathrm{~K}=350 \mathrm{kN} / \mathrm{m}$ & $\mu=0,36$ & 11 \\
\hline 82,8 & & \multicolumn{3}{|l|}{ Areia } & 13 \\
\hline 81,8 & & \multirow[t]{7}{*}{$\mathrm{C}=7,00$} & \multirow[t]{7}{*}{$\mathrm{K}=1000 \mathrm{kN} / \mathrm{m}$} & \multirow[t]{7}{*}{$\mu=0,26$} & 15 \\
\hline 80,8 & & & & & 20 \\
\hline 79,8 & & & & & 21 \\
\hline 78,8 & & & & & 29 \\
\hline 77,8 & & & & & 35 \\
\hline 76,8 & & & & & 33 \\
\hline 75,8 & & & & & 39 \\
\hline
\end{tabular}

FIGURA 50 - Sondagem SPT - Furo FS2

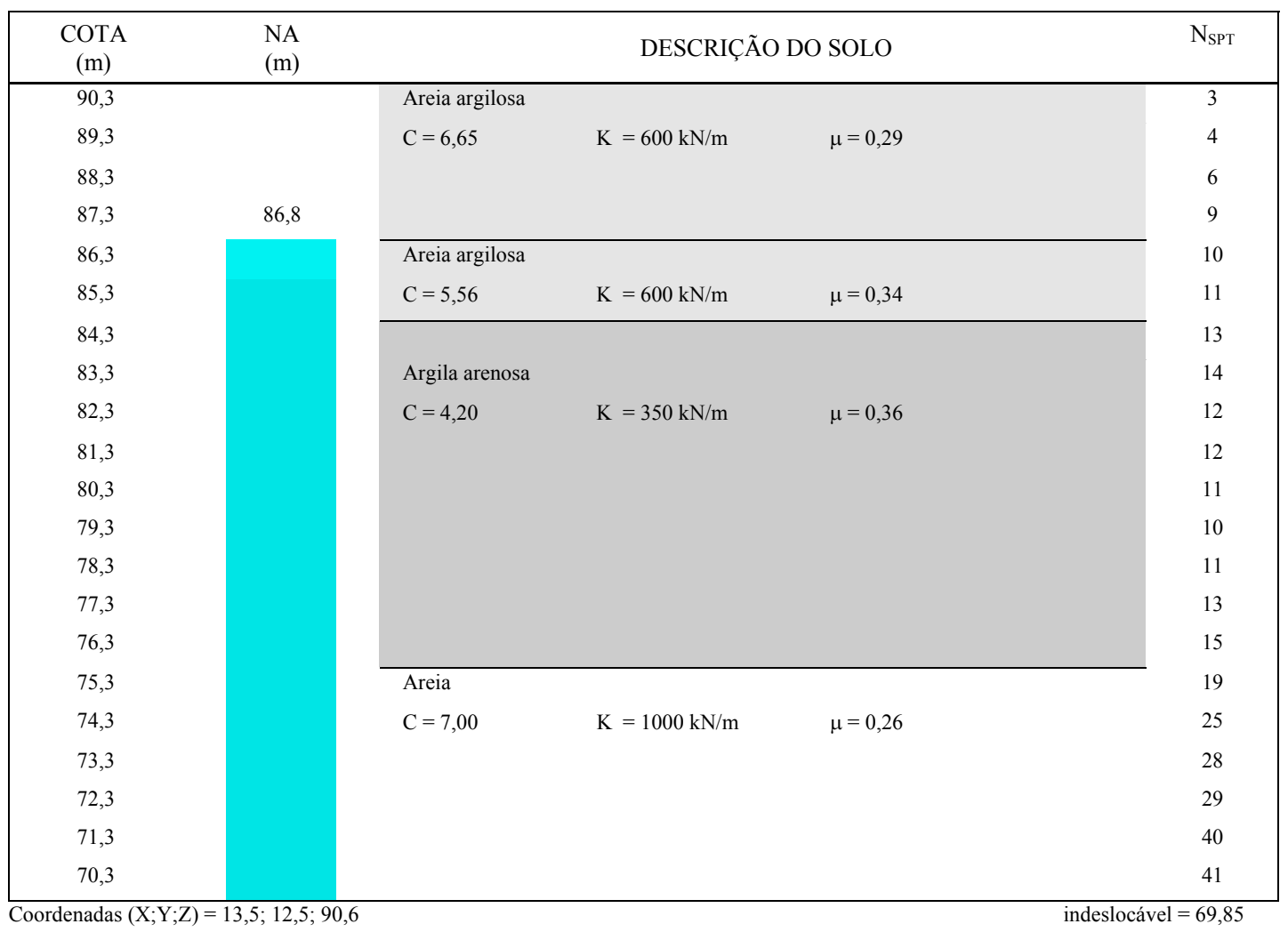

FIGURA 51 - Sondagem SPT - Furo FS3

Pela dificuldade em obter dados através de mapeamento geotécnico, estes não foram cadastrados e o software determinou automaticamente os parâmetros elásticos do maciço de 
acordo com o modelo básico (default) do MGDE, considerando a granulometria e a condição de saturação.

\begin{tabular}{|c|c|c|c|c|c|}
\hline $\begin{array}{c}\text { COTA } \\
(\mathrm{m})\end{array}$ & $\begin{array}{l}\text { NA } \\
(\mathrm{m})\end{array}$ & \multicolumn{3}{|c|}{ DESCRIÇÃO DO SOLO } & $\mathrm{N}_{\mathrm{SPT}}$ \\
\hline & & \multicolumn{3}{|l|}{ Areia argilosa } & \\
\hline 85,4 & & $\mathrm{C}=6,65$ & $\mathrm{~K}=600 \mathrm{kN} / \mathrm{m}$ & $\mu=0,29$ & 4 \\
\hline 84,4 & & \multicolumn{3}{|l|}{ Areia argilosa } & 5 \\
\hline 83,4 & & \multirow[t]{6}{*}{$\mathrm{C}=5,56$} & \multirow[t]{6}{*}{$\mathrm{K}=600 \mathrm{kN} / \mathrm{m}$} & \multirow[t]{6}{*}{$\mu=0,34$} & 10 \\
\hline 82,4 & & & & & 11 \\
\hline 81,4 & & & & & 9 \\
\hline 80,3 & & & & & 2 \\
\hline 79,4 & & & & & 10 \\
\hline 78,4 & & & & & 10 \\
\hline 77,4 & & \multicolumn{3}{|l|}{ Argila arenosa } & 11 \\
\hline 76,4 & & \multirow[t]{6}{*}{$\mathrm{C}=4,20$} & \multirow[t]{6}{*}{$\mathrm{K}=350 \mathrm{kN} / \mathrm{m}$} & \multirow[t]{6}{*}{$\mu=0,36$} & 11 \\
\hline 75,4 & & & & & 9 \\
\hline 74,4 & & & & & 8 \\
\hline 73,4 & & & & & 7 \\
\hline 72,4 & & & & & 17 \\
\hline 71,4 & & & & & 18 \\
\hline 70,4 & & \multicolumn{3}{|l|}{ Areia } & 24 \\
\hline 69,4 & & \multirow[t]{4}{*}{$\mathrm{C}=7,00$} & \multirow[t]{4}{*}{$\mathrm{K}=1000 \mathrm{kN} / \mathrm{m}$} & \multirow[t]{4}{*}{$\mu=0,26$} & 22 \\
\hline 68,4 & & & & & 40 \\
\hline 67,4 & & & & & 41 \\
\hline 66,4 & & & & & 39 \\
\hline
\end{tabular}

FIGURA 52 - Sondagem SPT - Furo FS4

\begin{tabular}{|c|c|c|c|c|c|}
\hline $\begin{array}{l}\text { COTA } \\
(\mathrm{m})\end{array}$ & $\begin{array}{l}\text { NA } \\
(\mathrm{m})\end{array}$ & \multicolumn{3}{|c|}{ DESCRIÇÃO DO SOLO } & $\mathrm{N}_{\mathrm{SPT}}$ \\
\hline & & \multicolumn{3}{|l|}{ Areia argilosa } & \\
\hline 86,2 & & $\mathrm{C}=6,65$ & $\mathrm{~K}=600 \mathrm{kN} / \mathrm{m}$ & $\mu=0,29$ & 1 \\
\hline 85,2 & & \multicolumn{3}{|l|}{ Areia argilosa } & 6 \\
\hline 84,2 & & \multirow[t]{3}{*}{$\mathrm{C}=5,56$} & \multirow[t]{3}{*}{$\mathrm{K}=600 \mathrm{kN} / \mathrm{m}$} & \multirow[t]{3}{*}{$\mu=0,34$} & 7 \\
\hline 83,2 & & & & & 8 \\
\hline 82,2 & & & & & 9 \\
\hline 81,2 & & \multicolumn{3}{|l|}{ Argila arenosa } & 10 \\
\hline 80,2 & & \multirow[t]{2}{*}{$\mathrm{C}=4,20$} & \multirow[t]{2}{*}{$\mathrm{K}=350 \mathrm{kN} / \mathrm{m}$} & \multirow[t]{2}{*}{$\mu=0,36$} & 9 \\
\hline 79,2 & & & & & 15 \\
\hline 78,2 & & \multicolumn{3}{|l|}{ Areia } & 20 \\
\hline 77,2 & & \multirow[t]{4}{*}{$\mathrm{C}=7,00$} & \multirow[t]{4}{*}{$\mathrm{K}=1000 \mathrm{kN} / \mathrm{m}$} & \multirow[t]{4}{*}{$\mu=0,26$} & 21 \\
\hline 76,2 & & & & & 29 \\
\hline 75,2 & & & & & 35 \\
\hline 74,2 & & & & & 38 \\
\hline
\end{tabular}

FIGURA 53 - Sondagem SPT - Furo FS5 


\subsubsection{ESTRUTURA DE FUNDAÇÃO}

A estrutura de fundação foi projetada em duas alternativas para os casos de maciço residual e maciço sedimentar. Para o maciço residual utilizou-se as soluções em sapatas e tubulões, enquanto para o maciço sedimentar aplicou-se modelo segundo as técnicas executivas de estacas cravadas e estacas escavadas de grande diâmetro (estacão).

Para este caso e para os seqüencialmente apresentados, o MTC adotado divide o fuste em 4 trechos, os quais transferem cargas correspondentes a $100 \%$ da resistência lateral ao solo. A ponta também transfere $100 \%$ de sua capacidade resistente, enquanto o coeficiente de segurança global é 1,0, condição de serviço.

Com a intenção de testar a proposta geral de pré-dimensionamento do StructsoiL utiliza-se o modelo próprio baseado na proposta de AOKI \& VELLOSO (1975), adequando coeficientes de correção da resistência de interface F1 para a base e F2 para o fuste, se houver, para cada técnica construtiva. A resistência de interface é pontual pela extrapolação linear de dados obtidos dos ensaios SPT. O coeficiente de segurança à ruptura é calculado considerando o peso próprio da peça enquanto para as estimativas de recalques este é desprezado.

\subsubsection{Solução em sapatas isoladas}

Para efeito de análise comparativa foi dimensionada a solução em sapatas isoladas com fator de correção da resistência F1 igual a 4,5. A TABELA 07 mostra a geometria, posição e coeficiente de segurança à ruptura da estrutura de fundação em sapatas apoiadas na cota fictícia 87,0 .

TABELA 07 - Estrutura de fundação - sapatas - edifício assimétrico

\begin{tabular}{cccccl}
\hline UF & Dimensões $(\mathrm{m})$ & CC $(\mathrm{kN})$ & PP $(\mathrm{kN})$ & $\mathrm{CS}$ & \multicolumn{1}{c}{ Observações } \\
\hline 1 & $2,45 \times 2,45$ & 1762 & -34 & 3,0 & $\mathrm{~F} 1=4,5$ \\
2 & $3,70 \times 3,70$ & 3720 & -103 & 3,0 & \\
3 & $2,50 \times 2,50$ & 1866 & -39 & 3,0 & \\
4 & $2,30 \times 2,30$ & 1779 & -28 & 3,0 & cota de apoio $=87,0 \mathrm{~m}$ \\
5 & $3,50 \times 3,50$ & 4475 & -92 & 3,0 & fck $=20 \mathrm{MPa}$ \\
6 & $3,15 \times 3,15$ & 3218 & -66 & 3,0 & $\mathrm{E}=22994,5 \mathrm{MPa}$ \\
7 & $2,50 \times 2,50$ & 2384 & -39 & 3,0 & $\mu=0,2$ \\
8 & $2,60 \times 2,60$ & 2303 & -47 & 3,0 & $\gamma=23,56 \mathrm{kN} / \mathrm{m}^{3}$ \\
\hline
\end{tabular}




\subsubsection{Solução em tubulões a céu aberto}

A solução em tubulões a céu aberto foi projetada adotando fatores de correção da resistência de interface de base (F1) e de fuste (F2) iguais a 4,5. A TABELA 08 mostra a geometria, posição e coeficiente de segurança à ruptura da estrutura de fundação.

TABELA 08 - Estrutura de fundação - tubulões - edifício assimétrico

\begin{tabular}{cccccccl}
\hline UF & $\phi_{\text {fuste }}(\mathrm{m})$ & $\phi_{\text {base }}(\mathrm{m})$ & $\mathrm{RL}(\mathrm{kN})$ & $\mathrm{CC}(\mathrm{kN})$ & $\mathrm{PP}(\mathrm{kN})$ & $\mathrm{CS}$ & \multicolumn{1}{c}{ Observações } \\
\hline 1 & 0,6 & 1,4 & 77 & 1212 & -46 & 2,1 & $\mathrm{~F} 1=4,5$ \\
2 & 0,8 & 2,0 & 85 & 2401 & -94 & 2,0 & $\mathrm{~F} 2=4,5$ \\
3 & 0,6 & 1,6 & 65 & 1294 & -54 & 2,0 & cota de topo $=88,0 \mathrm{~m}$ \\
4 & 0,6 & 1,2 & 108 & 1217 & -40 & 2,0 & cota de apoio $=83,0 \mathrm{~m}$ \\
5 & 0,8 & 1,9 & 108 & 3051 & -88 & 2,1 & fck $=13,5 \mathrm{Mpa}$ \\
6 & 0,8 & 1,8 & 96 & 2239 & -84 & 2,1 & $\mathrm{E}=19557,6 \mathrm{MPa}$ \\
7 & 0,6 & 1,3 & 101 & 1573 & -43 & 2,0 & $\mu=0,2$ \\
8 & 0,6 & 1,3 & 103 & 1637 & -43 & 2,1 & $\gamma=23,56 \mathrm{kN} / \mathrm{m}^{3}$ \\
\hline
\end{tabular}

\subsubsection{Solução em estacas cravadas}

A solução em estacas cravadas de seção quadrada foi projetada usando o método proposto pelo software, onde os fatores de correção de resistência de interface são os propostos originalmente por AOKI \& VELLOSO (1975). A TABELA 09 mostra a geometria, posição e coeficiente de segurança à ruptura da estrutura de fundação em estacas cravadas. Os coeficientes de segurança para estacas pré-moldadas são tomados considerando controle rigoroso de cravação.

TABELA 09 - Estrutura de fundação - estacas cravadas - edifício assimétrico

\begin{tabular}{cccccccl}
\hline UF & Dimensões $(\mathrm{m})$ & $\mathrm{L}(\mathrm{m})$ & $\mathrm{RL}(\mathrm{kN})$ & $\mathrm{CC}(\mathrm{kN})$ & $\mathrm{PP}(\mathrm{kN})$ & $\mathrm{CS}$ & Observações \\
\hline 1 & $0,30 \times 0,30$ & 8,0 & 416 & 912 & -17 & 1,6 & $\mathrm{~F} 1=1,75$ \\
2 & $0,40 \times 0,40$ & 9,0 & 611 & 1972 & -34 & 1,7 & $\mathrm{~F} 2=3,5$ \\
3 & $0,40 \times 0,40$ & 8,0 & 497 & 1012 & -30 & 1,7 & cota de topo $=88,0 \mathrm{~m}$ \\
4 & $0,40 \times 0,40$ & 8,0 & 609 & 1090 & -30 & 1,9 & \\
5 & $2(0,40 \times 0,40)$ & 8,5 & 1158 & 2289 & -64 & 1,6 & fck $=20 \mathrm{MPa}$ \\
6 & $2(0,30 \times 0,30)$ & 7,5 & 710 & 1748 & -32 & 1,7 & $\mathrm{E}=22994,5 \mathrm{MPa}$ \\
7 & $0,40 \times 0,40$ & 9,5 & 639 & 1250 & -36 & 1,6 & $\mu=0,2$ \\
8 & $0,40 \times 0,40$ & 8,5 & 552 & 1198 & -32 & 1,6 & $\gamma=23,56 \mathrm{kN} / \mathrm{m}^{3}$ \\
\hline
\end{tabular}

Os espaçamentos entre eixos das estacas em grupo é de $1,0 \mathrm{~m}$, na direção do eixo principal $\mathrm{X}$ 
Este caso serve para mostrar que o StructsoiL pode analisar grupos de estacas, mas considera nula a rigidez do bloco de capeamento. Outra habilidade do software, é que este possibilita o projeto de estacas com profundidade variável, como mostra a TABELA 09 e a TABELA 10.

\subsubsection{Solução em estacas escavadas de grande diâmetro (estacão)}

TABELA 10 - Estrutura de fundação - estacão - edifício assimétrico

\begin{tabular}{cccccccl}
\hline UF & $\phi_{\text {fuste }}(\mathrm{m})$ & $\mathrm{L}(\mathrm{m})$ & $\mathrm{RL}(\mathrm{kN})$ & $\mathrm{CC}(\mathrm{kN})$ & $\mathrm{PP}(\mathrm{kN})$ & $\mathrm{CS}$ & \multicolumn{1}{c}{ Observações } \\
\hline 1 & 0,50 & 8,0 & 486 & 1027 & -37 & 1,8 & $\mathrm{~F} 1=3,5$ \\
2 & 0,70 & 9,0 & 746 & 2383 & -82 & 2,0 & $\mathrm{~F} 2=4,0$ \\
3 & 0,50 & 11,0 & 614 & 1212 & -41 & 1,9 & cota de topo $=88,0 \mathrm{~m}$ \\
4 & 0,50 & 10,0 & 602 & 1173 & -46 & 1,9 & \\
5 & 0,80 & 12,0 & 1055 & 2561 & -142 & 1,7 & fck $=15 \mathrm{MPa}$ \\
6 & 0,70 & 11,0 & 861 & 1909 & -100 & 1,8 & $\mathrm{E}=20402,2 \mathrm{MPa}$ \\
7 & 0,60 & 12,0 & 816 & 1515 & -80 & 1,8 & $\mu=0,2$ \\
8 & 0,60 & 12,0 & 742 & 1479 & -80 & 1,8 & $\gamma=23,56 \mathrm{kN} / \mathrm{m}^{3}$ \\
\hline
\end{tabular}

A solução em estacão foi projetada usando o método proposto pelo sistema, onde os fatores de correção de resistência de interface são propostos como F1 igual a 3,5 e F2 igual a 4,0. A TABELA 10 mostra a geometria, posição e coeficiente de segurança à ruptura da estrutura de fundação em estacão.

\subsection{ESTRUTURA SIMÉTRICA EM RELAÇÃO A UM PLANO PRINCIPAL}

Para obter um edifício com configuração T em planta, duplicou-se a área em planta e o próprio pórtico rebatendo-se a estrutura do edifício assimétrico (item 4.2) em torno do plano YZ (FIGURA 54). Essa estrutura é formada por 13 pilares, também modelada com elementos de barras (vigas e pilares) e painéis (lajes). Denomina-se este caso como edifício simétrico.

De forma idêntica ao edifício assimétrico, o maciço de solos é exemplificado por três furos de sondagem em maciço residual executados na formação geológica Pimenteiras, região de Palmas - TO, e por cinco furos de sondagem fictícios em maciço sedimentar. A estrutura de fundação é modelada através da técnica em tubulão a céu aberto para o maciço residual e estaca cravada tipo SCAC para o maciço sedimentar. 


\subsubsection{PóRTICO ESPACIAL}

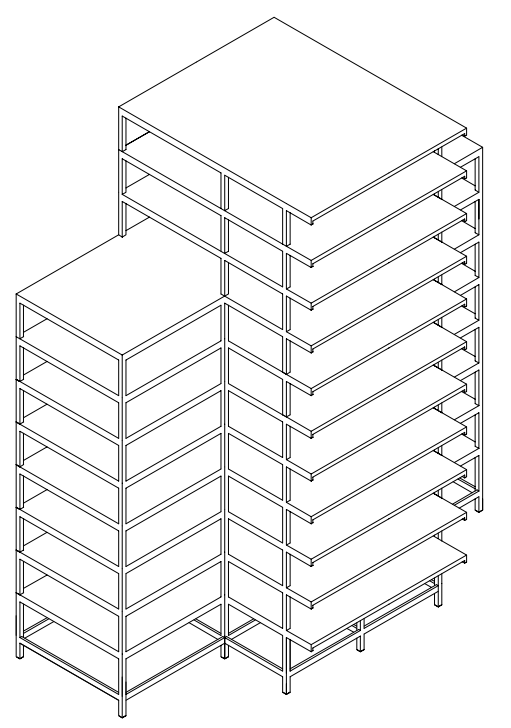

FIGURA 54 - Pórtico espacial - edifício simétrico

O pórtico espacial modelado na configuração T (FIGURA 54) possui 13 pilares engastados à fundação, com altura variável de 8 e 11 pavimentos. As vigas foram modeladas com seção $(0,15 \times 0,60) \mathrm{m}$; os pilares de canto e o P12, com seção $(0,4 \times 0,4) \mathrm{m}$ e os de meio de vão com seção $(0,5 \times 0,5) \mathrm{m}$; as lajes possuem espessura de $0,12 \mathrm{~m}$. Foram aplicadas cargas verticais de serviço ao longo da superfície das lajes de $2,5 \mathrm{kN} / \mathrm{m}^{2}$. O concreto armado utilizado tem como propriedades fck $=25 \mathrm{MPa}, \mathrm{E}=25322,9 \mathrm{MPa}, \mu=0,2$ e $\gamma=23,56$ $\mathrm{kN} / \mathrm{m}^{3}$. A TABELA 11 apresenta as coordenadas e as cargas aplicadas nos apoios.

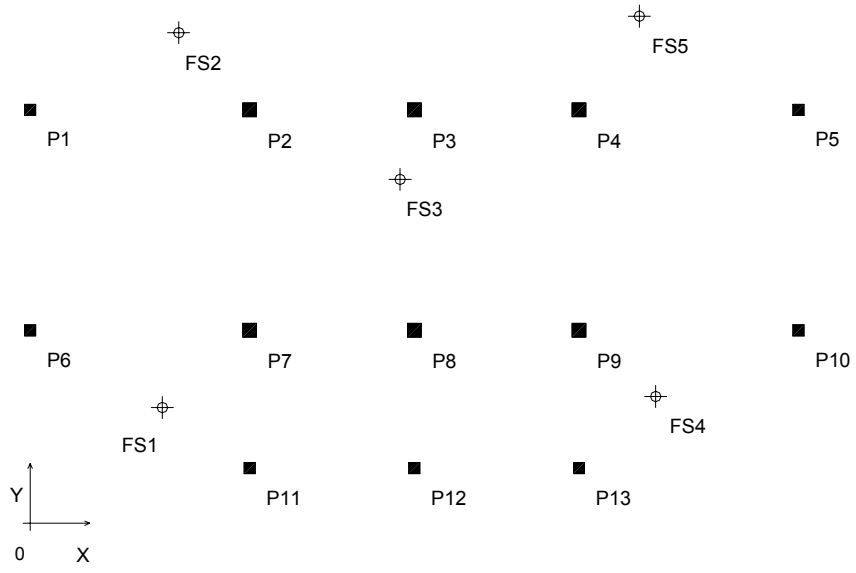

FIGURA 55 - Planta de locação dos pilares do edifício simétrico e dos furos de sondagem SPT em maciço de solos sedimentar 
TABELA 11 - Cargas nos apoios para a condição de apoios indeslocáveis - edifício simétrico

\begin{tabular}{cccccccc}
\hline UF & $\begin{array}{c}\text { Coordenadas } \\
\mathrm{X}, \mathrm{Y}, \mathrm{Z}\end{array}$ & $\begin{array}{c}\mathrm{HX} \\
(\mathrm{kN})\end{array}$ & $\begin{array}{c}\mathrm{HY} \\
(\mathrm{kN})\end{array}$ & $\begin{array}{c}\mathrm{V} \\
(\mathrm{kN})\end{array}$ & $\begin{array}{c}\mathrm{MX} \\
(\mathrm{kN} . \mathrm{m})\end{array}$ & $\begin{array}{c}\mathrm{MY} \\
(\mathrm{kN} . \mathrm{m})\end{array}$ & $\begin{array}{c}\mathrm{T} \\
(\mathrm{kN} . \mathrm{m})\end{array}$ \\
\hline 1 & $0 ; 15 ; 88,5$ & $-8,93$ & 8,16 & $-537,90$ & 4,59 & 2,52 & 0,00 \\
2 & $8 ; 15 ; 88,5$ & 5,08 & 16,88 & $-1108,17$ & $-0,89$ & $-0,09$ & 0,00 \\
3 & $14 ; 15 ; 88,5$ & 0,00 & 13,72 & $-1076,62$ & 2,16 & 0,00 & 0,00 \\
4 & $20 ; 15 ; 88,5$ & $-5,08$ & 16,88 & $-1108,17$ & $-0,09$ & $-0,09$ & 0,00 \\
5 & $28 ; 15 ; 88,5$ & 8,93 & 8,61 & $-537,90$ & 4,59 & $-2,52$ & 0,00 \\
6 & $0 ; 7 ; 88,5$ & $-8,91$ & $-10,73$ & $-559,03$ & 0,90 & 2,55 & 0,00 \\
7 & $8 ; 7 ; 88,5$ & 1,78 & $-16,79$ & $-1380,62$ & 13,48 & $-3,29$ & 0,01 \\
8 & $14 ; 7 ; 88,5$ & 0,00 & $-11,73$ & $-1528,02$ & 8,50 & 0,00 & 0,01 \\
9 & $20 ; 7 ; 88,5$ & $-1,78$ & $-16,79$ & $-1380,62$ & 13,48 & 3,29 & $-0,01$ \\
10 & $28 ; 7 ; 88,5$ & 8,19 & $-10,73$ & $-559,03$ & 0,90 & $-2,55$ & $-0,01$ \\
11 & $8 ; 2 ; 88,5$ & $-5,45$ & 0,25 & $-730,09$ & $-2,94$ & 1,03 & 0,00 \\
12 & $14 ; 2 ; 88,5$ & 0,00 & 1,56 & $-1349,68$ & $-1,73$ & 0,00 & 0,00 \\
13 & $20 ; 2 ; 88,5$ & 5,45 & 0,25 & $-730,09$ & $-2,94$ & $-1,02$ & 0,00 \\
\hline
\end{tabular}

\subsubsection{MACIÇO DE SOLOS}

O maciço de solos foi modelado através de dois conjuntos de sondagens, uma aplicada em maciço residual e outra em maciço sedimentar, conforme o item 4.2.2.

\subsubsection{ESTRUTURA DE FUNDAÇÃO}

Para a estrutura de fundação foi projetada uma alternativa para os casos de maciço residual e maciço sedimentar. Para maciço residual utilizou-se a solução em tubulões a céu aberto para estudar o comportamento da fundação pela influência da rigidez da superestrutura, enquanto para o maciço sedimentar aplicou-se modelo segundo a técnica executiva de estacas cravadas tipo SCAC.

Com a mesma intenção anterior, que é a de testar a proposta geral de prédimensionamento do StructsoiL, utiliza-se o método próprio do software. A resistência de interface é pontual pela extrapolação linear de dados obtidos dos ensaios SPT. O coeficiente de segurança à ruptura é calculado considerando o peso próprio da peça enquanto nas estimativas de recalques o mesmo é desprezado. 


\subsubsection{Solução em tubulões a céu aberto}

TABELA 12 - Estrutura de fundação - tubulões - edifício simétrico

\begin{tabular}{cccccccl}
\hline UF & $\phi_{\text {fuste }}(\mathrm{m})$ & $\phi_{\text {base }}(\mathrm{m})$ & $\mathrm{RL}(\mathrm{kN})$ & $\mathrm{CC}(\mathrm{kN})$ & $\mathrm{PP}(\mathrm{kN})$ & $\mathrm{CS}$ & Observações \\
\hline 1 & 0,6 & 1,2 & 144 & 1208 & -47 & 2,1 & $\mathrm{~F} 1=4,5$ \\
2 & 0,8 & 1,9 & 137 & 2402 & -100 & 2,0 & $\mathrm{~F} 2=4,5$ \\
3 & 0,8 & 1,7 & 153 & 2215 & -90 & 1,9 & cota de topo $=88,0 \mathrm{~m}$ \\
4 & 0,8 & 1,8 & 149 & 2522 & -98 & 2,1 & cota de apoio $=83,0 \mathrm{~m}$ \\
5 & 0,6 & 1,1 & 152 & 1102 & -45 & 1,9 & fck $=13,5 \mathrm{MPa}$ \\
6 & 0,6 & 1,1 & 195 & 1225 & -45 & 2,0 & $\mathrm{E}=19557,6 \mathrm{MPa}$ \\
7 & 0,8 & 1,6 & 221 & 3031 & -86 & 2,1 & $\mu=0,2$ \\
8 & 0,8 & 1,9 & 158 & 3258 & -100 & 2,0 & $\gamma=23,56 \mathrm{kN} / \mathrm{m}^{3}$ \\
9 & 0,8 & 1,9 & 153 & 3052 & -100 & 2,1 & \\
10 & 0,6 & 1,2 & 150 & 1325 & -47 & 2,2 & \\
11 & 0,6 & 1,1 & 208 & 1640 & -47 & 2,1 & \\
12 & 0,8 & 1,7 & 190 & 2954 & -47 & 2,1 & \\
13 & 0,6 & 1,4 & 148 & 1618 & -50 & 2,1 & \\
\hline
\end{tabular}

A solução em tubulões a céu aberto foi projetada adotando fatores de correção da resistência de interface de base (F1) e de fuste (F2) iguais a 4,5. A TABELA 12 mostra a geometria, posição e coeficiente de segurança a ruptura da estrutura de fundação.

TABELA 13 - Estrutura de fundação - estacas cravadas - edifício simétrico

\begin{tabular}{ccccccccc}
\hline UF & $\phi_{\text {externo }}(\mathrm{m})$ & $\phi_{\text {interno }}(\mathrm{m})$ & $\mathrm{L}(\mathrm{m})$ & $\mathrm{RL}(\mathrm{kN})$ & $\mathrm{CC}(\mathrm{kN})$ & $\mathrm{PP}(\mathrm{kN})$ & $\mathrm{CS}$ & Observações \\
\hline 1 & 0,33 & 0,19 & 9,0 & 372 & 1085 & -13 & 2,0 & $\mathrm{~F} 1=1,75$ \\
2 & 0,50 & 0,30 & 8,5 & 559 & 1862 & -25 & 1,6 & $\mathrm{~F} 2=3,5$ \\
3 & 0,50 & 0,30 & 10 & 623 & 1818 & -29 & 1,6 & cota de topo $=88,0 \mathrm{~m}$ \\
4 & 0,50 & 0,30 & 9,0 & 506 & 1753 & -26 & 1,6 & \\
5 & 0,33 & 0,19 & 9,0 & 335 & 875 & -13 & 1,7 & fck =35 MPa \\
6 & 0,33 & 0,19 & 10 & 452 & 950 & -14 & 1,6 & $\mathrm{E}=29432,1 \mathrm{MPa}$, \\
7 & 0,60 & 0,42 & 10 & 802 & 2247 & -39 & 1,6 & $\mu=0,2$ \\
8 & 0,60 & 0,42 & 10 & 757 & 2352 & -39 & 1,5 & $\gamma=23,56 \mathrm{kN} / \mathrm{m}^{3}$ \\
9 & 0,60 & 0,42 & 10 & 721 & 2280 & -39 & 1,6 & \\
10 & 0,33 & 0,19 & 10 & 397 & 917 & -14 & 1,6 & \\
11 & 0,50 & 0,30 & 9,0 & 616 & 1310 & -26 & 1,7 & \\
12 & 0,60 & 0,42 & 10 & 763 & 2324 & -39 & 1,7 & \\
13 & 0,50 & 0,30 & 8,5 & 488 & 1302 & -25 & 1,7 & \\
\hline
\end{tabular}




\subsubsection{Solução em estacas cravadas tipo SCAC}

A solução em estacas cravadas tipo SCAC foi projetada usando o método proposto pelo software StructsoiL. A TABELA 13 mostra a geometria, posição e coeficiente de segurança a ruptura da estrutura de fundação.

\subsection{EFEITOS DA INUNDAÇÃO DO MACIÇO DE SOLOS RESIDUAL}

O pórtico espacial mostrado na FIGURA 44 possuindo 8 pilares engastados à fundação, na configuração $\mathrm{L}$, com altura variável de 8 e 11 pavimentos foi modelado apoiado em maciço inundado. As vigas foram modeladas nas seções $(0,15 \times 0,60) \mathrm{m}$ e os pilares de canto na seção $(0,4 \times 0,4) \mathrm{m}$ e os de meio de vão (P2, P5 e P6) na seção $(0,5 \times 0,5)$ $\mathrm{m}$, as lajes possuem espessura de 0,12 $\mathrm{m}$. Foram aplicadas cargas verticais de serviço ao longo da superfície das lajes de $2,5 \mathrm{kN} / \mathrm{m}^{2}$, o concreto armado possui fck $=25 \mathrm{MPa}, \mathrm{E}=$ 25322,9 MPa, $\mu=0,2$ e $\gamma=23,56 \mathrm{kN} / \mathrm{m}^{3}$. A TABELA 06 apresenta coordenadas e cargas aplicadas nos apoios. O caso de maciço residual inundado é apresentado com o intuito de mostrar a capacidade do software em analisar o comportamento de edifícios apoiados em maciço de solos com variação permanente do nível do lençol freático. O maciço de solos do plano piloto de Palmas - TO sofrerá alteração uma alteração no nível do lençol freático a partir de 2001, quando o lago da UHE Lajeado estará sendo formado. Para exemplificar o caso, altera-se o nível do lençol freático nas sondagens em maciço residual elevando-o em 5 metros, fixando-o na cota fictícia $85,0 \mathrm{~m}$. Procede-se a análise do caso usando os dados restantes contidos no item 4.2, para as soluções em sapatas e tubulões a céu aberto. 


\section{RESULTADOS}

\subsection{ESTRUTURA COM DUPLA SIMETRIA}

\subsubsection{SOLUÇ̃̃O EM SAPATAS ISOLADAS}

A TABELA 14 mostra os recalques para a condição de superestrutura perfeitamente flexível (convencional), e na condição interada, mostra cargas aplicadas nos apoios e respectivos recalques. A solução em sapatas isoladas foi verificada usando fatores de correção da resistência de interface (F1) igual a 4,5.

TABELA 14 - Cargas e recalques nos apoios - sapatas - exemplo didático

\begin{tabular}{|c|c|c|c|c|c|c|c|c|}
\hline UF & $\begin{array}{c}\text { recalque } \\
\text { convencional } \\
\text { (m) }\end{array}$ & $\begin{array}{l}\mathrm{HX} \\
(\mathrm{kN})\end{array}$ & $\begin{array}{l}\mathrm{HY} \\
(\mathrm{kN})\end{array}$ & $\begin{array}{c}\mathrm{V} \\
(\mathrm{kN})\end{array}$ & $\begin{array}{c}\text { MX } \\
\text { (kN.m) }\end{array}$ & $\begin{array}{c}\text { MY } \\
\text { (kN.m) }\end{array}$ & $\begin{array}{c}\mathrm{T} \\
(\mathrm{kN} . \mathrm{m})\end{array}$ & $\begin{array}{c}\text { recalque } \\
\text { interado } \\
\text { (m) }\end{array}$ \\
\hline 1 & $-1,25 \mathrm{E}-2$ & $-6,30$ & 6,26 & $-421,38$ & $-5,97$ & $-6,33$ & 0,00 & $-1,37 \mathrm{E}-2$ \\
\hline 2 & $-1,49 \mathrm{E}-2$ & 0,26 & 6,92 & $-572,00$ & $-6,54$ & 0,20 & $-0,02$ & $-1,43 \mathrm{E}-2$ \\
\hline 3 & $-1,20 \mathrm{E}-2$ & 6,65 & 6,65 & $-424,61$ & $-6,18$ & 6,55 & 0,01 & $-1,33 \mathrm{E}-2$ \\
\hline 4 & $-1,52 \mathrm{E}-2$ & $-6,98$ & $-0,28$ & $-571,68$ & 0,53 & $-6,91$ & 0,01 & $-1,46 \mathrm{E}-2$ \\
\hline 5 & $-1,72 \mathrm{E}-2$ & $-0,02$ & 0,14 & $-756,14$ & 0,21 & 0,00 & 0,00 & $-1,59 \mathrm{E}-2$ \\
\hline 6 & $-1,53 \mathrm{E}-2$ & 6,95 & 0,22 & $-570,04$ & 0,21 & 6,94 & 0,02 & $-1,47 \mathrm{E}-2$ \\
\hline 7 & $-1,24 \mathrm{E}-2$ & $-6,90$ & $-6,69$ & $-430,66$ & 6,90 & $-6,75$ & $-0,01$ & $-1,38 \mathrm{E}-2$ \\
\hline 8 & $-1,61 \mathrm{E}-2$ & $-0,24$ & $-6,80$ & $-557,71$ & 7,11 & $-0,13$ & $-0,02$ & $-1,51 \mathrm{E}-2$ \\
\hline 9 & $-1,29 \mathrm{E}-2$ & 6,58 & $-6,42$ & $-429,02$ & 6,80 & 6,66 & 0,00 & $-1,43 \mathrm{E}-2$ \\
\hline
\end{tabular}

\subsubsection{SOLUÇão EM TUBULÕES A CÉU ABERTO}

A solução em tubulões a céu aberto foi verificada usando fatores de correção da resistência de interface F1 e F2 iguais a 4,5. A TABELA 15 mostra os recalques para a 
condição de superestrutura perfeitamente flexível (convencional), e na condição interada, mostra cargas aplicadas nos apoios e respectivos recalques.

TABELA 15 - Cargas e recalques nos apoios - tubulões - exemplo didático

\begin{tabular}{ccccccccc}
\hline UF & $\begin{array}{c}\text { recalque } \\
\text { convencional } \\
(m)\end{array}$ & $\begin{array}{c}\mathrm{HX} \\
(\mathrm{kN})\end{array}$ & $\begin{array}{c}\mathrm{HY} \\
(\mathrm{kN})\end{array}$ & $\begin{array}{c}\mathrm{V} \\
(\mathrm{kN})\end{array}$ & $\begin{array}{c}\mathrm{MX} \\
(\mathrm{kN} . \mathrm{m})\end{array}$ & $\begin{array}{c}\mathrm{MY} \\
(\mathrm{kN} . \mathrm{m})\end{array}$ & $\begin{array}{c}\mathrm{T} \\
(\mathrm{kN} \cdot \mathrm{m})\end{array}$ & $\begin{array}{c}\text { recalque } \\
\text { interado } \\
(\mathrm{m})\end{array}$ \\
\hline 1 & $-7,02 \mathrm{E}-3$ & $-6,29$ & 6,80 & $-417,89$ & $-5,90$ & $-4,89$ & $-0,04$ & $-8,12 \mathrm{E}-3$ \\
2 & $-1,04 \mathrm{E}-2$ & $-0,82$ & 6,78 & $-592,38$ & $-6,03$ & 0,56 & 0,03 & $-1,02 \mathrm{E}-2$ \\
3 & $-1,14 \mathrm{E}-2$ & 5,41 & 5,03 & $-387,64$ & $-4,49$ & 6,75 & 0,00 & $-1,17 \mathrm{E}-2$ \\
4 & $-1,11 \mathrm{E}-2$ & $-6,43$ & 0,36 & $-554,31$ & 0,50 & $-5,23$ & $-0,03$ & $-1,01 \mathrm{E}-2$ \\
5 & $-1,27 \mathrm{E}-2$ & 0,38 & 0,42 & $-783,03$ & 0,30 & 1,54 & 0,00 & $-1,21 \mathrm{E}-2$ \\
6 & $-1,18 \mathrm{E}-2$ & 7,15 & $-0,63$ & $-601,18$ & 1,14 & 8,27 & $-0,03$ & $-1,18 \mathrm{E}-2$ \\
7 & $-8,24 \mathrm{E}-3$ & $-6,53$ & $-6,45$ & $-444,54$ & 7,28 & $-5,47$ & 0,00 & $-1,02 \mathrm{E}-2$ \\
8 & $-1,39 \mathrm{E}-2$ & 0,17 & $-6,33$ & $-526,50$ & 7,01 & 1,20 & 0,03 & $-1,21 \mathrm{E}-2$ \\
9 & $-1,02 \mathrm{E}-2$ & 6,96 & $-5,99$ & $-425,75$ & 6,47 & 7,94 & 0,04 & $-1,19 \mathrm{E}-2$ \\
\hline
\end{tabular}

\subsubsection{SOLUÇÃO EM ESTACAS CRAVADAS}

TABELA 16 - Cargas e recalques nos apoios - estacas cravadas - exemplo didático

\begin{tabular}{|c|c|c|c|c|c|c|c|c|}
\hline UF & $\begin{array}{c}\text { recalque } \\
\text { convencional } \\
\text { (m) }\end{array}$ & $\begin{array}{l}\mathrm{HX} \\
(\mathrm{kN})\end{array}$ & $\begin{array}{l}\mathrm{HY} \\
(\mathrm{kN})\end{array}$ & $\begin{array}{c}\mathrm{V} \\
(\mathrm{kN})\end{array}$ & $\begin{array}{c}\text { MX } \\
\text { (kN.m) }\end{array}$ & $\begin{array}{c}\text { MY } \\
\text { (kN.m) }\end{array}$ & $\begin{array}{c}\mathrm{T} \\
\text { (kN.m) }\end{array}$ & $\begin{array}{c}\text { recalque } \\
\text { interado } \\
\text { (m) }\end{array}$ \\
\hline 1 & $-2,45 \mathrm{E}-3$ & $-5,64$ & 6,40 & $-384,68$ & $-6,11$ & $-4,86$ & $-0,03$ & $-2,68 \mathrm{E}-3$ \\
\hline 2 & $-3,34 \mathrm{E}-3$ & $-0,33$ & 9,31 & $-641,36$ & $-9,02$ & 0,42 & 0,01 & $-3,50 \mathrm{E}-3$ \\
\hline 3 & $-4,24 \mathrm{E}-3$ & 4,32 & 5,59 & $-380,15$ & $-5,40$ & 6,03 & 0,01 & $-4,49 \mathrm{E}-3$ \\
\hline 4 & $-3,04 \mathrm{E}-3$ & $-7,67$ & $-0,05$ & $-622,74$ & 0,30 & $-7,95$ & $-0,01$ & $-3,65 \mathrm{E}-3$ \\
\hline 5 & $-7,22 \mathrm{E}-3$ & 0,20 & $-0,45$ & $-675,18$ & $-0,21$ & 0,88 & 0,00 & $-7,18 \mathrm{E}-3$ \\
\hline 6 & $-3,92 \mathrm{E}-3$ & 9,07 & $-0,35$ & $-623,56$ & 0,50 & 9,69 & 0,00 & $-4,63 \mathrm{E}-3$ \\
\hline 7 & $-3,45 \mathrm{E}-3$ & $-6,48$ & $-6,51$ & $-390,23$ & 6,73 & $-5,80$ & $-0,01$ & $-3,08 \mathrm{E}-3$ \\
\hline 8 & $-3,79 \mathrm{E}-3$ & $-0,03$ & $-8,74$ & $-622,34$ & 8,92 & 0,61 & 0,01 & $-4,52 \mathrm{E}-3$ \\
\hline 9 & $-3,60 \mathrm{E}-3$ & 6,55 & $-6,09$ & $-392,99$ & 6,21 & 7,15 & 0,03 & $-4,32 \mathrm{E}-3$ \\
\hline
\end{tabular}

A solução em estacas pré-moldadas prismáticas foi calculada e verificada pelo software usando fatores de correção de resistência de interface F1 igual a 1,75 e F2 igual a 3,50. A TABELA 16 mostra os recalques para a condição de superestrutura perfeitamente flexível (convencional), e na condição interada, mostra cargas aplicadas nos apoios e respectivos recalques. 


\subsection{ESTRUTURA ASSIMÉTRICA}

\subsubsection{SOLUÇ̃̃O EM SAPATAS ISOLADAS}

A TABELA 17 mostra os recalques para a condição de superestrutura perfeitamente flexível (convencional), e na condição interada, mostra cargas aplicadas nos apoios e respectivos recalques para o caso de sapatas isoladas apoiadas em maciço residual.

TABELA 17 - Cargas e recalques nos apoios - sapatas - edifício assimétrico

\begin{tabular}{|c|c|c|c|c|c|c|c|c|}
\hline UF & $\begin{array}{c}\text { recalque } \\
\text { convencional } \\
\text { (m) }\end{array}$ & $\begin{array}{l}\mathrm{HX} \\
(\mathrm{kN})\end{array}$ & $\begin{array}{l}\mathrm{HY} \\
(\mathrm{kN})\end{array}$ & $\begin{array}{c}\mathrm{V} \\
(\mathrm{kN})\end{array}$ & $\begin{array}{c}\text { MX } \\
\text { (kN.m) }\end{array}$ & $\begin{array}{c}\text { MY } \\
\text { (kN.m) }\end{array}$ & $\begin{array}{c}\mathrm{T} \\
\text { (kN.m) }\end{array}$ & $\begin{array}{c}\text { recalque } \\
\text { interado } \\
\text { (m) }\end{array}$ \\
\hline 1 & $-1,38 \mathrm{E}-2$ & $-11,45$ & 9,78 & $-592,41$ & $-4,53$ & 27,41 & 0,61 & $-1,50 \mathrm{E}-2$ \\
\hline 2 & $-2,06 \mathrm{E}-2$ & 4,83 & 18,38 & $-1024,72$ & $-10,38$ & 30,11 & 1,32 & $-1,89 \mathrm{E}-2$ \\
\hline 3 & $-1,59 \mathrm{E}-2$ & 6,17 & 6,81 & $-694,23$ & 2,86 & 1,45 & 0,63 & $-1,87 \mathrm{E}-2$ \\
\hline 4 & $-1,32 \mathrm{E}-2$ & $-12,34$ & $-9,69$ & $-602,50$ & $-7,76$ & 27,10 & 0,75 & $-1,43 \mathrm{E}-2$ \\
\hline 5 & $-2,09 \mathrm{E}-2$ & 0,04 & $-16,35$ & $-1193,31$ & $-8,13$ & 26,27 & 1,25 & $-1,84 \mathrm{E}-2$ \\
\hline 6 & $-1,94 \mathrm{E}-2$ & 10,44 & $-8,26$ & $-925,89$ & $-13,80$ & 9,13 & 1,13 & $-1,84 \mathrm{E}-2$ \\
\hline 7 & $-1,62 \mathrm{E}-2$ & $-5,22$ & $-0,01$ & $-826,30$ & $-17,88$ & 2,74 & 0,30 & $-1,75 \mathrm{E}-2$ \\
\hline 8 & $-1,65 \mathrm{E}-2$ & 7,52 & $-0,67$ & $-773,97$ & $-17,08$ & 2,48 & 0,43 & $-1,75 \mathrm{E}-2$ \\
\hline
\end{tabular}

\subsubsection{SOLUÇÃO EM TUBULÕES A CÉU ABERTO}

TABELA 18 - Cargas e recalques nos apoios - tubulões - edifício assimétrico

\begin{tabular}{|c|c|c|c|c|c|c|c|c|}
\hline UF & $\begin{array}{c}\text { recalque } \\
\text { convencional } \\
\text { (m) }\end{array}$ & $\begin{array}{l}\mathrm{HX} \\
(\mathrm{kN})\end{array}$ & $\begin{array}{l}\mathrm{HY} \\
(\mathrm{kN})\end{array}$ & $\begin{array}{c}\mathrm{V} \\
(\mathrm{kN})\end{array}$ & $\begin{array}{c}\mathrm{MX} \\
\text { (kN.m) }\end{array}$ & $\begin{array}{c}\text { MY } \\
\text { (kN.m) }\end{array}$ & $\begin{array}{c}\mathrm{T} \\
\text { (kN.m) }\end{array}$ & $\begin{array}{c}\text { recalque } \\
\text { interado } \\
\text { (m) }\end{array}$ \\
\hline 1 & $-3,60 \mathrm{E}-2$ & $-9,61$ & 5,64 & $-479,254$ & $-81,21$ & 0,94 & 0,54 & $-2,92 \mathrm{E}-2$ \\
\hline 2 & $-3,60 \mathrm{E}-2$ & 9,32 & 19,55 & $-886,67$ & $-83,24$ & $-34,02$ & 1,09 & $-2,91 \mathrm{E}-2$ \\
\hline 3 & $-2,01 \mathrm{E}-2$ & 9,05 & 6,19 & $-760,52$ & $-45,25$ & $-34,25$ & 0,55 & $-2,59 \mathrm{E}-2$ \\
\hline 4 & $-1,31 \mathrm{E}-2$ & $-15,53$ & $-13,86$ & $-709,99$ & $-84,44$ & 18,11 & 0,69 & $-1,76 \mathrm{E}-2$ \\
\hline 5 & $-2,25 \mathrm{E}-2$ & $-2,91$ & $-14,86$ & $-1322,35$ & $-125,72$ & $-14,32$ & 1,03 & $-2,16 \mathrm{E}-2$ \\
\hline 6 & $-1,78 \mathrm{E}-2$ & 9,83 & $-6,02$ & $-1060,25$ & $-116,20$ & $-28,56$ & 0,91 & $-1,94 \mathrm{E}-2$ \\
\hline 7 & $-1,68 \mathrm{E}-2$ & $-6,43$ & 1,97 & $-799,77$ & $-75,37$ & $-23,69$ & 0,17 & $-1,79 \mathrm{E}-2$ \\
\hline 8 & $-1,85 \mathrm{E}-2$ & 6,27 & 1,38 & $-614,52$ & $-66,07$ & $-23,99$ & 0,33 & $-1,62 \mathrm{E}-2$ \\
\hline
\end{tabular}


A TABELA 18 mostra os recalques para a condição de superestrutura perfeitamente flexível (convencional), e na condição interada, mostra cargas aplicadas nos apoios e respectivos recalques para o caso de tubulões a céu aberto apoiados em maciço residual.

\subsubsection{SOLUÇÃO EM ESTACAS CRAVADAS}

A TABELA 19 mostra os recalques para a condição de superestrutura perfeitamente flexível (convencional), e na condição interada, mostra cargas aplicadas nos apoios e respectivos recalques para o caso de estacas cravadas imersas em maciço sedimentar.

TABELA 19 - Cargas e recalques nos apoios - estacas cravadas - edifício assimétrico

\begin{tabular}{ccccccccc}
\hline UF & $\begin{array}{c}\text { recalque } \\
\text { convencional } \\
(m)\end{array}$ & $\begin{array}{c}\mathrm{HX} \\
(\mathrm{kN})\end{array}$ & $\begin{array}{c}\mathrm{HY} \\
(\mathrm{kN})\end{array}$ & $\begin{array}{c}\mathrm{V} \\
(\mathrm{kN})\end{array}$ & $\begin{array}{c}\mathrm{MX} \\
(\mathrm{kN} . \mathrm{m})\end{array}$ & $\begin{array}{c}\mathrm{MY} \\
(\mathrm{kN} . \mathrm{m})\end{array}$ & $\begin{array}{c}\mathrm{T} \\
(\mathrm{kN} . \mathrm{m})\end{array}$ & $\begin{array}{c}\text { recalque } \\
\text { interado } \\
(\mathrm{m})\end{array}$ \\
\hline 1 & $-2,55 \mathrm{E}-3$ & $-8,08$ & 7,79 & $-521,16$ & 0,41 & 8,75 & 0,18 & $-2,86 \mathrm{E}-3$ \\
2 & $-3,40 \mathrm{E}-3$ & 7,28 & 17,61 & $-1122,68$ & $-2,96$ & 9,11 & 0,41 & $-3,36 \mathrm{E}-3$ \\
3 & $-2,85 \mathrm{E}-3$ & 5,42 & 8,92 & $-645,84$ & 16,37 & $-0,34$ & 0,28 & $-3,22 \mathrm{E}-3$ \\
4 & $-1,81 \mathrm{E}-3$ & $-8,49$ & $-11,53$ & $-565,40$ & $-3,21$ & 13,10 & 0,22 & $-2,08 \mathrm{E}-3$ \\
5 & $-3,48 \mathrm{E}-3$ & 0,00 & $-17,22$ & $-1403,15$ & 8,16 & 30,48 & 0,41 & $-3,28 \mathrm{E}-3$ \\
6 & $-5,26 \mathrm{E}-3$ & 6,48 & $-5,55$ & $-831,77$ & 7,91 & 27,80 & 0,37 & $-5,24 \mathrm{E}-3$ \\
7 & $-2,39 \mathrm{E}-3$ & $-7,66$ & 0,08 & $-774,70$ & $-7,52$ & 22,17 & 0,12 & $-3,00 \mathrm{E}-3$ \\
8 & $-4,99 \mathrm{E}-3$ & 5,05 & $-0,11$ & $-768,62$ & $-9,15$ & 21,88 & 0,14 & $-4,86 \mathrm{E}-3$ \\
\hline
\end{tabular}

\subsubsection{SOLUÇÃO EM ESTACAS ESCAVADAS DE GRANDE DIÂMETRO (ESTACÃO)}

TABELA 20 - Cargas e recalques nos apoios - estacão - edifício assimétrico

\begin{tabular}{ccccccccc}
\hline UF & $\begin{array}{c}\text { recalque } \\
\text { convencional } \\
(m)\end{array}$ & $\begin{array}{c}\mathrm{HX} \\
(\mathrm{kN})\end{array}$ & $\begin{array}{c}\mathrm{HY} \\
(\mathrm{kN})\end{array}$ & $\begin{array}{c}\mathrm{V} \\
(\mathrm{kN})\end{array}$ & $\begin{array}{c}\mathrm{MX} \\
(\mathrm{kN} . \mathrm{m})\end{array}$ & $\begin{array}{c}\mathrm{MY} \\
(\mathrm{kN} . \mathrm{m})\end{array}$ & $\begin{array}{c}\mathrm{T} \\
(\mathrm{kN} . \mathrm{m})\end{array}$ & $\begin{array}{c}\text { recalque } \\
\text { interado } \\
(\mathrm{m})\end{array}$ \\
\hline 1 & $-1,88 \mathrm{E}-3$ & $-9,11$ & 8,91 & $-532,79$ & 0,41 & 6,11 & 0,02 & $-1,77 \mathrm{E}-3$ \\
2 & $-1,83 \mathrm{E}-3$ & 5,49 & 17,13 & $-1112,19$ & $-8,00$ & 0,56 & 0,03 & $-2,28 \mathrm{E}-3$ \\
3 & $-2,18 \mathrm{E}-3$ & 4,77 & 6,63 & $-606,92$ & 5,43 & $-5,43$ & 0,13 & $-1,89 \mathrm{E}-3$ \\
4 & $-1,29 \mathrm{E}-3$ & $-8,90$ & $-10,43$ & $-561,09$ & $-3,25$ & 4,04 & 0,04 & $-1,35 \mathrm{E}-3$ \\
5 & $-1,53 \mathrm{E}-3$ & 1,02 & $-16,89$ & $-1383,04$ & 4,09 & 1,02 & 0,04 & $-1,54 \mathrm{E}-3$ \\
6 & $-2,11 \mathrm{E}-3$ & 7,75 & $-6,91$ & $-957,06$ & 0,63 & 4,96 & 0,02 & $-1,83 \mathrm{E}-3$ \\
7 & $-1,11 \mathrm{E}-3$ & $-6,83$ & 0,82 & $-769,60$ & $-7,03$ & 3,91 & 0,00 & $-1,38 \mathrm{E}-3$ \\
8 & $-1,95 \mathrm{E}-3$ & 5,80 & 0,74 & $-710,64$ & $-5,35$ & 3,54 & 0,00 & $-1,75 \mathrm{E}-3$ \\
\hline
\end{tabular}


A TABELA 20 mostra os recalques para a condição de superestrutura perfeitamente flexível (convencional), e na condição interada, mostra cargas aplicadas nos apoios e respectivos recalques para o caso de estacas escavadas de grande diâmetro instaladas em maciço sedimentar.

\subsection{ESTRUTURA SIMÉTRICA EM RELAÇÃO A UM PLANO PRINCIPAL}

\subsubsection{SOLUÇão EM TUBULÕES A CÉU ABERTO}

TABELA 21 - Cargas e recalques nos apoios - tubulões - edifício simétrico

\begin{tabular}{|c|c|c|c|c|c|c|c|c|}
\hline UF & $\begin{array}{c}\text { recalque } \\
\text { convencional } \\
\text { (m) }\end{array}$ & $\begin{array}{l}\mathrm{HX} \\
(\mathrm{kN})\end{array}$ & $\begin{array}{l}\mathrm{HY} \\
(\mathrm{kN})\end{array}$ & $\begin{array}{c}\mathrm{V} \\
(\mathrm{kN})\end{array}$ & $\begin{array}{c}\text { MX } \\
\text { (kN.m) }\end{array}$ & $\begin{array}{c}\text { MY } \\
(\mathrm{kN} . \mathrm{m})\end{array}$ & $\begin{array}{c}\mathrm{T} \\
(\mathrm{kN} . \mathrm{m})\end{array}$ & $\begin{array}{c}\text { recalque } \\
\text { interado } \\
\text { (m) }\end{array}$ \\
\hline 1 & $-9,93 \mathrm{E}-3$ & $-14,42$ & 6,37 & $-595,53$ & 0,37 & 27,00 & $-0,01$ & $-1,15 \mathrm{E}-2$ \\
\hline 2 & $-1,84 \mathrm{E}-2$ & $-0,03$ & 15,23 & $-989,32$ & 3,11 & 23,85 & $-0,06$ & $-1,62 \mathrm{E}-2$ \\
\hline 3 & $-1,48 \mathrm{E}-2$ & 3,51 & 14,35 & $-1170,53$ & 11,83 & $-16,24$ & $-0,07$ & $-1,61 \mathrm{E}-2$ \\
\hline 4 & $-1,44 \mathrm{E}-2$ & 3,49 & 18,75 & $-1108,99$ & 18,73 & $-39,08$ & $-0,11$ & $-1,44 \mathrm{E}-2$ \\
\hline 5 & $-8,30 \mathrm{E}-3$ & 14,33 & 8,38 & $-601,59$ & 11,09 & $-26,07$ & $-0,05$ & $-9,82 \mathrm{E}-3$ \\
\hline 6 & $-8,00 \mathrm{E}-3$ & $-15,53$ & $-12,71$ & $-657,82$ & $-3,16$ & 32,17 & $-0,03$ & $-1,04 \mathrm{E}-2$ \\
\hline 7 & $-1,94 \mathrm{E}-2$ & $-7,44$ & $-16,35$ & $-1170,67$ & 29,04 & 39,33 & $-0,07$ & $-1,61 \mathrm{E}-2$ \\
\hline 8 & $-2,00 \mathrm{E}-2$ & $-2,04$ & $-12,09$ & $-1346,363$ & 21,30 & 8,46 & $-0,07$ & $-1,75 \mathrm{E}-2$ \\
\hline 9 & $-1,77 \mathrm{E}-2$ & 6,04 & $-13,73$ & $-1343,40$ & 43,79 & $-35,65$ & $-0,10$ & $-1,71 \mathrm{E}-2$ \\
\hline 10 & $-8,67 \mathrm{E}-3$ & 15,62 & $-11,16$ & $-639,27$ & 7,56 & $-36,71$ & $-0,03$ & $-1,05 \mathrm{E}-2$ \\
\hline 11 & $-1,20 \mathrm{E}-2$ & $-6,75$ & 1,44 & $-964,07$ & 10,74 & 5,66 & $-0,03$ & $-1,70 \mathrm{E}-2$ \\
\hline 12 & $-1,83 \mathrm{E}-2$ & $-2,19$ & 0,18 & $-1302,86$ & 3,20 & 7,27 & $-0,08$ & $-1,75 \mathrm{E}-2$ \\
\hline 13 & $-1,84 \mathrm{E}-2$ & 4,69 & 0,87 & $-695,51$ & 10,67 & 1,84 & $-0,04$ & $-1,79 \mathrm{E}-2$ \\
\hline
\end{tabular}

A TABELA 21 mostra os recalques para a condição de superestrutura perfeitamente flexível (convencional), e na condição interada, mostra cargas aplicadas nos apoios e respectivos recalques para o caso de tubulões a céu aberto apoiados em maciço residual.

\subsubsection{SOLUÇÃO EM ESTACAS CRAVADAS TIPO SCAC}

A TABELA 22 mostra os recalques para a condição de superestrutura perfeitamente flexível (convencional), e na condição interada, mostra cargas aplicadas nos apoios e respectivos recalques para o caso de estacas cravadas executadas em maciço sedimentar. 
TABELA 22 - Cargas e recalques nos apoios - estacas cravadas - edifício simétrico

\begin{tabular}{ccccccccc}
\hline UF & $\begin{array}{c}\text { recalque } \\
\text { convencional } \\
(m)\end{array}$ & $\begin{array}{c}\mathrm{HX} \\
(\mathrm{kN})\end{array}$ & $\begin{array}{c}\mathrm{HY} \\
(\mathrm{kN})\end{array}$ & $\begin{array}{c}\mathrm{V} \\
(\mathrm{kN})\end{array}$ & $\begin{array}{c}\mathrm{MX} \\
(\mathrm{kN} . \mathrm{m})\end{array}$ & $\begin{array}{c}\mathrm{MY} \\
(\mathrm{kN} . \mathrm{m})\end{array}$ & $\begin{array}{c}\mathrm{T} \\
(\mathrm{kN} . \mathrm{m})\end{array}$ & $\begin{array}{c}\text { recalque } \\
\text { interado } \\
(\mathrm{m})\end{array}$ \\
\hline 1 & $-2,78 \mathrm{E}-3$ & $-8,78$ & 7,87 & $-540,38$ & 15,62 & 9,78 & 0,07 & $-2,83 \mathrm{E}-3$ \\
2 & $-3,99 \mathrm{E}-3$ & 5,14 & 15,51 & $-1087,33$ & 9,37 & 18,25 & 0,16 & $-3,68 \mathrm{E}-3$ \\
3 & $-4,36 \mathrm{E}-3$ & 0,65 & 12,87 & $-1083,37$ & 11,84 & 15,85 & 0,15 & $-4,47 \mathrm{E}-3$ \\
4 & $-5,54 \mathrm{E}-3$ & $-1,35$ & 19,14 & $-1073,56$ & 21,02 & 0,80 & 0,15 & $-4,67 \mathrm{E}-3$ \\
5 & $-3,25 \mathrm{E}-3$ & 11,87 & 8,96 & $-575,52$ & 10,66 & $-7,36$ & 0,06 & $-3,17 \mathrm{E}-3$ \\
6 & $-4,55 \mathrm{E}-3$ & $-7,63$ & $-11,01$ & $-542,21$ & 11,93 & 6,73 & 0,08 & $-4,10 \mathrm{E}-3$ \\
7 & $-4,26 \mathrm{E}-3$ & 3,15 & $-21,24$ & $-1377,92$ & 14,75 & 14,03 & 0,17 & $-4,22 \mathrm{E}-3$ \\
8 & $-5,37 \mathrm{E}-3$ & $-3,90$ & $-11,62$ & $-1439,98$ & 30,98 & 40,55 & 0,13 & $-5,12 \mathrm{E}-3$ \\
9 & $-6,17 \mathrm{E}-3$ & 0,05 & $-11,61$ & $-1516,72$ & 55,17 & 15,80 & 0,14 & $-7,75 \mathrm{E}-3$ \\
10 & $-4,14 \mathrm{E}-3$ & 14,01 & $-10,54$ & $-593,80$ & 7,11 & $-18,28$ & 0,07 & $-4,00 \mathrm{E}-3$ \\
11 & $-2,63 \mathrm{E}-3$ & $-8,23$ & $-3,12$ & $-765,94$ & $-9,33$ & 28,73 & 0,06 & $-3,46 \mathrm{E}-3$ \\
12 & $-4,87 \mathrm{E}-3$ & $-6,88$ & 1,89 & $-1587,48$ & 16,38 & 63,12 & 0,16 & $-6,00 \mathrm{E}-3$ \\
13 & $-1,02 \mathrm{E}-2$ & 1,17 & 2,45 & $-401,72$ & 19,90 & 33,07 & 0,05 & $-9,24 \mathrm{E}-3$ \\
\hline
\end{tabular}

\subsection{EFEITOS DA INUNDAÇÃO DO MACIÇO DE SOLOS RESIDUAL}

\subsubsection{SOLUÇãO EM SAPATAS ISOLADAS}

TABELA 23 - Cargas e recalques nos apoios - sapatas - edifício assimétrico - maciço residual inundado

\begin{tabular}{ccccccccc}
\hline UF & $\begin{array}{c}\text { recalque } \\
\text { convencional } \\
(\mathrm{m})\end{array}$ & $\begin{array}{c}\mathrm{HX} \\
(\mathrm{kN})\end{array}$ & $\begin{array}{c}\mathrm{HY} \\
(\mathrm{kN})\end{array}$ & $\begin{array}{c}\mathrm{V} \\
(\mathrm{kN})\end{array}$ & $\begin{array}{c}\mathrm{MX} \\
(\mathrm{kN} . \mathrm{m})\end{array}$ & $\begin{array}{c}\mathrm{MY} \\
(\mathrm{kN} . \mathrm{m})\end{array}$ & $\begin{array}{c}\mathrm{T} \\
(\mathrm{kN} . \mathrm{m})\end{array}$ & $\begin{array}{c}\text { recalque } \\
\text { interado } \\
(\mathrm{m})\end{array}$ \\
\hline 1 & $-1,41 \mathrm{E}-2$ & $-14,58$ & 10,20 & $-568,61$ & $-3,61$ & 33,84 & 0,94 & $-1,49 \mathrm{E}-2$ \\
2 & $-2,13 \mathrm{E}-2$ & 6,78 & 20,98 & $-1081,02$ & $-12,18$ & 2,77 & 2,07 & $-2,04 \mathrm{E}-2$ \\
3 & $-1,63 \mathrm{E}-2$ & 11,21 & 12,51 & $-605,35$ & 16,13 & $-31,72$ & 0,90 & $-1,70 \mathrm{E}-2$ \\
4 & $-1,36 \mathrm{E}-2$ & $-14,92$ & $-9,42$ & $-587,09$ & $-6,70$ & 38,60 & 1,08 & $-1,44 \mathrm{E}-2$ \\
5 & $-2,17 \mathrm{E}-2$ & $-0,72$ & $-20,37$ & $-1312,80$ & $-53,13$ & 32,68 & 1,97 & $-2,07 \mathrm{E}-2$ \\
6 & $-2,01 \mathrm{E}-2$ & 11,66 & $-4,77$ & $-980,95$ & $-27,12$ & 3,41 & 1,82 & $-2,01 \mathrm{E}-2$ \\
7 & $-1,67 \mathrm{E}-2$ & $-6,29$ & $-6,40$ & $-747,96$ & $-62,81$ & 13,11 & 0,56 & $-1,67 \mathrm{E}-2$ \\
8 & $-1,70 \mathrm{E}-2$ & 6,84 & $-2,75$ & $-749,54$ & $-42,60$ & 13,22 & 0,71 & $-1,76 \mathrm{E}-2$ \\
\hline
\end{tabular}

A TABELA 23 mostra os recalques para a condição de superestrutura perfeitamente flexível (convencional), e na condição interada, mostra cargas aplicadas nos apoios e respectivos recalques para o caso de sapatas isoladas apoiadas em maciço residual inundado. 


\subsubsection{SOLUÇÃO EM TUBULÕES A CÉU ABERTO}

A TABELA 24 mostra os recalques para a condição de superestrutura perfeitamente flexível (convencional), e na condição interada, mostra cargas aplicadas nos apoios e respectivos recalques para o caso de tubulões a céu aberto apoiados em maciço residual inundado.

TABELA 24 - Cargas e recalques nos apoios - tubulões - edifício assimétrico - maciço residual inundado

\begin{tabular}{|c|c|c|c|c|c|c|c|c|}
\hline UF & $\begin{array}{c}\text { recalque } \\
\text { convencional } \\
\text { (m) }\end{array}$ & $\begin{array}{l}\mathrm{HX} \\
(\mathrm{kN})\end{array}$ & $\begin{array}{c}\mathrm{HY} \\
(\mathrm{kN})\end{array}$ & $\begin{array}{c}\mathrm{V} \\
(\mathrm{kN})\end{array}$ & $\begin{array}{c}\mathrm{MX} \\
\text { (kN.m) }\end{array}$ & $\begin{array}{c}\text { MY } \\
\text { (kN.m) }\end{array}$ & $\begin{array}{c}\mathrm{T} \\
\text { (kN.m) }\end{array}$ & $\begin{array}{c}\text { recalque } \\
\text { interado } \\
\text { (m) }\end{array}$ \\
\hline 1 & $-3,87 \mathrm{E}-2$ & $-9,51$ & 6,02 & $-477,39$ & $-84,24$ & 1,12 & 0,57 & $-3,09 \mathrm{E}-2$ \\
\hline 2 & $-3,87 \mathrm{E}-2$ & 8,57 & 20,16 & $-870,56$ & $-87,42$ & $-28,85$ & 1,17 & $-3,09 \mathrm{E}-2$ \\
\hline 3 & $-2,14 \mathrm{E}-2$ & 8,21 & 5,54 & $-772,05$ & $-51,88$ & $-29,30$ & 0,58 & $-2,81 \mathrm{E}-2$ \\
\hline 4 & $-1,40 \mathrm{E}-2$ & $-15,61$ & $-13,47$ & $-715,14$ & $-87,45$ & 18,12 & 0,74 & $-1,91 \mathrm{E}-2$ \\
\hline 5 & $-2,39 \mathrm{E}-2$ & $-2,43$ & $-14,70$ & $-1332,47$ & $-135,38$ & $-17,13$ & 1,10 & $-2,31 \mathrm{E}-2$ \\
\hline 6 & $-1,91 \mathrm{E}-2$ & 10,41 & $-6,63$ & $-1050,90$ & $-128,34$ & $-31,41$ & 0,98 & $-2,06 \mathrm{E}-2$ \\
\hline 7 & $-1,79 \mathrm{E}-2$ & $-6,18$ & 1,75 & $-795,71$ & $-81,97$ & $-25,77$ & 0,18 & $-1,91 \mathrm{E}-2$ \\
\hline 8 & $-1,95 \mathrm{E}-2$ & 6,53 & 1,33 & $-691,12$ & $-71,15$ & $-26,06$ & 0,35 & $-1,71 \mathrm{E}-2$ \\
\hline
\end{tabular}




\section{ANÁLISE DOS RESULTADOS}

\subsection{ESTRUTURA COM DUPLA SIMETRIA}

Na prática da engenharia de fundações para edifícios de pequeno, médio ou mesmo de grande porte, é comum proceder o cálculo sem a preocupação com a análise de recalques e menos ainda com a variabilidade do maciço suporte. No entanto, a prática tem também mostrado que pelo menos a grande maioria dessas construções se comportam bem durante sua vida útil. Pergunta-se: a que se deve esse comportamento favorável? Utiliza-se o caso de uma estrutura com dupla simetria, aqui chamada exemplo didático, para dissertar sobre esta questão.

TABELA 25 - Coeficientes de segurança e recalques - sapatas - exemplo didático

\begin{tabular}{cccccc}
\hline UF & CC $(\mathrm{kN})$ & \multicolumn{2}{c}{$\mathrm{CS}$} & \multicolumn{2}{c}{$\mathrm{W}(\mathrm{m})$} \\
& & convencional & interado & convencional & interado \\
\hline 1 & 1211 & 3,2 & 2,9 & $-1,25 \mathrm{E}-2$ & $-1,37 \mathrm{E}-2$ \\
2 & 2044 & 3,4 & 3,6 & $-1,49 \mathrm{E}-2$ & $-1,43 \mathrm{E}-2$ \\
3 & 1322 & 3,5 & 3,1 & $-1,20 \mathrm{E}-2$ & $-1,33 \mathrm{E}-2$ \\
4 & 2050 & 3,4 & 3,6 & $-1,52 \mathrm{E}-2$ & $-1,46 \mathrm{E}-2$ \\
5 & 2942 & 3,6 & 3,9 & $-1,72 \mathrm{E}-2$ & $-1,59 \mathrm{E}-2$ \\
6 & 2114 & 3,5 & 3,7 & $-1,53 \mathrm{E}-2$ & $-1,47 \mathrm{E}-2$ \\
7 & 1335 & 3,5 & 3,1 & $-1,24 \mathrm{E}-2$ & $-1,38 \mathrm{E}-2$ \\
8 & 2136 & 3,6 & 3,8 & $-1,61 \mathrm{E}-2$ & $-1,51 \mathrm{E}-2$ \\
9 & 1375 & 3,6 & 3,2 & $-1,29 \mathrm{E}-2$ & $-1,43 \mathrm{E}-2$ \\
\hline
\end{tabular}

No caso de sapatas isoladas, pela maior rigidez relativa, foi notória a redistribuição de cargas e a homogeneização dos recalques. A TABELA 25 mostra o comportamento dos coeficientes de segurança à ruptura e dos recalques das unidades de fundação quando se procede cálculo para superestrutura perfeitamente flexível (convencional) e quando se considera a influência da rigidez da superestrutura (interado). Analisando a TABELA 25, 
vemos que o cálculo de resistência pelos métodos práticos estão de acordo com os resultados obtidos usando o método de cálculo de resistência de interface proposto pelo StructsoiL. Na análise convencional, os coeficientes de segurança são relativamente uniformes e superiores a 3,2, variando consideravelmente após a interação.

A FIGURA 56 mostra as curvas iso-recalques para as condições de análise convencional (superestrutura perfeitamente elástica) e análise considerando a rigidez da superestrutura. Os recalques indicados nos apoios representam a condição interativa. Os recalques estão expressos em milímetros $(\mathrm{mm})$ enquanto as coordenadas no plano XY são expressas em metros.

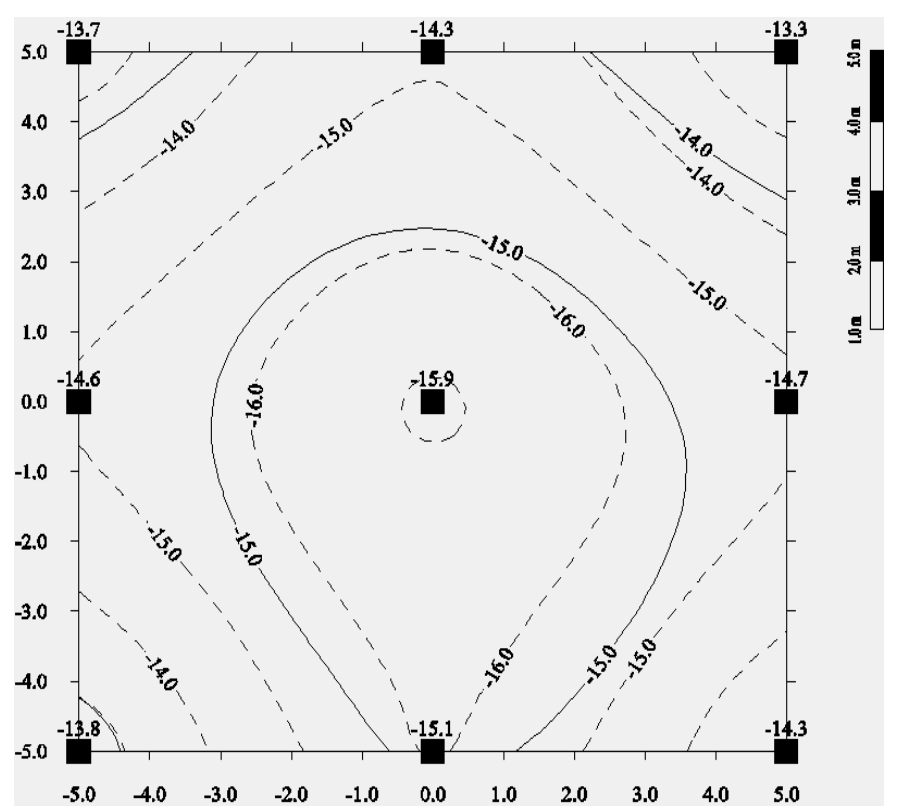

FIGURA 56 - Curvas iso-recalques, em milímetros, para análise convencional (tracejadas) e análise interativa (contínuas) - sapatas isoladas - exemplo didático

As curvas iso-recalques (FIGURA 56) mostram a homogeneização dos recalques, como conseqüência da interação da fundação com a superestrutura, pelo aumento do espaçamento entre as curvas contínuas relativamente às curvas tracejadas.

Para a solução em tubulões a céu aberto, pode-se visualizar, pela TABELA 26, que:

- os recalques foram da mesma ordem de grandeza dos recalques das sapatas; isso deve-se à grande distância entre as cotas de apoio e o horizonte indeslocável e pelo plano de apoio ter sido definido em camada pouco rígida;

- o cálculo convencional pode ser pouco econômico, pois o coeficiente de segurança médio calculado de acordo com o modelo de cálculo do StructsoiL é 
superior a 2,3, o que significa um possível desperdício da capacidade de carga da estrutura de fundação.

TABELA 26 - Coeficientes de segurança e recalques - tubulões - exemplo didático

\begin{tabular}{ccccccc}
\hline UF & RL $(\mathrm{kN})$ & $\mathrm{CC}(\mathrm{kN})$ & \multicolumn{2}{c}{$\mathrm{CS}$} & \multicolumn{2}{c}{$\mathrm{W}(\mathrm{m})$} \\
& & & convencional & interado & convencional & interado \\
\hline 1 & 101 & 1074 & 2,8 & 2,6 & $-7,02 \mathrm{E}-3$ & $-8,12 \mathrm{E}-3$ \\
2 & 88 & 1454 & 2,4 & 2,5 & $-1,04 \mathrm{E}-2$ & $-1,02 \mathrm{E}-2$ \\
3 & 95 & 929 & 2,5 & 2,4 & $-1,14 \mathrm{E}-2$ & $-1,17 \mathrm{E}-2$ \\
4 & 86 & 1434 & 2,4 & 2,6 & $-1,11 \mathrm{E}-2$ & $-1,01 \mathrm{E}-2$ \\
5 & 74 & 1765 & 2,1 & 2,3 & $-1,27 \mathrm{E}-2$ & $-1,21 \mathrm{E}-2$ \\
6 & 83 & 1340 & 2,2 & 2,2 & $-1,18 \mathrm{E}-2$ & $-1,18 \mathrm{E}-2$ \\
7 & 92 & 896 & 2,4 & 2,0 & $-8,24 \mathrm{E}-3$ & $-1,02 \mathrm{E}-2$ \\
8 & 77 & 1273 & 2,1 & 2,4 & $-1,39 \mathrm{E}-2$ & $-1,21 \mathrm{E}-2$ \\
9 & 85 & 817 & 2,2 & 1,9 & $-1,02 \mathrm{E}-2$ & $-1,19 \mathrm{E}-2$ \\
\hline
\end{tabular}

A FIGURA 57 mostra uma maior suavidade da superfície formada pelas curvas isorecalques para a análise interativa, relativamente à análise convencional. Isso se deve à influência da rigidez da superestrutura na planificação da superfície que contém os apoios.

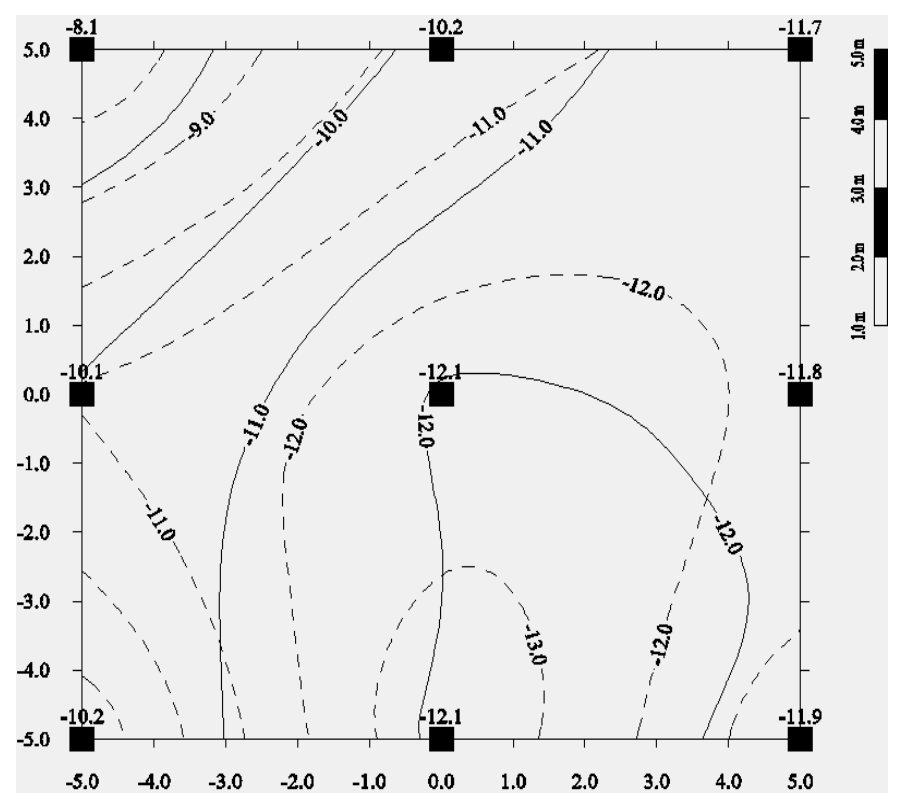

FIGURA 57 - Curvas iso-recalques, em milímetros, para análise convencional (tracejadas) e análise interativa (contínuas) - tubulões a céu aberto - exemplo didático 
A solução de estrutura de fundação em estacas cravadas apresentou os resultados mais interessantes. Pela TABELA 27, observa-se o quanto a variabilidade do maciço influencia na capacidade resistente da interface elemento estrutural - maciço de solos. Essa variabilidade de capacidade de carga é minimizada na instalação por imposição do processo construtivo (cravação). Por outro lado, o controle executivo, a nega por exemplo, pode não garantir a uniformidade do estaqueamento. A interação estrutura - maciço de solos condiciona a homogeneização dos recalques, uma redistribuição de cargas e a conseqüente homogeneização dos coeficientes de segurança. Este fato pode ser exemplificado no comportamento da unidade de fundação 5 que possui capacidade de carga de projeto igual a $1735 \mathrm{kN}$, mas pela variabilidade do solo apresenta capacidade de carga última local de 967 kN. A interação com a superestrutura fez com que parte da carga fosse transferida para outros apoios e o coeficiente de segurança aumentasse de 1,2 para 1,4.

TABELA 27 - Coeficientes de segurança e recalques - estacas cravadas - exemplo didático

\begin{tabular}{ccccccc}
\hline \multirow{2}{*}{ UF } & \multirow{2}{*}{$\mathrm{RL}(\mathrm{kN})$} & \multirow{2}{*}{$\mathrm{CC}(\mathrm{kN})$} & \multicolumn{2}{c}{$\mathrm{CS}$} & \multicolumn{2}{c}{$\mathrm{W}(\mathrm{m})$} \\
& & & convencional & interado & convencional & interado \\
\hline 1 & 390 & 920 & 2,4 & 2,4 & $-2,45 \mathrm{E}-3$ & $-2,68 \mathrm{E}-3$ \\
2 & 541 & 1434 & 2,4 & 2,2 & $-3,34 \mathrm{E}-3$ & $-3,50 \mathrm{E}-3$ \\
3 & 388 & 866 & 2,3 & 2,3 & $-4,24 \mathrm{E}-3$ & $-4,49 \mathrm{E}-3$ \\
4 & 522 & 1385 & 2,3 & 2,2 & $-3,04 \mathrm{E}-3$ & $-3,65 \mathrm{E}-3$ \\
5 & 755 & 967 & 1,2 & 1,4 & $-7,22 \mathrm{E}-3$ & $-7,18 \mathrm{E}-3$ \\
6 & 503 & 1306 & 2,2 & 2,1 & $-3,92 \mathrm{E}-3$ & $-4,63 \mathrm{E}-3$ \\
7 & 359 & 799 & 2,1 & 2,0 & $-3,45 \mathrm{E}-3$ & $-3,08 \mathrm{E}-3$ \\
8 & 442 & 1145 & 1,9 & 1,8 & $-3,79 \mathrm{E}-3$ & $-4,52 \mathrm{E}-3$ \\
9 & 307 & 673 & 1,8 & 1,7 & $-3,60 \mathrm{E}-3$ & $-4,32 \mathrm{E}-3$ \\
\hline
\end{tabular}

Outro fato considerável é o efeito tridimensional de interação através do maciço que condiciona o comportamento não convencional da unidade de fundação 7 , onde o coeficiente de segurança diminui de 2,1 para 2,0 concomitante à diminuição do valor do recalque, que passa de $3,45 \mathrm{~mm}$ para $3,08 \mathrm{~mm}$. Isso significa que o apoio foi mais carregado enquanto seu deslocamento foi minimizado, o que se deve à influência dos vizinhos e à não linearidade da transferência de carga.

A FIGURA 58 mostra uma pequena suavização dos recalques pela menor influência da rigidez da superestrutura no comportamento da edificação com fundação em estacas cravadas. Isso se deve à relativa proximidade entre a cota de apoio e o horizonte indeslocável e, consequentemente, aos inexpressivos recalques dos apoios. 


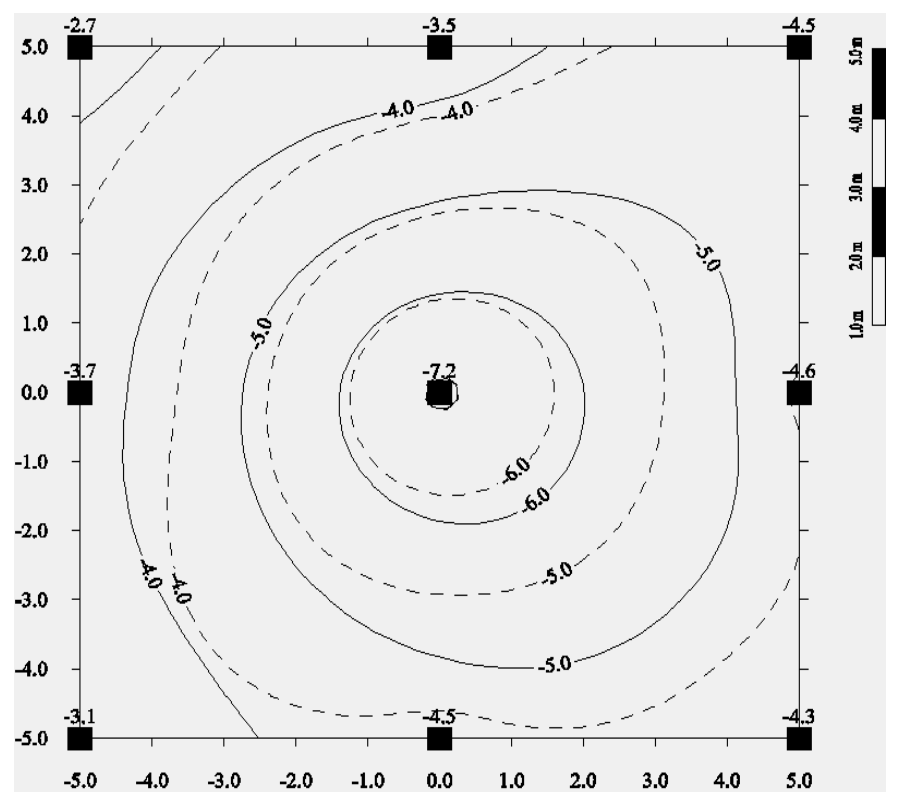

FIGURA 58 - Curvas iso-recalques, em milímetros, para análise convencional (tracejadas) e análise interativa (contínuas) - estacas cravadas - exemplo didático

Pelos resultados, visualiza-se que as estruturas de fundação projetadas pelos métodos convencionais, e executadas sem controle de qualidade in loco, alcançam comportamento aceitável devido a dois motivos:

- um possível super-dimensionamento imposto pelo método de cálculo convencional que despreza a variabilidade tridimensional do maciço suporte;

- efeitos positivos devido à interação estrutura - maciço de solos, como a minimização de recalques diferenciais.

Analisando conjuntamente a FIGURA 56, a FIGURA 57 e a FIGURA 58, pode-se verificar que a consideração da rigidez da superestrutura no comportamento do edifício suaviza a superfície formada pelas curvas iso-recalques, ou seja, aumenta o espaçamento entre essas curvas, tornando-as mais próximas de um plano. Verifica-se também que as curvas mantêm uma conformidade relativamente idêntica.

Para avaliar a eficiência da interação estrutura - maciço de solos para pórtico tridimensional utiliza-se como argumentos a média dos recalques absolutos e o desvio padrão desses recalques para a análise convencional e para a análise interativa com a superestrutura. Essa forma de análise foi procedida por GUSMÃO (1990) para comparar o comportamento estimado com o medido em edifícios monitorados; esse autor utiliza também o coeficiente de variação (quociente do desvio padrão pela média) como parâmetro de análise. 
Nos casos estudados neste trabalho, o coeficiente de variação sempre decresce com a consideração da interação da fundação com a superestrutura. Como a média dos recalques absolutos praticamente se manteve em todos os casos, admite-se que a análise desse parâmetro adimensional se mostrou irrelevante na análise qualitativa dos resultados.

A TABELA 28 mostra que o desvio padrão diminui sensivelmente nos casos de sapatas e tubulões, mas é mantido inalterado para o caso de estacas. Mostra ainda que, para os casos estudados, os recalques absolutos médios são idênticos para ambas as análises.

TABELA 28 - Eficiência da interação com a superestrutura - exemplo didático

\begin{tabular}{ccccc}
\hline \multirow{2}{*}{ Solução } & \multicolumn{2}{c}{$\mathrm{W}_{\text {médio }}(\mathrm{m})$} & \multicolumn{2}{c}{$\mathrm{W}_{\text {desvio padrão }}(\mathrm{m})$} \\
& convencional & interado & convencional & interado \\
\hline sapata isolada & $-1,43 \mathrm{E}-2$ & $-1,44 \mathrm{E}-2$ & $1,87 \mathrm{E}-3$ & $0,79 \mathrm{E}-3$ \\
tubulão a céu aberto & $-1,08 \mathrm{E}-2$ & $-1,09 \mathrm{E}-2$ & $2,12 \mathrm{E}-3$ & $1,35 \mathrm{E}-3$ \\
& & & & \\
estaca cravada & $-3,89 \mathrm{E}-3$ & $-4,23 \mathrm{E}-3$ & $1,35 \mathrm{E}-3$ & $1,35 \mathrm{E}-3$ \\
\hline
\end{tabular}

\subsection{ESTRUTURA ASSIMÉTRICA}

A TABELA 29, a TABELA 30, a TABELA 31 e a TABELA 32 mostram a relação de coeficientes de segurança na fundação e de recalques nos apoios, respectivamente, para os casos de estrutura de fundação em sapatas isoladas, tubulões a céu aberto, estacas cravadas e estacas escavadas (estacão), dimensionadas para suportar o aqui denominado edifício assimétrico. A FIGURA 59, a FIGURA 60, a FIGURA 61 e a FIGURA 62 mostram as curvas iso-recalques para os casos acima citados, considerando a análise convencional (superestrutura perfeitamente flexível) e a análise interativa (superestrutura relativamente rígida).

A TABELA 29 mostra que os apoios extremos das linhas de pilares do pórtico espacial absorvem carregamento transferido, diminuindo o coeficiente de segurança a ruptura, enquanto acontece o inverso com os apoios de meio de vão (unidades de fundação 2 , 5 e 6 ). 
TABELA 29 - Coeficientes de segurança e recalques - sapatas - edifício assimétrico

\begin{tabular}{ccccc}
\hline \multirow{2}{*}{ UF } & \multicolumn{2}{c}{ CS } & \multicolumn{2}{c}{$\mathrm{W}(\mathrm{m})$} \\
& convencional & interado & convencional & interado \\
\hline 1 & 3,0 & 2,8 & $-1,38 \mathrm{E}-2$ & $-1,50 \mathrm{E}-2$ \\
2 & 3,0 & 3,3 & $-2,06 \mathrm{E}-2$ & $-1,89 \mathrm{E}-2$ \\
3 & 3,0 & 2,5 & $-1,59 \mathrm{E}-2$ & $-1,87 \mathrm{E}-2$ \\
4 & 3,0 & 2,8 & $-1,32 \mathrm{E}-2$ & $-1,43 \mathrm{E}-2$ \\
5 & 3,0 & 3,5 & $-2,09 \mathrm{E}-2$ & $-1,84 \mathrm{E}-2$ \\
6 & 3,0 & 3,2 & $-1,94 \mathrm{E}-2$ & $-1,84 \mathrm{E}-2$ \\
7 & 3,0 & 2,8 & $-1,62 \mathrm{E}-2$ & $-1,75 \mathrm{E}-2$ \\
8 & 3,0 & 2,8 & $-1,65 \mathrm{E}-2$ & $-1,75 \mathrm{E}-2$ \\
\hline
\end{tabular}

A FIGURA 59 mostra uma forte homogeneização dos recalques das quatro unidades de fundação correspondentes aos pilares mais carregados (2, 3, 5 e 6), enquanto os pares de apoios extremos tendem a se deslocar uniformemente.

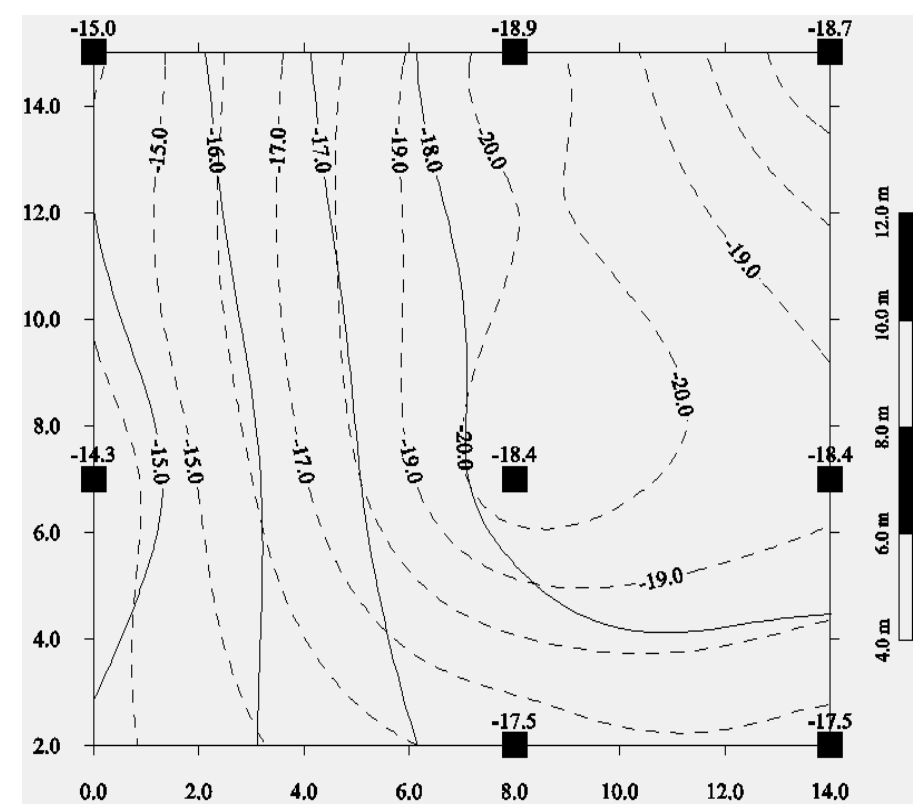

FIGURA 59 - Curvas iso-recalques, em milímetros, para análise convencional (tracejadas) e análise interativa (contínuas) - sapatas isoladas - maciço residual - edifício assimétrico

A solução em tubulões (TABELA 30) é a que sofre maior redistribuição de carga entre os apoios, e por isso compromete a estabilidade a ruptura de algumas unidades de fundação, principalmente as 3 e 4 (pilares de canto).

TABELA 30 - Coeficientes de segurança e recalques - tubulões - edifício assimétrico 


\begin{tabular}{ccccc}
\hline \multirow{2}{*}{ UF } & \multicolumn{2}{c}{ CS } & \multicolumn{2}{c}{ W (m) } \\
& convencional & interado & convencional & interado \\
\hline 1 & 2,1 & 2,3 & $-3,60 \mathrm{E}-2$ & $-2,92 \mathrm{E}-2$ \\
2 & 2,0 & 2,4 & $-3,60 \mathrm{E}-2$ & $-2,91 \mathrm{E}-2$ \\
3 & 2,0 & 1,6 & $-2,01 \mathrm{E}-2$ & $-2,59 \mathrm{E}-2$ \\
4 & 2,0 & 1,6 & $-1,31 \mathrm{E}-2$ & $-1,76 \mathrm{E}-2$ \\
5 & 2,1 & 2,2 & $-2,25 \mathrm{E}-2$ & $-2,16 \mathrm{E}-2$ \\
6 & 2,1 & 2,0 & $-1,78 \mathrm{E}-2$ & $-1,94 \mathrm{E}-2$ \\
7 & 2,0 & 1,9 & $-1,68 \mathrm{E}-2$ & $-1,79 \mathrm{E}-2$ \\
8 & 2,1 & 2,5 & $-1,85 \mathrm{E}-2$ & $-1,62 \mathrm{E}-2$ \\
\hline
\end{tabular}

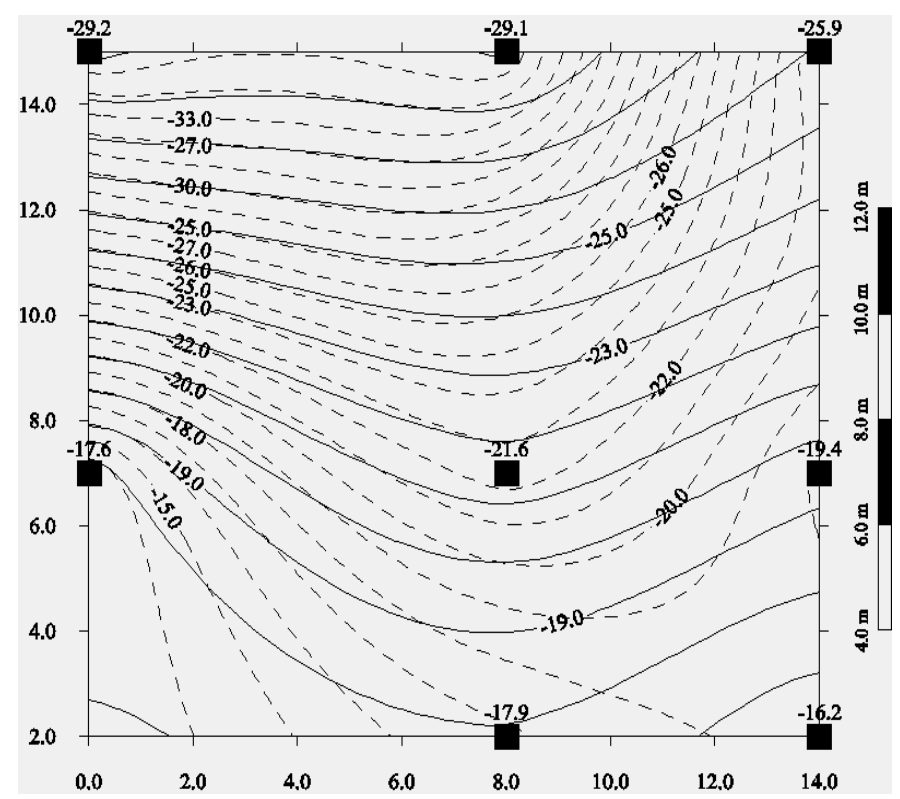

FIGURA 60 - Curvas iso-recalques, em milímetros, para análise convencional (tracejadas) e análise interativa (contínuas) - tubulões a céu aberto - maciço residual - edifício assimétrico

A FIGURA 60 mostra que o edifício sofre uma deflexão relativa máxima em torno de $10 \mathrm{~mm}$ na direção de maior inclinação e isso pode interferir na estabilidade da edificação. Por outro lado, essa inclinação tende a se homogeneizar ao longo da superfície formada pelas curvas iso-recalques deduzidos pela análise interativa.

Para fundação em estacas cravadas, a interação condiciona redistribuição significativa de cargas entre os apoios, mas devido aos inexpressivos recalques absolutos, não minimiza seus recalques diferenciais de forma sensível. As unidades de fundação 3,7 e 8 , referentes aos pilares de canto, têm sua estabilidade à ruptura comprometida (TABELA 31). A FIGURA 61 mostra, com clareza, que a interação com a superestrutura pouco 
influencia no comportamento dos recalques dos apoios, quando a estrutura de fundação é executada em estacas cravadas. A causa é que a espessura da camada deformável (distância vertical entre a cota de apoio e a superfície indeslocável) é pequena, o que minora o recalque absoluto e reduz a interação entre as unidades de fundação através do maciço suporte.

TABELA 31 - Coeficientes de segurança e recalques - estacas cravadas - edifício assimétrico

\begin{tabular}{ccccc}
\hline \multirow{2}{*}{ UF } & \multicolumn{2}{c}{ CS } & \multicolumn{2}{c}{$\mathrm{W}(\mathrm{m})$} \\
& convencional & interado & convencional & interado \\
\hline 1 & 1,6 & 1,7 & $-2,55 \mathrm{E}-3$ & $-2,86 \mathrm{E}-3$ \\
2 & 1,7 & 1,6 & $-3,40 \mathrm{E}-3$ & $-3,36 \mathrm{E}-3$ \\
3 & 1,7 & 1,5 & $-2,85 \mathrm{E}-3$ & $-3,22 \mathrm{E}-3$ \\
4 & 1,9 & 1,8 & $-1,81 \mathrm{E}-3$ & $-2,08 \mathrm{E}-3$ \\
5 & 1,6 & 1,6 & $-3,48 \mathrm{E}-3$ & $-3,28 \mathrm{E}-3$ \\
6 & 1,7 & 2,0 & $-5,26 \mathrm{E}-3$ & $-5,24 \mathrm{E}-3$ \\
7 & 1,6 & 1,4 & $-2,39 \mathrm{E}-3$ & $-3,00 \mathrm{E}-3$ \\
8 & 1,6 & 1,5 & $-4,99 \mathrm{E}-3$ & $-4,86 \mathrm{E}-3$ \\
\hline
\end{tabular}

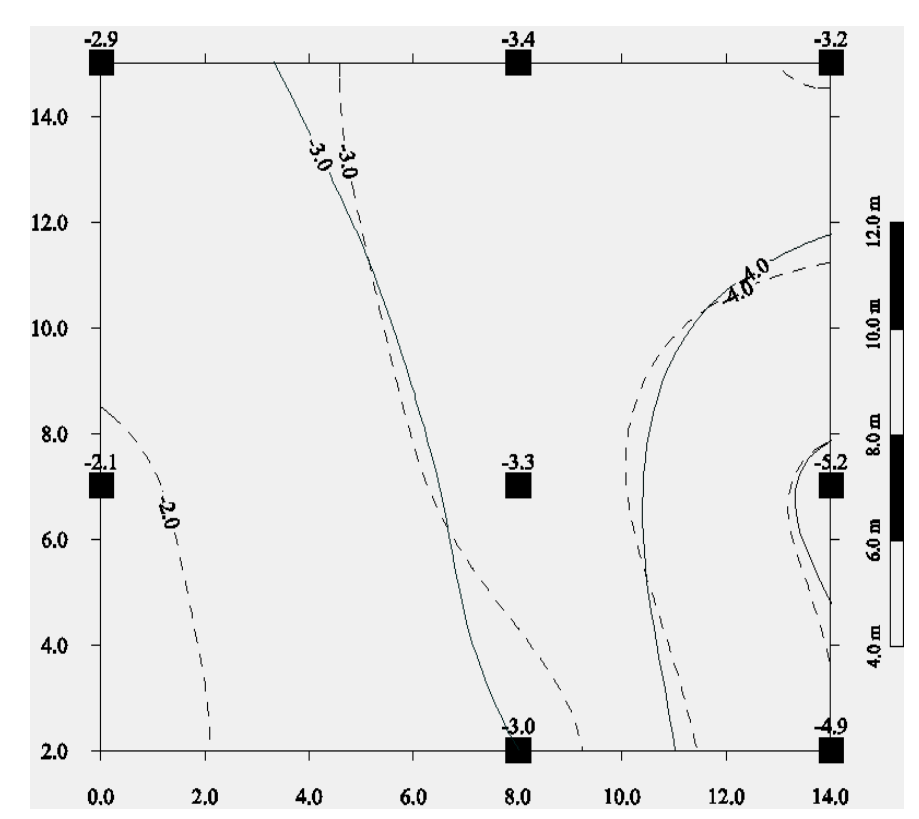

FIGURA 61 - Curvas iso-recalques, em milímetros, para análise convencional (tracejadas) e análise interativa (contínuas) - estacas cravadas - maciço sedimentar - edifício assimétrico

A solução em estacas escavadas (estacão) praticamente não sofre influência da interação estrutura - maciço de solos, seja na redistribuição de cargas nos apoios ou na 
minimização de seus inexpressivos recalques diferenciais (TABELA 32). A FIGURA 61 também mostra que a interação com a superestrutura pouco influencia no comportamento dos recalques dos apoios.

TABELA 32 - Coeficientes de segurança e recalques - estacão - edifício assimétrico

\begin{tabular}{ccccc}
\hline \multirow{2}{*}{ UF } & \multicolumn{2}{c}{ CS } & \multicolumn{2}{c}{ W (m) } \\
& convencional & interado & convencional & interado \\
\hline 1 & 1,8 & 1,8 & $-1,88 \mathrm{E}-3$ & $-1,77 \mathrm{E}-3$ \\
2 & 2,0 & 2,0 & $-1,83 \mathrm{E}-3$ & $-2,28 \mathrm{E}-3$ \\
3 & 1,9 & 1,9 & $-2,18 \mathrm{E}-3$ & $-1,89 \mathrm{E}-3$ \\
4 & 1,9 & 1,9 & $-1,29 \mathrm{E}-3$ & $-1,35 \mathrm{E}-3$ \\
5 & 1,7 & 1,7 & $-1,53 \mathrm{E}-3$ & $-1,54 \mathrm{E}-3$ \\
6 & 1,8 & 1,8 & $-2,11 \mathrm{E}-3$ & $-1,83 \mathrm{E}-3$ \\
7 & 1,8 & 1,8 & $-1,11 \mathrm{E}-3$ & $-1,38 \mathrm{E}-3$ \\
8 & 1,8 & 1,9 & $-1,95 \mathrm{E}-3$ & $-1,75 \mathrm{E}-3$ \\
\hline
\end{tabular}

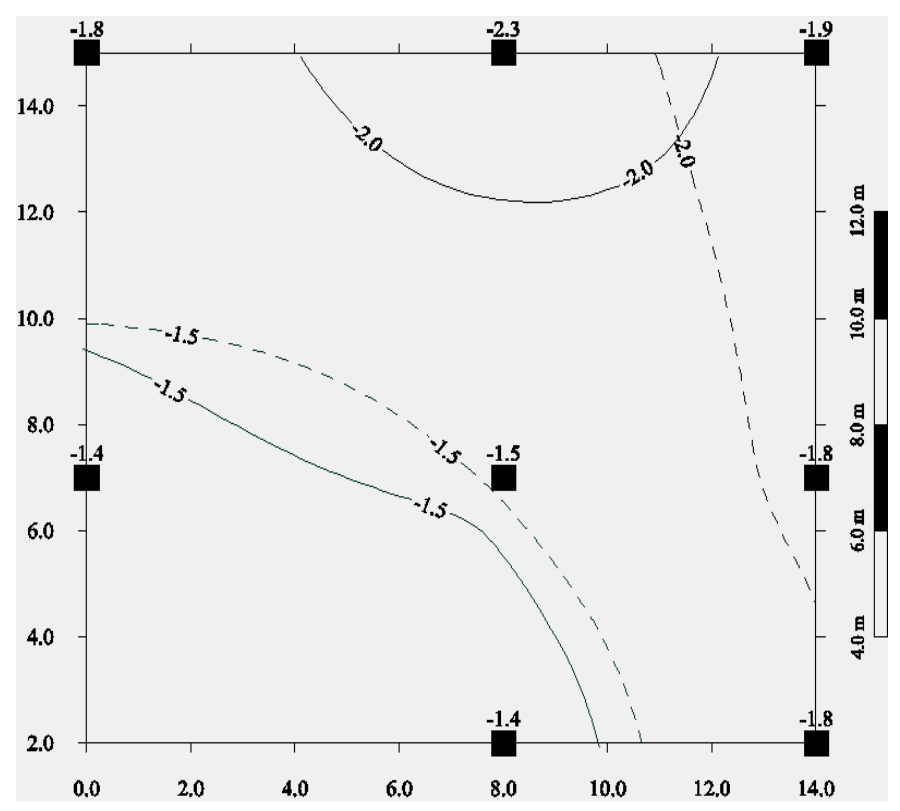

FIGURA 62 - Curvas iso-recalques, em milímetros, para análise convencional (tracejadas) e análise interativa (contínuas) - estacão - maciço sedimentar - edifício assimétrico

Nota-se que o comportamento das curvas iso-recalques para a análise interativa (contínuas) da FIGURA 59, da FIGURA 60, da FIGURA 61 e da FIGURA 62 demonstra a tendência do edifício em inclinar-se em uma determinada direção como um bloco de alta 
rigidez. A solução em tubulões a céu aberto condiciona a maior tendência de inclinação do prédio, seguida pela solução em sapatas, que também condiciona uma inclinação considerável. As soluções em estacas cravadas e escavadas garantem maior estabilidade à edificação. A tendência de inclinação é devida tanto à assimetria do edifício quanto à variabilidade do maciço suporte.

A TABELA 33 mostra que o desvio padrão diminui em todos os casos estudados, sendo esta diminuição mais acentuada nos casos de sapatas e tubulões. Como esperado, para os casos estudados, os recalques absolutos médios são idênticos para ambas as análises.

TABELA 33 - Eficiência da interação com a superestrutura - edifício assimétrico

\begin{tabular}{ccccc}
\hline \multirow{2}{*}{ Solução } & \multicolumn{2}{c}{$\mathrm{W}_{\text {médio }}(\mathrm{m})$} & \multicolumn{2}{c}{$\mathrm{W}_{\text {desvio padrão }}(\mathrm{m})$} \\
& convencional & interado & convencional & interado \\
\hline sapata isolada & $-1,71 \mathrm{E}-2$ & $-1,73 \mathrm{E}-2$ & $2,94 \mathrm{E}-3$ & $1,74 \mathrm{E}-3$ \\
tubulão a céu aberto & $-2,26 \mathrm{E}-2$ & $-2,21 \mathrm{E}-2$ & $8,69 \mathrm{E}-3$ & $5,27 \mathrm{E}-3$ \\
estaca cravada & $-3,34 \mathrm{E}-3$ & $-3,49 \mathrm{E}-3$ & $1,23 \mathrm{E}-3$ & $1,05 \mathrm{E}-3$ \\
estaca escavada & $-1,74 \mathrm{E}-3$ & $-1,72 \mathrm{E}-3$ & $0,39 \mathrm{E}-3$ & $0,30 \mathrm{E}-3$ \\
\hline
\end{tabular}

As soluções mais eficientes, ou seja, as que condicionaram menor inclinação do edifício e menor redistribuição de cargas, foram as em estacas escavadas e as em estacas cravadas. Estas soluções foram por isso, as menos influenciadas pelos efeitos positivos da interação estrutura - maciço de solos, ou seja, minimização dos recalques diferenciais. As soluções em sapatas e tubulões (principalmente esta última) condicionaram recalques absolutos médios elevados e significante influência da interação na minimização dos recalques diferenciais. O bom comportamento da fundação em estacas escavadas pode ser explicado pela influência da variação da cota de apoio de acordo com a variabilidade do maciço suporte (TABELA 10), alcançando cotas de apoio muito próximas da superfície modelada como indeslocável.

Conclui-se que a assimetria geométrica em planta e espacial do edifício obriga que a solução adotada na fundação seja rígida, de forma que iniba a interação com a superestrutura restringindo a inclinação do pórtico. Assim, para o caso de maciço residual, indica-se que a 
cota de apoio da solução em tubulões seja alterada para 81,0 (acima do NA), enquanto para o caso de maciço sedimentar deve-se definir a solução adotada através de análise de viabilidade econômica.

\subsection{ESTRUTURA SIMÉTRICA EM RELAÇÃO A UM PLANO PRINCIPAL}

A TABELA 34 e a TABELA 35 mostram, respectivamente, relação de coeficientes de segurança na fundação e recalques nos apoios para os casos de tubulões a céu aberto apoiados em maciço residual e estacas cravadas instaladas em maciço suporte sedimentar.

TABELA 34 - Coeficientes de segurança e recalques - tubulões - edifício simétrico

\begin{tabular}{ccccc}
\hline \multirow{2}{*}{ UF } & \multicolumn{2}{c}{ CS } & \multicolumn{2}{c}{$\mathrm{W}(\mathrm{m})$} \\
& convencional & interado & convencional & interado \\
\hline 1 & 2,1 & 1,9 & $-9,93 \mathrm{E}-3$ & $-1,15 \mathrm{E}-2$ \\
2 & 2,1 & 2,2 & $-1,84 \mathrm{E}-2$ & $-1,62 \mathrm{E}-2$ \\
3 & 2,1 & 1,8 & $-1,48 \mathrm{E}-2$ & $-1,61 \mathrm{E}-2$ \\
4 & 2,1 & 2,1 & $-1,44 \mathrm{E}-2$ & $-1,44 \mathrm{E}-2$ \\
5 & 2,2 & 1,7 & $-8,30 \mathrm{E}-3$ & $-9,82 \mathrm{E}-3$ \\
6 & 2,4 & 1,7 & $-8,00 \mathrm{E}-3$ & $-1,04 \mathrm{E}-2$ \\
7 & 2,0 & 2,4 & $-1,94 \mathrm{E}-2$ & $-1,61 \mathrm{E}-2$ \\
8 & 2,0 & 2,3 & $-2,00 \mathrm{E}-2$ & $-1,75 \mathrm{E}-2$ \\
9 & 2,0 & 2,1 & $-1,77 \mathrm{E}-2$ & $-1,71 \mathrm{E}-2$ \\
10 & 2,2 & 1,9 & $-8,67 \mathrm{E}-3$ & $-1,05 \mathrm{E}-2$ \\
11 & 2,2 & 1,6 & $-1,20 \mathrm{E}-2$ & $-1,70 \mathrm{E}-2$ \\
12 & 2,0 & 2,2 & $-1,83 \mathrm{E}-2$ & $-1,75 \mathrm{E}-2$ \\
13 & 2,1 & 2,2 & $-1,84 \mathrm{E}-2$ & $-1,79 \mathrm{E}-2$ \\
\hline
\end{tabular}

Os apoios extremos das linhas de pilares que compõem o pórtico espacial têm seus coeficientes de segurança decrescidos, exceto o apoio 13. Pela variação da rigidez do maciço suporte, o pilar P10 absorve parte da carga do pilar P13, demonstrando que a regra de pilares de canto só é válida para maciço homogeneamente estratificado (TABELA 34).

Usando os mesmos parâmetros de cálculo e sendo o maciço suporte uma continuidade do caso de edifício assimétrico, mostra-se que a solução em tubulão a céu aberto para o caso de edifício simétrico foi mais eficiente do que para edifício assimétrico. Isso se deve à menor tendência de inclinação intrínseca à geometria do pórtico espacial. $\mathrm{O}$ 
maciço suporte é uma continuidade do maciço utilizado para análise do edifício assimétrico (FIGURA 45).

Comparando a solução em tubulões nos casos de edifício assimétrico e simétrico pode-se concluir que a interação é eficiente se o pilar de canto for engastado em vigas contínuas nas duas direções e pertença a linhas de pilares com no mínimo três apoios.

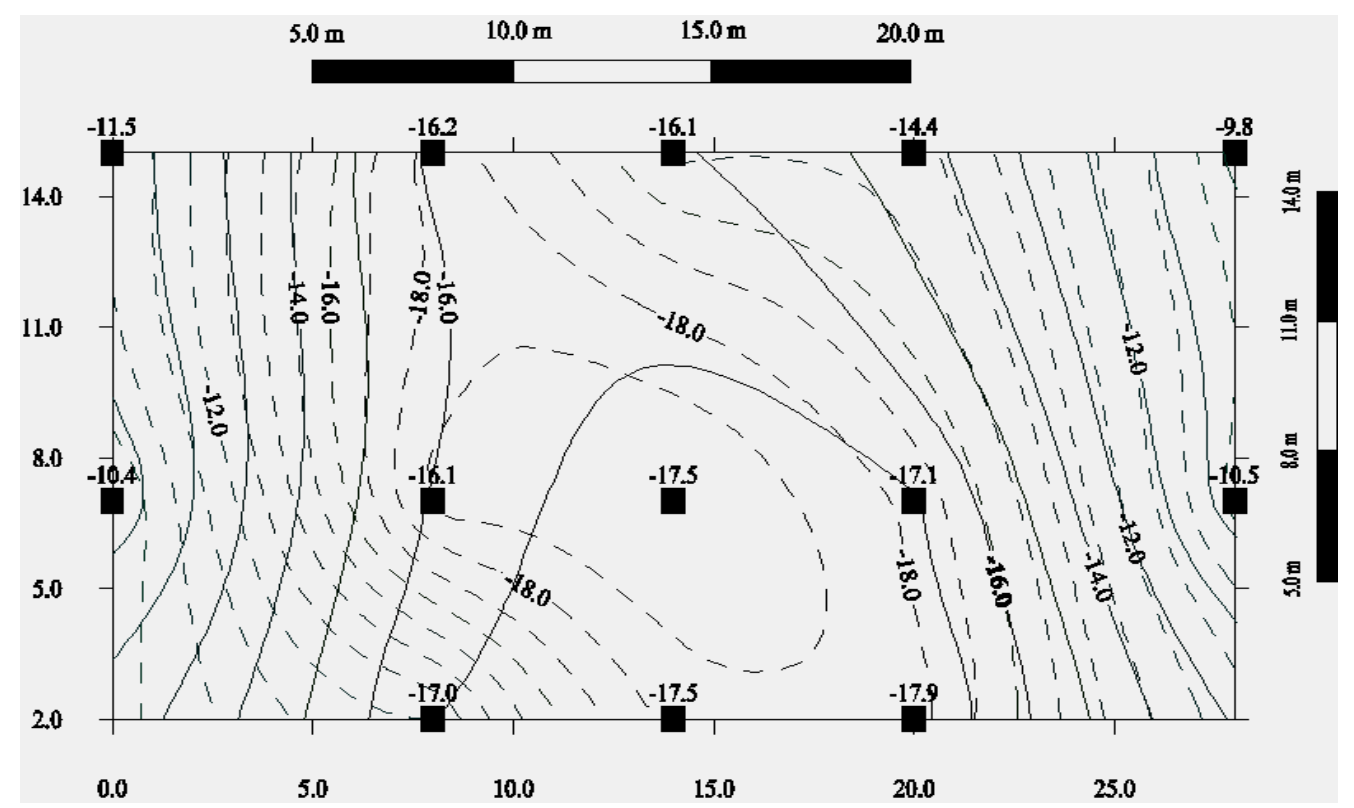

FIGURA 63 - Curvas iso-recalques, em milímetros, para análise convencional (tracejadas) e análise interativa (contínuas) - tubulões a céu aberto - maciço residual - edifício simétrico

O caso de estacas cravadas (TABELA 35) restringe ainda mais a aceitação da regra de que os pilares de canto absorvem cargas dos pilares centrais; isso se deve ao fato que nas camadas mais profundas aumenta-se a heterogeneidade do maciço suporte sedimentar (unidades de fundação 6, 12 e 13). Essa heterogeneidade somada à não-linearidade da transferência de carga e ao comportamento interativo dos elementos da fundação através do maciço, fazem com que a diminuição do coeficiente de segurança em uma unidade de fundação não necessariamente signifique maiores recalques da mesma e vice-versa (unidades de fundação 5 e 10). O comportamento da unidade de fundação 13 mostra que a interação com a superestrutura pode ser muito importante para o caso de deslocamento excessivo de uma unidade de fundação, resultando em transferência de cargas às outras unidades de fundações.

TABELA 35 - Coeficientes de segurança e recalques - estacas cravadas - edifício simétrico

\begin{tabular}{|c|c|c|c|c|}
\hline \multirow{2}{*}{ UF } & \multicolumn{2}{|c|}{$\mathrm{CS}$} & \multicolumn{2}{|c|}{$\mathrm{W}(\mathrm{m})$} \\
\hline & convencional & interado & convencional & interado \\
\hline
\end{tabular}




\begin{tabular}{lllll}
1 & 2,0 & 2,0 & $-2,78 \mathrm{E}-3$ & $-2,83 \mathrm{E}-3$ \\
2 & 1,6 & 1,7 & $-3,99 \mathrm{E}-3$ & $-3,68 \mathrm{E}-3$ \\
3 & 1,6 & 1,6 & $-4,36 \mathrm{E}-3$ & $-4,47 \mathrm{E}-3$ \\
4 & 1,6 & 1,6 & $-5,54 \mathrm{E}-3$ & $-4,67 \mathrm{E}-3$ \\
5 & 1,6 & 1,5 & $-3,25 \mathrm{E}-3$ & $-3,17 \mathrm{E}-3$ \\
6 & 1,6 & 1,7 & $-4,55 \mathrm{E}-3$ & $-4,10 \mathrm{E}-3$ \\
7 & 1,6 & 1,6 & $-4,26 \mathrm{E}-3$ & $-4,22 \mathrm{E}-3$ \\
8 & 1,5 & 1,6 & $-5,37 \mathrm{E}-3$ & $-5,12 \mathrm{E}-3$ \\
9 & 1,6 & 1,5 & $-6,17 \mathrm{E}-3$ & $-7,75 \mathrm{E}-3$ \\
10 & 1,6 & 1,5 & $-4,14 \mathrm{E}-3$ & $-4,00 \mathrm{E}-3$ \\
11 & 1,7 & 1,7 & $-2,63 \mathrm{E}-3$ & $-3,46 \mathrm{E}-3$ \\
12 & 1,7 & 1,4 & $-4,87 \mathrm{E}-3$ & $-6,00 \mathrm{E}-3$ \\
13 & 1,7 & 3,0 & $-1,02 \mathrm{E}-2$ & $-9,24 \mathrm{E}-3$ \\
\hline
\end{tabular}

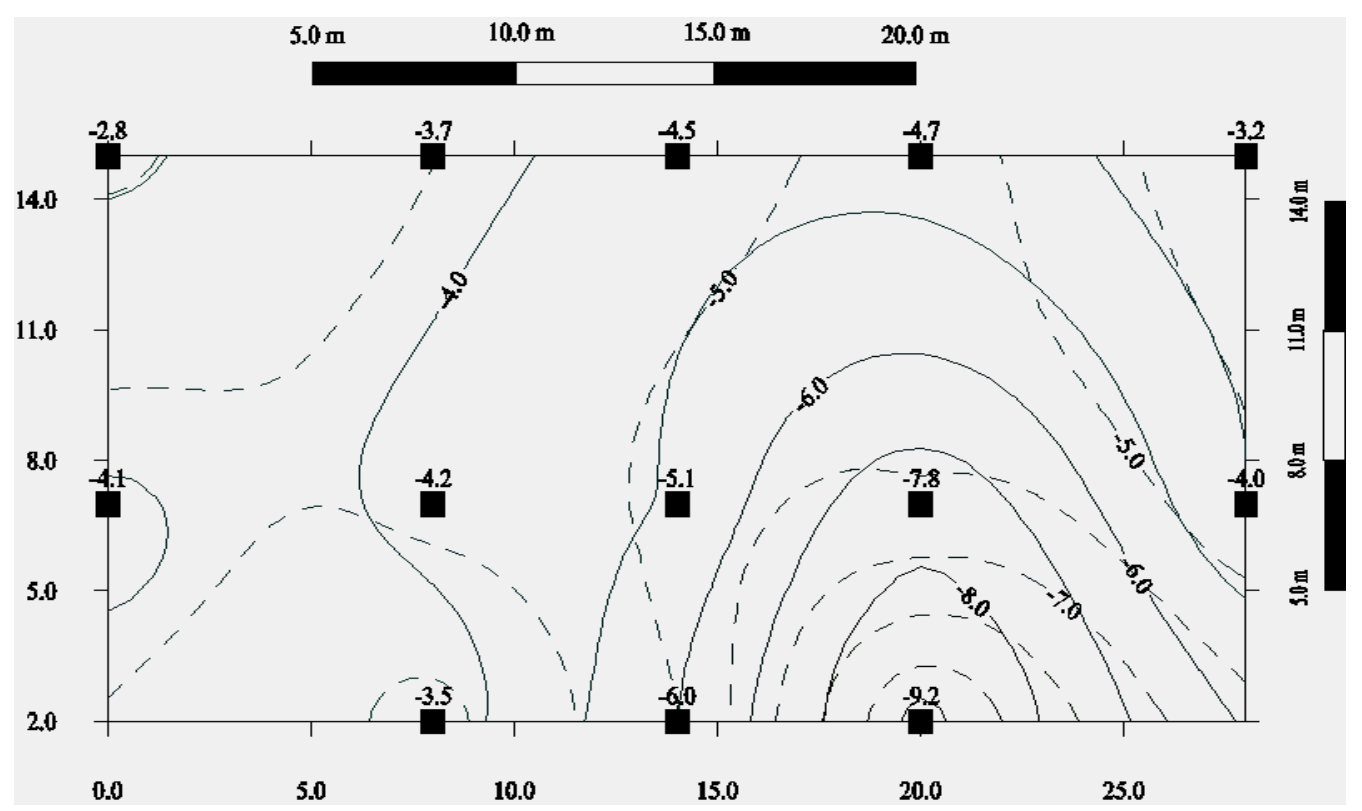

FIGURA 64 - Curvas iso-recalques, em milímetros, para análise convencional (tracejadas) e análise interativa (contínuas) - estacas cravadas - maciço sedimentar - edifício simétrico

Verificando a FIGURA 64 nota-se que a instabilidade local na unidade de fundação 13 foi a principal causa da não conformidade da superfície formadas pelas curvas isorecalques; mostra também que a influência da rigidez da superestrutura minimiza esse efeito. A TABELA 36 mostra que a solução em tubulões teve grande influência da interação com a superestrutura pela minimização de recalques diferenciais, enquanto para a solução em 
estacas esse efeito, no geral, foi inexpressivo. No entanto, para ambos os casos a migração de cargas entre os apoios foi importante.

TABELA 36 - Eficiência da interação com a superestrutura - edifício simétrico

\begin{tabular}{ccccc}
\hline \multirow{2}{*}{ Solução } & \multicolumn{2}{c}{$\mathrm{W}_{\text {médio }}(\mathrm{m})$} & \multicolumn{2}{c}{$\mathrm{W}_{\text {desvio padrão }}(\mathrm{m})$} \\
& convencional & interado & convencional & interado \\
\hline & & & & \\
tubulão a céu aberto & $-1,45 \mathrm{E}-2$ & $-1,48 \mathrm{E}-2$ & $4,58 \mathrm{E}-3$ & $3,08 \mathrm{E}-3$ \\
estaca cravada & $-4,78 \mathrm{E}-3$ & $-4,82 \mathrm{E}-3$ & $1,93 \mathrm{E}-3$ & $1,85 \mathrm{E}-3$ \\
\hline
\end{tabular}

\subsection{EFEITOS DA INUNDAÇÃO DO MACIÇO DE SOLOS RESIDUAL}

A TABELA 37 mostra a variação do comportamento do edifício assimétrico com fundação em sapatas isoladas apoiadas em maciço residual após inundação (elevação permanente do lençol freático), através dos parâmetros: coeficiente de segurança e recalques das unidades de fundação.

TABELA 37 - Comparação dos coeficientes de segurança e recalques obtidos para as condições de maciço residual natural e inundado - sapatas - edifício assimétrico

\begin{tabular}{ccccc}
\hline \multirow{2}{*}{ UF } & \multicolumn{2}{c}{$\mathrm{CS}_{\text {interado }}$} & \multicolumn{2}{c}{$\mathrm{W}_{\text {interado }}(\mathrm{m})$} \\
& normal & inundado & normal & inundado \\
\hline 1 & 2,8 & 2,9 & $-1,50 \mathrm{E}-2$ & $-1,49 \mathrm{E}-2$ \\
2 & 3,3 & 3,1 & $-1,89 \mathrm{E}-2$ & $-2,04 \mathrm{E}-2$ \\
3 & 2,5 & 2,9 & $-1,87 \mathrm{E}-2$ & $-1,70 \mathrm{E}-2$ \\
4 & 2,8 & 2,9 & $-1,43 \mathrm{E}-2$ & $-1,44 \mathrm{E}-2$ \\
5 & 3,5 & 3,2 & $-1,84 \mathrm{E}-2$ & $-2,07 \mathrm{E}-2$ \\
6 & 3,2 & 3,1 & $-1,84 \mathrm{E}-2$ & $-2,01 \mathrm{E}-2$ \\
7 & 2,8 & 3,0 & $-1,75 \mathrm{E}-2$ & $-1,67 \mathrm{E}-2$ \\
8 & 2,8 & 2,9 & $-1,75 \mathrm{E}-2$ & $-1,76 \mathrm{E}-2$ \\
\hline
\end{tabular}

Pela TABELA 37, nota-se a expressiva mudança de comportamento pela variação dos coeficientes de segurança das unidades de fundação nas duas condições estudadas. A 
FIGURA 65 mostra que a inundação interfere significativamente no comportamento da edificação, e isso pode ser visualizado especificamente pela variação do comportamento das quatro unidades de fundação mais carregadas (2, 3, 5 e 6). Na análise com maciço natural, essas unidades de fundação tiveram seus recalques perfeitamente homogeneizados, fato que não aconteceu na análise com elevação permanente do lençol freático. Além disso, ocorre maior tendência de inclinação do pórtico espacial.

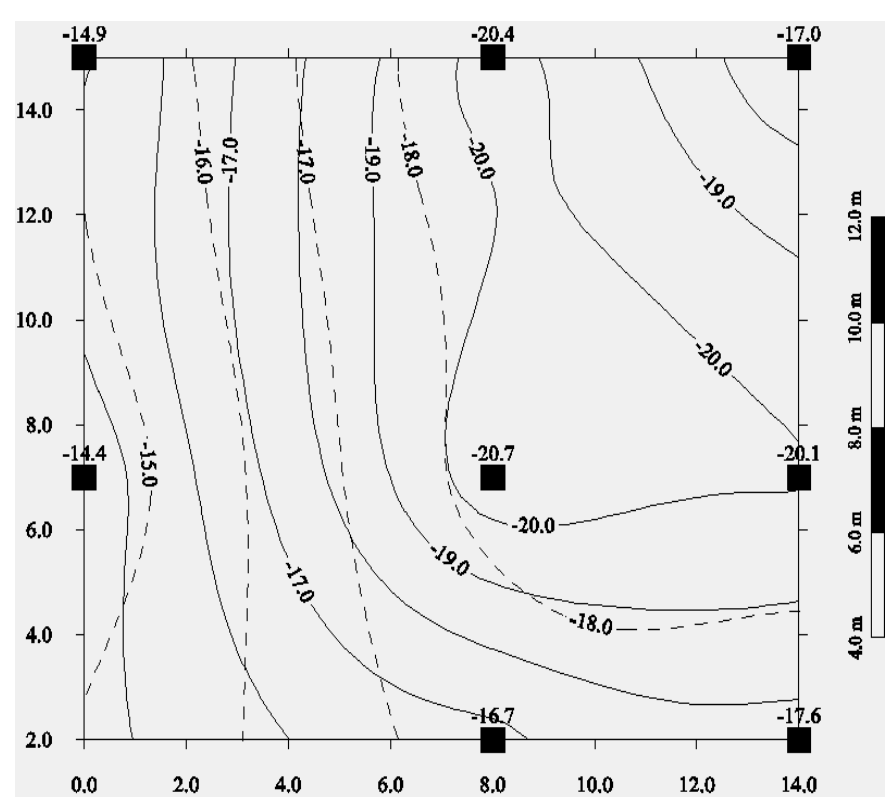

FIGURA 65 - Curvas iso-recalques, em milímetros, para análise interativa em condições naturais (tracejadas) e após inundação permanente (contínuas) - sapatas - maciço residual edifício assimétrico

TABELA 38 - Variação da eficiência da interação com a superestrutura - sapatas - edifício assimétrico - maciço residual (normal x inundado)

\begin{tabular}{ccccc}
\hline \multirow{2}{*}{ Condição } & \multicolumn{2}{c}{$\mathrm{W}_{\text {médio }}(\mathrm{m})$} & \multicolumn{2}{c}{$\mathrm{W}_{\text {desvio padrão }}(\mathrm{m})$} \\
& convencional & interado & convencional & interado \\
\hline normal & $-1,71 \mathrm{E}-2$ & $-1,73 \mathrm{E}-2$ & $2,94 \mathrm{E}-3$ & $1,74 \mathrm{E}-3$ \\
inundado & $-1,76 \mathrm{E}-2$ & $-1,77 \mathrm{E}-2$ & $3,11 \mathrm{E}-3$ & $2,46 \mathrm{E}-3$ \\
\hline
\end{tabular}

A TABELA 38 apresenta uma comparação entre os valores de recalques absolutos e desvios padrão para as análises de comportamento do edifício apoiado em sapatas sobre 
maciço de solos residual na condição natural e inundado. Mostra também que os recalques absolutos crescem juntamente com os recalques diferenciais; além disso, a minimização dos recalques diferenciais, pela influência da rigidez da superestrutura, é sensivelmente menor para a condição de maciço inundado.

TABELA 39 - Comparação dos coeficientes de segurança e recalques obtidos para as condições de maciço residual natural e inundado - tubulões - edifício assimétrico

\begin{tabular}{ccccc}
\hline \multirow{2}{*}{ UF } & \multicolumn{2}{c}{$\mathrm{CS}_{\text {interado }}$} & \multicolumn{2}{c}{$\mathrm{W}_{\text {interado }}(\mathrm{m})$} \\
& normal & inundado & normal & inundado \\
\hline 1 & 2,3 & 2,3 & $-2,92 \mathrm{E}-2$ & $-3,09 \mathrm{E}-2$ \\
2 & 2,4 & 2,5 & $-2,91 \mathrm{E}-2$ & $-3,09 \mathrm{E}-2$ \\
3 & 1,6 & 1,6 & $-2,59 \mathrm{E}-2$ & $-2,81 \mathrm{E}-2$ \\
4 & 1,6 & 1,6 & $-1,76 \mathrm{E}-2$ & $-1,91 \mathrm{E}-2$ \\
5 & 2,2 & 2,1 & $-2,16 \mathrm{E}-2$ & $-2,31 \mathrm{E}-2$ \\
6 & 2,0 & 2,0 & $-1,94 \mathrm{E}-2$ & $-2,06 \mathrm{E}-2$ \\
7 & 1,9 & 1,9 & $-1,79 \mathrm{E}-2$ & $-1,91 \mathrm{E}-2$ \\
8 & 2,5 & 2,5 & $-1,62 \mathrm{E}-2$ & $-1,71 \mathrm{E}-2$ \\
\hline
\end{tabular}

Para o caso de tubulão a céu aberto (TABELA 39), os coeficientes de segurança se mantêm estáveis, o que demonstra que praticamente não há interferência da inundação na redistribuição das cargas entre os apoios. A FIGURA 66 mostra que as curvas iso-recalques mantêm a mesma conformidade, e que não houve um aumento na deflexão relativa máxima, ou seja, não houve aumento da inclinação do pórtico relativamente à analise procedida com maciço suporte em condições naturais. A TABELA 40 mostra que há relativamente pouca influência no comportamento pela inundação do subsolo (elevação permanente do lençol freático), restringindo-se apenas ao acréscimo dos recalques absolutos dos apoios e proporcionalmente o desvio padrão desses valores.

O perfil geotécnico utilizado para analisar a influência da elevação do nível d'água não representa as piores condições encontradas no plano piloto de Palmas - TO, por isso esta análise é apenas qualitativa e objetiva veicular a importância do assunto. De acordo com o modelo básico (default) do MGDE, a elevação do lençol decresce em apenas $10 \%$ a rigidez da camada suporte imergida (veja item 4.2.2.1), por isso a influência é relativamente pequena. 


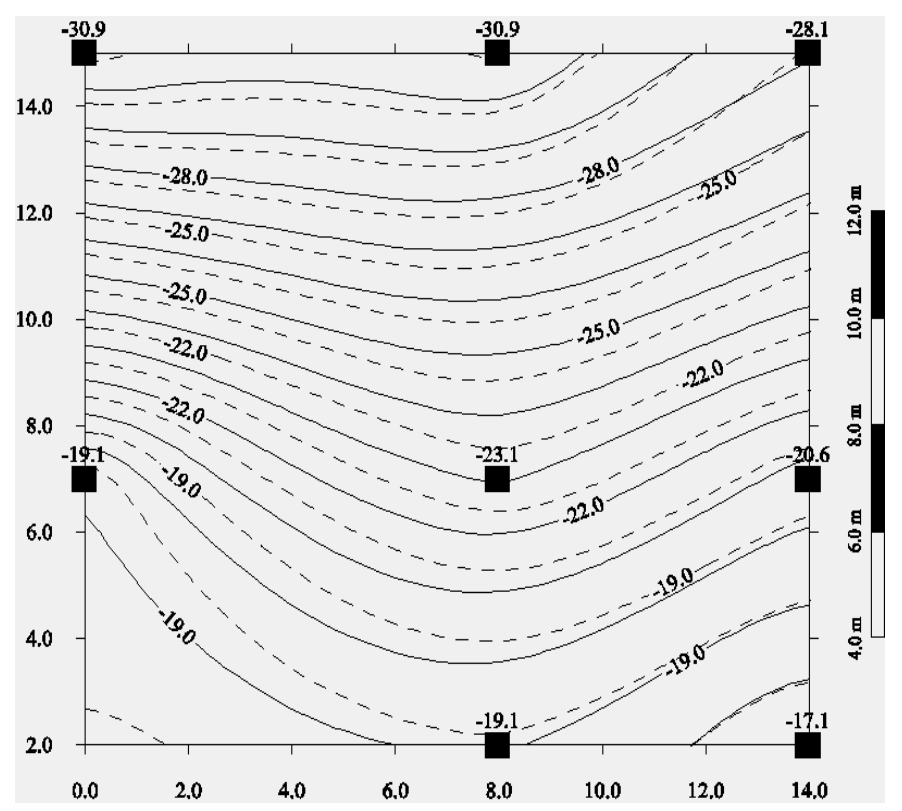

FIGURA 66 - Curvas iso-recalques, em milímetros, para análise interativa em condições naturais (tracejadas) e após inundação permanente (contínuas) - tubulões - maciço residual edifício assimétrico

TABELA 40 - Variação da eficiência da interação com a superestrutura - tubulões - edifício assimétrico - maciço residual (normal x inundado)

\begin{tabular}{ccccc}
\hline \multirow{2}{*}{ Condição } & \multicolumn{2}{c}{$\mathrm{W}_{\text {médio }}(\mathrm{m})$} & \multicolumn{2}{c}{$\mathrm{W}_{\text {desvio padrão }}(\mathrm{m})$} \\
& convencional & interado & convencional & interado \\
\hline normal & $-2,26 \mathrm{E}-2$ & $-2,21 \mathrm{E}-2$ & $8,69 \mathrm{E}-3$ & $5,27 \mathrm{E}-3$ \\
inundado & $-2,42 \mathrm{E}-2$ & $-2,36 \mathrm{E}-2$ & $9,41 \mathrm{E}-3$ & $5,59 \mathrm{E}-3$ \\
\hline
\end{tabular}

Qualitativamente, conclui-se que a solução em sapatas é mais suscetível a um comportamento inadequado que provoque danos à utilização da edificação que a solução em tubulões. Desde que a cota de apoio alcance camadas de rigidez suficiente para o comportamento adequado da edificação, a solução em tubulões é a mais indicada. Como foi sugerido no item 6.2, a solução em tubulão deve ter sua cota de apoio alterada para 81,0 por imposição do comportamento do pórtico, o que minimizaria ainda mais os efeitos da inundação do maciço suporte. 


\section{CONSIDERAÇÕES FINAIS}

A maioria dos trabalhos que analisaram aspectos da interação estrutura - maciço de solos modelam o maciço de solos como homogêneo, isotrópico e semi-infinito; poucos consideram estratificação. $\mathrm{O}$ trabalho apresentado considera a variabilidade tridimensional, pois modela o maciço de solos através de extrapolação espacial dos parâmetros pontuais definidos por ensaios SPT, e admite um horizonte indeslocável. A variabilidade do maciço se deve à origem natural dos materiais e a principal dificuldade reside na modelagem da forma do elemento de solo e na sua distribuição caótica (AOKI (1997)). Por elemento de solo entende-se o corpo tridimensional com forma de contorno indistinto e volume variável, formado por material heterogêneo de mesma granulometria e composição minerológica (AOKI \& CINTRA (1996)). O modelo de transferência de carga considera a não linearidade do material de modo indireto: a reação do solo é variável ao longo do fuste e base em função do nível de carregamento, e este é limitado pela plastificação do maciço envolvente, ou seja, pela resistência lateral última.

A ferramenta de cálculo desenvolvida pode contribuir com a engenharia de estruturas oferecendo subsídios à análise estrutural, e com a engenharia geotécnica oferecendo a verificação do comportamento das estruturas de fundação projetadas. O modelo possibilita a análise de recalques e de coeficientes de segurança à ruptura para cada apoio, levando em conta a variabilidade do maciço suporte e a rigidez da superestrutura. Além disso, o StructsoiL oferece um módulo de retaguarda que, à medida que for sendo utilizado, pode ser incrementado, transformando-se em um proveitoso banco de dados de conhecimento. O mais expressivo é que esses benefícios são obtidos sem custos adicionais, já que os dados do solo são coletados a partir de sondagens SPT e mapeamento geotécnico, se houver, e a análise estrutural é precedida pela utilização de qualquer software conceituado pela engenharia de estruturas.

Visualiza-se a perspectiva de produzir uma solução computacional que modele o sistema superestrutura - estrutura de fundação - maciço de solos de forma que se obtenha resposta a eventos (esforços ou deslocamentos) aplicados em um ponto do sistema, em 
outros pontos quaisquer do mesmo sistema. Por exemplo, o efeito do recalque de um apoio em uma determinada viga do pórtico, ou o efeito de um carregamento específico em um elemento da superestrutura no deslocamento de elementos da estrutura de fundação e de pontos do maciço suporte.

Os resultados obtidos confirmam as observações contidas na literatura especializada sobre os efeitos da interação estrutura-maciço de solos no comportamento estrutural, como:

- homogeneização dos recalques de apoio;

- redistribuição de cargas nos apoios através do pórtico e;

- o pórtico espacial tende a se comportar como um bloco rígido.

Mas os resultados mostram, também, que a regra publicada afirmando que um dos efeitos da interação estrutura - maciço de solos é a migração das cargas dos pilares centrais para os pilares de contorno e principalmente para os de canto, só é válida para o caso de maciço homogêneo horizontalmente, com estrutura de fundação apoiada na mesma cota e dimensionada para o mesmo coeficiente de segurança. Para os demais casos, pode ser observado um comportamento interativo inverso entre os apoios, havendo transferência de carga de apoios de extremidade para os apoios de centro de uma linha de pilares pertencente ao pórtico espacial.

A análise estrutural pode ser implementada através de procedimento que represente o acréscimo de rigidez e cargas em função do processo construtivo lento e a redução da rigidez dos engastes pela consideração dos efeitos da fissuração do concreto e da plastificação do aço para reduzir a rigidez do pórtico. A adoção de procedimento incremental e engastes parcialmente rígidos pode conduzir a níveis de rigidez estrutural mais realísticos. Isso faria com que os resultados obtidos pela análise da interação estrutura - maciço de solos em edifícios tivessem maior credibilidade.

Com relação ao comportamento dos solos, é conclusiva a necessidade de estudos mais criteriosos, mesmo para ensaios de uso comum como o SPT e provas de carga. Outra carência é o número ínfimo de edificações monitoradas que possam servir de subsídios para o estudo da interação estrutura - maciço de solos. Sem o avanço desses pontos fíca difícil aplicar, com segurança, técnicas de análise da interação estrutura - maciço de solos. $\mathrm{O}$ trabalho também define utilidade prática dos dados obtidos por provas de cargas de elementos de fundação profunda instrumentados ao longo do fuste e da base e de mapeamento geotécnico em escalas maiores, no âmbito da engenharia de fundações. 


\section{ANEXO I}

\section{Projeto de tabelas do software StructsoiL 1.0}

\section{TABELAS DA RETAGUARDA}

TABELA Empresa

\begin{tabular}{|l|l|l|c|c|c|}
\hline ITEM & CAMPO & DESCRIÇÃO GERAL & TIPO DE DADO & TAMANHO & EDIÇÃO \\
\hline 01 & Nome & Nome de fantasia & Caracter & 50 & Alfabéticos (a-z), (A-Z) \\
\hline 02 & Rsocial & Denominação da razão social & Caracter & 60 & Alfabéticos (a-z), (A-Z) \\
\hline 03 & Endereco & Endereço & Caracter & 100 & Alfabéticos (a-z), (A-Z) \\
\hline 04 & Cidade & Cidade & Caracter & 40 & Alfabéticos (a-z), (A-Z) \\
\hline 05 & UF & Unidade da federação & Caracter & 2 & Alfabéticos (a-z), (A-Z) \\
\hline 06 & Fone_fax & Telefone/fax de contato & Caracter & 20 & Dígitos (0-9) \\
\hline 07 & InscMun & Inscrição Municipal & Caracter & 20 & Dígitos (0-9) \\
\hline 08 & InscEst & Inscrição Estadual & Caracter & 20 & Dígitos (0-9) \\
\hline 09 & CNPJ & Cadastro Nacional de Pessoa Jurídica & & Dígitos (0-9) \\
\hline
\end{tabular}

TABELA Usuário

\begin{tabular}{|l|l|l|c|c|c|}
\hline ITEM & CAMPO & DESCRIÇÃO GERAL & TIPO DE DADO & TAMANHO & EDIÇÃO \\
\hline 01 & Nome & Nome do usuário cadastrado & Caracter & 30 & Alfabéticos (a-z), (A-Z) \\
\hline 02 & Senha & Senha de acesso & Caracter & 10 & Alfabéticos (a-z), (A-Z) \\
\hline 03 & SeUsuário & Tipo de usuário & Caracter & 1 & Dígitos (0-9) \\
\hline
\end{tabular}

TABela Tipo Fundação

\begin{tabular}{|l|l|l|c|c|c|}
\hline ITEM & CAMPO & DESCRIÇÃO GERAL & TIPO DE DADO & TAMANHO & EDIÇÃO \\
\hline 01 & Cod_TF & Código de identificação dos tipos de fundação & Inteiro & 2 & Dígitos (0-9) \\
\hline 02 & Nome & Tipo de fundaçao (superficial ou profunda) & Caracter & 12 & Alfabéticos (a-z), (A-Z) \\
\hline
\end{tabular}

TABELA Fundação

\begin{tabular}{|l|l|l|c|c|c|}
\hline ITEM & CAMPO & DESCRIÇÃO GERAL & TIPO DE DADO & TAMANHO & EDIÇÃO \\
\hline 01 & Cod_F & Código de identificação da técnica de fundação & Inteiro & 2 & Dígitos (0-9) \\
\hline 02 & Cod_TF & Código de identificação do tipo de fundação & Inteiro & 2 & Dígitos (0-9) \\
\hline 03 & ModoInst & Modo de instalação (escavação ou deslocamento) & Caracter & 15 & Alfabéticos (a-z), (A-Z) \\
\hline 04 & Descricao & $\begin{array}{l}\text { Descrição da técnica de execução da estrutura de } \\
\text { fundação }\end{array}$ & Caracter & 50 & Alfabéticos (a-z), (A-Z) \\
\hline 05 & Gfuste & Forma geométrica do fuste (circular/prismático) & Caracter & 20 & Alfabéticos (a-z), (A-Z) \\
\hline 06 & Fponta & Forma geométrica da ponta (simples, alargada e bulbo) & Caracter & 15 & Alfabéticos (a-z), (A-Z) \\
\hline 07 & FRRPonta & Fator de redução da resistência da ponta & Numérico & 3 & Dígitos (0-9). \\
\hline 08 & FRRLateral & Fator de redução da resistência lateral & Numérico & 3 & Dígitos (0-9) \\
\hline
\end{tabular}

TABEla Material de Construção

\begin{tabular}{|l|l|l|c|c|c|}
\hline ITEM & CAMPO & DESCRIÇÃO GERAL & TIPO DE DADO & TAMANHO & EDIÇÃO \\
\hline 01 & Cod_MCons & Código do material de construção & Inteiro & 2 & Dígitos (0-9) \\
\hline 02 & Descricao & Material de construção (concreto, aço, etc) & Caracter & 20 & Alfabéticos (a-z), (A-Z) \\
\hline 03 & Poisson & Coeficiente de Poisson & Numérico & 3 & Dígitos (0-9) \\
\hline 04 & Young & Módulo de Young & Numérico & 6 & Dígitos (0-9) \\
\hline
\end{tabular}


TABELA MTC Geral

\begin{tabular}{|l|l|l|c|c|c|}
\hline ITEM & CAMPO & DESCRIÇÃO GERAL & TIPO DE DADO & TAMANHO & EDIÇ̃̃O \\
\hline 01 & Cod_MTC & $\begin{array}{l}\text { Código de identificação do modelo de transferência de } \\
\text { carga }\end{array}$ & Inteiro & 2 & Dígitos (0-9) \\
\hline 02 & Descricao & Descrição do modelo de transferência de carga & Caracter & 50 & Alfabéticos (a-Z), (A-Z) \\
\hline 03 & CS & $\begin{array}{l}\text { Coeficiente de segurança adotado para a carga total em } \\
\text { serviço }\end{array}$ & Numérico & 3 & Dígitos (0-9) \\
\hline 04 & PTPonta & Percentual de transferência máxima pela ponta & Numérico & 3 & Dígitos (0-9) \\
\hline 05 & Ntrecho & $\begin{array}{l}\text { Número de trechos do fuste com diferente percentual de } \\
\text { transferência máxima de carga ao maciço }\end{array}$ & Inteiro & 1 & Dígitos (0-9) \\
\hline 06 & Tipo & $\begin{array}{l}\text { Tipo de transferência (uniforme, seqüencial completa e } \\
\text { parcial para fuste e base) }\end{array}$ & Caracter & 20 & Alfabéticos (a-z), (A-Z) \\
\hline
\end{tabular}

\section{TABELA MTC Local}

\begin{tabular}{|l|l|l|c|c|c|}
\hline ITEM & CAMPO & DESCRIÇÃO GERAL & TIPO DE DADO & TAMANHO & EDIÇÃO \\
\hline 01 & Cod_MTC & $\begin{array}{l}\text { Código de identificação do modelo de transferência de } \\
\text { carga }\end{array}$ & Inteiro & 2 & Dígitos (0-9) \\
\hline 02 & Cod_Trecho & Código do trecho & Inteiro & 2 & Dígitos (0-9) \\
\hline 03 & PTFuste & $\begin{array}{l}\text { Percentual de transferência máxima de carga ao maciço } \\
\text { de solos pelo trecho do fuste }\end{array}$ & Numérico & 3 & Dígitos (0-9) \\
\hline
\end{tabular}

\section{TABELA MGR}

\begin{tabular}{|l|l|l|c|c|c|}
\hline ITEM & CAMPO & DESCRIÇÃO GERAL & TIPO DE DADO & TAMANHO & EDIÇ̃̃O \\
\hline 01 & Cod_MGR & Código de identificação do MGR & Inteiro & 3 & Dígitos (0-9) \\
\hline 02 & Cod_CGran & $\begin{array}{l}\text { Código de identificação da tabela de classificação } \\
\text { granulométrica }\end{array}$ & Caracter & 25 & Alfabéticos (a-z), (A-Z) \\
\hline 03 & Cod_CnCmp & $\begin{array}{l}\text { Código de identificação de Consistência ou } \\
\text { Compacidade }\end{array}$ & Caracter & 25 & Alfabéticos (a-z), (A-Z) \\
\hline 04 & Ninf & $\mathrm{N}_{\mathrm{SPT}}-$ limite inferior de intervalo & Inteiro & 2 & Dígitos (0-9) \\
\hline 05 & Nsup & $\mathrm{N}_{\mathrm{SPT}}-$ limite superior de intervalo & Inteiro & 2 & Dígitos (0-9) \\
\hline 06 & FatorK & Fator K de correlação SPT/CPT & Numérico & 3 & Dígitos (0-9) \\
\hline 07 & FatorAlfa & Fator $\alpha$ de correlação SPT/CPT & Numérico & 4 & Dígitos $(0-9)$ \\
\hline 08 & Codigo & Código de classificação granulométrica & Inteiro & 3 & Dígitos (0-3) \\
\hline
\end{tabular}

TABELA MGDE

\begin{tabular}{|l|l|l|c|c|c|}
\hline ITEM & CAMPO & DESCRIÇÃO GERAL & TIPO DE DADO & TAMANHO & EDIÇ̃̃O \\
\hline 01 & Cod_MGDE & Código de identificação do MGDE & Inteiro & 2 & Dígitos (0-9) \\
\hline 02 & Cod_Rocha & Código da classificação da rocha de origem & Inteiro & 2 & Dígitos (0-9) \\
\hline 03 & Cod_GSolo & $\begin{array}{l}\text { Código do tipo de gênese (residual, sedimentar, } \\
\text { orgânica) }\end{array}$ & Inteiro & 2 & Dígitos (0-9) \\
\hline 04 & Cod_CE & $\begin{array}{l}\text { Código da característica especial da camada (laterítica, } \\
\text { saprolítica, colapsível) }\end{array}$ & Inteiro & 2 & Dígitos (0-9) \\
\hline 05 & Cod_CGran & Código da classificação granulométrica & Inteiro & 2 & Dígitos (0-9) \\
\hline 06 & Cod_Fgeol & Código da formação geológica & Inteiro & 2 & Dígitos (0-9) \\
\hline 07 & CondSat & Condição de saturação (saturada / não saturada) & Caracter & 15 & Alfabéticos (a-z) \\
\hline 08 & C & Fator C de correlação Módulo de Young/SPT & Numérico & 3 & Dígitos (0-9) \\
\hline 09 & Poisson & Coeficiente de Poisson & Numérico & 3 & Dígitos (0-9) \\
\hline
\end{tabular}

TABELA MCSC Coesivo

\begin{tabular}{|l|l|l|c|c|c|}
\hline ITEM & CAMPO & DESCRIÇ̃̃O GERAL & TIPO DE DADO & TAMANHO & EDIÇ̃̃O \\
\hline 01 & Cod_ACSC & $\begin{array}{l}\text { Código de identificação da aterro complementar em solo } \\
\text { coesivo }\end{array}$ & Inteiro & 2 & Dígitos (0-9) \\
\hline 02 & Cod_Textura & Código da textura do solo & Inteiro & 2 & Dígitos (0-9) \\
\hline 03 & Cod_CnCmp & Código da consistência ou compacidade & Inteiro & 2 & Dígitos (0-9) \\
\hline 04 & Cod_CGran & Código da classificação granulométrica & Inteiro & 2 & Dígitos (0-9) \\
\hline 05 & PespInf & Limite inferior do intervalo de peso específico & Numérico & 4 & Dígitos (0-9) \\
\hline 06 & PespSup & Limite superior do intervalo de peso específico & Numérico & 4 & Dígitos (0-9) \\
\hline 07 & DRInf & Limite inferior do intervalo de densidade relativa & Numérico & 4 & Dígitos (0-9) \\
\hline 08 & DRSup & Limite superior do intervalo de densidade relativa & Numérico & 4 & Dígitos (0-9) \\
\hline 09 & CoesãoInf & Limite inferior do intervalo de coesão & Numérico & 4 & Dígitos $(0-9)$ \\
\hline 10 & CoesãoSup & Limite superior do intervalo de coesão & Numérico & 4 & Dígitos $(0-9)$ \\
\hline 11 & NSPTequiv & Número de golpes SPT equivalente & Inteiro & 3 & Dígitos (0-9) \\
\hline
\end{tabular}

TABELA MCSC Granular

\begin{tabular}{|l|l|l|c|c|c|}
\hline ITEM & CAMPO & DESCRIÇÃO GERAL & TIPO DE DADO & TAMANHO & EDIÇÃO \\
\hline 01 & Cod_ACSG & $\begin{array}{l}\text { Código de identificação da aterro complementar em solo } \\
\text { granular }\end{array}$ & Inteiro & 2 & Dígitos (0-9) \\
\hline 02 & Cod_Textura & Código da textura do solo & Inteiro & 2 & Dígitos (0-9) \\
\hline
\end{tabular}


TABELA MCSC GRanular (cont.)

\begin{tabular}{|l|l|l|c|c|c|}
\hline ITEM & CAMPO & DESCRIÇÃO GERAL & TIPO DE DADO & TAMANHO & EDIÇÃO \\
\hline 03 & Cod_CnCmp & Código doda Consistência/Compacidade & Inteiro & 2 & Dígitos (0-9) \\
\hline 04 & Cod_CGran & Código da classificação granulométrica & Inteiro & 2 & Dígitos (0-9) \\
\hline 05 & PespInf & Limite inferior do intervalo de peso específico & Numérico & 4 & Dígitos (0-9) \\
\hline 06 & PespSup & Limite superior do intervalo de peso específico & Numérico & 4 & Dígitos (0-9) \\
\hline 07 & DRInf & Limite inferior do intervalo de densidade relativa & Numérico & 4 & Dígitos (0-9) \\
\hline 08 & DRSup & Limite superior do intervalo de densidade relativa & Numérico & 4 & Dígitos (0-9) \\
\hline 09 & AatritoInf & Limite inferior do intervalo de angulo de atrito & Numérico & 4 & Dígitos (0-9) \\
\hline 10 & AatritoSup & Limite superior do intervalo de angulo de atrito & Numérico & 4 & Dígitos (0-9) \\
\hline 11 & NSPTequiv & Número de golpes SPT equivalente & Inteiro & 3 & Dígitos (0-9) \\
\hline
\end{tabular}

TABELA Característica Especial

\begin{tabular}{|l|l|l|c|c|c|}
\hline ITEM & CAMPO & DESCRIÇÃO GERAL & TIPO DE DADO & TAMANHO & EDIÇÃO \\
\hline 01 & Cod_CE & $\begin{array}{l}\text { Código de identificação da característica especial do } \\
\text { maciço }\end{array}$ & Inteiro & 2 \\
\hline 02 & Descricao & $\begin{array}{l}\text { Denominação da característica especial (laterítica, } \\
\text { saprolítica, colapsível, etc.) }\end{array}$ & Caracter & 15 & Alfabéticos (a-z), (A-Z) \\
\hline
\end{tabular}

TABELA Classificação Granulométrica

\begin{tabular}{|l|l|l|c|c|c|}
\hline ITEM & CAMPO & DESCRIÇÃO GERAL & TIPO DE DADO & TAMANHO & EDIÇÃO \\
\hline 01 & Cod_CGran & Código de identificação da classificação granulométrica & Inteiro & 2 & Dígitos (0-9) \\
\hline 02 & Descricao & Descrição da classificação granulométrica & Caracter & 30 & Alfabéticos (a-z), (A-Z) \\
\hline 03 & Código & $\begin{array}{l}\text { Código de entrada de dados da classificação } \\
\text { granulométrica }\end{array}$ & Caracter & 3 & Dígitos (0-9) \\
\hline
\end{tabular}

TABEla Consistência/Compacidade

\begin{tabular}{|l|l|l|c|c|c|}
\hline ITEM & CAMPO & DESCRIÇÃO GERAL & TIPO DE DADO & TAMANHO & EDIÇÃO \\
\hline 01 & Cod_CnCmp & $\begin{array}{l}\text { Código de identificação da Consistência ou } \\
\text { Compacidade }\end{array}$ & Inteiro & 2 & Dígitos (0-9) \\
\hline 02 & Descricao & Denominação da Consistência ou Compacidade & Caracter & 15 & Alfabéticos (a-z), (A-Z) \\
\hline
\end{tabular}

TABEla Rocha Mãe

\begin{tabular}{|l|l|l|c|c|c|}
\hline ITEM & CAMPO & DESCRIÇÃO GERAL & TIPO DE DADO & TAMANHO & EDIÇÃO \\
\hline 01 & Cod_Rocha & Código de identificação da rocha mãe & Inteiro & 2 & Dígitos (0-9) \\
\hline 02 & Descricao & $\begin{array}{l}\text { Denominação da rocha mãe (gnaisse, basalto, granito, } \\
\text { arenito) }\end{array}$ & Caracter & 15 & Alfabéticos (a-z), (A-Z) \\
\hline
\end{tabular}

\section{TABELA Textura}

\begin{tabular}{|l|l|l|c|c|c|}
\hline ITEM & CAMPO & DESCRIÇÃO GERAL & TIPO DE DADO & TAMANHO & EDIÇÃO \\
\hline 01 & Cod_Textura & Código de identificação da textura do solo de aterro & Inteiro & 2 & Dígitos (0-9) \\
\hline 02 & Descrição & Descrição da textura (fina, média, grossa, etc.) & Caracter & 15 & Alfabéticos (a-z), (A-Z) \\
\hline
\end{tabular}

\section{TABELA Formação Geológica}

\begin{tabular}{|l|l|l|c|c|c|}
\hline ITEM & CAMPO & DESCRIÇÃO GERAL & TIPO DE DADO & TAMANHO & EDIÇÃO \\
\hline 01 & Cod_Fgeol & Código de identificação da textura do solo de aterro & Inteiro & 2 & Dígitos (0-9) \\
\hline 02 & Descricao & Descrição da textura (fina, média, grossa, etc.) & Caracter & 15 & Alfabéticos (a-z), (A-Z) \\
\hline
\end{tabular}

\section{TABEla Gênese do Solo}

\begin{tabular}{|l|l|l|c|c|c|}
\hline ITEM & CAMPO & DESCRIÇÃO GERAL & TIPO DE DADO & TAMANHO & EDIÇÃO \\
\hline 01 & Cod_Gsolo & Código de identificação da gênese do solo & Inteiro & 2 & Dígitos (0-9) \\
\hline 02 & Descricao & $\begin{array}{l}\text { Descrição da gênese (residual, sedimentar, orgânica e } \\
\text { aterro) }\end{array}$ & Caracter & 15 & Alfabéticos (a-z), (A-Z) \\
\hline
\end{tabular}


Tabelas do Principal

TABELA Obra

\begin{tabular}{|l|l|l|c|c|c|}
\hline ITEM & CAMPO & DESCRIÇÃO GERAL & TIPO DE DADO & TAMANHO & EDIÇÃO \\
\hline 01 & Cod_Obra & Código de identificação da obra & Inteiro & 4 & Dígitos (0-9) \\
\hline 02 & Nome & Denominação do empreendimento & Caracter & 30 & Alfabéticos (a-z), (A-Z) \\
\hline 03 & Propr & Nome do proprietário, incorporador & Caracter & 30 & Alfabéticos (a-z), (A-Z) \\
\hline 04 & Data & Data de cadastro & Caracter & & Dígitos (0-9) \\
\hline 05 & Obs & Observações pertinentes sobre a obra & Caracter & 200 & Qualquer caracter \\
\hline
\end{tabular}

TABELA Superestrutura

\begin{tabular}{|l|l|l|c|c|c|}
\hline ITEM & CAMPO & DESCRIÇÃO GERAL & TIPO DE DADO & TAMANHO & EDIÇÃO \\
\hline 01 & Cod_Obra & Código de identificação da obra & Inteiro & 3 & Dígitos (0-9) \\
\hline 02 & Cod_SE & $\begin{array}{l}\text { Código de identificação da superestrutura (apenas para } \\
\text { manter a hierarquia das tabelas) }\end{array}$ & Inteiro & 3 & Dígitos (0-9) \\
\hline 03 & Cod_MCons & Código do material de construção (concreto, aço, etc.) & Inteiro & 2 & Alfabético (a-z), (A-Z) \\
\hline 04 & ProcConst & Processo construtivo (pré-moldados, moldado in loco,...) & Caracter & 20 & Alfabético (a-z), (A-Z) \\
\hline 05 & NRApoio & Nível de referência dos apoios & Numérico & 7 & Dígitos (0-9) \\
\hline 06 & SAE & Software de análise estrutural & Caracter & 15 & Alfabético (a-z), (A-Z) \\
\hline 07 & ProjEst & Projetista da superestrutura & Caracter & 30 & Alfabético (a-z), (A-Z) \\
\hline
\end{tabular}

TABELA Locação

\begin{tabular}{|l|l|l|c|c|c|}
\hline ITEM & CAMPO & DESCRIÇÃO GERAL & TIPO DE DADO & TAMANHO & EDIÇÃO \\
\hline 01 & Cod_SE & Código de identificação da superestrutura & Inteiro & 3 & Dígitos (0-9) \\
\hline 02 & Cod_Pilar & Código do apoio & Caracter & 7 & Dígitos (0-9) \\
\hline 03 & Pilar & Identificação do pilar & Numérico & 7 & Alfabético (a-z), (A-Z) \\
\hline 04 & PosicaoX & Coordenadas do centro da peça em relação ao eixo X & Numérico & 7 & Dígitos (0-9) \\
\hline 05 & PosicaoY & Coordenadas do centro da peça em relação ao eixo Y & Dígitos (0-9) \\
\hline 06 & PosicaoZ & Coordenadas do centro da peça em relação ao eixo Z & Numérico & 7 & Dígitos (0-9) \\
\hline 07 & DimensaoX & $\begin{array}{l}\text { Dimensão no sentido do eixo principal com menor } \\
\text { rotação em relação à Y }\end{array}$ & Numérico & 7 & Dígitos (0-9) \\
\hline 08 & DimensaoY & $\begin{array}{l}\text { Dimensão no sentido do eixo principal com menor } \\
\text { rotação em relação à Y }\end{array}$ & Numérico & 7 & Dígitos (0-9) \\
\hline 09 & Angulo & $\begin{array}{l}\text { Menor rotação horária de um dos eixos principais em } \\
\text { relação ao eixo X }\end{array}$ & Numérico & 5 & \multicolumn{2}{|c|}{} \\
\hline
\end{tabular}

TABEla Cargas

\begin{tabular}{|c|c|c|c|c|c|}
\hline ITEM & CAMPO & DESCRIÇÃO GERAL & TIPO DE DADO & TAMANHO & EDIÇÃO \\
\hline 01 & Cod_SE & Código de identificação da superestrutura & Inteiro & 3 & Dígitos (0-9) \\
\hline 02 & Cod_UF & Código do apoio influenciado & Inteiro & 3 & Dígitos (0-9) \\
\hline 03 & $\mathrm{HX}$ & Carga horizontal na direção $\mathrm{X}$ & Numérico & 7 & Dígitos (0-9) \\
\hline 04 & HY & Carga horizontal na direção Y & Numérico & 7 & Dígitos (0-9) \\
\hline 05 & $\mathrm{~V}$ & Carga vertical & Numérico & 7 & Dígitos (0-9) \\
\hline 06 & VAux $^{*}$ & Carga vertical auxiliar, correspondente à última interação & Numérico & 7 & Dígitos (0-9) \\
\hline 07 & VAux2 $^{*}$ & Carga vertical auxiliar, correspondente à interação anterior & Numérico & 7 & Dígitos (0-9) \\
\hline 08 & VAux3 $^{*}$ & Carga vertical auxiliar, correspondente à interação anterior & Numérico & 7 & Dígitos (0-9) \\
\hline 09 & VAux $4^{*}$ & Carga vertical auxiliar, correspondente à interação anterior & Numérico & 7 & Dígitos (0-9) \\
\hline 10 & VAux $5^{*}$ & Carga vertical auxiliar, correspondente à interação anterior & Numérico & 7 & Dígitos (0-9) \\
\hline 11 & VAux6 ${ }^{*}$ & Carga vertical auxiliar, correspondente à interação anterior & Numérico & 7 & Dígitos (0-9) \\
\hline 12 & MX & Momento em torno do eixo $\mathrm{X}$ & Numérico & 7 & Dígitos (0-9) \\
\hline 13 & MY & Momento em torno do eixo Y & Numérico & 7 & Dígitos (0-9) \\
\hline 14 & $\mathrm{~T}$ & Momento em torno do eixo $\mathrm{Z}$ & Numérico & 7 & Dígitos (0-9) \\
\hline 15 & $\mathrm{~W}$ & Recalque de apoio & Numérico & 7 & Dígitos (0-9) \\
\hline 16 & WAux & Recalque correspondente à interação anterior & Numérico & 7 & Dígitos (0-9) \\
\hline
\end{tabular}

TABELA MRS

\begin{tabular}{|l|l|l|c|c|c|}
\hline ITEM & CAMPO & DESCRIÇÃO GERAL & TIPO DE DADO & TAMANHO & EDIÇÃO \\
\hline 01 & Cod_SE & Código de identificação da superestrutura & Inteiro & 3 & Dígitos (0-9) \\
\hline 02 & Cod_UF & Código do apoio influenciado & Inteiro & 3 & Dígitos (0-9) \\
\hline 03 & Cod_UFD & Código do apoio deslocado verticalmente da unidade & Inteiro & 3 & Dígitos (0-9) \\
\hline 04 & fHX & Fator de carga horizontal na direção X & Numérico & 7 & Dígitos (0-9) \\
\hline 05 & fHY & Fator de carga horizontal na direção Y & Numérico & 7 & Dígitos (0-9) \\
\hline 06 & fV & Fator de carga na direção Z & Numérico & 7 & Dígitos (0-9) \\
\hline 07 & fMX & Fator de momento em torno do eixo X & Numérico & 7 & Dígitos (0-9) \\
\hline 08 & fMY & Fator de momento em torno do eixo Y & Numérico & 5 & Dígitos (0-9) \\
\hline 09 & fT & Fator de momento em torno do eixo Z & Dígitos (0-9) \\
\hline
\end{tabular}


TABELA Estrutura de Fundação

\begin{tabular}{|l|l|l|c|c|c|}
\hline ITEM & CAMPO & DESCRIÇÃO GERAL & TIPO DE DADO & TAMANHO & EDIÇÃO \\
\hline 01 & Cod_Obra & Código de identificação da obra & Inteiro & 3 & Dígitos (0-9) \\
\hline 02 & Cod_EF & $\begin{array}{l}\text { Código de identificação da estrutura de fundação (apenas } \\
\text { para manter a hierarquia das tabelas) }\end{array}$ & Inteiro & 1 & Dígitos (0-9) \\
\hline 03 & Cod_F & Código da técnica de execução da estrutura de fundação & Inteiro & 2 & Dígitos (0-9) \\
\hline 04 & Cod_MTC & Código do Modelo de Transferência de Carga adotado & Inteiro & 2 & Dígitos (0-9) \\
\hline 05 & Cod_MCon & $\begin{array}{l}\text { Código do material de construção empregado (concreto } \\
\text { armado, perfil metálico e madeira) }\end{array}$ & Inteiro & 1 & Dígitos (0-9) \\
\hline 06 & Tipo & Tipo de fundação (superficial/profunda) & Caracter & 10 & Alfabético (a-z), (A-Z) \\
\hline 07 & ProjFund & Projetista da fundação & Caracter & 40 & Alfabético (a-z), (A-Z) \\
\hline
\end{tabular}

TABELA UFCircular (Unidade de Fundação Circular)

\begin{tabular}{|l|l|l|c|c|c|}
\hline ITEM & CAMPO & DESCRIÇÃO GERAL & TIPO DE DADO & TAMANHO & EDIÇÃO \\
\hline 01 & Cod_EF & $\begin{array}{l}\text { Código de identificação da estrutura de fundação (apenas } \\
\text { para manter hierarquia das tabelas) }\end{array}$ & Inteiro & 1 & Dígitos (0-9) \\
\hline 02 & Cod_UF & Código de identificação da unidade de fundação & Inteiro & 2 & Dígitos (0-9) \\
\hline 03 & Angulo & $\begin{array}{l}\text { Ângulo da direção principal relativa ao eixo X (menor } \\
\text { rotação horária) }\end{array}$ & Numérico & 5 & Digitos (0-9) \\
\hline 04 & Nelem & Número do elemento na unidade de fundação & Inteiro & 2 & Dígitos (0-9) \\
\hline 05 & NOrdem & $\begin{array}{l}\text { Identificação da ordem de entrada dos elementos, } \\
\text { referente ao bloco/pilar (sequencial) }\end{array}$ & Caracter & 5 & Qualquer caracter \\
\hline
\end{tabular}

TABEla EFCircular (Elemento de Fundação Circular)

\begin{tabular}{|l|l|l|c|c|c|}
\hline ITEM & CAMPO & DESCRIÇÃO GERAL & TIPO DE DADO & TAMANHO & EDIÇÃO \\
\hline 01 & Cod_UF & Código de identificação da unidade de fundação & Inteiro & 2 & Dígitos (0-9) \\
\hline 02 & Cod_EFC & $\begin{array}{l}\text { Código de identificação dos elementos de fundação } \\
\text { circulares }\end{array}$ & Inteiro & 2 & Dígitos (0-9) \\
\hline 03 & N & Número de ordem do elemento de fundação & Inteiro & 2 & Dígitos (0-9) \\
\hline 04 & PosX & Posição do elemento em relação ao eixo X & Numérico & 5 & Dígitos (0-9) \\
\hline 05 & PosY & Posição do elemento em relação ao eixo Y & Numérico & 5 & Dígitos (0-9) \\
\hline 06 & PosZ & Posição do elemento em relação ao eixo Z & Numérico & 5 & Dígitos (0-9) \\
\hline 07 & Dfuste & Diâmetro externo do fuste da estaca & Numérico & 5 & Dígitos (0-9) \\
\hline 08 & Dinterno & Diâmetro interno da estaca vazada & Numérico & 5 & Dumérico \\
\hline 09 & Dbase & Diâmetro da base alargada ou do bulbo & 5 & Dígitos (0-9) \\
\hline 10 & L & Comprimento da estaca vertical & Numérico & 10 & Dígitos (0-9) \\
\hline 11 & We & Recalque devido à deformação longitudinal da peça & Numérico & 10 & Dígitos (0-9) \\
\hline 12 & Ws & $\begin{array}{l}\text { Recalque devido ao deslocamento vertical da } \\
\text { extremidade da peça }\end{array}$ & & \\
\hline
\end{tabular}

TABELA EDCircular (Elemento Discreto Circular)

\begin{tabular}{|l|l|l|c|c|c|}
\hline ITEM & CAMPO & DESCRIÇÃO GERAL & TIPO DE DADO & TAMANHO & EDIÇÃO \\
\hline 01 & Cod_EFC & $\begin{array}{l}\text { Código de identificação dos elementos de fundação } \\
\text { circulares }\end{array}$ & Inteiro & 2 \\
\hline 02 & Cod_EDC & $\begin{array}{l}\text { Código de identificação dos elementos discretos } \\
\text { circulares }\end{array}$ & Inteiro & 3 \\
\hline 03 & TED & Tipo de elemento discreto (fuste/base) & Caracter & 5 & Alfabético (a-z) \\
\hline 04 & Zinicial & Cota inicial & Numérico & 7 & Dígitos (0-9) \\
\hline 05 & Zfinal & Cota final & Numérico & 7 & Dígitos (0-9) \\
\hline 06 & Ainterface & Área de interface elemento discreto - maciço de solos & Numérico & 7 & Dígitos (0-9) \\
\hline 07 & Rinterface & $\begin{array}{l}\text { Resistência de interface elemento discreto - maciço de } \\
\text { solos }\end{array}$ & Numérico & 7 & Dígitos (0-9) \\
\hline
\end{tabular}

TABELA UFSupCircular (Unidade de Fundação Superficial Circular)

\begin{tabular}{|l|l|l|c|c|c|}
\hline ITEM & CAMPO & DESCRIÇÃO GERAL & TIPO DE DADO & TAMANHO & EDIÇÃO \\
\hline 01 & Cod_EF & $\begin{array}{l}\text { Código de identificação da estrutura de fundação (apenas } \\
\text { para manter hierarquia das tabelas) }\end{array}$ & Inteiro & 1 & Dígitos (0-9) \\
\hline 02 & Cod_UF & Código de identificação da unidade de fundação & Inteiro & 2 & Dígitos (0-9) \\
\hline 03 & PosicaoX & Posição do elemento em relação ao eixo X & Numérico & 5 & Dígitos (0-9) \\
\hline 04 & PosicaoY & Posição do elemento em relação ao eixo Y & Numérico & 5 & Dígitos (0-9) \\
\hline 05 & PosicaoZ & Posição do elemento em relação ao eixo Z & Numérico & 5 & Dígitos (0-9) \\
\hline 06 & Dbase & Diâmetro da base & Numérico & 5 & Dígitos (0-9) \\
\hline 07 & Dinterno & $\begin{array}{l}\text { Lado sob a direção principal relativa ao Y (rotação }(0-9) \\
\text { horária) }\end{array}$ & Numérico & 7 & Dígitos (0-9) \\
\hline 08 & AInterface & Área de interface elemento - maciço de solos & Numérico & 7 & Dígitos (0-9) \\
\hline 09 & RInterface & Resistência de interface elemento - maciço de solos & Numérico & 7 & Dígitos (0-9) \\
\hline 10 & Ws & Recalque do apoio & Inteiro & 2 \\
\hline 11 & NrOrdem & $\begin{array}{l}\text { Identificação da ordem de entrada dos elementos, } \\
\text { referente ao pilar (sequencial) }\end{array}$ & Dígitos (0-9) \\
\hline
\end{tabular}


TABELA UFPrismático (Unidade de Fundação Prismática)

\begin{tabular}{|l|l|l|c|c|c|}
\hline ITEM & CAMPO & DESCRIÇÃO GERAL & TIPO DE DADO & TAMANHO & EDIÇÃO \\
\hline 01 & Cod_EF & $\begin{array}{l}\text { Código de identificação da estrutura de fundação (apenas } \\
\text { para manter hierarquia das tabelas) }\end{array}$ & Inteiro & 3 & Dígitos (0-9) \\
\hline 02 & Cod_UF & Código de identificação da unidade de fundação & Inteiro & 2 & Dígitos (0-9) \\
\hline 03 & Angulo & $\begin{array}{l}\text { Angulo da direção principal relativa ao eixo X (menor } \\
\text { rotação horária) }\end{array}$ & Numérico & 5 & Dígitos (0-9) \\
\hline 04 & Nelem & Número do elemento na unidade de fundação & Inteiro & 2 & Dígitos (0-9) \\
\hline 05 & NOrdem & $\begin{array}{l}\text { Identificação da ordem de entrada dos elementos, } \\
\text { referente ao bloco/pilar (sequencial) }\end{array}$ & Caracter & 5 & Qualquer \\
\hline
\end{tabular}

TABela EFPrismatico (Elemento de Fundação Prismático)

\begin{tabular}{|l|l|l|c|c|c|}
\hline ITEM & CAMPO & DESCRIÇÃO GERAL & TIPO DE DADO & TAMANHO & EDIÇÃO \\
\hline 01 & Cod_EFP & $\begin{array}{l}\text { Código de identificação dos elementos de fundação } \\
\text { prismáticos }\end{array}$ & Inteiro & 2 \\
\hline 02 & Cod_UF & Código de identificação da unidade de fundação & Inteiro & 2 & Dígitos (0-9) \\
\hline 03 & N & Número do elemento na unidade de fundação & Inteiro & 2 & Dígitos (0-9) \\
\hline 04 & PosX & Posição do elemento em relação ao eixo X & Numérico & 5 & Dígitos (0-9) \\
\hline 05 & PosY & Posição do elemento em relação ao eixo Y & Numérico & 5 & Dígitos (0-9) \\
\hline 06 & PosZ & Posição do elemento em relação ao eixo Z & 5 & Dígitos (0-9) \\
\hline 07 & LadoX & $\begin{array}{l}\text { Lado sob a direção principal relativa ao eixo X (rotação } \\
\text { horária) }\end{array}$ & Numérico & 5 \\
\hline 08 & LadoY & $\begin{array}{l}\text { Lado sob a direção principal relativa ao eixo Y (rotação }(0-9) \\
\text { horária) }\end{array}$ & Numérico & 5 & Dígitos (0-9) \\
\hline 09 & L & Comprimento da estaca vertical & Numérico & 5 & Dígitos (0-9) \\
\hline 10 & We & Recalque devido à deformação longitudinal da peça & Numérico & 10 & Dígitos (0-9) \\
\hline 11 & Ws & $\begin{array}{l}\text { Recalque devido ao deslocamento vertical da } \\
\text { extremidade da peça }\end{array}$ & Numérico & 10 & Dígitos (0-9) \\
\hline
\end{tabular}

TABELA EDPrismatico (Elemento Discreto Prismático)

\begin{tabular}{|l|l|l|c|c|c|}
\hline ITEM & CAMPO & DESCRIÇÃO GERAL & TIPO DE DADO & TAMANHO & EDIÇÃO \\
\hline 01 & Cod_EFP & $\begin{array}{l}\text { Código de identificação dos elementos de fundação } \\
\text { prismáticos }\end{array}$ & Inteiro & 2 \\
\hline 02 & Cod_EDP & $\begin{array}{l}\text { Código de identificação dos elementos discretos } \\
\text { prismáticos }\end{array}$ & Inteiro & 3 \\
\hline 03 & TED & Tipo de elemento discreto (fuste/base) & Caracter & 5 & Dígitos (0-9) \\
\hline 04 & Zinicialos (0-9) & Numérico & 7 & Dígitos (0-9) \\
\hline 05 & Zfinal & Cota inicial & Numérico & 7 & Dígitos (0-9) \\
\hline 06 & Ainterface & Área de interface elemento discreto - maciço de solos & Numérico & 7 & Dígitos (0-9) \\
\hline 07 & Rinterface & $\begin{array}{l}\text { Resistência de interface elemento discreto - maciço de } \\
\text { solos }\end{array}$ & Numérico & Dígitos (0-9) \\
\hline
\end{tabular}

TABELA UFSupPrismático (Unidade de Fundação Superficial Prismática)

\begin{tabular}{|l|l|l|c|c|c|}
\hline ITEM & CAMPO & DESCRIÇÃO GERAL & TIPO DE DADO & TAMANHO & EDIÇÃO \\
\hline 01 & Cod_EF & $\begin{array}{l}\text { Código de identificação da estrutura de fundação (apenas } \\
\text { para manter a hierarquia das tabelas) }\end{array}$ & Inteiro & Dígitos (0-9) \\
\hline 02 & Cod_UF & Código de identificação da unidade de fundação & Inteiro & 2 & Dígitos (0-9) \\
\hline 03 & PosicaoX & Posição do elemento em relação ao eixo X & Numérico & 5 & Dígitos (0-9) \\
\hline 04 & PosicaoY & Posição do elemento em relação ao eixo Y & Numérico & 5 & Dígitos (0-9) \\
\hline 05 & PosicaoZ & Posição do elemento em relação ao eixo Z & Numérico & 5 & Dígitos (0-9) \\
\hline 06 & LadoX & $\begin{array}{l}\text { Lado sob a direção principal relativa ao eixo X (rotação } \\
\text { horária) }\end{array}$ & Numérico & 5 & Dígitos (0-9) \\
\hline 07 & LadoY & $\begin{array}{l}\text { Lado sob a direção principal relativa ao eixo Y (rotação } \\
\text { horária) }\end{array}$ & Numérico & 5 & Dígitos (0-9) \\
\hline 08 & AngRotação & $\begin{array}{l}\text { Ângulo da direção principal relativa ao eixo X (menor } \\
\text { rotação horária) }\end{array}$ & Numérico & 5 & Dígitos (0-9) \\
\hline 09 & AInterface & Área de interface elemento - maciço de solos & Numérico & 7 & Dígitos (0-9) \\
\hline
\end{tabular}

TABELA UFSupPrismático (Unidade de Fundação Prismática)

\begin{tabular}{|l|l|l|c|c|c|}
\hline ITEM & CAMPO & DESCRIÇÃO GERAL & TIPO DE DADO & TAMANHO & EDIÇÃO \\
\hline 10 & RInterface & Resistência de interface elemento - maciço de solos & Numérico & 7 & Dígitos (0-9) \\
\hline 11 & Ws & Recalque do apoio & Numérico & 7 & Dígitos (0-9) \\
\hline 12 & NrOrdem & $\begin{array}{l}\text { Identificação da ordem de entrada dos elementos, } \\
\text { referente ao pilar (sequencial) }\end{array}$ & Inteiro & 2 & Dígitos (0-9) \\
\hline
\end{tabular}


TABELA MFEF (Matriz de Flexibilidade da Estrutura de Fundação)

\begin{tabular}{|l|l|l|c|c|c|}
\hline ITEM & CAMPO & DESCRIÇÃO GERAL & TIPO DE DADO & TAMANHO & EDIÇÃO \\
\hline 01 & Cod_EF & $\begin{array}{l}\text { Código de identificação da estrutura de fundação (apenas } \\
\text { para manter a hierarquia das tabelas) }\end{array}$ & Inteiro & 1 & Dígitos (0-9) \\
\hline 02 & Cod_UF & Código de identificação da unidade de fundação & Inteiro & 5 & Dígitos (0-9) \\
\hline 03 & Cod_EUF & Código de identificação do elemento de fundação & Inteiro & 5 & Dígitos (0-9) \\
\hline 04 & Cod_UDF & Código de identificação do elemento discreto & Inteiro & 5 & Dígitos $(0-9)$ \\
\hline 05 & FWe & Fator de recalque & Numérico & 10 & Dígitos $(0-9)$ \\
\hline
\end{tabular}

TABELA Maciço de Solos

\begin{tabular}{|l|l|l|c|c|c|}
\hline ITEM & CAMPO & DESCRIÇÃO GERAL & TIPO DE DADO & TAMANHO & EDIÇÃO \\
\hline 01 & Cod_Obra & Código de identificação da obra & Inteiro & 3 & Dígitos (0-9) \\
\hline 02 & Cod_MS & $\begin{array}{l}\text { Código de identificação do maciço de solos (apenas para } \\
\text { manter hierarquia das tabelas) }\end{array}$ & Inteiro & 3 & Dígitos (0-9) \\
\hline 03 & Cod_Fgeol & $\begin{array}{l}\text { Código de identificação da formação geológica à qual } \\
\text { pertence o maciço }\end{array}$ & Inteiro & 2 & Dígitos (0-9) \\
\hline 04 & TipoAterro & $\begin{array}{l}\text { Tipo de aterro empregado em uma possível } \\
\text { movimentação de terra (granular ou coesivo) }\end{array}$ & Caracter & 10 & Quaquer Caracter \\
\hline
\end{tabular}

TABela Ponto Maciço (cabeçalho de sondagem SPT)

\begin{tabular}{|l|l|l|c|c|c|}
\hline ITEM & CAMPO & DESCRIÇÃO GERAL & TIPO DE DADO & TAMANHO & EDIÇÃO \\
\hline 01 & Cod_MS & $\begin{array}{l}\text { Código de identificação do maciço de solos (apenas para } \\
\text { manter hierarquia das tabelas) }\end{array}$ & Inteiro & 3 & Dígitos (0-9) \\
\hline 02 & Cod_PMS & Código de identificação do ponto no maciço de solos & Inteiro & 2 & Dígitos (0-9) \\
\hline 03 & Nfuro & Identificação do ponto no maciço de solos & Caracter & 6 & Qualquer Caracter \\
\hline 04 & Data & Data de execução da sondagem & Caracter & 10 & Dígitos (0-9) \\
\hline 05 & NA & Nível d'água & Numérico & 7 & Dígitos (0-9) \\
\hline 06 & PosX & Posição em relação ao eixo X & Numérico & 7 & Dígitos (0-9) \\
\hline 07 & PosY & Posição em relação ao eixo Y & Numérico & 7 & Dígitos (0-9) \\
\hline 08 & PosZ & Posição em relação ao eixo Z & Numérico & 7 & Dígitos (0-9) \\
\hline 09 & ProfMax & Profundidade (comprimento) do furo & Caracter & 50 & Alfabético (a-z), (A-Z) \\
\hline 10 & EESond & Empresa Executora da Sondagem (SPT) & & \\
\hline
\end{tabular}

TABEla Dados SPT

\begin{tabular}{|l|l|l|c|c|c|}
\hline ITEM & CAMPO & DESCRIÇ̃̃O GERAL & TIPO DE DADO & TAMANHO & EDIČ̃̃O \\
\hline 01 & Cod_PMS & Código de identificação do ponto no maciço de solos & Inteiro & 2 & Dígitos (0-9) \\
\hline 02 & Cod_SPT & $\begin{array}{l}\text { Código de identificação do horizonte do ensaio de } \\
\text { penetração }\end{array}$ & Inteiro & 2 & Dígitos (0-9) \\
\hline 03 & Prof & Profundidade analisada & Numérico & 7 & Dígitos (0-9) \\
\hline 04 & NSPT & Número de golpes do SPT & Inteiro & 2 & Dígitos (0-9) \\
\hline 05 & Cod_CGran & Código da classificação granulométrica & Inteiro & 3 & Dígitos (0-3) \\
\hline 06 & Descricao & $\begin{array}{l}\text { Descrição da granulometria e compacidade ou } \\
\text { consistência }\end{array}$ & Caracter & 60 & Alfabético (a-z), (A-Z) \\
\hline
\end{tabular}

TABELA CCSCoesivo (Camada Complementar em Solo Coesivo)

\begin{tabular}{|l|l|l|c|c|c|}
\hline ITEM & CAMPO & DESCRIÇÃO GERAL & TIPO DE DADO & TAMANHO & EDIÇÃO \\
\hline 01 & Cod_MS & $\begin{array}{l}\text { Código de identificação do maciço de solos (apenas para } \\
\text { manter hierarquia das tabelas) }\end{array}$ & Inteiro & Dígitos (0-9) \\
\hline 02 & Cod_CCSC & $\begin{array}{l}\text { Código de identificação da camada complementar em } \\
\text { solo coesivo }\end{array}$ & Inteiro & 2 & Dígitos (0-9) \\
\hline 03 & Cod_Textura & Código da textura do solo & Inteiro & 2 & Dígitos (0-9) \\
\hline 04 & Cod_CnCmp & Código de identificação da consistência ou compacidade & Inteiro & 2 & Dígitos (0-9) \\
\hline 05 & Cod_CGran & Código da classificação granulométrica & Inteiro & 2 & Dígitos (0-9) \\
\hline 06 & PesEsp & Peso específico & Numérico & 7 & Dígitos (0-9) \\
\hline 07 & DR & Densidade relativa & Numérico & 5 & Dígitos (0-9) \\
\hline 08 & Coesão & Coesão & Inteiro & 2 & Dígitos (0-9) \\
\hline 09 & NSPT & Número de golpes no ensaio SPT & Numérico & 3 & Dígitos (0-9) \\
\hline 10 & FatorK & Fator K de correlação SPT/CPT & Numérico & 4 & Dígitos (0-9) \\
\hline 11 & FatorAlfa & Fator $\alpha$ de correlação SPT/CPT & Numérico & 5 & Dígitos (0-9) \\
\hline 12 & RLUU & Resistência Lateral Ultima Unitária & Numérico & 5 & Dígitos (0-9) \\
\hline 13 & RPUU & Resistência de Ponta Ultima Unitária & Numérico & 3 & Dígitos (0-9) \\
\hline 14 & Young & Modulo de Young & Dígitos (0-9) \\
\hline 15 & Poisson & Coeficiente de Poisson & & 7 \\
\hline
\end{tabular}


TABELA CCSGranular (Camada Complementar em Solo Granular)

\begin{tabular}{|l|l|l|c|c|c|}
\hline ITEM & CAMPO & DESCRIÇÃO GERAL & TIPO DE DADO & TAMANHO & EDIÇ̃̃O \\
\hline 01 & Cod_MS & $\begin{array}{l}\text { Código de identificação do maciço de solos (apenas para } \\
\text { manter hierarquia das tabelas) }\end{array}$ & Inteiro & 3 & Dígitos (0-9) \\
\hline 02 & Cod_CCSC & $\begin{array}{l}\text { Código de identificação da camada complementar em } \\
\text { solo granular }\end{array}$ & Inteiro & 2 & Dígitos (0-9) \\
\hline 03 & Cod_Textura & Código da textura do solo & Inteiro & 2 & Dígitos (0-9) \\
\hline 04 & Cod_CnCmp & Código doda Consistência/Compacidade & Inteiro & 2 & Dígitos $(0-9)$ \\
\hline 05 & Cod_CGran & Código da classificação granulométrica & Inteiro & 2 & Dígitos (0-9) \\
\hline 06 & PesEsp & Peso específico & Numérico & 7 & Dígitos (0-9) \\
\hline 07 & DR & Densidade relativa & Numérico & 5 & Dígitos $(0-9)$ \\
\hline 08 & Aatrito & Angulo de atrito & Numérico & 5 & Dígitos $(0-9)$ \\
\hline 09 & NSPT & Número de golpes no ensaio SPT & Inteiro & 2 & Dígitos $(0-9)$ \\
\hline 10 & FatorK & Fator K de correlação SPT/CPT & Numérico & 3 & Dígitos (0-9) \\
\hline 11 & FatorAlfa & Fator $\alpha$ de correlação SPT/CPT & Numérico & 4 & Dígitos $(0-9)$ \\
\hline 12 & RLUU & Resistência Lateral Última Unitária & Numérico & 5 & Dígitos $(0-9)$ \\
\hline 13 & RPUU & Resistência de Ponta Última Unitária & Numérico & 5 & Dígitos $(0-9)$ \\
\hline 14 & Young & Modulo de Young & Numérico & 7 & Dígitos $(0-9)$ \\
\hline 15 & Poisson & Coeficiente de Poisson & Numérico & 3 & Dígitos $(0-9)$ \\
\hline
\end{tabular}

TABELA Mapeamento Geotécnico

\begin{tabular}{|l|l|l|r|c|c|}
\hline ITEM & CAMPO & DESCRIÇÃO GERAL & TIPO DE DADO & TAMANHO & EDIÇÃO \\
\hline 01 & Cod_PMS & Código de identificação do ponto no maciço de solos & Inteiro & 2 & Dígitos (0-9) \\
\hline 02 & Cod_SPT & Código do horizonte ensaiado & Inteiro & 2 & Dígitos (0-9) \\
\hline 03 & Cod_Genese & Código da gênese do solo & Inteiro & 2 & Dígitos (0-9) \\
\hline 04 & Cod_Rocha & Código da rocha de origem & Inteiro & 2 & Dígitos (0-9) \\
\hline 05 & Cod_CEsp & Código da característica especial & Inteiro & 2 & Dígitos (0-9) \\
\hline
\end{tabular}

TABela Modelo do Maciço

\begin{tabular}{|l|l|l|c|c|c|}
\hline ITEM & CAMPO & DESCRIÇÃO GERAL & TIPO DE DADO & TAMANHO & EDIÇÃO \\
\hline 01 & Cod_MS & $\begin{array}{l}\text { Código de identificação do maciço de solos (apenas para } \\
\text { manter hierarquia das tabelas) }\end{array}$ & Inteiro & 3 \\
\hline 02 & Cod_MMS & $\begin{array}{l}\text { Código de identificação da modelagem do maciço de } \\
\text { solos }\end{array}$ & Inteiro & 2 & Dígitos (0-9) \\
\hline 03 & Cod_PMS & Código de identificação do ponto no maciço de solos & Inteiro & 2 & Dígitos (0-9) \\
\hline 04 & Cod_SPT & Código do horizonte ensaiado & Inteiro & 2 & Dígitos (0-9) \\
\hline 05 & Young & Módulo de Young & Numérico & 7 & Dígitos (0-9) \\
\hline 06 & Poisson & Coeficiente de Poisson & Numérico & 3 & Dígitos (0-9) \\
\hline 07 & RLUU & Resistência Lateral Última Unitária & Numérico & 5 & Dígitos (0-9) \\
\hline 08 & RPUU & Resistência de Ponta Última Unitária & 5 & Dígitos (0-9) \\
\hline
\end{tabular}

TABELA MFMS (Matriz de Flexibilidade do Maciço de Solos)

\begin{tabular}{|l|l|l|c|c|c|}
\hline ITEM & CAMPO & DESCRIÇ̃̃O GERAL & TIPO DE DADO & TAMANHO & EDIÇ̃̃O \\
\hline 01 & Cod_MS & $\begin{array}{l}\text { Código de identificação do maciço de solos (apenas para } \\
\text { manter hierarquia das tabelas) }\end{array}$ & Inteiro & 3 & Dígitos (0-9) \\
\hline 02 & Cod_UF & $\begin{array}{l}\text { Código de identificação da unidade de fundação } \\
\text { influenciada }\end{array}$ & Inteiro & 5 & Dígitos (0-9) \\
\hline 03 & Cod_EUF & $\begin{array}{l}\text { Código de identificação do elemento de fundação } \\
\text { influenciado }\end{array}$ & Inteiro & 5 & Dígitos (0-9) \\
\hline 04 & Cod_UFaux & $\begin{array}{l}\text { Código de identificação da unidade de fundação } \\
\text { carregada }\end{array}$ & Inteiro & 5 & Dígitos (0-9) \\
\hline 05 & $\begin{array}{l}\text { Cod_EUFau } \\
\mathrm{x}\end{array}$ & $\begin{array}{l}\text { Código de identificação do elemento de fundação } \\
\text { carregado }\end{array}$ & Inteiro & 5 & Dígitos (0-9) \\
\hline 06 & Cod_EDaux & Código de identificação do elemento discreto carregado & Inteiro & 5 & Dígitos (0-9) \\
\hline 07 & fWs & Fator de recalque & Numérico & 10 & Dígitos (0-9) \\
\hline
\end{tabular}

TABELA Camada (auxiliar)

\begin{tabular}{|l|l|l|c|c|c|}
\hline ITEM & CAMPO & DESCRIÇÃO GERAL & TIPO DE DADO & TAMANHO & EDIÇÃO \\
\hline 01 & NCamada & Código de identificação da subcamada & Inteiro & 5 & Dígitos (0-9) \\
\hline 02 & E & Módulo de elasticidade da subcamada & Numérico & 7 & Dígitos (0-9) \\
\hline 03 & mi & Coeficiente de Poisson do material da subcamada & Numérico & 7 & Dígitos (0-9) \\
\hline 04 & Zmédio & Cota média da subcamada & Numérico & 7 & Dígitos (0-9) \\
\hline 05 & Zsup & Cota superior da subcamada & Numérico & 7 & Dígitos (0-9) \\
\hline 06 & Zinf & Cota inferior da subcamada & Numérico & 7 & Dígitos (0-9) \\
\hline 07 & Espessura & Espessura da camada & Dígitos (0-9) \\
\hline
\end{tabular}

OBS: O objeto camada pode receber os atributos Cod_MS, Cod Camada, Cod UF, Cod EUF e armazenaros dados de modelagem do maciço de solos, localmente a cada elemento de fundação. 
TABELA Resultados

\begin{tabular}{|c|c|c|c|c|c|}
\hline ITEM & CAMPO & DESCRIÇÃO GERAL & TIPO DE DADO & TAMANHO & EDIÇÃO \\
\hline 01 & Cod_Obra & Código de identificação da obra & Inteiro & 2 & Dígitos (0-9) \\
\hline 02 & Cod_UF & Código de identificação da unidade de fundação & Inteiro & 2 & Dígitos (0-9) \\
\hline 03 & $\mathrm{Vi}$ & Carga vertical (apoio indeslocável) & Numérico & 7 & Dígitos (0-9) \\
\hline 04 & $\mathrm{HXi}$ & $\begin{array}{l}\text { Carga horizontal no eixo principal da peça menos } \\
\text { rotacionado em relação ao eixo X (apoio indeslocável) }\end{array}$ & Numérico & 7 & Dígitos (0-9) \\
\hline 05 & $\mathrm{HYi}$ & $\begin{array}{l}\text { Carga horizontal eixo principal da peça menos } \\
\text { rotacionado em relação ao eixo Y (apoio indeslocável) }\end{array}$ & Numérico & 7 & Dígitos (0-9) \\
\hline 06 & $\mathrm{MXi}$ & $\begin{array}{l}\text { Momento em torno do eixo principal menos rotacionado } \\
\text { em relação ao eixo X (apoio indeslocável) }\end{array}$ & Numérico & 7 & Dígitos (0-9) \\
\hline 07 & MYi & $\begin{array}{l}\text { Momento em torno do eixo principal menos rotacionado } \\
\text { em relação ao eixo Y (apoio indeslocável) }\end{array}$ & Numérico & 7 & Dígitos (0-9) \\
\hline 08 & $\mathrm{Ti}$ & Torsor - momento em torno de Z (apoio indeslocável) & Numérico & 7 & Dígitos (0-9) \\
\hline 09 & DVrn & Deslocamento vertical (rigidez nula) & Numérico & 7 & Dígitos $(0-9)$ \\
\hline 10 & $\mathrm{~V}$ & Carga vertical & Numérico & 7 & Dígitos (0-9) \\
\hline 11 & HX & $\begin{array}{l}\text { Carga horizontal no eixo principal da peça menos } \\
\text { rotacionado em relação ao eixo X }\end{array}$ & Numérico & 7 & Dígitos (0-9) \\
\hline 12 & HY & $\begin{array}{l}\text { Carga horizontal eixo principal da peça menos } \\
\text { rotacionado em relação ao eixo Y }\end{array}$ & Numérico & 7 & Dígitos (0-9) \\
\hline 13 & $\mathrm{MX}$ & $\begin{array}{l}\text { Momento em torno do eixo principal menos rotacionado } \\
\text { em relação ao eixo } \mathrm{X}\end{array}$ & Numérico & 7 & Dígitos (0-9) \\
\hline 14 & MY & $\begin{array}{l}\text { Momento em torno do eixo principal menos rotacionado } \\
\text { em relação ao eixo Y }\end{array}$ & Numérico & 7 & Dígitos (0-9) \\
\hline 15 & $\mathrm{~T}$ & Torsor - momento em torno de $\mathrm{Z}$ & Numérico & 7 & Dígitos (0-9) \\
\hline 16 & DV & Deslocamento vertical & Numérico & 7 & Dígitos (0-9) \\
\hline
\end{tabular}




\section{ANEXO II}

\section{Algoritmos e fontes do StructsoiL 1.0}

O ANEXO II mostra os algoritmos referentes processamento do StructsoiL 1.0 e para melhor entendimento destes, apresenta-se algumas fontes relativas ao pré-processamento. $\mathrm{O}$ algoritmo construído anteriormente ao software possui algumas inconsistências com o modelo de tabelas, devido à adaptações na implementação. A TABELA A01 mostra o nome das tabelas no projeto, o nome da tabela física e a denominação de campos que porventura podem ter denominação diferente no projeto de tabelas e nas tabelas físicas. Essa tabela de correções auxilia na compreensão do algoritmo.

As tabelas que estiverem expressas no algoritmo e não estiverem no projeto de tabelas (ANEXO I), são tabelas lógicas e auxiliares criadas pelas unidades gerentes de tabelas e servem para melhor gerenciar o fluxo de dados e o armazenamento no banco de dados físico.

O algoritmo é apresentado pelas unidades Processamento e Interação, além disso incluiu-se fontes em Pascal de procedimentos e funções do pré-processamento contidas em outras unidades do StructsoiL 1.0. 
TABELA A01 - Tabelas de dados e campos de tabelas alterados no algoritmo

\begin{tabular}{|c|c|c|c|}
\hline \multicolumn{2}{|c|}{ tabelas de dados } & \multicolumn{2}{|c|}{ campos de tabelas } \\
\hline Projeto & algoritmo & projeto & algoritmo \\
\hline Empresa & TbEmpresa & & \\
\hline Usuário & TbUsuario & & \\
\hline Tipo Fundação & TbTipoFund & Cod_TF & Cod_TipoFund \\
\hline Fundação & TbTipoFundacao & $\begin{array}{l}\text { Cod_F } \\
\text { Cod_TF }\end{array}$ & $\begin{array}{l}\text { Cod_TF } \\
\text { Cod_TipoFund }\end{array}$ \\
\hline Material de Construção & TbMaterialConstrucao & Cod Mcons & Cod Material \\
\hline MTC Geral & TbMTCGeral & & \\
\hline MTC Local & TbMTCLocal & & \\
\hline MGR & TbModeloSPT & $\begin{array}{l}\text { Cod_CGran } \\
\text { Cod_CnComp }\end{array}$ & $\begin{array}{l}\text { Cod_ClasGran } \\
\text { Cod_ConsComp }\end{array}$ \\
\hline MGDE & TbModeloGeotecnico & $\begin{array}{l}\text { Cod_Gsolo } \\
\text { Cod_CE } \\
\text { Cod_CGran } \\
\text { Cod_Fgeol } \\
\text { CondSat }\end{array}$ & $\begin{array}{l}\text { Cod_GeneseSolo } \\
\text { Cod_CGeotecnica } \\
\text { Cod_ClasGran } \\
\text { Cod_Formgeologica } \\
\text { CodSan }\end{array}$ \\
\hline MCSC Coesivo & TbACSCoesivo & $\begin{array}{l}\text { Cod_CGran } \\
\text { Cod_CnComp }\end{array}$ & $\begin{array}{l}\text { Cod_ClasGran } \\
\text { Cod_ConsComp }\end{array}$ \\
\hline MCSC Granular & TbACSGranular & $\begin{array}{l}\text { Cod_CGran } \\
\text { Cod_CnComp }\end{array}$ & $\begin{array}{l}\text { Cod_ClasGran } \\
\text { Cod_CConsComp }\end{array}$ \\
\hline Características Especiais & TbCaracGeotecnica & Cod_CE & Cod_CGeotecnica \\
\hline Classificação Granulométrica & TbClasGranulometrica & Cod_CGran & Cod_ClasGran \\
\hline Consitência/Compacidade & TbConsCompacidade & Cod_CnComp & Cod_ConsComp \\
\hline Rocha Mãe & TbRocha & & \\
\hline Textura & TbTextura & & \\
\hline Formação Geológica & TbFormGeologica & Cod_Fgeol & Cod_Formgeologica \\
\hline Gênese do Solo & TbGeneseSolo & Cod_Gsolo & Cod_GeneseSolo \\
\hline Obra & TbObra & & \\
\hline Superestrutura & TbSuperEstrutura & Cod_SE & Cod_Obra \\
\hline Locação & TbLocacaoPilar & Cod SE & Cod_Obra \\
\hline Cargas & TbCarregamento & Cod_SE & Cod_Obra \\
\hline MRS & TbRigSuperestrutura & Cod_SE & Cod_Obra \\
\hline Estrutura de Fundação & TbEstFundacao & & \\
\hline UFCircular & TbUFCircular & & \\
\hline EFCircular & TbEFCircular & & \\
\hline EDCircular & TbEdCircular & & \\
\hline UFSupCircular & TbUFSupCircular & & \\
\hline UFPrismático & TbUFPrismático & & \\
\hline EFPrismático & TbEFPrismático & & \\
\hline EDPrismático & TbEDPrismático & & \\
\hline UFSupPrismático & TbUFSupPrismático & & \\
\hline MFEF & Tbfe & Cod_SE & Cod_Obra \\
\hline Maciço de Solos & TbMacico & Cod_MS* & \\
\hline Ponto Maciço & TbPontoMacico & Cod_MS & Cod_Obra \\
\hline Dados SPT & TbSPT & & \\
\hline CCSCoesivo & TbCCSCoesivo & Cod_MS & Cod_Obra \\
\hline CCSGranular & TbCCSGranular & Cod_MS & Cod_Obra \\
\hline Mapeamento Geotécnico & TbMapaGeotecnico & & \\
\hline Modelo do Maciço & TbModeloMacico & Cod_MS & Cod_Obra \\
\hline MFMS & TbMIF & Cod_MS & $*$ \\
\hline Camada & TbCamada & & \\
\hline Resultados & TbResultado & & \\
\hline
\end{tabular}

$(*)$ : Na implementação gera-se um arquivo tabela MFMS para cada obra 


\section{Unidade Processamento}

interface

declarações privadas

função YoungEquivalente(reais: $X, Y, Z)$ : real;

função PoissonEquivalente(reais: $X, Y, Z)$ : real;

função PosicaoIndeslocavel(reais: X, Y): real;

função SoluçãoMINDLIN(reais: E, $\mu, \mathrm{c}, \mathrm{x}, \mathrm{y}, \mathrm{z}, \mathrm{r}$; inteiro: quantelementos): real;

procedimento ModeloElasticoCamadas (reais: $\mathrm{X}_{\mathrm{B}}, \mathrm{Y}_{\mathrm{B}}, \mathrm{Z}_{\mathrm{B}}, \mathrm{NR}_{\text {Apoio }}, \mathrm{Z}_{\text {Indeslocavel }}$; inteiro: $\mathrm{N}_{\text {Camada }}$; tabela: Camada);

função FatorRecalqueBaseCircular(reais: $\mathrm{X}_{\mathrm{B}}, \mathrm{Y}_{\mathrm{B}}, \mathrm{X}_{\mathrm{A}}, \mathrm{Y}_{\mathrm{A}}, \mathrm{Z}_{\mathrm{A}}, \phi_{\mathrm{Base}}, \mathrm{NR}_{\mathrm{Apoio}}$; tabela: Camada): real;

função FatorRecalqueFusteCircular(reais: $\mathrm{X}_{\mathrm{B}}, \mathrm{Y}_{\mathrm{B}}, \mathrm{X}_{\mathrm{A}}, \mathrm{Y}_{\mathrm{A}}, \mathrm{Z}_{\mathrm{A}}, \phi_{\mathrm{Fuste}}, \mathrm{L}, \mathrm{NR}_{\text {Apoio }}$; tabela: Camada): real;

função FatorRecalqueBasePrismatica(reais: $X_{B}, Y_{B}, X_{A}, Y_{A}, Z_{A}, L_{X}, L_{Y}, \alpha, N R_{\text {Apoio }}$; tabela: Camada): real;

função FatorRecalqueFustePrismatico(reais: $X_{B}, Y_{B}, X_{C}, Y_{C}, Z_{C}, L_{X}, L_{Y}, \alpha, L, N R_{\text {Apoio }}$; tabela: Camada): real;

função GravaFatorRecalque (inteiros: uf, euf, ufaux, eufaux, edeufaux; reais: N): lógico;

procedimento MFMS(reais: $\mathrm{NR}_{\text {Apoio }}$ )

declarações públicas

procedimento MFEF

declarações de variáveis

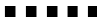

implementação

usa DMSoil, DMCalculo, Interação, Menuprincipal e relatórios

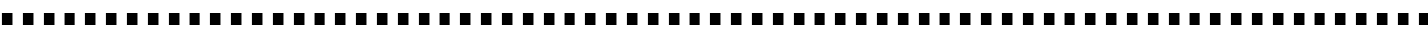

procedimento MFEF

declaração de variáveis

reais: area, E;

início

com o gerenciador de tabelas DMCalculo faça

posicione a variável chave da TbTipoFundacao em TbEstFundacao['Cod TF'];

se TbTipoFundacao['Cod TipoFund'] = 1 então

\{isso implica que a fundação tipo superficial possui código 1 \}

sair do procedimento;

fim se;

se $o$ estado de TbEstFundacao $=$ Inativo então

abre TbEstFundacao;

fim se;

se TbEstFundacao['Cod $\left.\mathrm{TF}^{\prime}\right]=$ nulo então

mostre mensagem ('Erro calculando a Matriz de Flexibilidade da Estrutura de Fundação, sair do procedimento; não existe Tipo de Fundação cadastrado na Estrutura de Fundação');

fim se;

se estado TbTipoFundacao $=$ Inativo então

abre TbTipoFundacao;

enquanto não finalizar TbMFEF faça

delete TbMFEF;

fim enquanto;

posicione a variável chave da TbTipoFundacao em TbEstFundacao['Cod TF'];

se não (TbTipoFundacao['Gfuste'] = 'Prismático') então

abre TbMFEF;

posiciona no primeiro campo da TbUFCircular;

enquanto não finalizar TbUFCircular faça

enquanto não TbEFCircular faça

$\mathrm{E}:=$ TbMaterialConstrucao['Young'];

se TbTipoFundacao['Gfuste'] = 'Circular' então

area $:=\operatorname{Sqr}($ TbEFCircular['Dfuste']) $* \pi / 4$

senão

area $:=\left(\operatorname{Sqr}\left(\operatorname{TbEFCircular}\left[{ }^{[} D\right.\right.\right.$ fuste'] $)-\operatorname{Sqr}\left(\operatorname{TbEFCircular}\left[{ }^{[} \text {Dinterno'] }\right)\right)^{*} \pi / 4$;

fim se

enquanto não finalizar TbEDCircular faça

coloque TbMFEF em modo de inserção;

TbMFEF['Cod_UF'] := TbUFCircular['Cod_UF'];

TbMFEF['Cod_EUF'] $:=$ TbEFCircular['Cod_EFC'] 
TbMFEF['Cod_EDF'] := TbEDCircular['Cod_EDC'];

TbMFEF['Valor'] := (TbEDCircular['Zinicial']-TbEDCircular['Zfinal'])/(area*E); retire TbMFEF de modo de inserção;

Acresça a variável chave de TbEDCircular de um valor unitário;

fim enquanto;

Acresça a variável chave de TbEFCircular de um valor unitário;

fim enquanto;

Acresça a variável chave de TbUFCircular de um valor unitário;

fim enquanto;

\{fuste circular ou circular vazado\}

senão

posiciona TbUFPrismatico no primeiro valor da variável chave principal; enquanto não finalizar TbUFPrismatico faça

enquanto não finalizar TbEFPrismatico faça

$\mathrm{E}:=$ TbMaterialConstrucao['Young'];

area $:=$ TbEFPrismatico['LadoX']*TbEFPrismatico['LadoY'];

enquanto não finalizar TbEDPrismatico faça

coloque TbMFEF em modo de inserção;

TbMFEF['COD_UF'] := TbUFPrismatico['Cod_UF'];

TbMFEF['COD_EUF'] := TbEFPrismatico['Cod_EFP'];

TbMFEF['COD_EDF'] := TbEDPrismatico['Cod_EDP']

TbMFEF['Valor'] := (TbEDPrismatico['Zinicial']-TbEDPrismatico['Zfinal'])/(area*E);

acresça a variável chave de TbEDPrismatico de um valor unitário;

fim enquanto;

acresça a variável chave de TbEFPrismatico de um valor unitário;

fim enquanto;

acresça a variável chave de TbUFPrismatico de um valor unitário;

fim enquanto;

feche TbMFEF;

fim se; \{prismático\}

fim com;

\{procedimento de cálculo da MFEF\}

fim procedimento;

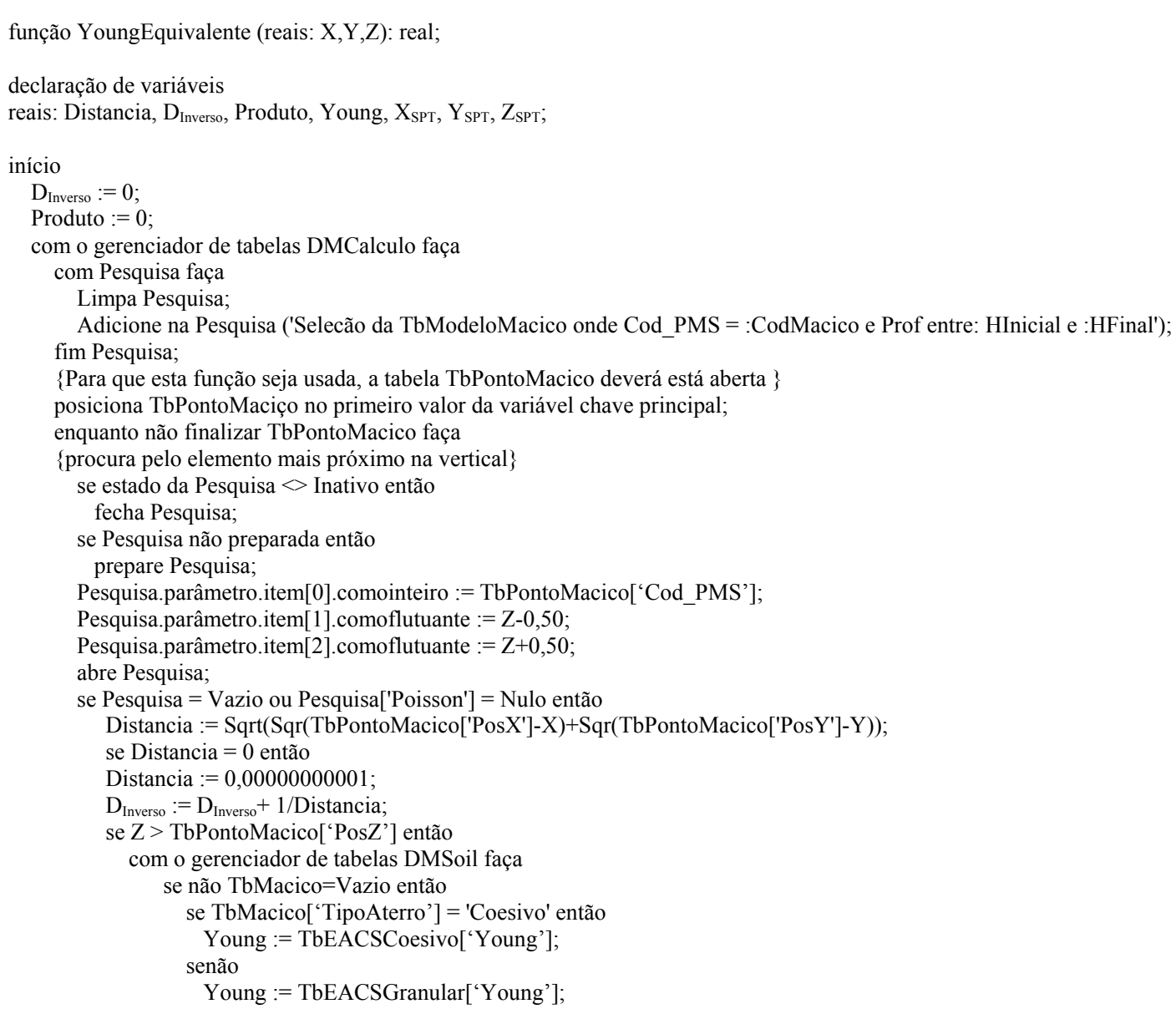




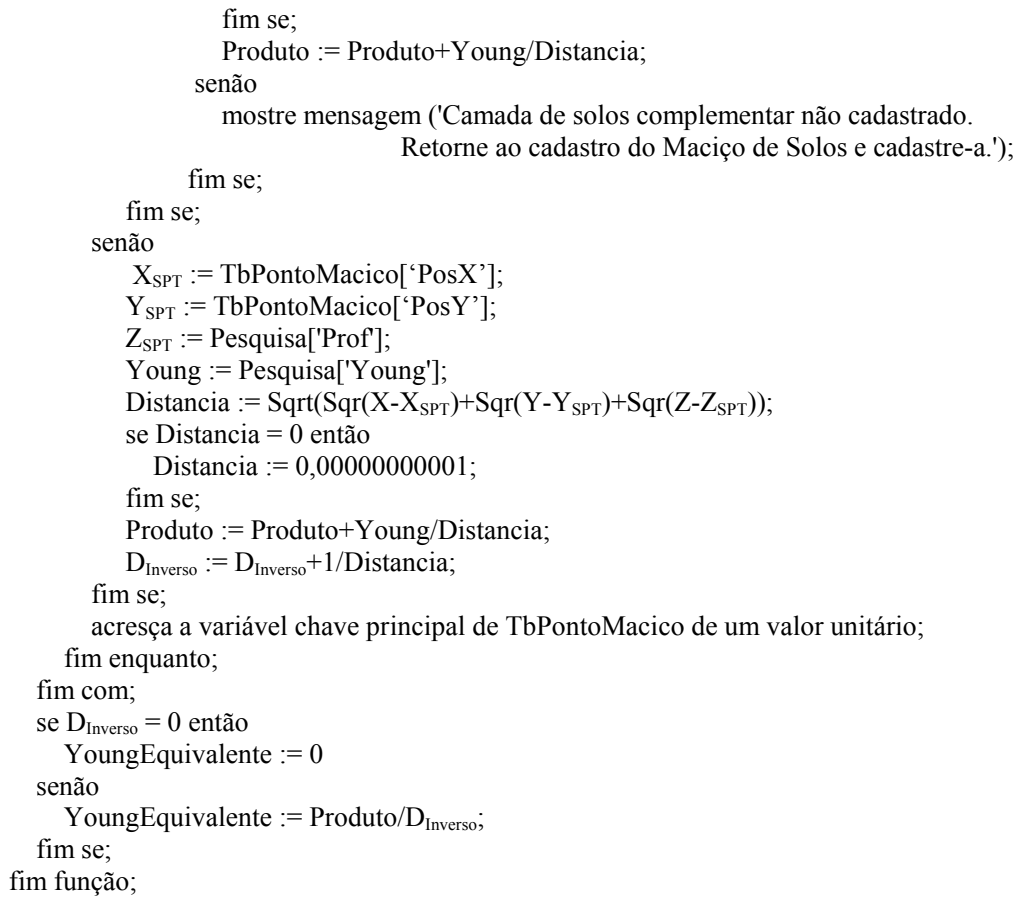

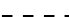

função PoissonEquivalente (reais: $\mathrm{X}, \mathrm{Y}, \mathrm{Z})$ : real;

declaração de variáveis

reais: Distancia, $\mathrm{D}_{\text {Inverso }}$, Produto, Poisson, $\mathrm{X}_{\mathrm{SPT}}, \mathrm{Y}_{\mathrm{SPT}}, \mathrm{Z}_{\mathrm{SPT}}$;

início

$\mathrm{D}_{\text {Inverso }}:=0$

Produto : $=0$;

com o gerenciador de tabelas DMCalculo faça

com Pesquisa faça

Limpa Pesquisa;

Adicione na Pesquisa ('Selecão da TbModeloMacico onde Cod_PMS = :CodMacico e

fim Pesquisa;

Prof entre: FxInicial e :FxFinal');

\{Para que esta função seja usada, a tabela TbPontoMacico deverá está aberta \}

posiciona TbPontoMaciço no primeiro valor da variável chave principal;

enquanto não finalizar TbPontoMacico faça

\{procura pelo elemento mais próximo na vertical\}

se estado da Pesquisa $<>$ Inativo então

fecha Pesquisa;

se Pesquisa não preparada então

prepare Pesquisa;

Pesquisa.parâmetro.item[0].comointeiro := TbPontoMacico['Cod_PMS'];

Pesquisa.parâmetro.item[1].comoflutuante : $=\mathrm{Z}-0,50$;

Pesquisa.parâmetro.item[2].comoflutuante $:=\mathrm{Z}+0,50$;

abre Pesquisa;

se Pesquisa $=$ Vazio ou Pesquisa['Poisson'] $=$ Nulo então

Distancia := Sqrt(Sqr(TbPontoMacico['PosX']-X)+Sqr(TbPontoMacico['PosY']-Y));

se Distancia $=0$ então

Distancia $:=0,00000000001$;

DInverso := DInverso+ 1 /Distancia;

se Z > TbPontoMacico['PosZ'] então

com o gerenciador de tabelas DMSoil faça

se não TbMacico=Vazio então

se TbMacico['TipoAterro'] = 'Coesivo' então

Poisson := TbEACSCoesivo['Poisson'];

senão

Poisson := TbEACSGranular['Poisson'];

fim se

Produto := Produto+Poisson/Distancia;

senão

mostre mensagem ('Camada de solos complementar não cadastrado. 


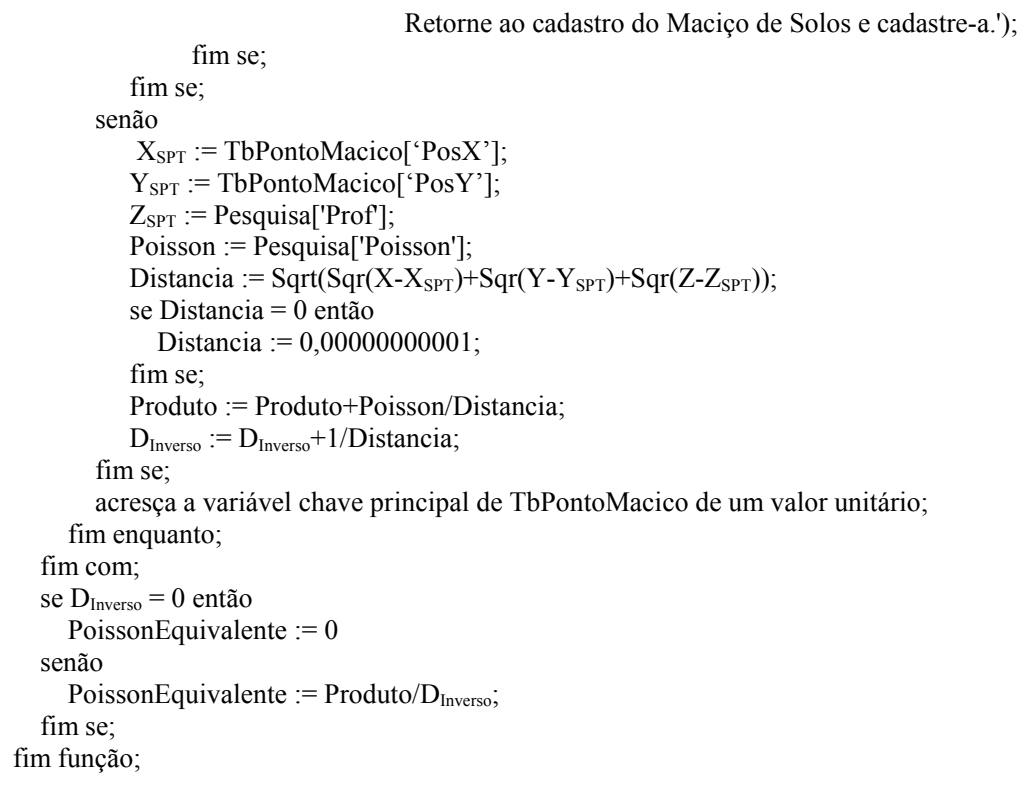

função PosicaoIndeslocavel(reais: X, Y): real;

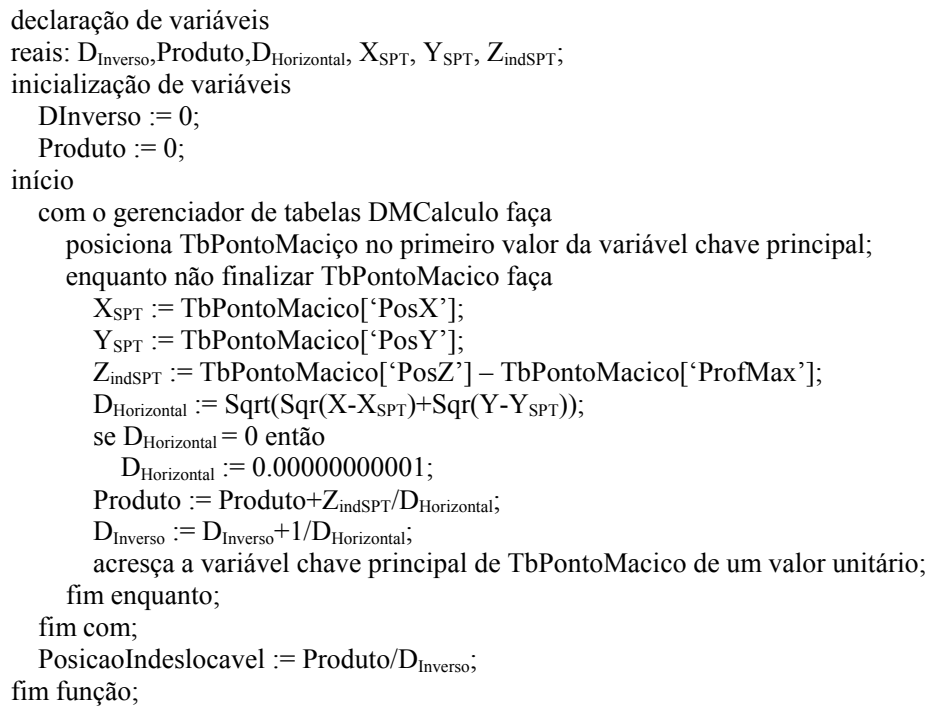

função SoluçãoMINDLIN (reais: E, $\mu$, c, $\mathrm{x}, \mathrm{y}, \mathrm{z}$, r; inteiro: quantelementos): real;

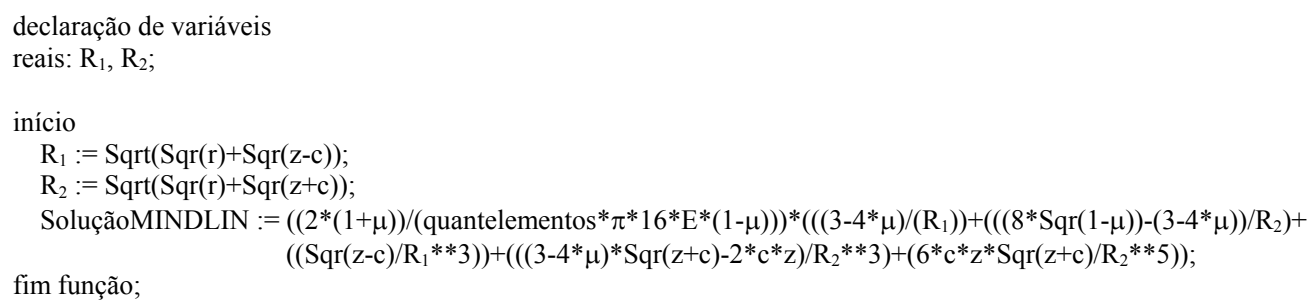

procedimento ModeloElasticoCamadas (reais: $\mathrm{X}_{\mathrm{B}}, \mathrm{Y}_{\mathrm{B}}, \mathrm{Z}_{\mathrm{B}}, \mathrm{NR}_{\mathrm{Apoio}}, \mathrm{Z}_{\text {Indeslocavel }}$ inteiro: $\mathrm{N}_{\text {Camada }}$; tipo tabela: Camada);

declaração de variáveis inteiro: $\mathrm{i}$; 


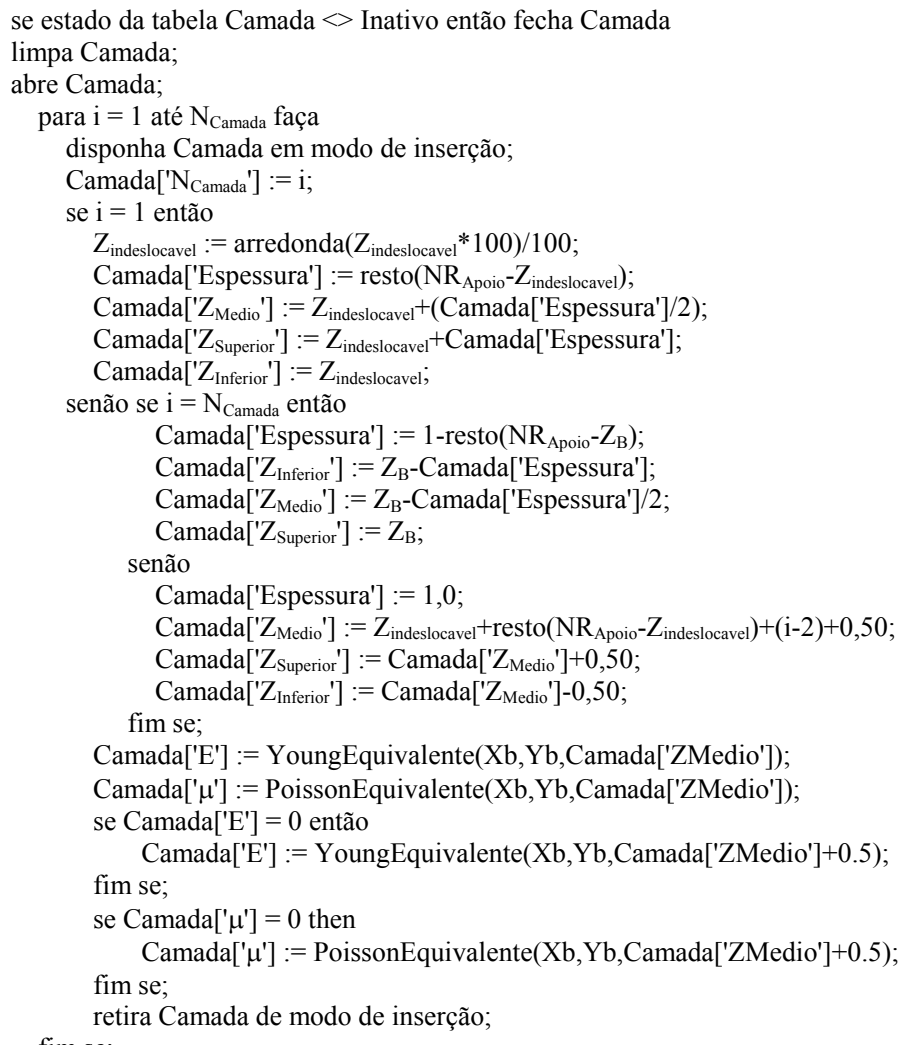

fim se;

\{Este procedimento carrega a tabela física TbCamada com os parâmetros geométricos e elásticos do maciço entre o ponto B em estudo (apoio da base) e o indeslocável na mesma direção vertical\} fim procedimento;

função FatorRecalqueBaseCircular(reais: $\mathrm{X}_{\mathrm{B}}, \mathrm{Y}_{\mathrm{B}}, \mathrm{X}_{\mathrm{A}}, \mathrm{Y}_{\mathrm{A}}, \mathrm{Z}_{\mathrm{A}}, \phi_{\mathrm{Base}}, \mathrm{NR}_{\mathrm{Apoio}}$; tabela: Camada): real;

declaração de constante

$\mathrm{cd}=0,10$;

declaração de variáveis

reais: fms, w, c, $x, y, \alpha, \beta, \theta, r_{0}, \rho, r$ : Real;

inteiros: $\mathrm{i}, \mathrm{j}, \mathrm{m}, \mathrm{n}$;

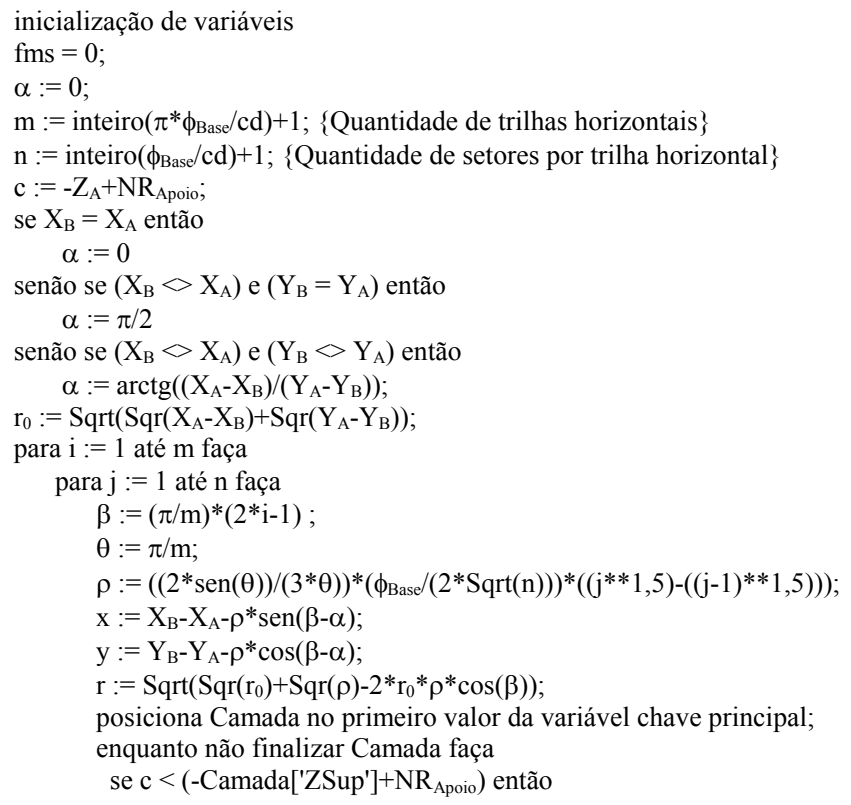


\{neste trecho do algoritmo aplica-se a hipótese de STEINBRENNER (1936) para considerar o indeslocável e a extensão dessa proposta por GIROUD (1972) para modelar a estratificação a cada metro\}

$\mathrm{w}:=$ SoluçãoMINDLIN(Camada['E'], Camada[' $\mu$ '], c, x, y, -Camada['Z $\left.Z_{\text {Superior }}{ }^{\prime}\right]+\mathrm{NR}_{\text {Apoio }}, \mathrm{r}, \mathrm{n}$ *m) -

SoluçãoMINDLIN(Camada['E'], Camada[' $\left.\mu^{\prime}\right]$, c, x, y, -

Camada[' $Z_{\text {Inferior }}$ '] $\left.\mathrm{NR}_{\text {Apoio }}, \mathrm{r}, \mathrm{n} * \mathrm{~m}\right)$;

senão se c $<$ (-Camada['Z $Z_{\text {Inferior }}$ '] $\left.+\mathrm{NR}_{\text {Apoio }}\right)$ então

$\mathrm{w}:=$ SoluçãoMINDLIN(Camada['E'], Camada[' $\mu$ '], c, x, y, C+0.00001, r, n*m)senão

SoluçãoMINDLIN(Camada['E'], Camada[' $\mu$ '], C, x, y, -Camada['Z $Z_{\text {Inferior }}$ ']+NR Apoio $_{\text {A }}$, r, n*m);

$\mathrm{w}:=0$;

fim se;

fim se;

fms := fms + w;

acresça a variável chave principal de Camada de um valor unitário;

fim enquanto;

fim para;

fim para;

FatorRecalqueBaseCircular := fms;

\{retorna o fator de recalque de um elemento discreto $(\mathrm{i}, \mathrm{j}, \mathrm{k})$ em relação ao ponto sob a ponta do elemento $(\mathrm{u}, \mathrm{v})\}$ fim função;

função FatorRecalqueFusteCircular(reais: $\mathrm{X}_{\mathrm{B}}, \mathrm{Y}_{\mathrm{B}}, \mathrm{X}_{\mathrm{A}}, \mathrm{Y}_{\mathrm{A}}, \mathrm{Z}_{\mathrm{A}}$, $\phi_{\mathrm{Fuste}}, \mathrm{L}, \mathrm{NR}_{\mathrm{Apoio}}$; tabela: Camada): real;

declaração de constantes

$\mathrm{cd}=0.10$

declaração de variáveis

reais: fms, w, c, $\mathrm{x}, \mathrm{y}, \alpha, \beta, \mathrm{r}_{0}$, r: Real;

inteiros: $\mathrm{i}, \mathrm{k}, \mathrm{m}, \mathrm{d}$;

inicialização de variáveis

fms $=0$;

$\alpha:=0$;

$\mathrm{m}:=$ inteiro $\left(\pi^{*} \phi_{\mathrm{Fust}} / \mathrm{cd}\right)+1 ;\{$ Quantidade de setores por trilha vertical $\}$

$\mathrm{n}:=$ inteiro $(\mathrm{L} / \mathrm{cd})+1 ;$ Q Quantidade de trilhas verticais\}

se $X_{B}=X_{A}$ então

$\alpha:=0$

senão se $\left(\mathrm{X}_{\mathrm{B}}>\mathrm{X}_{\mathrm{A}}\right)$ e $\left(\mathrm{Y}_{\mathrm{B}}=\mathrm{Y}_{\mathrm{A}}\right)$ então

$\alpha:=\pi / 2$

senão se $\left(X_{B}<X_{A}\right)$ e $\left(Y_{B}<>Y_{A}\right)$ então

$\alpha:=\operatorname{arctg}\left(\left(\mathrm{X}_{\mathrm{A}}-\mathrm{X}_{\mathrm{B}}\right) /\left(\mathrm{Y}_{\mathrm{A}}-\mathrm{Y}_{\mathrm{B}}\right)\right)$;

$\mathrm{r}_{0}:=\operatorname{Sqrt}\left(\operatorname{Sqr}\left(\mathrm{X}_{\mathrm{A}}-\mathrm{X}_{\mathrm{B}}\right)+\operatorname{Sqr}\left(\mathrm{Y}_{\mathrm{A}^{-}}-\mathrm{Y}_{\mathrm{B}}\right)\right)$;

para $\mathrm{i}=1$ até $\mathrm{m}$ faça

$\beta:=(2 * \pi * \mathrm{i}) / \mathrm{m}$

$\mathrm{x}:=\mathrm{X}_{\mathrm{B}}-\mathrm{X}_{\mathrm{A}}-\phi_{\mathrm{Fust}} / 2 * \operatorname{sen}(\beta-\alpha)$;

$\mathrm{y}:=\mathrm{Y}_{\mathrm{B}}-\mathrm{Y}_{\mathrm{A}}-\phi_{\mathrm{Fuste}} / 2 * \cos (\beta-\alpha)$;

$\mathrm{r}:=\operatorname{Sqrt}\left(\operatorname{Sqr}\left(\mathrm{r}_{0}\right)+\operatorname{Sqr}\left(\phi_{\text {Fuste }} / 2\right)-2 * \mathrm{r}_{0} *\left(\phi_{\text {Fuste }} / 2\right) * \cos (\beta)\right)$;

para $\mathrm{k}=1$ até $\mathrm{d}$ faça

$\mathrm{c}:=\left(-\mathrm{Z}_{\mathrm{A}}+\mathrm{NR}_{\mathrm{Apoio}}\right)+(\mathrm{L} /(2 * \mathrm{~d}))+(\mathrm{L} / \mathrm{d}) *(\mathrm{k}-1)$;

posiciona Camada no primeiro valor da variável chave principal;

enquanto não finalizar Camada faça

se c $<$ (-Camada['ZSup'] $+\mathrm{NR}_{\text {Apoio }}$ ) então

$\mathrm{w}:=$ SoluçãoMINDLIN(Camada['E'], Camada[' $\mu$ '], c, x, y, -Camada['Z $Z_{\text {Superior }}$ '] $+\mathrm{NR}_{\text {Apoio }}, \mathrm{r}, \mathrm{m}$ *d) -

SoluçãoMINDLIN(Camada['E'], Camada['mi'], c, x, y, -Camada['Z Inferior']+NR Apoio, r, m*d)

senão se $\mathrm{c}<\left(-\right.$ Camada[' $\left.\left.Z_{\text {Inferior }}{ }^{\prime}\right]+\mathrm{NR}_{\text {Apoio }}\right)$ então

$\mathrm{w}:=$ SoluçãoMINDLIN(Camada['E'], Camada[' $\mu$ '], c, x, y, c+0.00001, r, m*d)senão

SoluçãoMINDLIN(Camada['E'], Camada[' $\mu$ '], c, x, y, -Camada['Z $Z_{\text {Inferior' }}$ ] $+N_{\text {Apoio }}, r, m * d$ ) $\mathrm{w}:=0$

fim se;

fim se;

$\mathrm{fms}:=\mathrm{fms}+\mathrm{w}$

acreş̧a a variável chave principal de Camada de um valor unitário;

fim enquanto;

fim para;

fim para;

FatorRecalqueFusteCircular : = fms;

\{retorna o fator de recalque de um elemento discreto $(\mathrm{i}, \mathrm{j}, \mathrm{k})$ em relação ao ponto sob a ponta do elemento $(\mathrm{u}, \mathrm{v})$ \} fim função; 


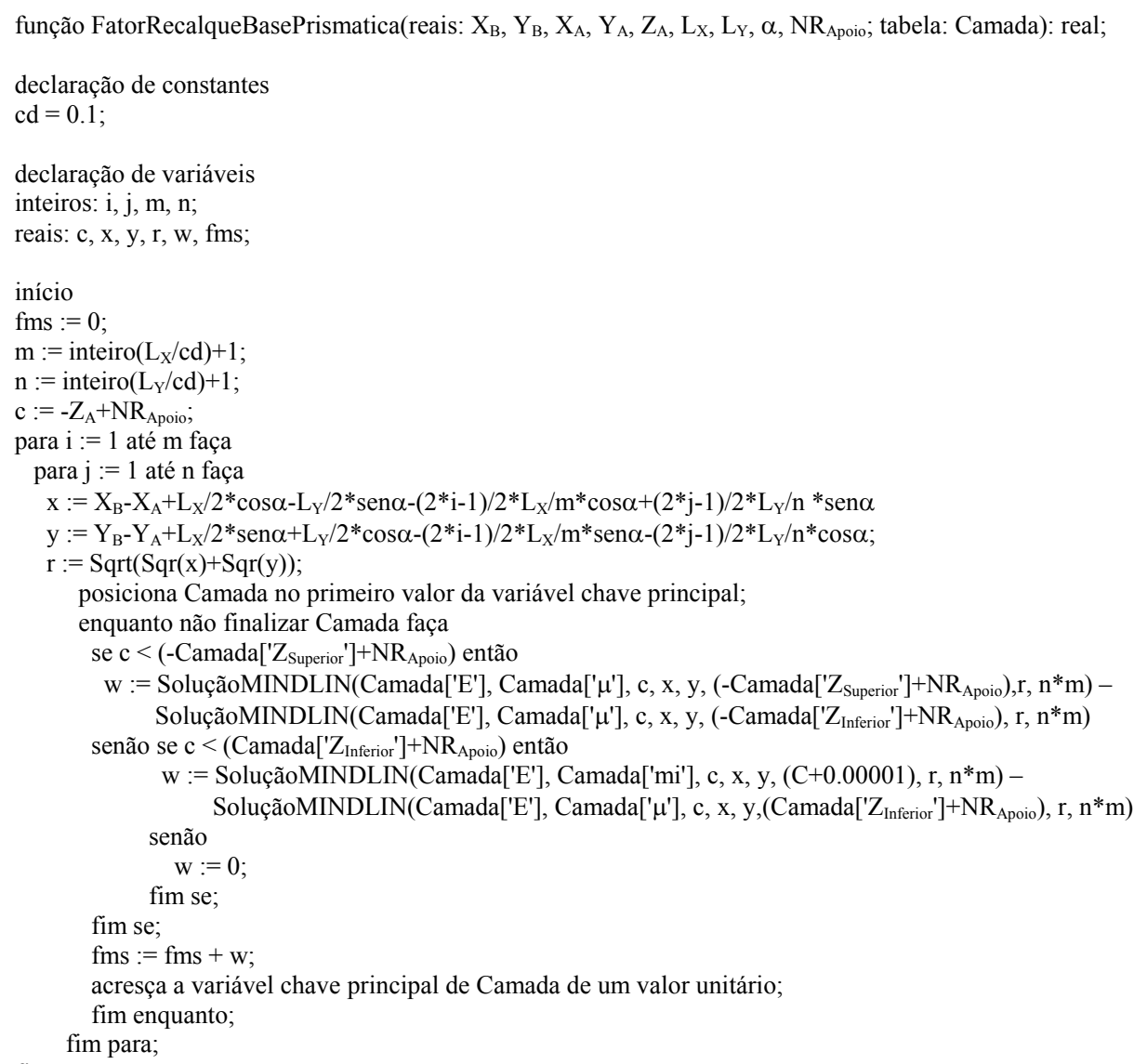
fim para;

FatorRecalqueBasePrismatica := fms;

\{retorna o fator de recalque de um elemento discreto $(\mathrm{i}, \mathrm{j}, \mathrm{k})$ em relação ao ponto sob a ponta do elemento $(\mathrm{u}, \mathrm{v})$ \} fim função;

função FatorRecalqueFustePrismatico(reais: $\mathrm{X}_{\mathrm{B}}, \mathrm{Y}_{\mathrm{B}}, \mathrm{X}_{\mathrm{C}}, \mathrm{Y}_{\mathrm{C}}, \mathrm{Z}_{\mathrm{C}}, \mathrm{L}_{\mathrm{X}}, \mathrm{L}_{\mathrm{Y}}, \alpha, \mathrm{L}, \mathrm{NR}_{\text {Apoio }}$; tabela: Camada): real;

declaração de constantes

$\mathrm{cd}=0.1$

declaração de variáveis

inteiros: $\mathrm{m}, \mathrm{n}, \mathrm{d}$;

reais: $\mathrm{X}_{\mathrm{A}}, \mathrm{Y}_{\mathrm{A}}, \mathrm{X}_{\mathrm{E}}, \mathrm{Y}_{\mathrm{E}}, \mathrm{X}_{\mathrm{F}}, \mathrm{Y}_{\mathrm{F}}, \mathrm{X}_{\mathrm{G}}, \mathrm{Y}_{\mathrm{G}}$;

função FatorRecalqueLadoFustePrismatico(reais: $\mathrm{X}_{\mathrm{M}}, \mathrm{Y}_{\mathrm{M}}, \mathrm{X}_{\mathrm{N}}, \mathrm{Y}_{\mathrm{N}}$; inteiros: nh, nv): real;

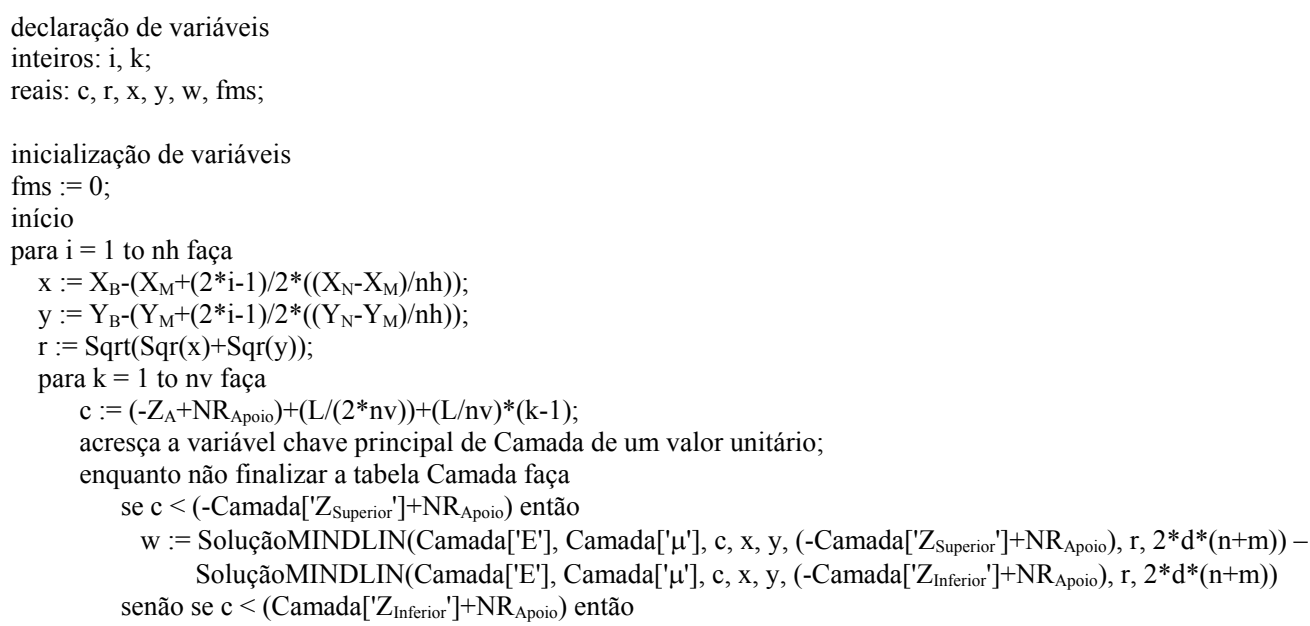




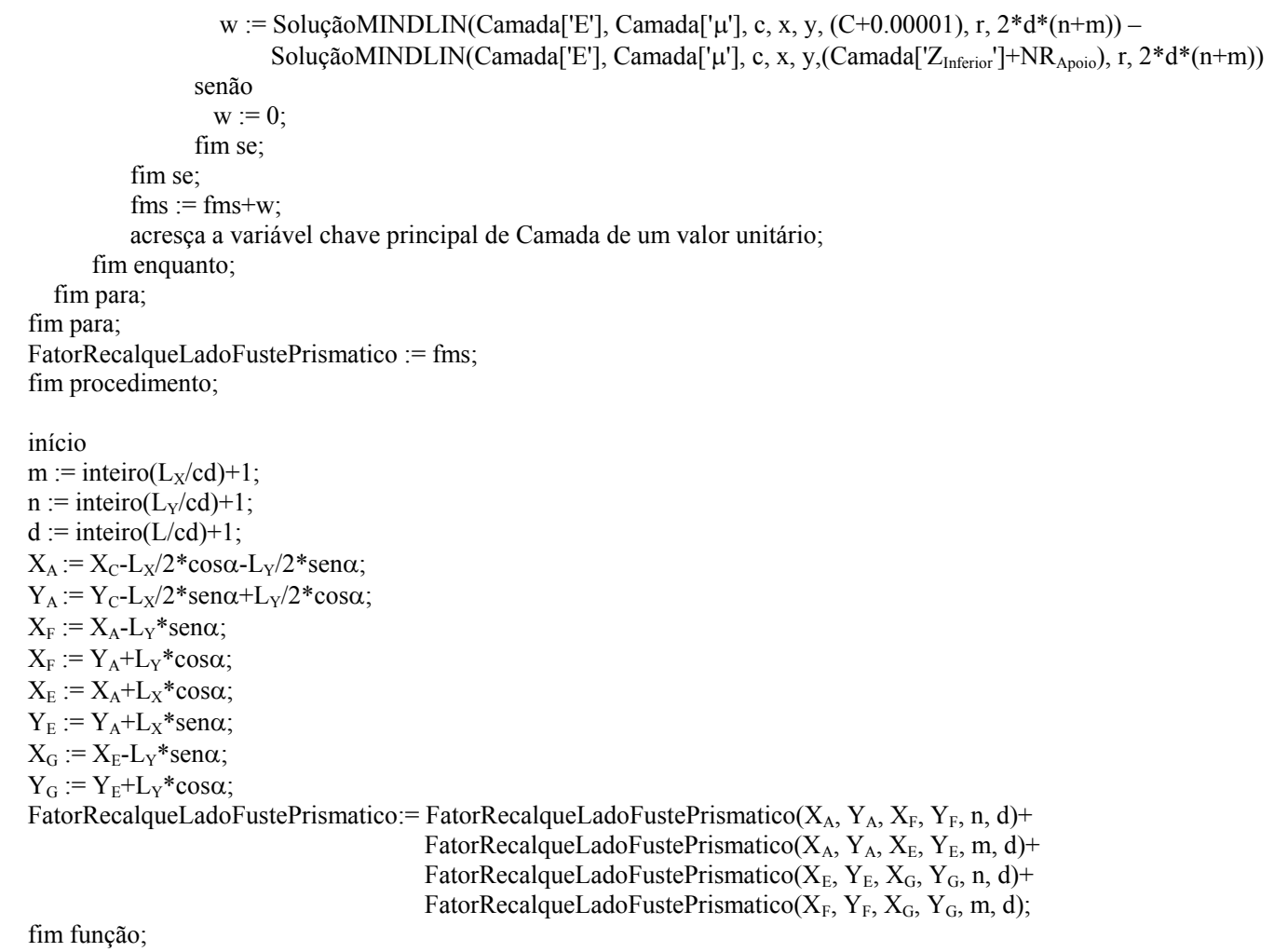

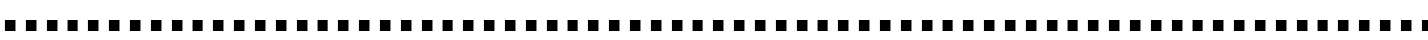

função GravaFatorRecalque (inteiros: uf, euf, ufaux, eufaux, edeufaux; reais: N): lógico;

com DMCalculo faça

tente

se estado TbMFMS = Inativo então

abra TbMFMS

coloque TbMFMS em modo de inserção

TbMFMS['Cod_UF'] :=uf;

TbMFMS['Cod EUF'] := euf;

TbMFMS['Cod_UFAUX'] := ufaux;

TbMFMS['Cod_EUFAUX'] := eufaux;

TbMFMS['Cod EDEUFAUX'] := edeufaux;

TbMFMS['N'] := N;

Retire TbMMS de modo de inserção;

GravaFatorRecalque := Verdadeiro;

senão

GravaFatorRecalque :=Falso;

fim tentativa;

fim com;

fim função;

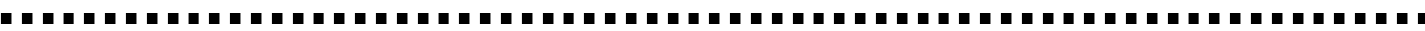

procedimento MFMS(reais: $\mathrm{NR}_{\text {Apoio }}$ );

declaração de variáveis

reais: $\mathrm{X}, \mathrm{Y}, \mathrm{Z}, \mathrm{X}_{\mathrm{B}}, \mathrm{Y}_{\mathrm{B}}, \mathrm{Z}_{\mathrm{B}}, \mathrm{Z}_{\text {indeslocavel }}, \phi_{\text {Base }}, \phi_{\text {Fuste }}, \mathrm{L}$, Valor;

inteiros: $\mathrm{N}_{\text {Camada }}$

lógicos: SeSuperficial, SePrismatica;

\{Procedimentos a serem tomados antes deiniciar cálculo da MFMS:

1- verificar se a obra esta aberta;

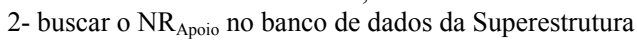

3- verificar se a Estrutura de Fundação é Circular ou Prismatica\}

início

com o gerenciador de tabelas DMCalculo faça

se TbMFMS $<$ Inativo então

fecha TbMFMS; 


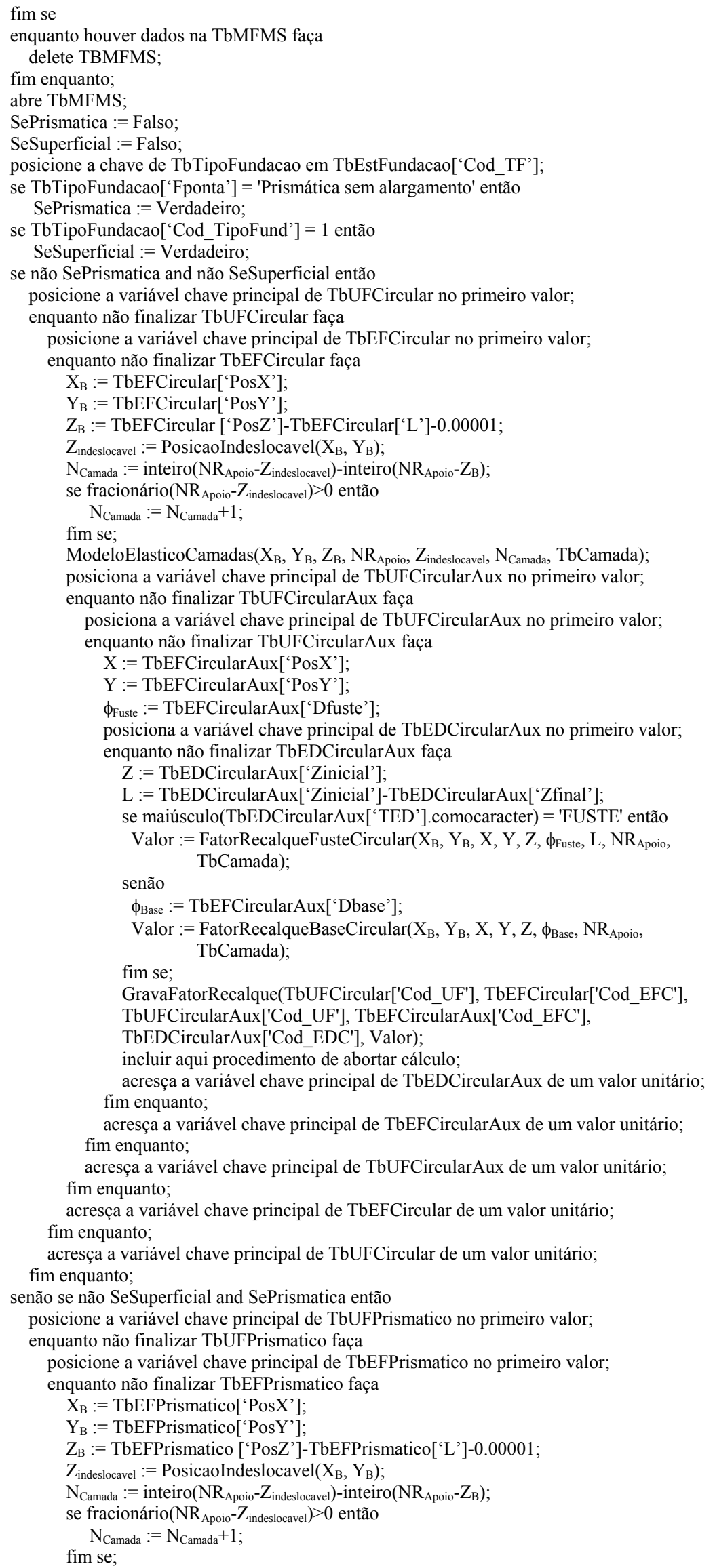


ModeloElasticoCamadas $\left(\mathrm{X}_{\mathrm{B}}, \mathrm{Y}_{\mathrm{B}}, \mathrm{Z}_{\mathrm{B}}, \mathrm{NR}_{\text {Apoio }}, \mathrm{Z}_{\text {indeslocavel }}, \mathrm{N}_{\text {Camada }}\right.$, TbCamada); posiciona a variável chave principal de TbUFPrismaticoAux no primeiro valor; enquanto não finalizar TbUFPrismaticoAux faça

posiciona a variável chave principal de TbUFPrismaticoAux no primeiro valor; enquanto não finalizar TbUFPrismaticoAux faça

$\mathrm{X}:=$ TbEFPrismaticoAux['PosX'];

$\mathrm{Y}:=$ TbEFPrismaticoAux['PosY'];

posiciona a variável chave principal de TbEDPrismaticoAux no primeiro valor; enquanto não finalizar TbEDPrismaticoAux faça

$\mathrm{Z}:=$ TbEDPrismaticoAux['Zinicial'];

$\mathrm{L}:=$ TbEDPrismaticoAux['Zinicial']-TbEDPrismaticoAux['Zfinal'];

se maiúsculo(TbEDPrismaticoAux['TED'].comocaracter) = 'FUSTE' então

Valor := FatorRecalqueFustePrismatico $\left(\mathrm{X}_{\mathrm{B}}, \mathrm{Y}_{\mathrm{B}}, \mathrm{X}, \mathrm{Y}, \mathrm{Z}\right.$,

TbEFPrismaticoAux['LadoX'], TbEFPrismaticoAux['LadoY'],

(TbUFPrismaticoAux['Angulo']* $\pi / 180$ ), L, $\mathrm{NR}_{\text {Apoio }}$, TbCamada);

senão

Valor := FatorRecalqueBasePrismatico $\left(\mathrm{X}_{\mathrm{B}}, \mathrm{Y}_{\mathrm{B}}, \mathrm{X}, \mathrm{Y}, \mathrm{Z}\right.$,

TbEFPrismaticoAux['LadoX'], TbEFPrismaticoAux['LadoY'],

(TbUFPrismaticoAuxAngulo.Value* $\pi / 180$ ), $\mathrm{NR}_{\text {Apoio }}$,

fim se;

TbCamada);

GravaFatorRecalque(TbUFPrismatico['Cod UF'],

TbEFPrismatico['Cod_EFP'],

TbUFPrismaticoAux['Cod UF'],

TbEFPrismaticoAux['Cod EFP'],

TbEDPrismaticoAux['Cod_EDP'], Valor);

incluir aqui procedimento de abortar cálculo;

acresça a variável chave de TbEDPrismaticoAux de um valor unitário;

fim enquanto;

acresça a variável chave principal de TbEFPrismaticoAux de um valor unitário; fim enquanto;

acresça a variável chave principal de TbUFPrismaticoAux de um valor unitário; fim enquanto;

acresça a variável chave principal de TbEFPrismatico de um valor unitário;

fim enquanto;

acresça a variável chave principal de TbUFPrismatico de um valor unitário; fim enquanto;

fim se;

se não SePrismatica e SeSuperficial então

posicione a variável chave principal de TbUFSupCircular no primeiro valor;

enquanto não finalizar TbUFSupCircular faça

$\mathrm{X}_{\mathrm{B}}:=$ TbUFSupCircular['PosicaoX'];

$\mathrm{Y}_{\mathrm{B}}:=$ TbUFSupCircular['PosicaoY'];

$Z_{\mathrm{B}}:=$ TbUFSupCircular['PosicaoX']-0.00001,

$\mathrm{Z}_{\text {indeslocavel }}:=$ PosicaoIndeslocavel $(\mathrm{Xb}, \mathrm{Yb})$;

$\mathrm{N}_{\text {Camada }}:=$ inteiro( $\left(\mathrm{NR}_{\text {Apoio }}-Z_{\text {indeslocavel }}\right)$-inteiro $\left(\mathrm{NR}_{\text {Apoio }}-Z_{\mathrm{B}}\right)$;

se fração( $\left(\mathrm{NR}_{\text {Apoio }}-Z_{\text {indeslocavel }}\right)>0$ então

$\mathrm{N}_{\text {Camada }}:=\mathrm{N}_{\text {Camada }}+1$

fim se;

ModeloElasticoCamadas $\left(X_{B}, Y_{B}, Z_{B}, N_{\text {Apoio }}, Z_{\text {indeslocavel }}, N_{\text {Camada }}, T b C a m a d a\right)$;

posicione a variável chave principal de TbUFSupCircularAux no primeiro valor; enquanto não finalizar TbUFSupCircularAux faça

$X:=$ TbUFSupCircularAux['PosicaoX'];

$\mathrm{Y}:=$ TbUFSupCircularAux['PosicaoY'];

$Z:=$ TbUFSupCircularAux['PosicaoZ'];

$\phi_{\text {Base }}:=$ TbUFSupCircularAux['DBase'];

Valor := FatorRecalqueBaseCircular $\left(\mathrm{X}_{\mathrm{B}}, \mathrm{Y}_{\mathrm{B}}, \mathrm{X}, \mathrm{Y}, \mathrm{Z}, \phi_{\text {Base }}, \mathrm{NR}_{\text {Apoio }}\right.$, TbCamada);

GravaFatorRecalque(TbUFSupCircular['Cod_UF'], TbUFSupCircular['Cod_UF'], TbUFSupCircularAux['Cod_UF']

TbUFSupCircularAux['Cod UF'],

TbUFSupCircularAux['Cod_UF'], Valor);

incluir aqui procedimento de abortar cálculo;

acresça a variável chave principal de TbSupCircularAux de um valor unitário;

fim enquanto;

acresça a variável chave principal de Tb SupCircular de um valor unitário;

fim enquanto;

senão se SePrismatica e SeSuperficial então

posicione a variável chave principal de TbUFSupPrismatico no primeiro valor;

enquanto não finalizar TbUFSupPrismatico faça

$\mathrm{X}_{\mathrm{B}}:=$ TbUFSupPrismatico ['PosicaoX'];

$\mathrm{Y}_{\mathrm{B}}:=$ TbUFSupPrismatico ['PosicaoY'];

$\mathrm{Z}_{\mathrm{B}}:=$ TbUFSupPrismatico ['PosicaoX']-0.00001; 


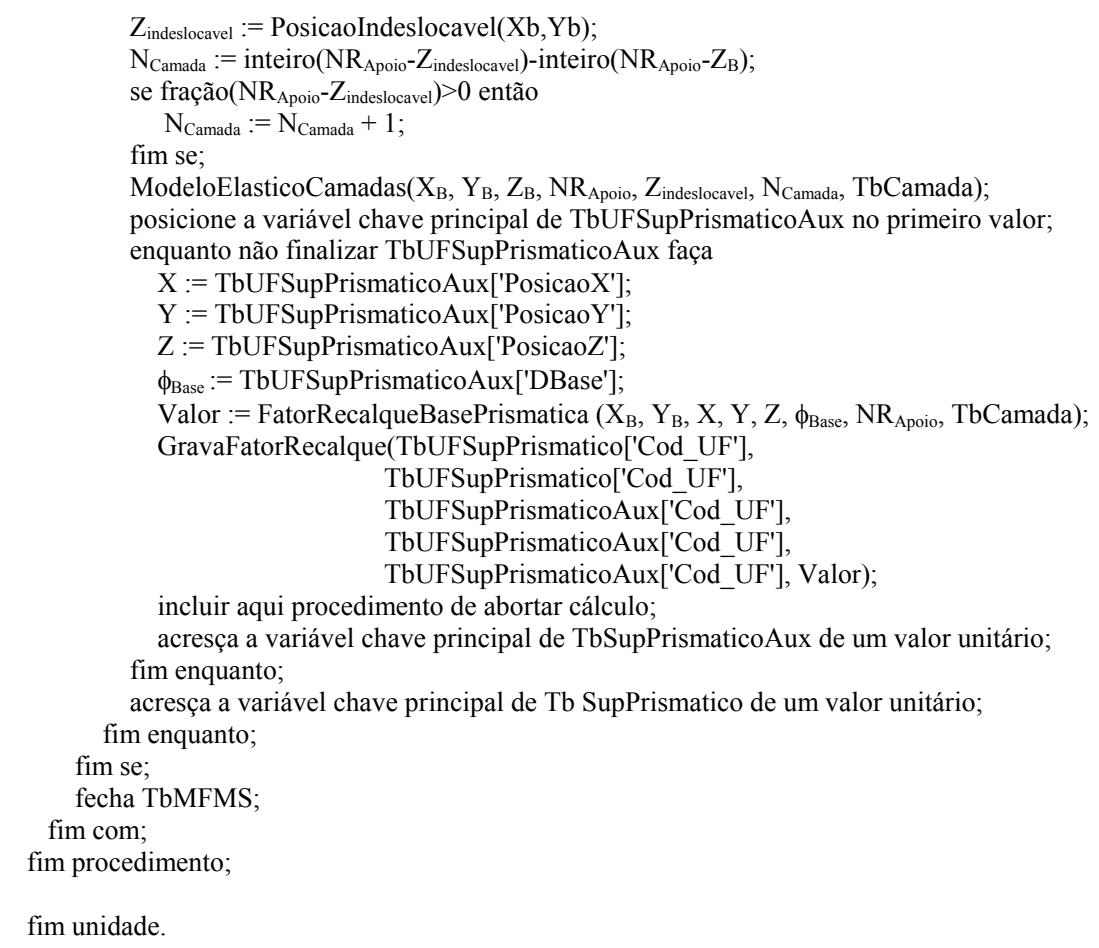




\section{Unidade Interacao}

interface

declarações privadas

procedimento Interacao;

função Convergencia(tabela: TbUF): lógico;

procedimento RecalqueFundacaoProfunda(tabelas: TbUF, TbEF, TbUFAux, TbEFAux, TbEDAux; logica: SePrismatica); procedimento RecalqueFundacaoSuperficial(tabelas: TbUF, TbUFAux);

declarações públicas

função CarregarMFMS: lógico;

declarações de variáveis

tipos formulários (janelas) e variáveis lógicas de eventos

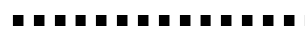

implementação

usa DMSoil, DMCalculo, Menuprincipal e relatórios

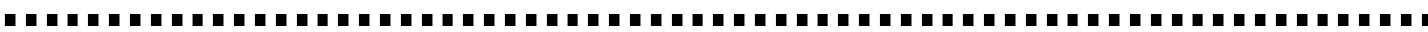

procedimento Interacao;

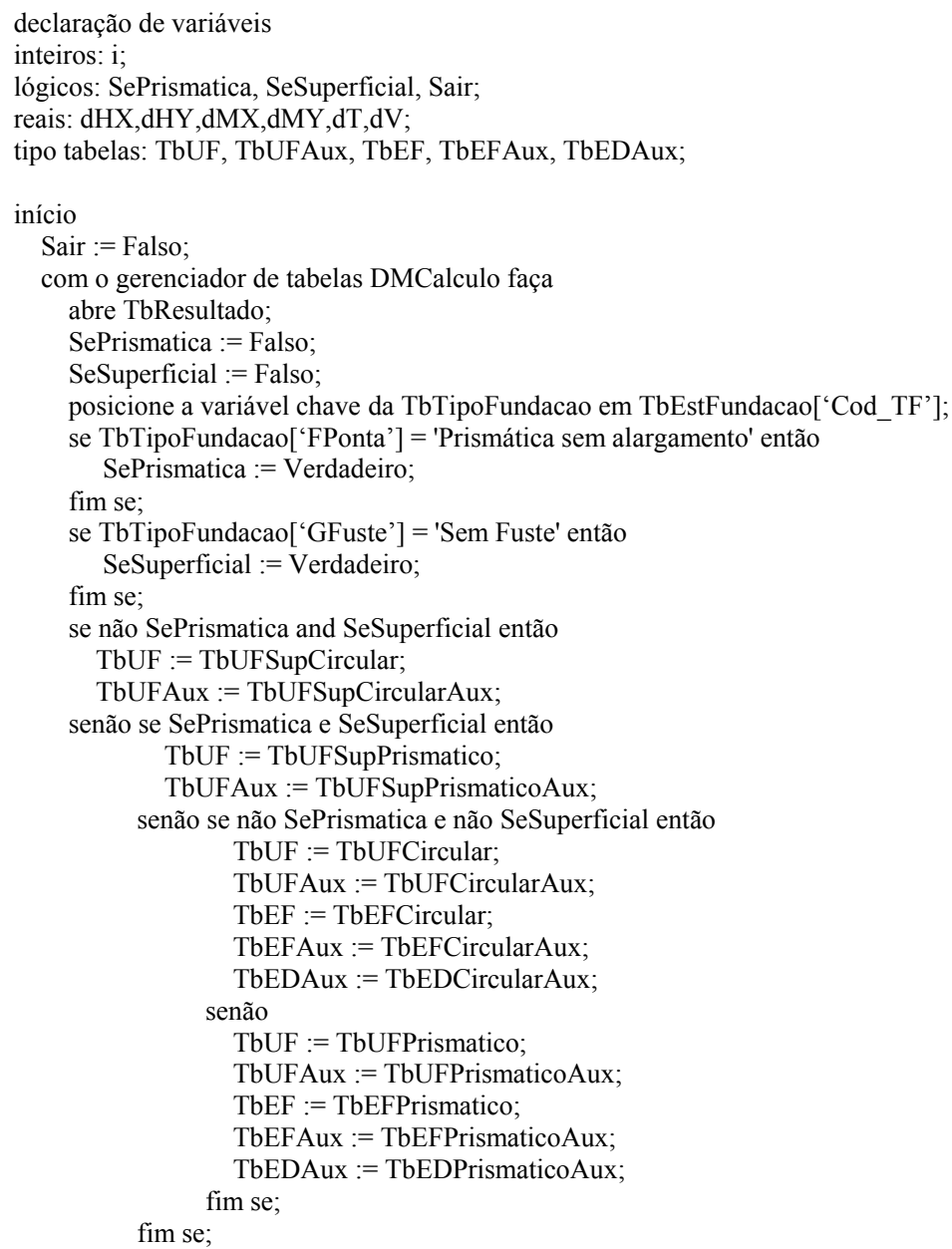


TbCarregamento['VAux1'] := TbCarregamento['V'];

TbCarregamento['VAux2'] := TbCarregamento[' $\mathrm{V}$ ']

TbCarregamento['VAux3'] := TbCarregamento['V'];

TbCarregamento['VAux4'] := TbCarregamento['V'];

TbCarregamento['VAux5'] := TbCarregamento['V'];

TbCarregamento['VAux6'] := TbCarregamento[' $\mathrm{V}$ '];

TbCarregamento['W'] :=0;

TbCarregamento['WAux'] := 0

retire TbCarregamento do modo de edição;

se a posicão de TbResultado for (TbObra['Cod_Obra'],TbUF['Cod_UF']) então

coloque TbResultado em modo de edição;

senão

coloque TbResultado em modo de inserção;

fim se;

TbResultado['Cod Obra'] := TbObra['Cod Obra'];

TbResultado['Cod_UF'] := TbUF['Cod_UF'];

TbResultado['Vi'] := TbCarregamento[' ${ }^{-} \mathrm{V}$ '];

TbResultado['HXi'] := TbCarregamento['HX']e;

TbResultado['HYi'] := TbCarregamento['HY'];

TbResultado['MXi'] := TbCarregamento['MX'];

TbResultado['MYi'] := TbCarregamento['MY'];

TbResultado['Ti'] := TbCarregamento['T'];

incremente a variável chave principal de TbUF da unidade;

fim enquanto

$\mathrm{i}:=0$;

repita

$\mathrm{i}:=\mathrm{i}+1$;

TbUF.First;

enquanto não finalizar TbUF faça

posicione as variáveis chaves da TbCarregamento na posição (TbObra['Cod Obra'],

TbUF['Cod_UF']);

coloque TbCarregamento em modo de edição;

TbCarregamento['VAux6'] := TbCarregamento['VAux5'];

TbCarregamento['VAux5'] := TbCarregamento['VAux4'];

TbCarregamento['VAux4'] := TbCarregamento['VAux3'];

TbCarregamento['VAux3'] := TbCarregamento['VAux2']

TbCarregamento['VAux2'] := TbCarregamento['VAux1'];

TbCarregamento['VAux1'] := TbCarregamento['V'];

TbCarregamento['V'] := (TbCarregamento['VAux1']+

TbCarregamento['VAux2']+TbCarregamento['VAux3']

TbCarregamento['VAux4']+TbCarregamento['VAux5']+

TbCarregamento['VAux6'])/6;

TbCarregamento['WAux'] := TbCarregamento['W'];

retire TbCarregamento do modo de edição;

incremente a variável chave principal de TbUF da unidade;

fim enquanto;

se SeSuperficial então

RecalqueFundacaoSuperficial(TbUF, TbUFAux)

senão

RecalqueFundacaoProfunda(TbUF, TbEF, TbUFAux, TbEFAux, TbEDAux,

SePrismatica);

posicione a variável chave da TbUFAux no primeiro valor; enquanto não finalizar TbUFAux faça

posicione as variáveis chaves da TbCarregamento na posição (TbObra['Cod_Obra'], TbUFAux['Cod UF']);

se $\mathrm{i}=1$ então

posicione as variáveis chaves da TbResultados na posição (TbObra['Cod_Obra'],

TbUFAux['Cod UF']]);

coloque a TbResultado em modo de edição;

TbResultado['DVrn'] := TbCarregamento['W'];

retire TbResultado do modo de edição;

fim se;

$\mathrm{dV}:=0$

posicione a variável chave da TbUF no primeiro valor;

enquanto não finalilizar TbUF faça

posicione as variáveis chaves da TbRigSuperestrutura na posição

(TbObra['Cod_Obra'], TbUF['Cod_UF'], TbUFAux['Cod_UF']]);

posicione as variáveis chaves da TbCarregamento na posição (TbObra['Cod Obra'],

$\mathrm{dV}:=\mathrm{dV}+$ TbCarregamento['W'] * TbRigSuperestrutura['fV'];

TbUF['Cod_UF']);

incremente a variável chave principal de TbUF da unidade;

fim enquanto;

posicione as variáveis chaves da TbResultado na posição ([TbObra['Cod_Obra'], 
TbUFAux['Cod_UF']]);

posicione as variáveis chaves da TbCarregamento na posição (TbObra['Cod_Obra'],

coloque TbCarregamento em modo de edição;

TbUFAux['Cod_UF']);

TbCarregamento['V'] := TbResultado['Vi'] + dV;

retire TbCarregamento de modo de edição;

incremente a variável chave de TbUFAux da unidade;

fim enquanto;

se i $>99$ então

Sair := não se Confirma('Processa mais uma interação?') = Verdadeiro; \{função lógica prédefinida $\}$ até Convergencia(TbUF) ou Sair;

se SeSuperficial então

RecalqueFundacaoSuperficial(TbUF, TbUFAux); senão

RecalqueFundacaoProfunda(TbUF,TbEF,TbUFAux,TbEFAux,TbEDAux,SePrismatica); posicione a variável chave da TbUFAux no primeiro valor; enquanto não TbUFAux faça

posicione as variáveis chaves da TbCarregamento na posição (TbObra['Cod Obra'], TbUFAux['Cod_ÜF']);

posicione as variáveis chaves da TbResultado na posição (TbObra['Cod Obra'],

coloque a TbResultado em modo de edição; TbUFAux['Cod_UF']]);

TbResultado['V'] := TbCarregamento[' $\mathrm{V}$ ']

TbResultado['DV'] := TbCarregamento['W'];

retire a TbResultado de modo de edição;

$\mathrm{dHX}:=0$;

$\mathrm{dHY}:=0$;

$\mathrm{dMX}:=0$

$\mathrm{dMY}:=0$

$\mathrm{dT}:=0$

posicione a variável chave da TbUF no primeiro valor;

enquanto não TbUF faça

posicione as variáveis chaves da TbRigSuperestrutura na posição

(TbObra['Cod_Obra'], TbUF['Cod_UF'], TbUFAux['Cod_UF']]);

posicione as variáveis chaves da TbCarregamento na posição (TbObra['Cod Obra'] TbUF['Cod_UF']);

$\mathrm{dHX}:=\mathrm{dHX}+\mathrm{TbCarregamento[}[\mathrm{W}$ ']*TbRigSuperestrutura['fHX']

$\mathrm{dHY}:=\mathrm{dHY}+\mathrm{TbCarregamento[}[\mathrm{W}$ '].Value*TbRigSuperestrutura['fHY'];

$\left.\mathrm{dMX}:=\mathrm{dMX}+\mathrm{TbCarregamento[} \mathrm{W}^{\prime}\right]$.Value*TbRigSuperestrutura['fMX'];

$\mathrm{dMY}:=\mathrm{dMY}+\mathrm{TbCarregamento[}{ }^{\prime} \mathrm{W}$ '].Value*TbRigSuperestrutura['fMY'];

$\mathrm{dT}:=\mathrm{dT}+\mathrm{TbCarregamento[}{ }^{\prime} \mathrm{W}$ '].Value*TbRigSuperestrutura['fT'];

incremente a variável chave de TbUFAux da unidade;

fim enquanto;

posicione as variáveis chaves da TbCarregamento na posição (TbObra['Cod_Obra'],

TbUFAux['Cod ÜF']);

posicione as variáveis chaves da TbResultado na posição (TbObra['Cod_Obra'],

coloque a TbCarregamento em modo de edição;

TbUFAux['Cod_UF']]);

coloque a TbResultado em modo de edição;

TbResultado['HX'] := TbResultado['HXi']+dHX;

TbResultado['HY'] := TbResultado['HYi']+dHY;

TbResultado['MX'] := TbResultado['MXi'].Value $+\mathrm{dMX}$

TbResultado['MY'] := TbResultado['Myi']+dMY;

TbResultado['T'] := TbResultado['Ti']+dT;

TbCarregamento['V'] := TbResultado['Vi'];

TbCarregamento['VAux1'] :=0;

TbCarregamento['VAux2'] : $=0$;

TbCarregamento['VAux3'] :=0;

TbCarregamento['VAux4'] :=0;

TbCarregamento['VAux5'] :=0;

TbCarregamento['VAux6'] :=0;

TbCarregamento['WAux'] :=0;

retire TbCarregamento de modo de edição;

retire TbCarregamento de modo de edição;

incremente a variável chave de TbUFAux da unidade;

fim enquanto;

fecha TbResultado;

fim com;

fim procedimento

função Convergencia(tabela: TbUF): lógica; 


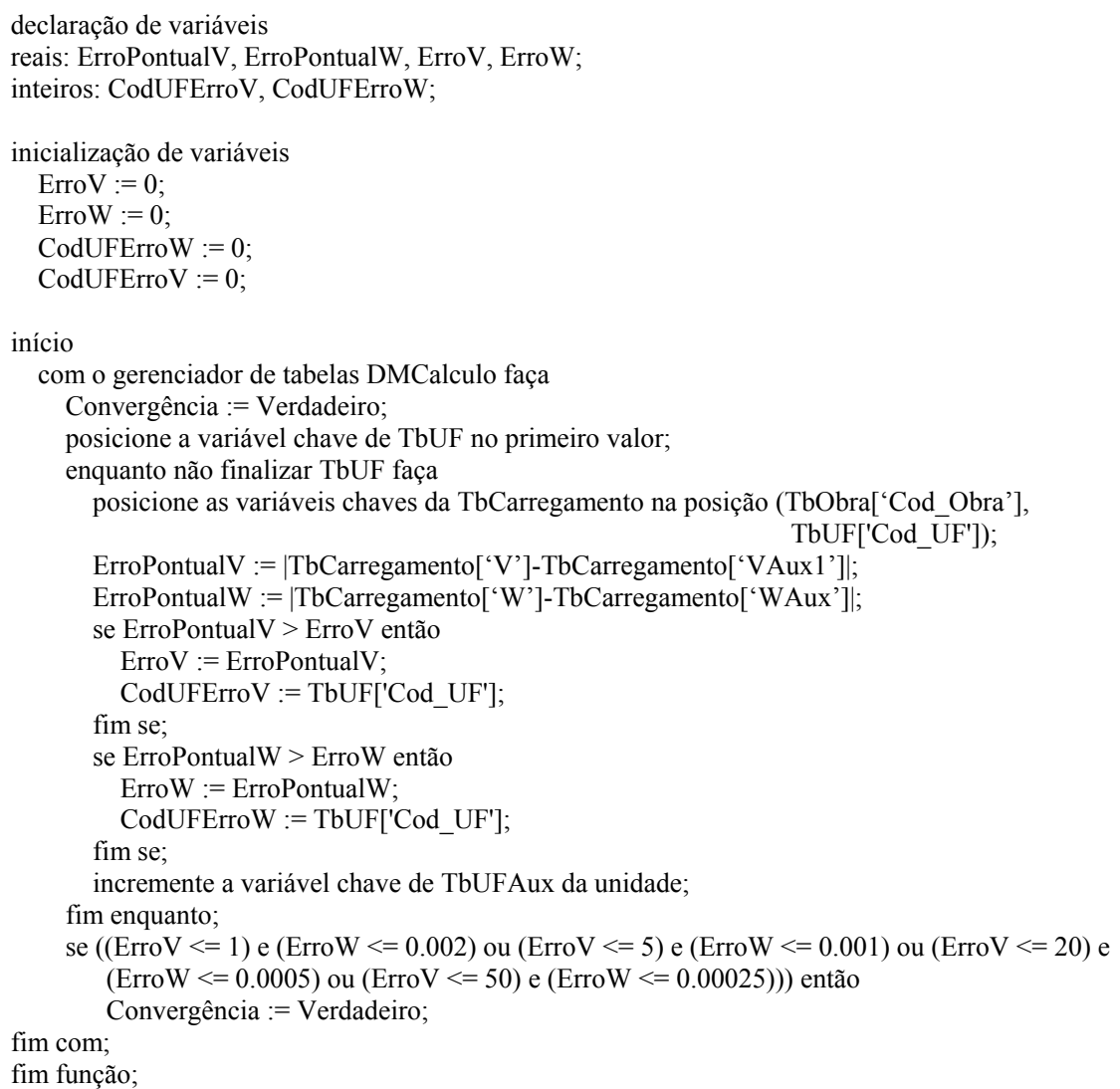

procedimento RecalqueFundacaoProfunda(tabelas: TbUF, TbEF, TbUFAux, TbEFAux, TbEDAux; SePrismatica: lógica);

declaração de variáveis

reais: Soma, CS, PTP, CargaUF, CargaEF, Resto, Pd, Pn, W;

inteiro: qe;

lógica: Acabou

byte: TF,i;

caracter: TT;

vetores $[1 . .10]$ de reais: PTF,q;

início

com o gerenciador de tabelas DMSoil faça

abra TbMTCGeral;

posicione a variável chave de TbMTCGeral em DMCalculo.TbEstFundacao['Cod_MTC'];

$\mathrm{CS}:=$ TbMTCGeral['CS'];

PTP $:=$ TbMTCGeral['PTPonta'];

$\mathrm{TF}:=$ TbMTCGeral['NTrecho']

TT := TbMTCGeral['Tipo'];

posicione a variável chave principal de TbMTCLocal no primeiro valor;

enquanto não finalizar TbMTCLocal faça

PTF[TbMTCLocal.NoArquivo] := TbMTCLocalPTFuste.comoflutuante;

incremente a variável chave principal de TbMTCLocal da unidade;

fim enquanto;

feche TbMTCGeral;

fim com;

com o gerenciador de tabelas DMCalculo faça

posicione a variável chave principal de TbUF no primeiro valor;

enquanto não finalizar TbUF faça

posicione a variável chave principal de TbEF no primeiro valor;

enquanto não finalizar TbEF faça

coloque TbEF em modo de edição;

$\mathrm{TbEF}\left[\mathrm{We}^{\prime}\right]:=0$;

$\mathrm{TbEF}\left[{ }^{\prime} \mathrm{Ws}\right]$ : $:=0$;

incremente a variável chave da TbEF da unidade;

fim enquanto; 
incremente a variável chave da TbUF da unidade;

fim enquanto;

posicione a variável chave principal de TbUFAux no primeiro valor;

enquanto não finalizar TbUFAux faça

posicione a variável chave principal de TbCarregamento em (TbObra['Cod_Obra'], TbUFAux['Cod UF']]);

CargaUF := TbCarregamento['V'];

CargaEF $:=$ CargaUF/TbEFAux.QtdedeArquivos;

posicione a variável chave principal de TbEFAux no primeiro valor;

enquanto não finalizar TbEFAux faça

qe := inteiro((TbEDAux.QtdedeArquivos-1)/TF);

Resto := resto((TbEDAux.QtdedeArquivos-1)/TF);

para $i:=1$ até $\mathrm{TF}$ faça

$\mathrm{q}[\mathrm{i}]:=\mathrm{qe}$

fim para;

$\mathrm{i}:=1$;

enquanto Resto $>0$ faça

$\mathrm{q}[\mathrm{i}]:=\mathrm{qe}+1$;

$\mathrm{i}:=\mathrm{i}+1$;

Resto := Resto-1;

fim enquanto;

i : $=1$;

Soma $:=0$

Resto := CargaEF;

Acabou :=False;

posicione a variável chave principal de TbEDAux no primeiro valor;

enquanto não finalizar TbEDAux faça

se TbEDAux. $\mathrm{N}^{\circ}$ Arquivo $>\mathrm{q}[\mathrm{i}]+$ Soma então

Soma :=Soma $+\mathrm{q}[\mathrm{i}]$

$\mathrm{I}:=\mathrm{i}+1$;

fim se;

se finalizou a TbEDAux então

$\mathrm{Pd}:=$-(TbEDAux['RInterface']/CS)*(PTP/100)

senão

$\mathrm{Pd}:=-($ TbEDAux['RInterface']/CS)*(PTF[i]/100);

fim se;

se $\mathrm{Pd}<=$ Resto então

Acabou := Verdadeiro;

$\mathrm{Pd}:=$ Resto;

fim se;

posicione a variável chave principal da TbUF no primeiro valor;

enquanto não finalizar TbUF faça

posicione a variável chave principal da TbEF no primeiro valor;

enquanto não finalizar TbEF faça

se SePrismatica então

posicione a variável chave de TbMFMS em (TbUF['Cod UF'], TbEF['Cod EFP'], TbUFAux['Cod_UF'],

TbEFAux['Cod_EFP'], TbEDAux['Cod_EDP'])

senão

posicione a variável chave de TbMFMS em (TbUF['Cod UF'],

TbEF['Cod EFC'], TbUFAux['Cod ÜF'],

coloque TbEF em modo de ediçào;

EFC'], TbEDAux['Cod EDC'])

TbEF['Ws'] := TbEF['Ws']+Pd*TbMFMS['N'];

retire TbEF do modo de edição;

incremente a variável chave de TbEF da unidade;

fim enquanto;

incremente a variável chave de TbUF da unidade;

fim enquanto;

$\operatorname{Pn}:=(2 *$ Resto-Pd $) / 2$;

se SePrismatica então

posicione a variável chave de TbMFEF em (TbObra['Cod Obra'], TbUFAux['Cod UF'], TbEFAux['Cod EFP'], TbEDAux['Cod_EDP'])

senão

posicione a variável chave de TbMFEF em (TbObra['Cod Obra'], TbUFAux['Cod UF'], TbEFAux['Cod EFC'],

fim se;

TbEDAux['Cod_EDC']);

coloque TbEFAux em modo de edição;

TbEFAux['We'] := TbEFAux['We']+Pn*TbMFEF['Valor'];

retire TbEFAux de modo de edição;

se não Acabou então

Resto := Resto - Pd

senão

fim enquanto;

fim se; 
incremente a variável chave de TbEDAux da unidade;

fim enquanto;

se Resto $<0$ então

se maiúsculo(TT) = 'SEQUENCIAL' então

posicione a variável chave principal de TbEDAux no primeiro valor;

enquanto não finalizar TbEDAux faça

se TbEDAux. $\mathrm{N}^{\circ}$ Arquivo > q[i]+Soma então

Soma $:=$ Soma $+\mathrm{q}[\mathrm{i}]$;

$\mathrm{i}:=\mathrm{i}+1$;

fim se;

se finalizou TbEDAux então

$\mathrm{Pd}:=-($ TbEDAux['RInterface'] $]$ CS $) *(\mathrm{PTP} / 100)$

senão

$\mathrm{Pd}:=-($ TbEDAux['RInterface']/CS)*(PTF[i]/100);

fim se;

se $\mathrm{Pd}<=$ Resto então

Acabou := Verdadeiro;

$\mathrm{Pd}:=$ Resto;

fim se;

posicione a variável chave de TbUF no primeiro valor;

enquanto não finalizar TbUF faça

posicione a variável chave de TbUF no primeiro valor; enquanto não finalizar TbEF faça

se SePrismatica então

posicione a variável principal de TbMFMS em

(TbUF['Cod_UF'], TbEF['Cod_EFP'], TbUFAux['Cod_UF'], senão

posicione a variável principal de TbMFMS em

(TbUF['Cod UF'], TbEF['Cod EFC'], TbUFAux['Cod UF'],

TbEFAux['Cod_EFC'], TbEDAux['Cod_EDC']]);

fim se;

coloque TbEF em modo de edição;

TbEF['Ws'] := TbEF['Ws'] +Pd*TbMIF['N'];

retire TbEF de modo de edição;

incremente a variavel principal de TbEF da unidade;

fim enquanto;

incremente a variável chave principal TbUF da unidade;

fim enquanto;

Pn := $(2 *$ Resto-Pd $) / 2$.

se SePrismatica então

posicione a variável chave principal de TbMFEF em (TbObra['Cod_Obra'],

TbUFAux['Cod UF'],

TbEFAux['Cod_EFP'],

TbEDAux['Cod_EDP'])

senão

posicione a variável chave principal de TbMFEF em (TbObra['Cod_Obra'],

TbUFAux['Cod UF']

TbEFAux['Cod_EFC'],

fim se;

TbEDAux['Cod EDC']);

coloque TbEF em modo de edição;

TbEF['We'] := TbEF['We']+Pn*TbMFEF['Valor'];

retire TbEF do modo de edição;

se não Acabou então

Resto := Resto - Pd

senão

fim enquanto;

incremente a variável chave principal de TbEDAux da unidade; fim enquanto;

fim se;

se Resto $<0$ então

posicione a variável principal de TbUF no primeiro valor;

enquanto não finalizar TbUF faça

posicione a variável principal de TbEF no primeiro valor;

enquanto não finalizar TbEF faça

se SePrismatica então

posicione a variável chave principal de TbMFMS em (TbUF['Cod UF'],

TbEF['Cod_EFP'],

TbUFAux['Cod UF']

TbEFAux['Cod EFP'],

senão 
posicione a variável chave principal de TbMFMS em (TbUF['Cod_UF'],

TbEF['Cod_EFC'],

TbUFAux['Cod UF'],

TbEFAux['Cod_EFC'],

fim se;

TbEDAux['Cod $\bar{E}$ DC']);

coloque TbEF em modo de edição;

TbEF['Ws'] := TbEF['Ws']+Resto*TbMFMS['N'];

retire TbEF do modo de edição;

incremente a variável chave principal de TbEF da unidade;

fim enquanto;

incremente a variável chave principal de TbUF da unidade;

fim enquanto;

fim se;

fim se;

incremente a variável chave principal de TbEFAux da unidade; fim enquanto;

incremente a variável chave principal de TbUFAux da unidade;

fim enquanto;

posicione a variável chave principal de TbUF no primeiro valor;

enquanto não finalizar TbUF faça

$\mathrm{W}:=0$

posicione a variável chave principal de TbUF no primeiro valor;

enquanto não finalizar TbEF faça

$\mathrm{W}:=\mathrm{W}+\mathrm{TbEF}\left[{ }^{\prime} \mathrm{Ws}\right.$ '] $+\mathrm{TbEF}\left[{ }^{\prime} \mathrm{We} '\right]$;

incremente a variável chave principal de TbEF da unidade;

fim enquanto;

$\mathrm{W}:=\mathrm{W} /$ TbEF.QtdedeArquivos;

se as variáveis chave de TbCarregamento $=($ TbObra['Cod_Obra'],

coloque TbCarregamento em modo de edição;

TbUF['Cod UF']]) então

TbCarregamento['W'] := W;

retire TbCarregamento do modo de edição;

fim se;

incremente a variável chave principal de TbUF da unidade;

fim enquanto;

fim com;

fim procedimento;

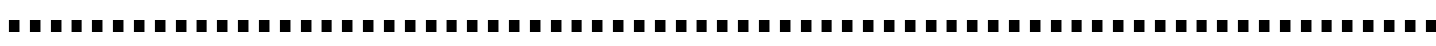

procedimento RecalqueFundacaoSuperficial (tabelas: TbUF, TbUFAux);

declaração de variáveis

reais: Ws;

início

com o gerenciador de tabelas DMCalculo faça

posicione as variáveis chave de TbUF no primeiro valor;

enquanto não finalizar TbUF faça

Ws : $=0$;

posicione as variáveis chave de TbUFAux no primeiro valor;

enquanto não finalizar TbUFAux faça

posicione as variáveis chave de TbMFMS em (TbUF['Cod_UF'], TbUF['Cod_UF'],

TbUFAux['Cod UF'], TbUFAux['Cod UF'],

Ws : = Ws + TbCarregamento['V']*TbMFMS['N'];

TbUFAux['Cod_UF']) então

incremente as variáveis chave de TbUFAux da unidade;

fim enquanto;

coloque TbUF em modo de edição;

TbUF['Ws'] := Ws;

retire TbUF de modo de edição;

posicione as variáveis chave de TbCarregamento em (TbObra['Cod_Obra'],

coloque TbCarregamento em modo de edição;

TbUF['Cod_UF']);

TbCarregamento['W'] := Ws;

retire TbCarregamento do modo de edição;

incremente as variáveis chave de TbUF da unidade;

fim enquanto;

fim com;

fim procedimento; 


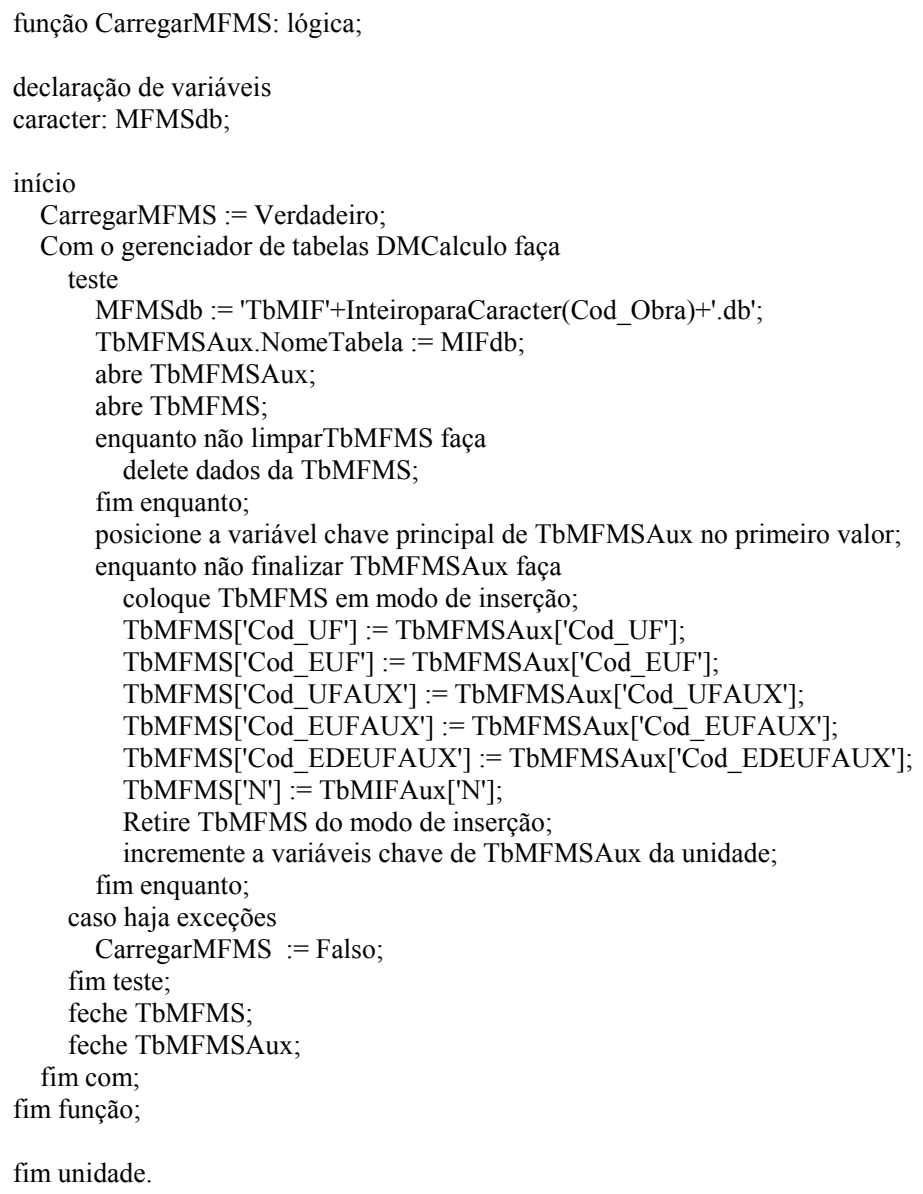




\section{Procedimentos e funções auxiliares (pré-processamento)}

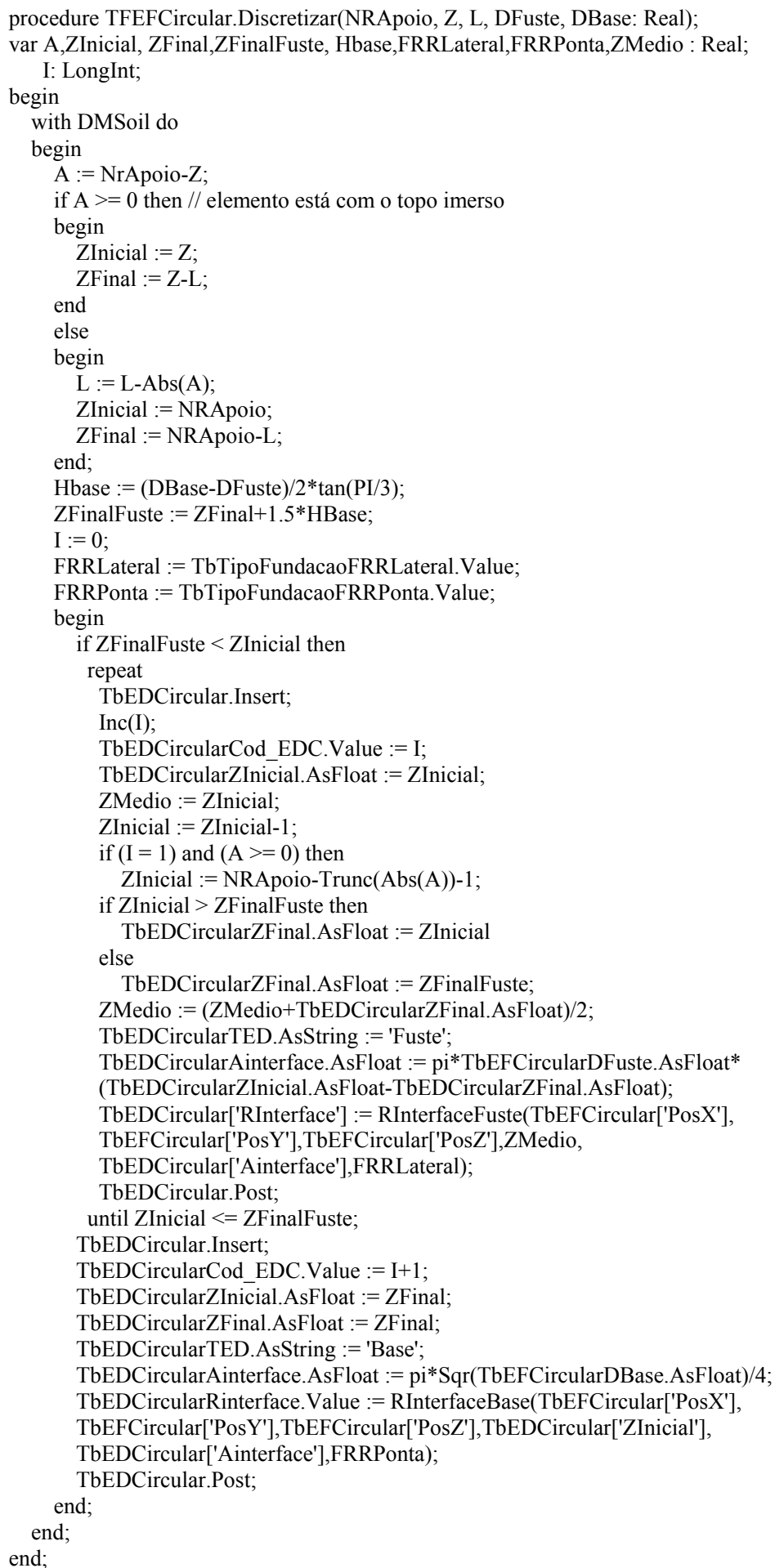

procedure TFEFPrismatico.Discretizar(NRApoio, Z, L: Real);

var A, ZInicial, ZFinal,FRRLateral,FRRPonta,ZMedio: Real;

I: LongInt;

begin

with DMSoil do

begin

A := NrApoio-Z;

if $\mathrm{A}>=0$ then 


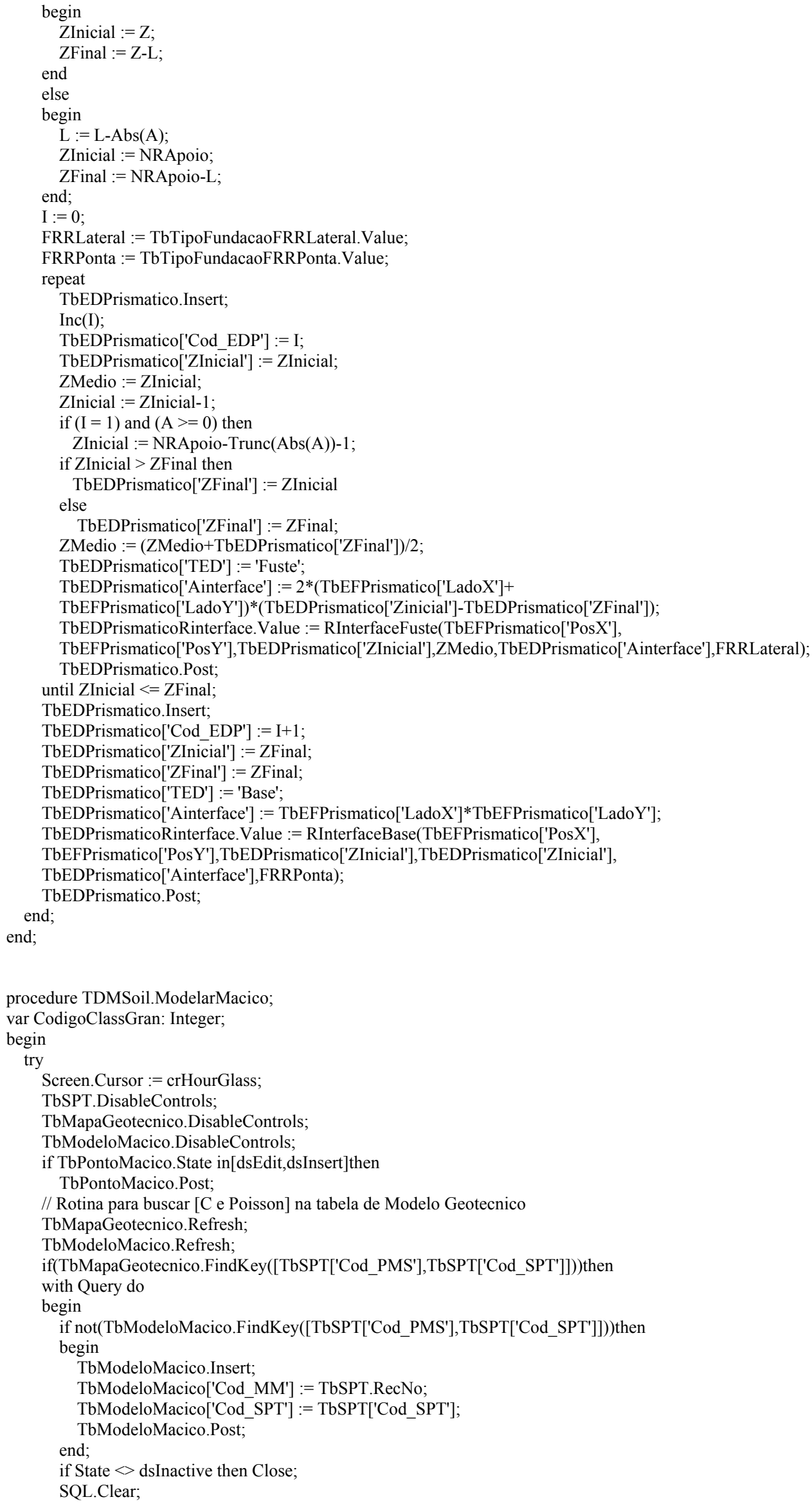


SQL.Add('Select * From TbClasGranulometrica Where Codigo = :prCodigo');

if not prepared then prepare;

if TbSPT['Cod_CGran'] = NULL then

Params.Items[0].AsInteger $:=0$

else

Params.Items[0].AsInteger := TbSPT['Cod_CGran'];

Open;

if not IsEmpty then

CodigoClassGran := Query['Cod_CGran'];

if State $<$ dsInactive then Close;

SQL.Clear;

SQL.Add('Select * From TbModeloGeotecnico Where $($ Cod_ClasGran = :prClasGran)');

SQL.Add(' and (Cod_Rocha $=$ :PrRocha) and $($ Cod_Genese $=:$ PrGenese) $)$ and $($ Cod_CGeotecnica $=$ :PrCGeotecnica)');

SQL.Add(' and (Cod FormGeologica $=:$ PrFormGeo $)$ and $\left.(\text { CodSan }=: \text { PrCondSat })^{\prime}\right)$;

if not Prepared then Prepare;

if TbSPT['Cod_CGran'] = NULL then

Params.Items[0].AsInteger $:=0$

else

Params.Items[0].AsInteger := CodigoClassGran;

if TbMapaGeotecnico['Cod_Rocha'] = NULL then

Params.Items[1].AsInteger : $=0$

else

Params.Items[1].AsInteger := TbMapaGeotecnico['Cod_Rocha'];

if TbMapaGeotecnico['Cod_Genese'] = NULL then

Params.Items[2].AsInteger $:=0$

else

Params.Items[2].AsInteger := TbMapaGeotecnico['Cod_Genese'];

if TbMapaGeotecnico['Cod_CGeotecnica'] = NULL then

Params.Items[3].AsInteger $:=0$

else

Params.Items[3].AsSmallInt := TbMapaGeotecnico['Cod_CGeotecnica'];

if TbMapaGeotecnico['Cod_FormGeo'] = NULL then

Params.Items[4].AsInteger $:=0$

else

Params.Items[4].AsSmallInt := TbMapaGeotecnico['Cod_FormGeo'];

if TbPontoMacico['NA'] >= TbSPT['Prof'] then // Condição saturada

Params.Items[5].AsString := 'Saturada'

else // Condição Não-Saturada

Params.Items[5].AsString := 'Não-Saturada';

Open;// executa a Sql

if not IsEmpty then

begin // resultados de $\mathrm{C}$ e Poisson

TbModeloMacico.Edit;

TbModeloMacico['Young'] := FieldValues['C']*TbModeloMacico['RPUU'];

TbModeloMacico['Poisson'] := FieldValues['Poisson']; end;

TbModeloMacico.Post;

end;// with query

// CalculaRIterface;

finally

TbSPT.EnableControls;

TbMapaGeotecnico.EnableControls;

TbModeloMacico.EnableControls;

Screen.Cursor : $=$ crDefault;

end;

end;

function TDMSoil.Requivalente(X,Y,Z,Zmedio,Ainterface:Real;TED:String):Double; var Distancia, Produto, DInverso, ResistenciaAterro: Real;

begin

if Query.State $>$ dsInactive then

Query.Close;

Query.SQL.Clear;

Query.SQL.Add('Select * From TbModeloMacico Where Cod_PMS = :CodMacico ');

Query.SQL.Add('and (Prof between :FxInicial and :FxFinal)');

Produto $:=0$

DInverso : $=0$;

TbPontoMacico.First;

//ShowMessage(InttoStr(TbPontoMacico.RecordCount));

while not TbPontoMacico.EOF do

begin 


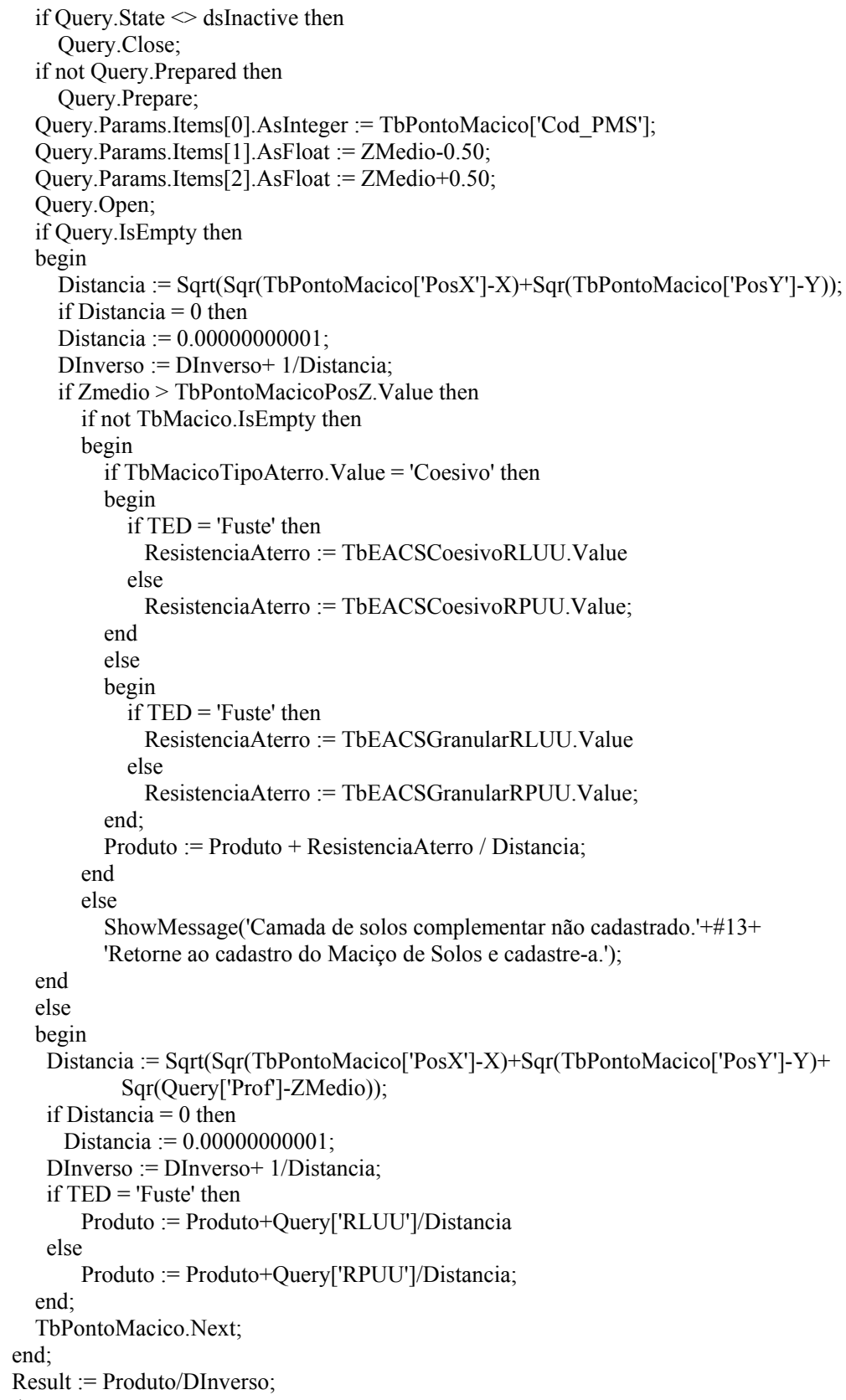


AbreTabela(TbPontoMacico);

AbreTabela(TbTipoFund);

AbreTabela(TbTipoFundacao);

AbreTabela(TbEstFundacao);

AbreTabela(TbUFCircular);

AbreTabela(TbUFPrismatico);

AbreTabela(TbEFCircular);

AbreTabela(TbEFPrismatico);

AbreTabela(TbEDCircular);

AbreTabela(TbEDPrismatico);

AbreTabela(TbUFSupCircular);

AbreTabela(TbUFSupPrismatico);

TbPontoMacico.DisableControls;

TbEstFundacao.Refresh;

FRRLateral :=0;

if TbEstFundacao.IsEmpty then

begin

ShowMessage('Estrutura de Fundação não encontrada.');

Exit;

end;

TbTipoFund.FindKey([TbEstFundacao['Tipo']]);

if TbTipoFundacao.FindKey([TbEstFundacao['Cod_TF']]) then

begin

FRRPonta := TbTipoFundacao['FRRPonta'];

if TbTipoFundacao['FRRLateral'] $<>$ NULL then

FRRLateral := TbTipoFundacao['FRRLateral']

end

else

begin

ShowMessage('Tipo de Fundação não cadastrado na Estrutura.');

Exit;

end;

if TbTipoFundacaoCod TipoFund.Value $=1$ then $/ /$ tipo fundacao $=$ superficial

begin // Condição de unidade superficial circular

if $(($ DMSoil.TbTipoFundacaoFPonta.Value $)=$ 'Circular sem alargamento')or

$(($ DMSoil.TbTipoFundacaoFPonta.Value $)=$ 'Circular alargada') then

begin

with DMSoil do

begin

TbUFSupCircular.First;

while not TbUFSupCircular.EOF do

begin

TbUFSupCircular.Edit;

TbUFSupCircular['RInterface'] := RInterfaceBase

(TbUFSupCircular['PosicaoX'],TbUFSupCircular['PosicaoY'],

TbUFSupCircular['PosicaoZ'],TbUFSupCircular['PosicaoZ'],

TbUFSupCircular['Ainterface'],FRRPonta);

TbUFSupCircular.Post;

TbUFSupCircular.Next;

end

else // Condição de unidade superficial Prismatica

begin

with DMSoil do

begin

TbUFSupPrismatico.First;

while not TbUFSupPrismatico.Eof do

begin

TbUFSupPrismatico.Edit;

TbUFSupPrismatico['RInterface'] := RInterfaceBase

(TbUFSupPrismatico['PosicaoX'], TbUFSupPrismatico['PosicaoY'],

TbUFSupPrismatico['PosicaoZ'], TbUFSupPrismatico['PosicaoZ'],

TbUFSupPrismatico['Ainterface'], FRRPonta);

TbUFSupPrismatico.Post;

TbUFSupPrismatico.Next end;

end;

end

else $/ /$ tipo fundacao $=$ Profunda

begin

if(AnsiUpperCase(TbTipoFundacaoGFuste.Value)= 'CIRCULAR') or 


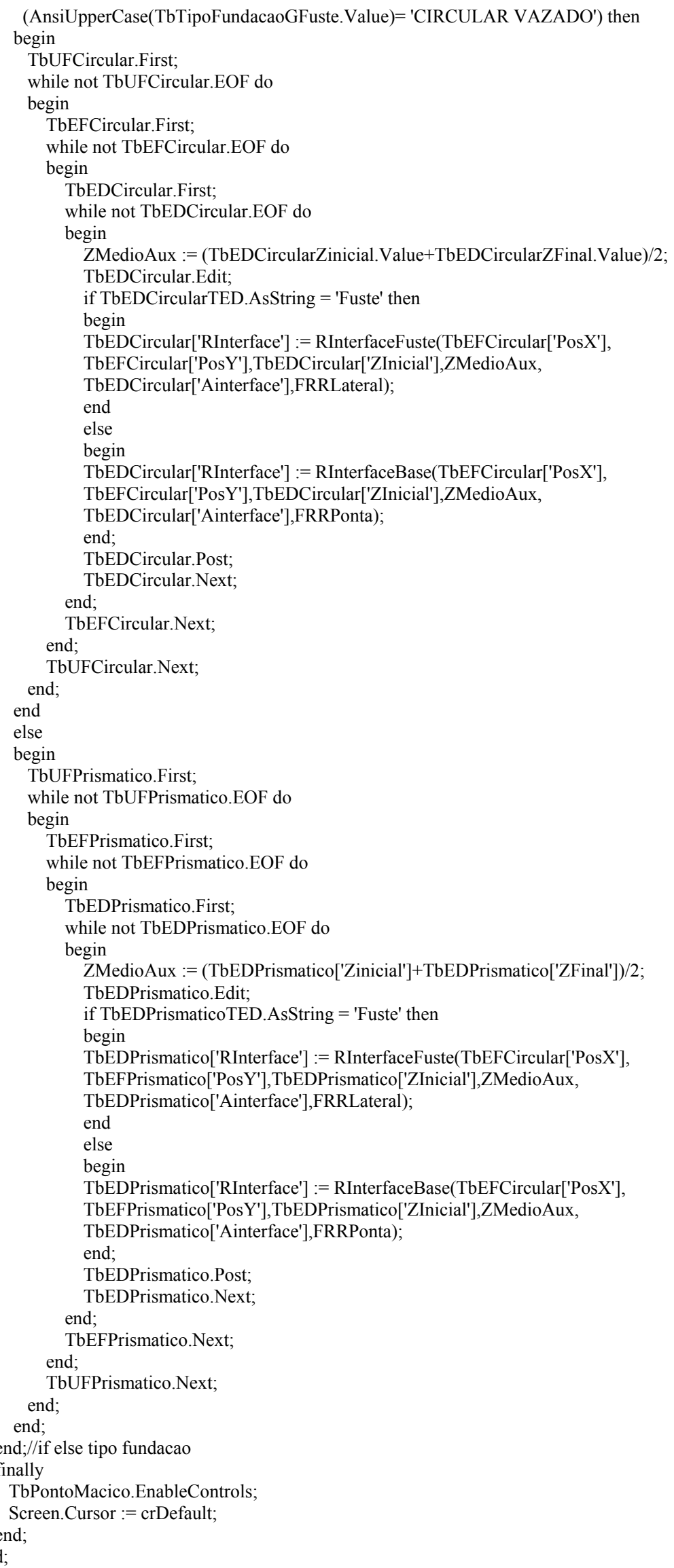




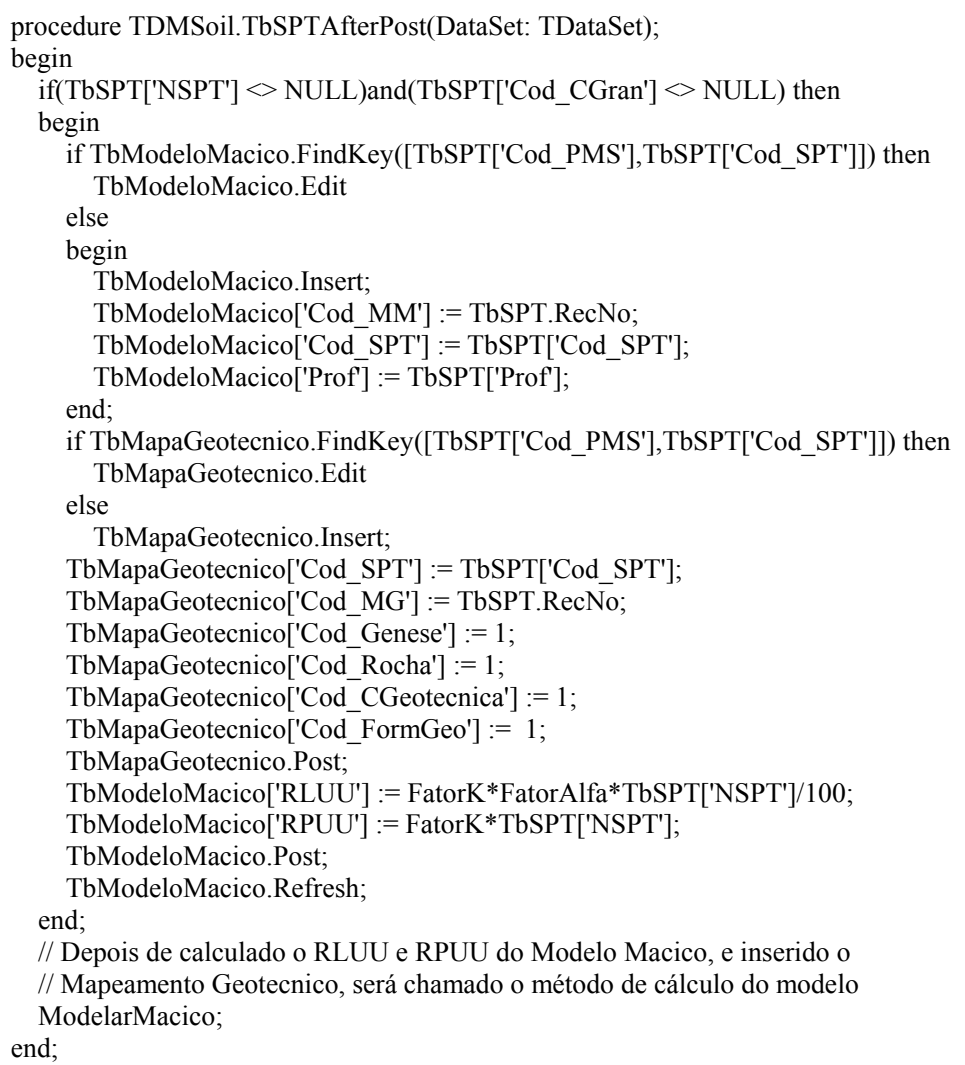




\section{REFERÊNCIAS BIBLIOGRÁFICAS}

AOKI, N.. Considerações sobre projeto e execução de fundações profundas. /Apresentado no Seminário de Fundações, Sociedade Mineira de Engenharia, Belo Horizonte, 1979/

AOKI, N. (1982). Considerações sobre o comportamento de grupo de estacas. In: Simpósio sobre o Comportamento de Fundações, PUC-RJ, Rio de Janeiro, p. 151-177.

AOKI, N. (1985). Considerações sobre previsão e desempenho de alguns tipos de fundações sobre ação de cargas verticais. In: Teoria e Prática de Fundações Profundas, UFRGS, Porto Alegre, p. 211-245.

AOKI, N.. Modelo simples de transferência de carga de estaca vertical sujeita a carga axial de compressão. /Apresentado no III Ciclo de palestras sobre Engenharia de Fundações, ABMS/NR Nordeste, Recife, 1987/

AOKI, N. (1997). Aspectos geotécnicos da interação estrutura - maciço de solos. In: Anais das Jornadas Sul - Americanas de Engenharia Estrutural, 28, v. 1, São Carlos, p. VII-XI.

AOKI, N.; AOKI, P. C. (1989). SOILDEF - Soil Deformation Program. Versão 3.0, São Paulo.

AOKI, N.; CINTRA, J. C. A. (1996). Influência da variabilidade do maciço de solos no comprimento de estacas. In: Seminário de Engenharia de Fundações Especiais e Geotecnia, 3, ABEF/ABMS-SP, v. I, novembro, São Paulo.

AOKI, N.; LOPES, F. R. (1975). Estimating stress and settlement due to deep foundation. Proceedings of $V^{\text {th }}$ Panamerican Conference on Soil Mechanics and Foundation Engineering, Tomo I, Buenos Aires, p. 377-386.

AOKI, N.; VELLOSO, D. A. (1975). An approximate method to estimate the bearing capacity of piles. Proceedings of $V^{\text {th }}$ Panamerican Conference on Soil Mechanics and Foundation Engineering, Buenos Aires, Tomo I, 367-376.

BAKER Jr., C. N.; AZAM, Ir. T.; JOSEPH, L. S. (1994). Settlement analysis for 450 meters tall KLCC towers. Geotechnical Special Publication, ASCE, v.2, n.40, p.1650-1671.

BARATA, F. E., (1987). Recalques de edifícios em fundações direta. Influência da rigidez da estrutura. Tese Professor Titular, UFRJ, Rio de Janeiro. 
BROWN, P. T.; YU, S. K. R. (1986). Load sequence and structure - foundation interaction. Journal of Geotechnical Engineering, ASCE, v. 112, nº GT3, p. 481-488.

BUTTERFIELD, R.; BANERJEE, P. K. (1971). The problem of pile group - pile cap interation. Geotechnique, v. 21, n. 2, p. 135-142.

BURLAND, J. B.; WROTH, C. P. (1974). Settlements of Buildings and associated damage. Proc. of Conference on Settlements of Structures, Cambridge, p. 611-654.

CHAMECKI, S. (1955). Consideração da rigidez da estrutura no cálculo dos recalques da fundação. In: Boletim Técnico do Departamento Nacional de Obras de Saneamento, Ministério da Viação e Obras Públicas, agosto, p. 05-29.

CHANDRASHEKHARA, K.; ANTONY, S. J. (1993). Theorical and experimental investigation framed structure - layered soil interation problems. Computers \& Structures, v. 48, n. 2, p. 263-271.

CHOW, Y. K. (1991). Pile-cap-pile-group interaction in nonhomogeneous soil. Journal of Geotechnical Engineering, v. 117, n. 11, p. 1655-1668.

DÉCOURT. L.; QUARESMA, A. R. (1978). Capacidade de carga de estacas a partir dos valores do SPT. In: Anais do VI COBRAMSEF, Salvador.

FONTE, A. O. C.; PONTES FILHO, I.; JUCÁ, J. F. T. (1994). Interação solo-estrutura em edifícios altos. In: Anais do X COBRAMSEF, Foz do Iguaçu, vol. 1, p. 239-246.

FRASER, R. A.; WARDLE, L. J. (1976). Numerical analysis of retangular rafts on layered foundation. Geotechnique, v. 26, n. 4, p. 613-630.

GERE, J. M.; WEAVER Jr., W. (1981). Análise de estruturas reticuladas. Rio de Janeiro, Ed. Guanabara Dois.

GIROUD, J. P. (1972). Tables pour le calcul des foundations. Dunod, Paris, toma 1, p. 10.

GODBOLE, P. N.; VILADKAR, M. N.; NOORZAEI, J. (1990). Nonlinear soil-structure interation analysis using coupled finite-infinite elements. Computers \& Structures, v. 36, n. 7, p. 1089-1096.

GUSMÃO, A. D. (1990). Estudo da interação solo-estrutura e sua influência em recalques de edificações. Dissertação(mestrado), COPPE/UFRJ, Rio de Janeiro.

GUSMÃO, A. D.; GUSMÃo FILHO, J. A . (1990). Um caso prático dos efeitos da interação solo-estrutura em edificações. In: Anais do IX COBRAMSEF, v.2, Salvador, p. 437-446.

GUSMÃO, A. D.; LOPES, F.R. (1990). Um método simplificado para consideração da interação solo-estrutura em edificações. In: Anais do IX COBRAMSEF, Salvador, p.447454. 
GUSMÃO, A . D.; GUSMÃO FILHO, J. A. (1994a). Avaliação da influência da interação solo-estrutura em edificações. In: Anais do X COBRAMSEF, Foz do Iguaçu, p. 67-72.

GUSMÃO, A .D.; GUSMÃO FILHO, J. A. (1994b). Constrution sequency effect on settlements of buildings. Proceedings of XIII ICSMFE, v. 2, New Delhi, p. 1803-1806.

GUSMÃO FILHO, J. A.; GUIMARÃES, L. J. N. (1997). Limit stiffness in soil structure interaction. Proceedings of XIV ICSMFE, p. 807-808.

HANSBO, S. (1993). Interaction problems related to the instalation of pile groups. In: Deep Foundations and Auger Piles, Van Impe (ed.), Balkema, Rotterdam, p. 59-67.

JUCÁ, J. F. T.; FONTES, A. O. C.; PONTES FILHO, I. D. S. (1994). Building performance founded on na improved sand in Recife, Brasil. Geotechnical Special Publication, ASCE, New York, , vol. 2, n. 40, p. 1202-1213.

KATZENBACH, R.; ARSLAN, U.; GUTWALD, J. (1994). A numerical study on pile foundation of the $300 \mathrm{~m}$ high Commerzbank tower in Frankfurt on main. In: Numerical Methods in Engineering Geotechnical, Smith (ed.), A. A. Balkema, Rotterdam, p.271277.

KATZENBACH, R.; ARSLAN, U.; GUTWALD, J.; HOLZHAÜSER, J. (1997). Soilstruture- interation of the $300 \mathrm{~m}$ high Commerzbank tower in Frankfurt main measurements and numerical studies. Proceedings of XIV ICSMFE, p. 1081-1084.

LANARCH, W. J. (1970). Computacion of settlements in building frames. In: Civil Egng. Pub. Wks. Rev., v. 65, p. 1040-1043.

LOPES, F. R.; GUSMÃO, A. D. (1991). On the soil-structure interation and its influence in the distribution of foundation loads and settlements. Proceedings of Xth ICSMFE, Firenze, vol. 1, p. 475-478.

MINDLIN, R. D. (1936). Force at a point in the inferior of a semi-infinite solid. In: Physics, vol. 7, p. 195-202.

MENDONÇA, J. C.; REIS, J. H. C.; AOKI, N. (1998). Considerações sobre a influência recíproca de fundações de prédios vizinhos em regiões de argila mole. In: Anais do XI COBRAMSEG, v. III, Brasília, p. 1527-1534.

MOURA, A. R. L. U. (1995). Interação solo-estrutura em edifícios. Dissertação (mestrado), UFPE, Recife.

NOORZAEI, J. ; VILADKAR, M. N.; GODBOLE, P. N. (1991). Soil-struture interation of space frame-raft-soil system - a parametric study. Computers \& Structures, v. 40, n. 5, p. 1235-1247. 
NOORZAEI, J.; GODBOLE, P.N.; VILADKAR, M. N. (1993). Nonlinear soil-structure interation of plane frames - a parametric study. Computers \& Structures, v. 49, n. 3, p. 561-566.

NOORZAEI, J.; VILADKAR, M. N.; GODBOLE, P. N. (1995a). Elastoplastic analysis for soil-structure interation in framed strutures. Computers \& Structures, v. 55, n. 5, p.797807.

NOORZAEI, J.; VILADKAR, M. N.; GODBOLE, P. N. (1995b). Influence of strain hardening on soil structure interaction of framed structures. Computers \& Structures, v. 55, n. 5, p. 789-795.

O’NEILL, M. W.; GHAZZALY, O. I.; HA, H. B. (1977). Analyses of three dimensional pile groups with non-linear response and pile-soil-pile interation. Proceedings of 9th Annual Offshore Technical Conference, Paper n. OTC 2838.

PINHO, C. R. A.; DE BRITO, P. S. V. (1986). TREFIC-86 - Interação estrutura-solo. Trabalho Especial de Fim de Curso, IME.

POLO, J. M.; CLEMENTE, J. L. M. (1988). Pile groups settlement using independent shaft and point loads. Journal of Geoth. Eng. Division, ASCE, v. 114, n. GT4, p. 469-487.

POULOS, H. G. (1968). The influence of a rigid pile cap on the settlement behavior of an axially loaded pile. In: Civil Eng. Trans. Inst. Civil Engrs. Aust., v. 1, CE 10, p. 206-208.

POULOS, H. G. (1972). Load-settlement prediction of piles and piers. Journal Soil Mechanics and Foundation Division, ASCE, v. 98, n. SM9, p. 879-897.

POULOS, H. G. (1975). Settlement analysis of structural foundation systems. Proceedings of IVth South-East Asian Conference on Soil Engineering, Kuala Lumpur, v. IV, p. 52-62.

POULOS, H. G.; DAVIS, E. H. (1980). Pile foundation analysis and design. New York, Jonh Wiley and Sons, 397p..

RAMALHO, M. A; CORREA, M. R. S. (1991). Interação solo-estrutura para edifícios sobre fundações direta. In: Anais das Jornadas Sul-Americanas de Engenharia Estrutural, 25,Porto Alegre, v. II, p. 433-444.

RANDOLPH, M. F.; WROTH, C. P. (1979). An analysis of the vertical deformation of piles groups. Geotechnique, v. 29, n. 4, p. 423-439.

RIBEIRO, J. L. S.; REIS, R. (1990). Sistema computacional da interação estrutura - solo. Trabalho Especial de Fim de Curso, IME.

RUMBAUGH, JAMES; BLAHA, MICHAEL; PREMERLANI, WILLIAM; EDDY, FREDERICK; LORENSEN, WILLIAM. (1994). Modelagem e projetos baseados em objetos. Trad. de Dalton Conde de Alencar, Rio de Janeiro, Campus , 648p.. 
SALES, M. M. (2000). Analise do comportamento de sapatas estaqueadas. Tese (Doutorado em Geotecnia). Departamento de Eng. Civil, UnB (em desenvolvimento).

SCHIEL, F., (1957). Estática de estaqueamento. Publicação n ${ }^{0}$ 10, Escola de Engenharia de São Carlos, USP, 142 p..

STAMATO, M. C., (1971). Cálculo elástico de estaqueamento. Publicação no 70, Escola de Engenharia de São Carlos, USP, 86p..

STEINBRENNER, W. (1934). Tafeln sur Setzungsberechnung. Die Strasse, v. 1, 121 p..

SRINIVASA RAO, P.; RAMBADU, K. V.; ALLAM, M. M. (1995). Representation of soil support in analysis of open plane frames. Computers \& Structures, v. 56, n. 6, p. 917-925.

VÉSIC, A. S. (1975). Principles of pile foundation design. Soil Mechanics Series, n. 38, School of Engineering, Duke University.

VÉSIC, A. S. (1977). Problems of development of a mathematical model predict performance of a pile group. Working Paper, Federal Highway Adm. Research Review Conference, Atlanta, George.

VELLOSO, D. A.; SANTOS, S. H. C. (1994). Análise de provas de cargas sobre estacas em solo. In: Anais do Ciclo de Palestras sobre Estacas Escavadas, Clube de Engenharia, Rio de Janeiro.

VILADKAR, M. N.; SARAN, S. (1994). Shuttle technique for soil-structures interation in framed structures. Proceedings of XIIIth ICSMFE, New Delhi, p. 595-598.

VILADKAR, M. N.; GODBOLE, P. N.; NOORZAEI, J. (1991). Soil-struture interation in plane frames using coupled finite-infinite elements. Computers \& Strutures, v. 39, n. 5, p. 535-546.

ZAMBROZUSKI, N. J. M.; BASSILI, A. P.; CRACIV, A. M.; SALES, R. J. M. (1985). Estudo da interação estrutura-solo. Trabalho Especial de Fim de Curso, IME.

ZEEVAERT, L. (1987). Soil-structure interation of deep foundations in tall buildings. Proceedings of VIII CPMSIF- PCSMFE, p. 16-21, Cartagena, Colômbia. 


\section{APÊNDICE}

\section{METODOLOGIA COMPUTACIONAL}

\section{GENERALIDADES}

Apresenta-se uma metodologia de projeto orientada a objetos, compatível com linguagens de alto nível e baseada na análise de sistemas. Essa metodologia computacional (modelo de análise) é uma adaptação da proposta de RUMBAUGH et al. (1994) e foi utilizada no desenvolvimento do StructsoiL 1.0. Descreve-se também os principais conceitos sobre a modelagem do software para melhor entendimento da programação orientada a objetos.

\section{ANÁLISE DE SISTEMAS}

O projeto de sistemas é a estratégia de alto nível usada para resolver e elaborar uma solução. É a primeira etapa do projeto em que é selecionada a abordagem básica para solucionar um problema. Inclui decisões sobre organização do sistema em subsistemas e adequação desses subsistemas ao comportamento do hardware e de softwares, além de decisões conceituais e políticas que formam a infra-estrutura do projeto detalhado. No projeto de sistemas, decide-se como o problema será resolvido, primeiro em alto nível, e depois em níveis cada vez mais detalhados.

Durante o projeto do sistema, a estrutura geral e o estilo são decididos. A arquitetura do sistema é definida de acordo com sua organização geral em componentes denominados subsistemas. A arquitetura fornece o contexto em que são tomadas decisões detalhadas em estágios posteriores do projeto. Ao tomar decisões de alto nível, que se aplicam a todo o software, o projetista subdivide o problema em subsistemas, de forma que o trabalho 
subsequente possa ser executado por mais de um projetista trabalhando de maneira integrada, em vários subsistemas.

A fase de análise determina o que se deve fazer, e a fase do projeto de sistemas determina o plano de ataque. A fase de projeto de objetos determina as definições complexas das classes e associações usadas na implementação, bem como as interfaces e algoritmos dos métodos usados para implementar as operações. A fase de projeto de objetos acrescenta e otimiza estruturas de dados e algoritmos.

Durante a fase de projeto de objetos executa-se as tarefas definidas pelo projeto de sistemas e acrescenta-se detalhes. Existe um desvio na ênfase dos conceitos do domínio da aplicação para os conceitos do computador. Os objetos descobertos durante a análise servem como base para o projeto, mas o projetista deve buscar diferentes maneiras de implementá-lo buscando minimizar o tempo de execução, uso de memória e outros custos. Em especial, as operações identificadas durante a análise devem ser expressas como algoritmos, com operações complexas decompostas em operações internas mais simples.

\section{MODELO DE ANÁLISE DO SISTEMA}

O modelo de análise adotado aborda três aspectos dos objetos:

a) estrutura estática (modelo de objeto);

b) seqüência de interações (modelo dinâmico) e;

c) transformações de dados (modelo funcional).

Esses três sub-modelos não são igualmente importantes em todos os problemas. Mas quase todos os problemas têm úteis modelos de objetos derivados de entidades do mundo real. Os problemas relativos a interações e tempo, com interfaces com o usuário, e controle de processos, têm importantes modelos dinâmicos. Problemas que contêm computações significativas, caso de cálculos de engenharia, têm modelos funcionais importantes.

\subsection{MODELAGEM DE OBJETOS}

O modelo de objetos é o mais importante dos três modelos, pois incorpora a estrutura estática de um sistema, mostrando os objetos pertencentes a esse sistema, os relacionamentos entre objetos, os atributos e as operações que caracterizam cada classe de objeto. 
Na modelagem de objetos são usados os conceitos de objetos e classes (sendo uma classe uma implementação de um tipo de objeto), métodos, solicitações, herança e encapsulamento.

\subsubsection{Objeto}

O objeto é algo que faz sentido no contexto de uma aplicação. Pode ser definido como um conceito, uma abstração, algo com limites nítidos e significativos em relação ao problema em causa. Em Engenharia Estrutural o objeto pode ser uma peça, como um pilar, uma viga ou uma estaca. Em Geotecnia, pode ser definido como um estrato (camada). Os objetos têm identidade e são distinguíveis. Um objeto pode ser composto de outros objetos, bem como ter relação com outros objetos. Por exemplo, um grupo de estacas unidas por bloco rígido é composto pelos objetos estacas e pelo objeto bloco, e suporta o objeto pilar e os objetos vigas baldrame. Estado de Objeto é uma coleção de objetos que se aplicam ao objeto, ou a coleção de associações (atributos) que um objeto tem. O Diagrama de Objetos fornece uma notação gráfica formal para a modelagem do objeto e seus interrelacionamentos. São úteis para a modelagem abstrata e também para o projeto de programas reais. Esses diagramas são concisos, fáceis de entender e funcionam bem na prática.

\subsubsection{Classes}

Uma classe de objeto descreve um grupo de objetos com propriedades semelhantes, mesmo comportamento (operações), mesmos relacionamentos com outros objetos e mesma semântica.

\subsubsection{Métodos}

Os métodos especificam a maneira pela qual os dados de um objeto são manipulados e são exclusivos ao tipo de objeto especificado. Um objeto é, dessa forma, uma coisa, com seus atributos (propriedades) representados pelos tipos de dados e seu comportamento representado pelos seus métodos.

\subsubsection{Solicitação}


Uma solicitação faz com que uma operação seja invocada. A operação executa o método apropriado e, opcionalmente, retorna uma resposta. Os códigos que constituem a solicitação contêm o nome do objeto, o nome da operação, e, às vezes, um grupo de parâmetros.

\subsubsection{Generalização e especialização da estrutura}

A generalização é o relacionamento entre uma classe e uma ou mais versões refinadas dela. A classe que estiver em processo de refinamento é chamada de superclasse e cada versão refinada é chamada de subclasse. Os atributos e operações comuns a um grupo de subclasse são incluídos na superclasse e compartilhados por todas as subclasses. A generalização possibilita que todas as instâncias de um conceito mais específico também sejam instâncias de um conceito geral - mas não necessariamente o contrário. Por outro lado, a especialização é o oposto da generalização. Por exemplo, o elemento sapata e o elemento estaca são elementos estruturais de fundação e possuem atributos comuns (generalização), mas são categorizados em superficial e profunda, respectivamente (especialização).

\subsubsection{Módulos}

Um módulo é uma construção lógica para agrupar classes, associações e generalizações. Um módulo incorpora uma perspectiva ou visão de uma situação. Um módulo de objetos pode consistir de um ou mais módulos. Os módulos permitem que se divida um módulo de objetos em partes passíveis de manipulação. Eles proporcionam uma unidade intermediária de empacotamento entre um modelo de objetos completo e os blocos básicos de construção de classe e associação. Nomes de classes e de associações devem ser únicos dentro de um módulo.

\subsection{MODELAGEM DINÂMICA}

Ao modelo dinâmico correspondem os aspectos de um sistema relativos ao tempo a às modificações. O controle é o aspecto de um sistema que descreve as seqüências de operações que ocorrem em resposta a estímulos externos, sem consideração ao que as operações fazem, sobre o que elas atuam e como são implementadas. Os principais conceitos da modelagem dinâmica são os eventos, que representam estímulos externos, e os estados, que representam valores dos objetos. 


\subsubsection{Eventos e Estados}

Os valores de atributos e as ligações mantidas por um objeto constituem o seu estado. Com o tempo os objetos estimulam uns aos outros, resultando em uma série de alterações em seus estados. Um estímulo individual de um objeto para outro é um evento. A reação a um evento depende do estado do objeto que o recebe, e pode incluir uma modificação de estado ou o envio de outro evento para o remetente original ou para um terceiro objeto. O padrão de eventos, estados e transições para um determinada classe pode ser abstraído e representado como um Diagrama de Estados.

\subsubsection{Eventos}

Um evento é uma transmissão ou informação unidirecional de um objeto para outro. Não é como a chamada de uma subrotina, que retorna um valor. Um objeto que envia um evento a outro objeto pode esperar uma resposta, mas essa resposta é um outro evento sob controle do segundo objeto, que pode resolver enviá-lo ou não. Um evento conduz informações de um objeto para outro. Os valores de dados conduzidos por um evento são seus atributos, como os valores de dados mantidos por objetos.

\subsubsection{Estados}

Um estado especifica a reação de um objeto aos eventos de entrada. A reação a um evento recebido por um objeto pode variar quantitativamente dependendo dos valores exatos de seus atributos, mas a reação é qualitativamente a mesma para todos os valores no interior do mesmo estado, e pode ser qualitativamente diferente para mesmos valores em diferentes estados. Um estado é uma abstração dos valores de atributos e ligações de um objeto. Um estado corresponde ao intervalo entre dois eventos recebidos por um objeto. Os eventos representam pontos no tempo e os estados representam intervalos de tempo.

\subsubsection{Operações}

As operações vinculadas a estados ou transações são executadas em resposta aos respectivos estados ou eventos. 


\subsubsection{Concorrências}

O modelo dinâmico descreve um conjunto de objetos concorrentes, cada um com seu estado e diagrama de estados próprios. Os objetos de um sistema são intrinsecamente concorrentes e podem mudar de estado de forma independente. O estado de todo o sistema não pode ser representado por um único estado de um único objeto, ele é o produto dos estados de todos os objetos dele.

\subsection{MODELAGEM FUNCIONAL}

$\mathrm{O}$ modelo funcional descreve os cálculos executados em um sistema. O modelo funcional especifica o que acontece, o modelo dinâmico especifica quando acontece, e o modelo de objetos, a quem acontece.

O modelo funcional mostra como os valores de saída de um processamento derivam dos valores de entrada, sem preocupação com a ordem em que os valores são processados. $O$ modelo funcional é composto de múltiplos diagramas de fluxos de dados mostrando os valores provenientes das entradas externas, passando por operações e depósitos internos de dados, a caminho das saídas externas. Programas interativos possuem modelo funcional significativo.

\subsubsection{Diagramas de Fluxo de Dados (DFD's)}

O modelo funcional é composto por múltiplos diagramas de fluxo de dados que especificam o significado das operações e restrições. O DFD mostra os relacionamentos funcionais dos valores calculados por um sistema, incluindo valores de entrada, de saída e depósitos internos de dados. Os DFD's não mostram informações de controle, como o momento em que os processos são executados, ou decisões entre vias alternativas de dados. Um DFD contém processos que transformam dados, fluxos de dados que movimentam dados, objetos atores que produzem e consomem dados e objetos depósitos que armazenam dados passivamente.

\subsubsection{Processos}

Um processo transforma valores de dados. Um processo é desenhado como uma elipse contendo uma descrição da transformação, geralmente sem nome. Cada processo tem 
um número fixo de setas de dados de entrada e saída. As entradas e saídas podem ser rotuladas para mostrar os seus papéis no processamento, porém é suficiente o tipo do valor no fluxo de dados.

\subsubsection{Fluxo de dados}

O fluxo de dados interliga a saída de um objeto ou processo à saída de outro objeto ou processo. Ele representa um valor intermediário de dados em uma computação. A flecha é rotulada com descrição de dados, geralmente seu nome ou seu tipo. O mesmo valor pode ser enviado a diversos lugares.

\subsubsection{Objetos atores}

Objetos atores são executáveis independentes acionados através do sistema representados por retângulo de cantos arredondados. No caso do StructsoiL, são representados pelo bloco de notas EditStructsoiL.

\subsubsection{Depósito de dados}

Um depósito de dados é um objeto passivo, em um diagrama de fluxo de dados, que armazena dados para o futuro. O depósito de dados permite que os acessos aos valores seja feito em uma ordem diferente daquela em que eles foram gerados. Os depósitos são desenhados com um par de linhas paralelas contendo o nome do depósito. As setas de entrada indicam informações ou operações de valores que modificam os dados armazenados.

\subsubsection{Fluxo de Controle}

Um DFD mostra todos os caminhos possíveis da computação de valores, mas não são mostrados quais caminhos são executados e em que ordem. As decisões e seqüências de decisões são problemas de controle que fazem parte do modelo dinâmico, mas, às vezes, é útil incluí-las no modelo funcional para que não sejam esquecidas e para que as dependências de seus dados possam ser mostradas.

\subsubsection{Restrições}


Uma restrição mostra o relacionamento entre dois objetos ao mesmo tempo ou entre diferentes valores do mesmo objeto em momentos distintos. Uma restrição pode ser expressa como uma função total, ou parcial. As restrições podem aparecer em todos os tipos de modelos. As restrições de objetos especificam que alguns objetos dependem inteira ou parcialmente de outros objetos. As restrições dinâmicas especificam relacionamentos entre estados ou eventos de diferentes objetos. As restrições funcionais especificam restrições sobre restrições. Uma restrição entre valores de um objeto ao longo do tempo costuma ser chamada invariante.

\section{AS BASES DA ORIENTAÇÃO A OBJETOS}

A programação orientada a objetos (POO) é baseada na premissa de que os dados e não as funções (programação tradicional) são a parte mais importante do sistema. A decomposição do sistema interpreta um software como sendo uma quantidade de estruturas de dados isoladas que formam, no seu todo, a estrutura base do sistema.

Os principais ganhos com a utilização da $\mathrm{POO}$ em substituição à metodologia tradicional são:

- exatidão - a POO é mais interativa, o que diminui o risco do produto final não atender as expectativas;

- potencialidade - a POO aumenta a capacidade do software de reação a erros imprevistos, minimizando a possibilidade de "estrago" dos dados e de saídas drásticas do sistema;

- extensibilidade - maior capacidade da adaptar o software a novas especificações;

- reutilização - maior possibilidade de utilização de código gerado para outro software sem qualquer adaptação prévia.

A programação orientada a objetos possui princípios para serem seguidos:

- abstração de dados - é o processo de criar novos tipos de dados, ou seja, a capacidade de abstrair algo, porém, reconhecendo todas as suas características básicas;

- encapsulação - a encapsulação consiste em ocultar do usuário o funcionamento interno de uma classe, desta forma, todos os detalhes de um objeto, que são insignificantes ao programador, não serão aparentes;

- herança - permite a criação de uma nova classe a partir de outras existentes sem contudo duplicar código algum. A nova classe se comportará de forma análoga à de origem, diferenciando-se naquilo que for acrescentado;

- polimorfismo - permite que diferentes classes possam definir métodos de mesmo nome. 


\section{METODOLOGIA DE PROJETO E IMPLEMENTAÇÃO}

A análise de sistemas é uma poderosa ferramenta, fundamental para demonstrar a capacidade humana de lidar com coisas complexas e a história dos povos, em qualquer época, nos mostra como artistas, artesãos e principalmente engenheiros têm se destacado na construção de modelos antes de executá-los. A construção de um software não é uma exceção. Para se construir sistemas complexos, o desenvolvedor deve abstrair diferentes visões do sistema, verificar se os modelos satisfazem os requisitos do sistema e acrescentar detalhes gradativamente para transformar o modelo em uma implementação. Por outro lado, o desenvolvimento de um produto deve ter como objetivo a qualidade, e a obtenção da qualidade em um software é resultado direto de seu processo de desenvolvimento. Neste enfoque, um processo sistemático e definido que permita disciplinar as várias etapas que compõem o seu desenvolvimento, se torna necessário. A metodologia se constitui no meio que permite melhorar e acompanhar a qualidade do software. Isto porque a qualidade de cada fase e seu produto associado garantem a qualidade do software.

A adoção de uma metodologia de projeto possibilita que atividades de controle de qualidade estejam presentes em cada fase do desenvolvimento e em estudos futuros. $\mathrm{O}$ controle de qualidade se compõe pela definição dos critérios de qualidade de cada uma das fases e seus produtos associados, verificação e avaliação destes critérios e definição dos procedimentos necessários para a validação de cada produto e de sua fase respectiva.

Um projeto estruturado de um sistema desenvolvido comercialmente consta de cinco fases básicas, as quais são: Anteprojeto, Projeto Lógico e Físico, Programação, Implantação e Operação. No desenvolvimento do StructsoiL o Anteprojeto e o Manual de Viabilidade se tornaram documentos básicos de consulta durante a implementação. A fase de programação foi executada gerando os fontes do programa, e as fases de implantação e operação geraram os resultados apresentados.

\subsection{ANTEPROJETO}

Esta fase visa identificar o tipo de serviço de processamento de dados a ser executado (manutenção de um software existente ou criação de um outro), os objetivos a serem alcançados, recursos, prazos necessários para a execução do projeto. O resultado é um documento que contém o modelo lógico preliminar do software. 


\subsection{Projeto lógico e físico}

Nesta fase, o objetivo é a especificação detalhada dos elementos do software, primeiramente a nível lógico. Além disso, detalha-se os procedimentos externos ao computador, tais como:

- captação das informações;

- preparo e envio para processamento;

- crítica e correções e;

- distribuição das saídas.

Tendo como base o Projeto Lógico, detalha-se os elementos do software a nível físico (Projeto Físico). O produto dessa fase foi o Manual de Viabilidade do Software, que contém a especificação técnica completa do software, usado na sua implementação.

\subsection{ProgramaÇão}

O objetivo desta fase é o desenvolvimento e simulação do software especificado no Projeto Físico. O resultado são os programas fontes, devidamente testados. Na fase de implementação, pode haver necessidade de otimização do projeto. As alterações que forem necessárias são documentadas e anexadas ao Manual de Viabilidade.

\subsection{IMPLANTAÇão}

Tem como objetivo o treinamento do usuário, a conversão ou inicialização de arquivos e a implantação do software para produção. Nesta fase, baseado no Manual de Viabilidade do Software, é elaborado o Manual do Usuário.

\subsection{OPERAÇÃo}

Nesta fase são executadas as atividades de produção do software pelo usuário, com acompanhamento inicial da execução das rotinas, avaliação da performance, pequenos ajustes e análise dos resultados. O produto é um relatório descritivo dos problemas encontrados pelo usuário e as soluções adotadas, e a documentação do software, como um todo, devidamente revisada. 


\section{GLOSSÁRIO}

ajuda online - Nome dado às informações de ajuda que podem ser consultadas diretamente na tela durante o uso de um programa aplicativo. A ajuda possui a função de orientação do usuário e permite consultar na tela informações referentes ao comando, procedimento ou modo operacional que está sendo utilizado.

atributo - É algum dado (informação de estado) para o qual cada objeto em uma classe tem seu próprio valor.

banco de dados - Um banco de dados orientado a objetos contém tipos de dados abstratos (objetos) e é controlado por um sistema gerenciador de banco de dados orientado a objetos.

Borland Delphi 3.0 - Linguagem de programação baseada no Pascal e orientada a objetos, produzida pela Borland, na versão 3.0.

projeto orientado a objetos - O projeto orientado a objetos é o resultado da análise orientada a objetos transformada em um modelo de implementação do sistema. Análise orientada a objetos é o exame de um problema modelando-o como grupo de objetos de interação. Um objeto é definido por classe, elementos de dados (atributos) e comportamento (serviços).

classe master - Classe é a descrição de um ou mais objetos através de um conjunto uniforme de atributos e serviços. A classe master é a mais importante na hierarquia do modelo de objetos do sistema.

Diagrama Entidade - Relacionamento (DER) - Define os serviços transferidos entre os principais objetos do sistema.

relacionamento - Representa a transferência de serviços e dados entre objetos.

entidade - Sinônimo de classe ou objeto.

Menu Configuração - Menu de retaguarda (banco de dados de conhecimento), é composto pelos submenus: ir, cadastro, configuração e ajuda.

módulo de comunicação - Módulo que gerencia a operação de software de análise estrutural e entrada de dados automática da superestrutura.

Menu Principal - Menu de trabalho do sistema composto pelos sub-menus: controle, entrada de dados, processamento, relatórios, gráficos e ajuda. 
objeto - É uma abstração de alguma coisa no domínio de um problema ou em sua implementação, refletindo a capacidade do sistema para manter informações sobre ela, interagir com ela, ou ambos: um encapsulamento de valores de atributos e seus serviços exclusivos.

objeto filho - Objeto hierarquicamente subordinado ao pai, do qual herda atributos.

usuário - É o indivíduo, pessoa, que se beneficia, direta o indiretamente, dos recursos de um sistema de computador e usa seus recursos para realizar atividades profissionais, gerenciais e técnicas.

usuário master - Usuário que, além de usar diretamente os benefícios do software, pode ter acesso ao Menu Configuração e alterar, excluir e incluir dados da base de conhecimento e configuração, tem como pré-requisito ser um especialista da área de fundações, especialista em geotecnia.

$S G B D$ - Sistema de gerenciamento de banco de dados oferecido junto com a linguagem de programação Delphi ${ }^{\circ} 3.0$, superior ou similar (BDE Administrator $\left.{ }^{\circ}\right)$.

superclasse - Classe que define atributos e serviços de várias classes.

serviço - É um comportamento específico por cuja exibição um objeto é responsável. 